NARA BALLAMINUT

\title{
CARACTERIZAÇÃO DO PROCESSO DE DESCOLORAÇÃO DE CORANTE REATIVO DIAZO POR BASIDIOMICETOS TROPICAIS
}

Tese apresentada ao Programa de Pós Graduação Interunidades em Biotecnologia USP/Instituto Butantan/IPT para obtenção de título de Doutor em Biotecnologia. 


\section{CARACTERIZAÇÃO DO PROCESSO DE DESCOLORAÇÃO DE CORANTE REATIVO DIAZO POR BASIDIOMICETOS TROPICAIS}

Tese apresentada ao Programa de Pós Graduação Interunidades em Biotecnologia USP/Instituto Butantan/IPT para obtenção de título de Doutor em Biotecnologia.

Área de Concentração: Biotecnologia

Orientador: Prof. Dr. Dácio Roberto Matheus

Co-orientadora: Prof ${ }^{a}$. Dra. Elizabete Campos de Lima

"Versão corrigida. A versão original eletrônica, encontra-se disponível tanto na biblioteca do ICB quanto na biblioteca digital de teses e dissertações da USP (BDTD).” 


\section{CATALOGAÇÃO NA PUBLICAÇÃO (CIP) \\ Serviço de Biblioteca e informação Biomédica \\ do Instituto de Ciências Biomédicas da Universidade de São Paulo}

Ficha Catalográfica elaborada pelo(a) autor(a)

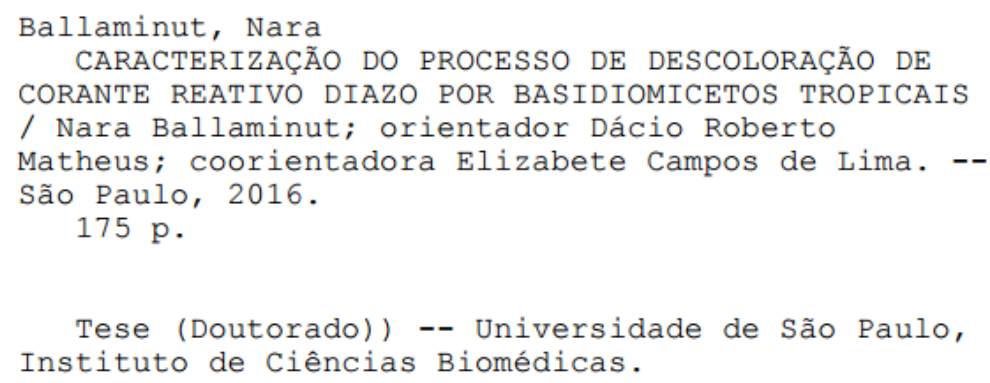

1. Biodegradação. 2. Lacases. 3. MnP. 4. Quelantes e redutores de ferro. 5. Via metabólica. I. Matheus, Dácio Roberto, orientador. II. Campos de Lima, Elizabete, coorientador. III. Título. 


\section{UNIVERSIDADE DE SÃO PAULO \\ Programa de Pós-Graduação Interunidades em Biotecnologia}

Universidade de São Paulo, Instituto Butantan, Instituto de Pesquisas Tecnológicas

Candidato(a): Nara Ballaminut

Título da Tese: Caracterização do processo de descoloração de corante reativo diazo por basidiomicetos tropicais

Orientador(a): Prof. Dr. Dácio Roberto Matheus

A Comissão Julgadora dos trabalhos de Defesa da Tese de Doutorado, em sessão pública realizada a .... considerou

\section{( ) Aprovado(a) ( ) Reprovado(a)}

Examinador(a): $\quad$ Assinatura:

Nome:

Instituição:

Examinador(a): Assinatura:

Nome:

Instituição:

Examinador(a): Assinatura:

Nome:

Instituição:

Examinador(a): Assinatura:

Nome:

Instituição:

Presidente: Assinatura:

Nome:

Instituição: 
À todos aqueles que me amaram de alguma forma, dedico. 


\section{AGRADECIMENTOS}

Agradeço, antes de mais nada, à Universidade de São Paulo, em especial ao meu orientador Dr. Dácio Roberto Matheus, por ter acreditado em mim e nos rumos da nossa pesquisa; à Secretaria de Biotecnologia, especialmente à Fábia Reis Vila Nova de Lima e Eliane de Araújo Campos Gouveia, pela disposição e paciência; e ao CNPq pela oportunidade e apoios acadêmico e financeiro para o desenvolvimento dessa pesquisa.

Muito obrigada também ao Instituto de Botânica da Secretaria do Meio Ambiente do Estado de São Paulo, com agradecimento especial ao Núcleo de Pesquisa em Micologia, seus pesquisadores e apoio técnico, com destaque aos doutores Michel Navarro Benatti, José Ivanildo de Souza e Adriana de Mello Gugliotta. Agradeço ainda à Dra Vera Maria Valle Vitali, Dra. Vera Lúcia Ramos Bononi, à doutorada Luci Kimie Okino Silva e Dra. Ana Cristina Bolaños pelo carinho, apoio e paciência sem fim, além da amizade sincera que atravessa, e ainda atravessará, décadas em nossas vidas; à Universidade Federal do $\mathrm{ABC}$, seus técnicos, pesquisadores e alunos de iniciação científica, pelo acolhimento, e à Dra. Elizabete Campos de Lima por ter participado do meu processo de amadurecimento acadêmico; ao SENAI unidade Francisco Matarazzo, em especial ao Professor Dr. Jorge Marcos Rosa e ao Programa de Apoio à Pesquisa SENAI.

Aos meus “ajudantes” Mariana Haruca Silva e Eduardo Ballaminut da Silva, que possibilitaram a finalização de cada dia de trabalho duro, com um enorme sorriso de satisfação. Ao meu amigo Alex Almeida Alcântara, que sempre fez todo o possível para que minha estadia no Laboratório de Micologia Aplicada fosse sempre uma grande alegria.

Agradeço ainda à Vera Vitali, pelo companheirismo e confiança, além das inúmeras vezes em que esteve presente em minha vida, trazendo força e acalento; ao Dácio pela amizade "paternal” que possibilitou minha evolução profissional; ao meu filhote Iago Ballaminut da Silva, que é e sempre será a razão do meu viver; à minha mãe Arlete Gomes Ballaminut, que mesmo na hora em que eu quis desistir de tudo, não deixou de acreditar no meu sucesso; aos meus filhos Iago e Letícia pela ajuda prontamente disposta nas noites em que me ajudaram, incansavelmente, a organizar meus dados brutos; e, por fim, à minha neta Maria Clara, que renova minha fé na vida todos os dias da minha existência.

Ao Eduardo, meu amigo e companheiro, marido muito amado, meu muito obrigada por estar comigo sempre, apoiando e acreditando em mim, em todos os momentos, mesmo quando eu pensei que não seria possível continuar. 
Obrigada a todos que facilitaram meu caminho nessa jornada tão cheia de tropeços e dificuldades, todos aqueles que, de forma direta ou indireta, possibilitam a realização da pesquisa científica nesse país. 


\section{RESUMO}

BALLAMINUT, N. Caracterização do processo de descoloração de corante reativo diazo por basidiomicetos tropicais. 2016. $175 \mathrm{f}$. Tese (Doutorado em Biotecnologia) - Instituto de Ciências Biomédicas, Universidade de São Paulo. São Paulo, 2016.

Corantes reativos têxteis, conhecidos por sua recalcitrância, podem ser degradados pelo mecanismo ligninolítico de basidiomicetos, constituído por enzimas oxidativas e hidrolíticas, e ainda compostos de baixa massa molar, embora a ação desses últimos venha sendo negligenciada em estudos de degradação. Foi nesse contexto que foi avaliada a biodegradação de CI Reactive Blue 222 por Peniophora cinerea CCIBt 2541, Pleurotus ostreatus CCIBt 2347 e Trametes villosa CCIBt 2628, selecionando condições ótimas para maximizar a eficiência do processo. Foram definidas concentrações ótimas de cobre e manganês, além de fonte conhecida de ácidos graxos insaturados, adicionados ao cultivo fúngico. $P$. ostreatus foi mais eficiente na descoloração quando cultivos de 25 dias, contendo $0,446 \mathrm{mM}$ de sulfato de cobre e $0,821 \mathrm{mM}$ de sulfato de manganês, sem adição de ácido graxo insaturado foram empregados. $T$. villosa também mostrou máxima eficiência com cultivos de 25 dias, contendo $1 \mathrm{mM}$ de sulfato de cobre e de manganês, na presença de 3,75\% de fonte de ácido graxo insaturado. Já $P$. cinerea foi mais eficiente quando cultivos com 18 dias, contendo $1 \mathrm{mM}$ de sulfato de cobre, 0,106 mM de sulfato de manganês e $4 \%$ de fonte de ácido graxo insaturado foram empregados. Foi avaliada ainda a ação dos sistemas mediados por lacase-ABTS, lacase-RBBR e lacase-ABTSRBBR na descoloração empregando os três basidiomicetos, em tratamentos individuais, onde a presença desses mediadores no efluente sintético favoreceu a descoloração, quando $2 \mathrm{mM}$ de ABTS estavam presentes, para qualquer um dos basidiomicetos estudados, embora RBBR influenciou positivamente apenas os tratamentos com $P$. ostreatus e $P$. cinerea, sendo ótima a concentração de $0,2 \mu \mathrm{M}$ para esse mediador. Contudo, é importante ressaltar que o processo é dinâmico, ficando sugerido que são necessárias intervenções sucessivas para maximizar a eficiência do processo, em suas diferentes fases. A degradação foi confirmada por cromatografia de camada delgada e testes de descoloração com inibição seletiva das principais enzimas mostraram que os mecanismos ligninolíticos funcionam diferentemente, de acordo com cada espécie estudada. A partir da interpretação dos resultados foi sugerido que as lacases de $P$. ostreatus oxidam o grupo cromóforo azo, ligado ao radical fenólico da molécula do corante nas primeiras 24 horas, concomitantemente à ação não enzimática de hidroxilização. Já as lacases de $P$. cinerea, capazes de oxidar $\mathrm{Mn}^{+2}$ e quinona, possibilitam a via de Fenton, hidroxilisando assim a molécula do corante, paulatinamente, a partir das ligações mais vulneráveis. T. villosa inicia a descoloração fazendo uso de um mecanismo prioritariamente envolvendo a via de Fenton, promovendo a hidroxilização gradativa da molécula do corante. Conclui-se que embora a maioria de estudos desse tipo foquem na produção enzimática, associando-as à descoloração, a participação dos compostos de baixa massa molar não pode ser negligenciada, uma vez que processos in vivo fazem uso de componentes enzimáticos e não enzimáticos, simultaneamente, para efetivar a degradação de poluentes.

Palavras-chave: Biodegradação. Enzimas ligninolíticas. Quelantes e redutores de ferro. Via metabólica. Compostos de baixa massa molar. 
BALLAMINUT, N. Characterization of reactive disazo dye decolorization by tropical basidiomycetes. 2016. 175 p. Thesis (Ph. D. Thesis in Biotechnology) - Instituto de Ciências Biomédicas, Universidade de São Paulo, São Paulo, 2016.

Reactive textile dyes are known for their recalcitrance, can be degraded by ligninolytic mechanism of basidiomycetes, comprising oxidative and hydrolytic enzymes, as well as low molecular weight compounds, although the action of the latter have been neglected in degradation studies. In this context that was evaluated the CI Reactive Blue 222 decolorization by Peniophora cinerea CCIBt 2541, Pleurotus ostreatus CCIBt 2347 and Trametes villosa CCIBt 2628, selecting optimal conditions to maximize process efficiency. Copper and manganese concentrations were defined, in addition was defined a known source of unsaturated fatty acids, added into the fungal culture. P. ostreatus was more efficient in the decolorization when 25-day cultures, containing $0.446 \mathrm{mM}$ copper sulphate and $0.821 \mathrm{mM}$ manganese sulphate, without the addition of unsaturated fatty acid, were employed. $T$. villosa also showed maximum efficiency with 25-day cultures, containing $1 \mathrm{mM}$ copper and manganese sulphate, in the presence of $3.75 \%$ unsaturated fatty acid source. $P$. cinerea was more efficient when cultures with 18-day cultures, containing $1 \mathrm{mM}$ of copper sulphate, $0.106 \mathrm{mM}$ of manganese sulphate and $4 \%$ of unsaturated fatty acid source were used. It was evaluated the action of laccase mediated systems, laccase-ABTS, laccase-RBBR, and laccase-ABTS-RBBR in decolorization employing the basidiomycetes mentioned, in individual treatments, where the presence of these mediators in the synthetic effluent favoured the decolorization, when $2 \mathrm{mM}$ ABTS were present, for any of the basidiomycetes studied, although RBBR influenced positively only the treatments with $P$. ostreatus and $P$. cinerea, being optimal $0.2 \mu \mathrm{M}$ for this mediator. However, it is important to emphasize that the process is dynamic, and it is suggested that successive interventions are necessary to maximize the efficiency of the process, in its different phases. The degradation was confirmed by thin layer chromatography and the selective decolorization with inhibition tests of the main enzymes showed that the ligninolytic mechanisms function differently, according to each species studied. From the interpretation of the results, it was suggested that $P$. ostreatus laccases oxidize the azo chromophore group, linked to the phenolic radical of the dye molecule in the first 24 hours, concomitantly with the non-enzymatic action of hydroxylation. The $P$. cinerea laccases, capable of oxidizing $\mathrm{Mn}^{+2}$ and quinone, enable the Fenton pathway, thus hydrolysing the dye molecule, gradually, from the most vulnerable linkages. T. villosa initiates decolorization using a mechanism primarily involving the Fenton pathway, promoting the gradual hydroxylation of the dye molecule. Concludes that although most such studies focus on enzyme production, associating these with the decolorization, the share of low molecular weight compounds cannot be neglected, since in vivo processes make use of enzymatic and non-enzymatic components, simultaneously, to effect the pollutant degradation.

Keywords: Biodegradation. Ligninolytic enzymes. Iron chelators and reducers. Metabolic pathway. Low molecular weight compounds. 


\section{LISTA DE FIGURAS}

Figura 1 - Estrutura química de CI Reactive Blue 222 ............................................................................34

Figura 2 - Biomassa de Pleurotus ostreatus monitorada durante contato in vivo com RB222 (•) e no

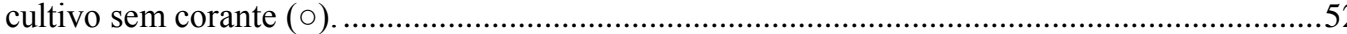

Figura 3 - (A) pH dos sistemas com Pleurotus ostreatus CCIBt 2347 e corante $(\boldsymbol{\Delta})$ e sem corante $(\Delta)$; (B) sistemas com corante em água $(\mathrm{O})$ e em meio basal $(\bullet)$, ambos sem fungo.........................53

Figura 4 - Descoloração do RB222 a 610 nm durante tratamento in vivo por Pleurotus ostreatus CCIBt 2347 ( $\Delta$ ), nos seus controles abióticos com corante em água ( $($ ) e em meio basal $(\bullet)$...............55

Figura 5 - Sistemas de tratamento de CI Reactive Blue 222 por Pleurotus ostreatus CCIBt 2347, onde (A) controle abiótico no tempo inicial e (B) sistemas com fungo e corante após 6 horas, (C) após 12 horas e (D) após 24 horas de contato

Figura 6 - Espectros de absorção de RB222 tratado com Pleurotus ostreatus CCIBt 2347e seus controles abióicos

Figura 7 - Curva - concentração de RB222 versus absorbância a 526 nm................................................57

Figura 8 - Biomassa seca por litro de cultivo de Pleurotus ostreatus CCIBt 2347 (घ), Peniophora cinerea CCIBt 2541 () e Trametes villosa CCIBt 2628 (ロ)

Figura 9 - Espectros de absorção da fase líquida dos tratamentos de RB222 com Pleurotus ostreatus CCIBt 2347.

Figura 10 - Descoloração de RB222, a 526 nm e 610 nm, e atividades enzimáticas produzidas por Pleurotus ostreatus CCIBt 2347 in vivo na presença de inibidores enzimáticos.

Figura 11 - Descoloração de RB222, a 526 nm e 610 nm, e atividades enzimáticas produzidas por Peniophora cinerea CCIBt 2541 in vivo na presença de inibidores enzimáticos.

Figura 12 - Descoloração de RB222, a 526 nm e 610 nm, e atividades enzimáticas e produzidas por Trametes villosa CCIBt 2628 in vivo na presença de inibidores enzimáticos.

Figura 13 - Fase líquida dos tratamentos após 48 horas de contato in vivo com basidiomicetos. ......................90

Figura 14 - Placa de cromatografia de camada delgada dos tratamentos com Peniophora cinerea CCIBt 2541, sob luz ultravioleta a $365 \mathrm{~nm}$.

Figura 15 - Placas de cromatografia de camada delgada dos tratamentos com Pleurotus ostreatus CCIBt 2347 (à esquerda) e Trametes villosa CCIBt 2628 (à direita), sob luz ultravioleta a 365 nm.......92

Figura 16 - Possiveis metabólitos da degradação de RB222 após tratamentos com basidiomicetos. Metaprint2D 


\section{LISTA DE TABELAS}

Tabela 1 - Algumas das principais técnicas físico-químicas de tratamento de efluentes têxteis, coloridos por corantes orgânicos e suas limitações.

Tabela 2 - Variáveis avaliadas por DCCR $2^{3}$ para avaliação de concentrações de sulfato de cobre e sulfato de manganês, no meio de cultivo de basidiomicetos, e do tempo de incubação do cultivo desses fungos para descoloração de RB222.....

Tabela 3 - Bloco experimental DCCR $2^{3}$ para avaliação das variáveis: concentrações de sulfato de cobre

e de sulfato de manganês no meio, e idade fisiológica do cultivo. .............................................42

Tabela 4 - Variáveis avaliadas por DCCR $2^{3}$ para diferentes concentrações da fonte de ácido graxo, no meio de cultivo, e dos mediadores das atividades enzimáticas, ABTS e RBBR, nos tratamentos de descoloração in vivo de RB222 por Pleurotus ostreatus e Peniophora cinerea. ...44

Tabela 5 - Variáveis avaliadas por DCCR $2^{4}$ para diferentes concentrações da fonte de ácido graxo, no meio de cultivo, e dos mediadores das atividades enzimáticas, ABTS e RBBR, nos tratamentos de descoloração in vivo de RB222 por Trametes villosa.

Tabela 6 - Bloco experimental DCCR $2^{3}$ para avaliação das variáveis: concentrações de ABTS, RBBR e da fonte de ácido graxo.............................................................................................. 45

Tabela 7 - Bloco experimental DCCR $2^{4}$ para avaliação das variáveis: concentrações de ABTS, RBBR, da fonte de ácido graxo e de $\mathrm{MnSO}_{4}$.

Tabela 8 - Sais e nutrientes constituintes do meio líquido, utilizado para cultivo de basidiomicetos a serem empregados em tratamentos de descoloração de RB222 in vivo.....................................48

Tabela 9 - Atividades enzimáticas (U/L) produzidas por Pleurotus ostreatus CCIBt 2347 durante contato in vivo com RB222.

Tabela 10 - Descoloração in vitro de RB222 por extrato bruto de basidiomicetos com diferentes idades fisiológicas, em diferentes concentrações de corante.

Tabela 11 - Atividades enzimáticas produzidas por basidiomicetos, durante cultivo líquido em meio enriquecido, para aplicação na descoloração in vitro.

Tabela 12 - Correlação entre atividades enzimáticas nos extratos brutos de basidiomcetos e descoloração in vitro de RB222, por grama de biomassa seca, durante cultivo líquido.

Tabela 13 - Descoloração a 610nm e atividades enzimáticas produzidas pelos tratamentos avaliados empregando Pleurotus ostreatus CCIBt 2347, apresentados com os fatores não codificados e codificados (entre parênteses).

Tabela 14 - Coeficiente de regressão para descoloração a 610 nm, atividade de fenoloxidases, de lacase e MnP de Pleurotus ostreatus CCIBt 2347.

Tabela 15 - Valores estimados para a descoloração a $610 \mathrm{~nm}$ in vivo de RB222 e lacase produzida por Pleurotus ostreatus CCIBt 2347 durante contato in vivo.

Tabela 16 - Descoloração a $610 \mathrm{~nm}$ e atividades enzimáticas produzidas pelos tratamentos com Trametes villosa CCIBt 2628, apresentados com os fatores não codificados e codificados (entre parênteses).

Tabela 17 - Coeficiente de regressão para descoloração a 610 nm, atividade de fenoloxidases, de lacase e de MnP produzidas por Trametes villosa CCIBt 2628.

Tabela 18 - Descoloração a 610 nm e atividades enzimáticas produzidas pelos tratamentos com Peniophora cinerea CCIBt 2541, apresentados com os fatores não codificados e codificados (entre parênteses).

Tabela 19 - Coeficiente de regressão para descoloração a 610 nm, atividade de fenoloxidases, de lacase e MnP poduzidas por Peniophora cinerea CCIBt 2541.............................................................72

Tabela 20 - Descoloração e atividades enzimáticas (U/L.dia-1 ${ }^{-1}$ produzidas por Pleurotus ostreatus CCIBt 2347, seus fatores não codificados e codificados (entre parênteses). Áreas em destaque representam maiores valores

Tabela 21 - Coeficiente de regressão para descoloração a 610 nm e atividades enzimáticas para Pleurotus ostreatus CCIBt 2347.

Tabela 22 - Descoloração a 610 nm, fenoloxidases e MnP estimados para sistemas de tratamento com

Tabela 22 - Descoloração a 610 nm, fenoloxidases e MnP estimados para sistemas de tratamento com
Pleurotus ostreatus CCIBt 2347 com 24 horas de contato in vivo. ............................................78

Tabela 23 - Descoloração a $610 \mathrm{~nm}$, fenoloxidases e MnP estimados para sistemas de tratamento com Pleurotus ostreatus CCIBt 2347 com 48 horas de contato in vivo.

Tabela 24 - Descoloração e atividades enzimáticas (U/L . dia ${ }^{-1}$ ) produzidas por Peniophora cinerea CCIBt 2541, com seus fatores não codificados e codificados (entre parêneses). Áreas em destaque representam maiores valores. 
Tabela 25 - Descoloração e atividades enzimáticas produzidas por Trametes villosa CCIBt 2628, com seus fatores não codificados e codificados (entre parênteses). Áreas em destaque representam maiores valores.

Tabela 26 - Coeficiente de regressão para descoloração a 526 nm e lacases de Trametes villosa CCIBt 2347 em 24 horas de contato in vivo.

Tabela 27 - Dados estimados para descoloração a 526 nm e produção de lacase por Trametes villosa CCIBt 2628 após 24 horas de contato in vivo.

Tabela 28 - Compostos de baixa massa molar no extrato bruto do cultivo de basidiomicetos antes do contato in vivo com RB222.

Tabela 29 - Coeficiente Pearson de correlação entre as atividades enzimáticas e a descoloração, e entre os CBMM e a descoloração, em $610 \mathrm{~nm}$ e $526 \mathrm{~nm}$. 


\section{LISTA DE ABREVIATURAS E SIGLAS}

ABTS - 2,2'-azinobis-(3-etilbenzotiazolino-6-sulfonato)

ATD - Atividade Total de Descoloração

BDA - Batata Dextrose Agar

CAS - Cromo Azurol S

CBMM - Compostos de Baixa Massa Molar

CCIBt - Coleção de Culturas de Algas, Cianobactérias e Fungos do Instituto de Botânica da Secretaria do Meio Ambiente do Estado de São Paulo

CI - Colour Index

CONAMA - Conselho Nacional do Meio Ambiente

DCCR - Delineamento Central Composto Rotacional

HBT - Hidroxibenzotriazol

HDTMA - Brometo de Hexa-eciltrimetilamônio

LiP - Lignina Peroxidase

MB - Meio Basal

MnP - Peroxidase dependente do Manganês

RB222 - CI Reactive Blue 222

RBBR - Remazol Brilliant Blue R (CI Reactive Blue 19)

ROS - Espécies Reativas de Oxigênio

TLC - Thin Layer Chromatography (Cromatografia de Camada Delgada)

VP - Peroxidase versátil 


\section{SUMÁRIO}

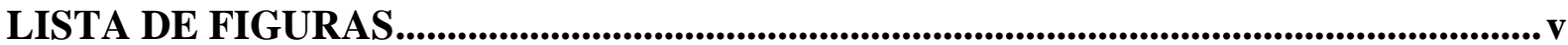

LISTA DE TABELAS ................................................................................................... vi

LISTA DE ABREVIATURAS E SIGLAS …....................................................................viii

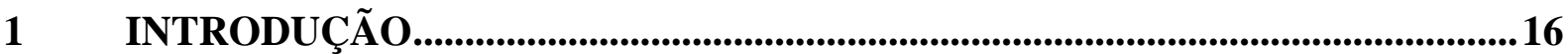

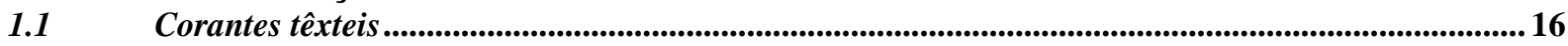

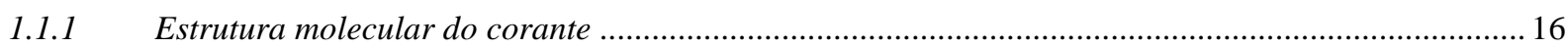

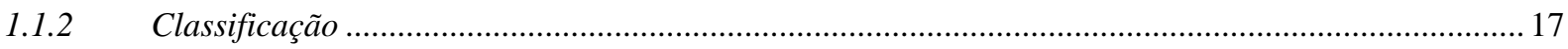

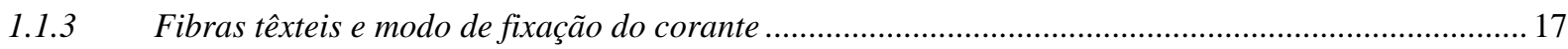

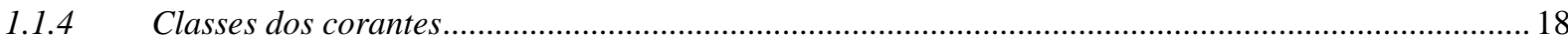

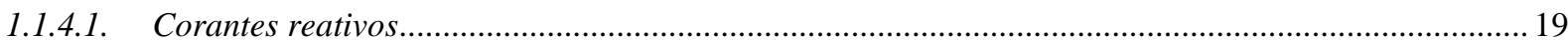

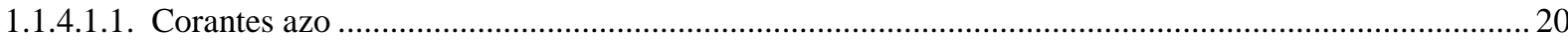

1.2. Efluentes têxteis: características e tratamento ....................................................................................... 21

1.3. Biodegradação de corantes................................................................................................................... 23

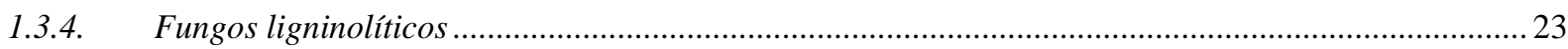

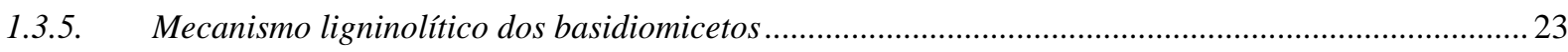

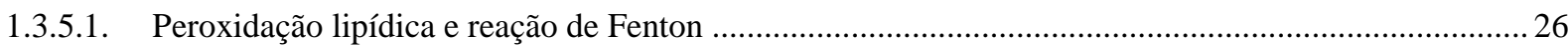

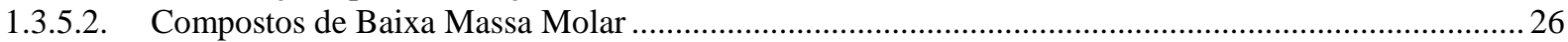

1.4. Fatores importantes de tratamentos de descoloração empregando basidiomicetos ............................. 28

1.4.4. Os gêneros de basidiomicetos: Pleurotus, Peniophora e Trametes ..................................................... 30

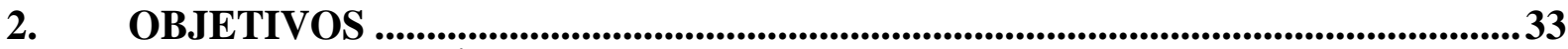

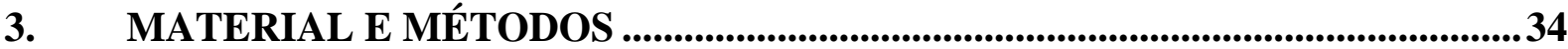

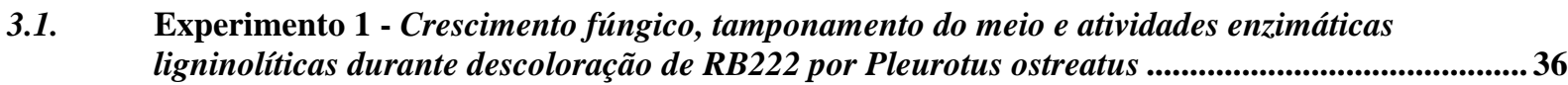

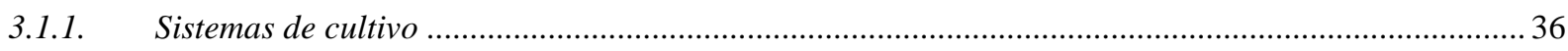

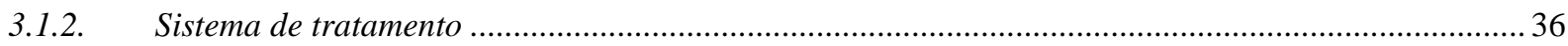

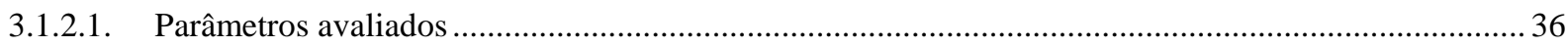

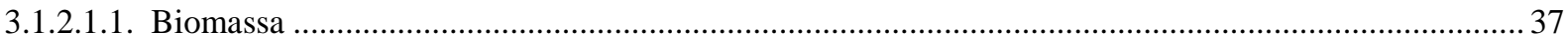

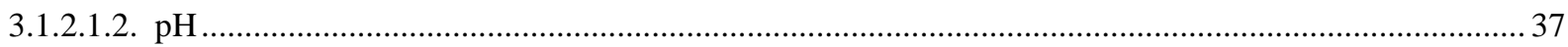

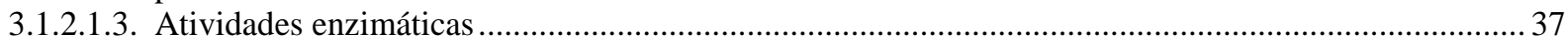

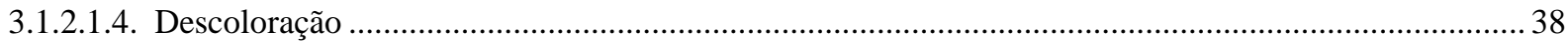

3.1.3. Coeficiente de Extinção Molar ( $(\varepsilon)$ de RB222 em 526nm................................................................... 38

3.2. Experimento 2 - Influência da idade fisiológica de basidiomicetos e da concentração de RB222 na descoloração ........................................................................................................................................... 39

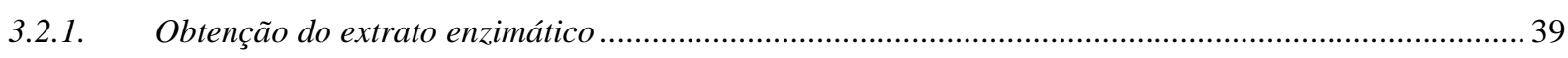

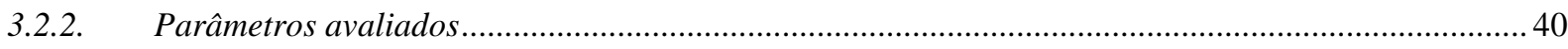

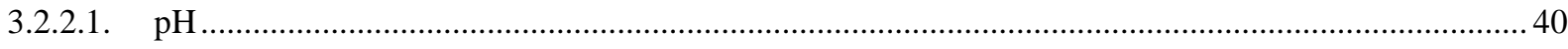

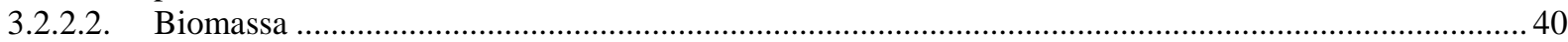

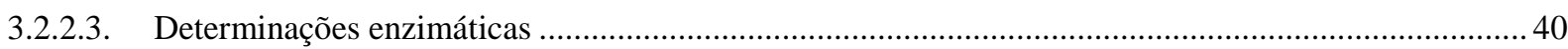

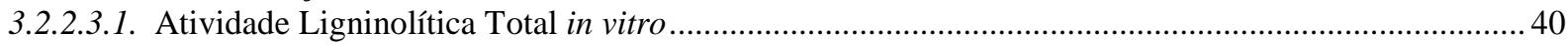

3.3. $\quad$ Experimento 3: Efeito da concentração de cobre e manganês, no meio de cultivo, e da idade fisiológica do cultivo na descoloração in vivo de RB222 por basidiomicetos....................................... 41

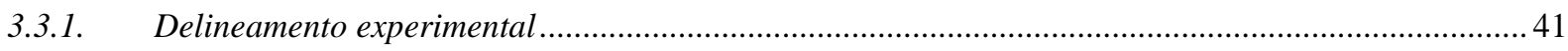

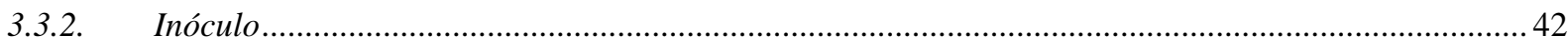




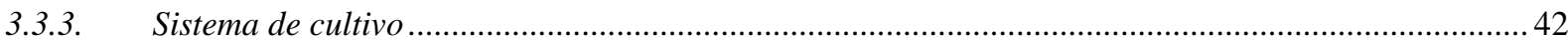

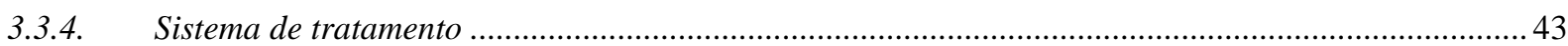

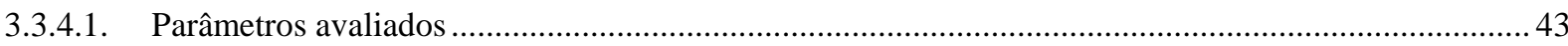

3.4. $\quad$ Experimento 4: Influência de diferentes concentrações de fonte de ácido graxo conhecida e de dois mediadores do sistema enzimático ligninolítico na descoloração in vivo de RB222 por

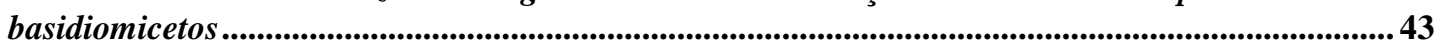

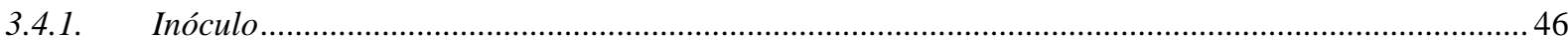

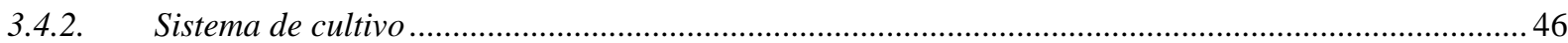

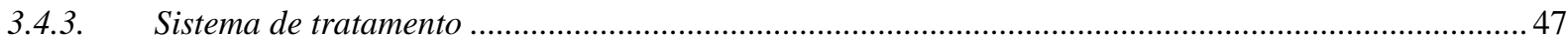

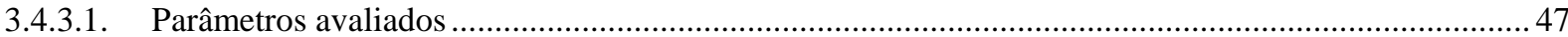

3.5. Experimento 5: Caracterização do processo de descoloração de RB222 por basidiomicetos ........... 47

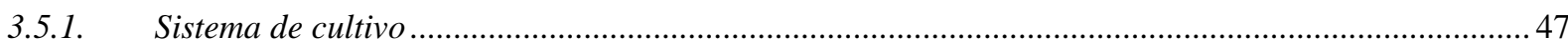

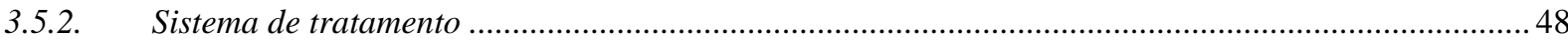

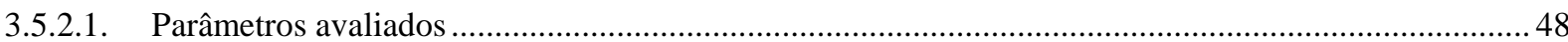

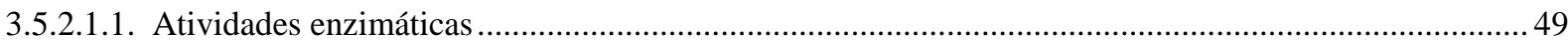

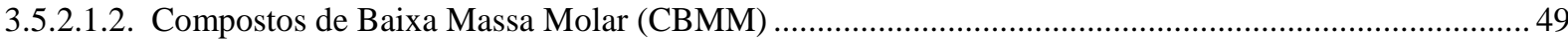

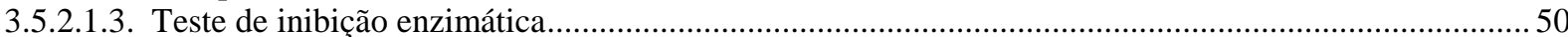

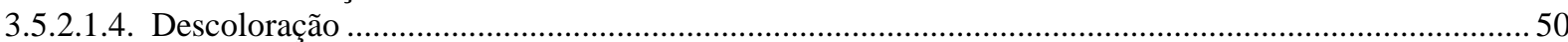

3.5.2.1.5. Detecção de metabólitos por cromatografia de camada delgada (Thin Layer Chromatography - TLC) 51

3.5.3. Previsão de metabólitos 51

4. RESULTADOS E DISCUSSÕES............................................................................ 52

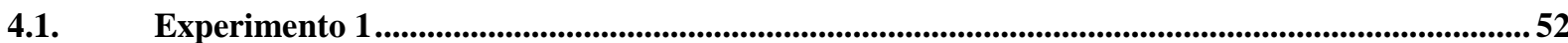

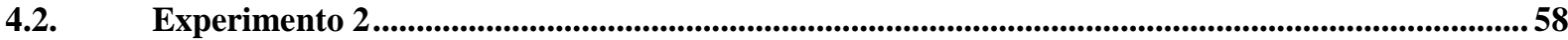

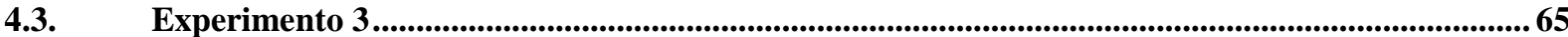

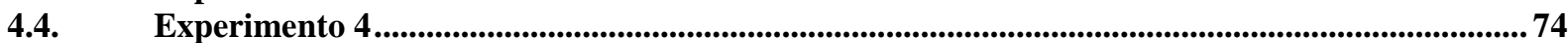

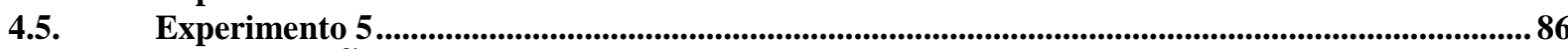

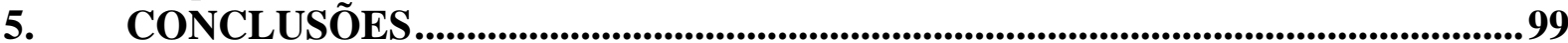

REFERÊNCIAS

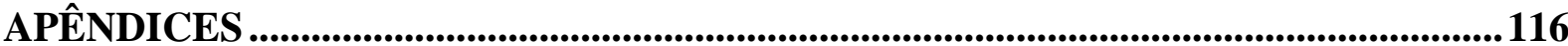

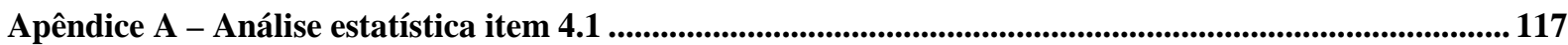

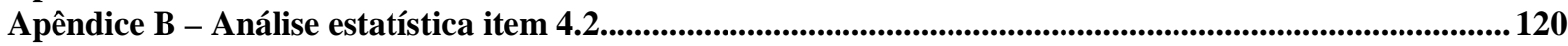

Apêndice C - Análise estatística item $4.3 \ldots 132$

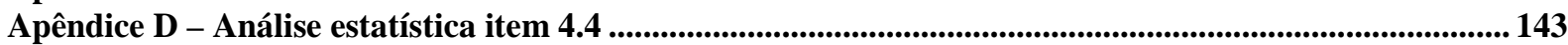

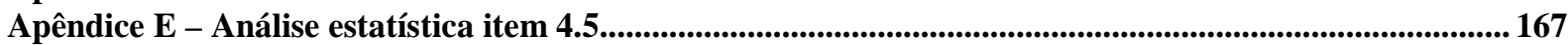




\section{INTRODUÇÃO}

Dentre as inúmeras atividades impactantes, atualmente conhecidas, o tratamento de efluentes é um dos principais desafios enfrentados pela gestão ambiental. A indústria têxtil emprega principalmente corantes, e a presença desses compostos nos efluentes finais está entre os problemas mais complexos enfrentados pelo setor têxtil.

\subsection{Corantes têxteis}

Corantes têxteis existem no mercado em extensa variedade de tipos e classes, sendo inicialmente classificados de acordo com sua natureza e origem, como: corantes naturais, aqueles que são extraídos de fonte animais e vegetais, e sintéticos. Esses últimos surgiram na segunda metade do século XIX, iniciando pela anilina, seguida por alguns corantes azo sintetizados por diazonização. Os corantes sintéticos são produzidos pela síntese química de aromáticos e possuem, dentro de suas estruturas, anéis aromáticos que contêm elétrons deslocados, além de diferentes grupos funcionais (KYZAS et al., 2013; POLAK; JAROSZWILKOLAZKA, 2012; ZAHARIA; SUTEU, 2012).

\subsubsection{Estrutura molecular do corante}

Segundo Ali (2010), desde o século XIX, mais de 100.000 diferentes corantes foram produzidos ao redor do mundo, com uma produção anual de cerca de 700.000 toneladas métricas. A cor desses compostos é devida à sua estrutura insaturada denominada cromogenecromóforo, considerada como o aceptor de elétrons, e sua capacidade de coloração é devida ao grupo auxócromo, considerado como doador de elétrons. Essas estruturas são os componentes mais importantes da molécula do corante. O cromogene é constituído de uma estrutura aromática, geralmente baseada em anéis de benzeno, naftaleno ou antraceno, que são ligados aos cromóforos, os quais contêm ligações duplas conjugadas com os elétrons deslocados e, frequentemente, contêm heteroátomos (nitrogênio, enxofre e oxigênio) com elétrons não ligados. Os grupos auxócromos são ionizáveis, o que confere aos corantes a capacidade de ligação química com o material têxtil (ALI, 2010; KYZAS et al., 2013; ZAHARIA; SUTEU, 2012).

A configuração dos cromóforos é representada por grupos azo $(-\mathrm{N}=\mathrm{N}-)$, azoxila $\left(-\mathrm{N}=\mathrm{N}^{+}\right.$$\left.\mathrm{O}^{-}\right)$; azoamino $(-\mathrm{N}=\mathrm{N}-\mathrm{NH})$; etileno $(=\mathrm{C}=\mathrm{C}=)$, azometino $(-\mathrm{C}=\mathrm{NH},-\mathrm{C}=\mathrm{N}-)$; metino $(-\mathrm{CH}=)$, carbonil $(=\mathrm{C}=\mathrm{O})$, carbono-nitrogênio $(=\mathrm{C}=\mathrm{NH} ;-\mathrm{CH}=\mathrm{N}-)$, carbono-enxofre $(=\mathrm{C}=\mathrm{S}$; $\equiv \mathrm{CS}$-; S- 
$\mathrm{C} \equiv)$, nitro (-NO 2 ; -NO-OH) e nitroso (-N=O; =N-OH). Os grupos mais comuns de auxócromos são os amino (- $\left.\mathrm{NH}_{2}\right)$, metilamino $\left(-\mathrm{NHCH}_{3}\right)$; dimetilamino $\left(-\mathrm{N}\left(\mathrm{CH}_{3}\right)_{2}\right)$; ácido sulfônico ($\left.\mathrm{SO}_{3} \mathrm{H}\right)$; ácido carboxílico (-COOH); cloro (-Cl); metila (- $\left.\mathrm{CH}_{3}\right)$; metoxila (-OCH$)$; carboxila ($\mathrm{COOH})$, ciano $(\mathrm{CN})$; acetila $\left(-\mathrm{COCH}_{3}\right)$; amido $\left(-\mathrm{CONH}_{2}\right)$; e hidroxila $(-\mathrm{OH})(\mathrm{KYZAS}$ et al., 2013; SARAYU; SANDHYA, 2012; ZAHARIA; SUTEU, 2012).

\subsubsection{Classificação}

Os corantes orgânicos são classificados, principalmente, i) com base na estrutura química do composto colorante, bem como ii) pelas características de uso e suas aplicações à fibra, sendo essa última a classificação adotada pelo Colour Index (CI) e formalmente adotada em estudos de pesquisa (GUARATINI; ZANONI, 2000; KYZAS et al., 2013; ZAHARIA; SUTEU, 2012).

\subsubsection{Fibras têxteis e modo de fixação do corante}

As fibras têxteis estão divididas em dois grandes grupos, as i) fibras naturais, de constituição baseada em cadeias poliméricas lineares de glucose (celulose) e em polímeros complexos compostos de diferentes aminoácidos (proteína), presentes na lã, seda, algodão e linho; e as ii) sintéticas, compostas por xantato de celulose (viscose), acetato de celulose extraído da madeira, condensado de ácido adípico e hexametileno diamina (poliamida), polímero de ácido tereftálico e etilenoglicos (poliéster) e polímero de acrilonitrila (acrílico) (GUARATINI; ZANONI, 2000; KYZAS et al., 2013; ZAHARIA; SUTEU, 2012).

A fixação do corante às essas fibras é feita geralmente em meio aquoso, envolvendo quatro tipos de interações. Em geral, as fibras têxteis podem atrair corantes para suas estruturas como resultado da força de Van der Waals, das ligações de hidrogênio e de interações hidrofóbicas, que são características da adsorção física. Especificamente as interações i) iônicas promovem coloração baseada em interações entre os centros positivos dos grupos amino e carboxilato presentes na fibra e a carga iônica da molécula do corante, e vice-versa. Comuns a tintura de lã, seda e poliamida. As interações de ii) Van der Waals apresentam colorações baseadas na aproximação máxima entre orbitais $\pi$ das moléculas do corante e da fibra, ancorando firmemente a molécula do corante à fibra, sem formação de ligação propriamente dita. Características da tintura de lã e poliéster. As interações iii) de hidrogênio mostram coloração proveniente da ligação entre átomos de hidrogênio, covalentemente ligados no corante, com pares de elétrons livres de átomos doadores, presentes na fibra, coloração 
característica de fibras acrílicas. Finalmente, a interação mais forte corante-fibra é aquela que resulta da iv) ligação covalente, com interação eletrostática entre o grupo reativo do corante (eletrofílico) e resíduos nucleofílicos da fibra, de cargas opostas. Tal tipo de coloração é considerada como quimiosorção, característica da tintura de fibra de algodão (GUARATINI; ZANONI, 2000; KYZAS et al., 2013; ZAHARIA; SUTEU, 2012).

\subsubsection{Classes dos corantes}

A classificação dos corantes, de acordo com o Colour Index, está representada pelas seguintes classes:

a) diretos: esses corantes são solúveis em água na presença de eletrólitos, além de apresentar alta afinidade com fibras de celulose, formando interações Van der Waals com esse tipo de fibra. A maioria dos corantes dessa classe são poliazo;

b) dispersos: são corantes insolúveis em água, aplicados em fibras hidrofóbicas, tais como poliéster, poliamida, poliacrilonitrila, polipropileno, acetato, e fibras acrílicas. Quimicamente esses corantes são predominantemente azo e antraquinônicos, tendo baixo peso molecular e contendo nitrobenzenosulfonato, que auxiliam na formação de dispersões aquosas estáveis;

c) à cuba: são corantes insolúveis em água, mas podem ser aplicados, principalmente em fibras de celulose, convertendo-se para sua forma leuco. Em seguida, sofrem oxirredução e são solubilizados para recuperar a forma original do corante sobre a fibra. Tal processo é chamado de processo à cuba. São em sua maioria antraquinônicos e indigóides;

d) de enxofre: são compostos insolúveis em água, que são aplicados na forma de sais de sódio por processo de redução utilizando sulfeto de sódio $\left(\mathrm{Na}_{2} \mathrm{~S}\right)$ como agente redutor, sob condições alcalinas. Após a aplicação, caracterizam-se por compostos macromoleculares contendo pontes polissulfeto $\left(-\mathrm{S}_{\mathrm{n}}{ }^{-}\right)$;

e) básicos: são catiônicos e solúveis em água. São utilizados quando o brilho é mais necessário do que a resistência à luz e à lavagem;

f) ácidos: são aniônicos e contêm grupos sulfônicos, o que os torna solúveis em água. Na coloração o corante é previamente neutralizado e se liga à fibra por meio de troca iônica, envolvendo o par de elétrons livres dos grupos amino e carboxilato da fibra protéica, na forma protonada; 
g) reativos: são corantes que formam ligações químicas covalentes com os grupos hidroxila das fibras celulósicas, com os grupos amino, hidroxila e tióis das fibras protéicas, bem como com os grupos amino das poliamidas. Os principais corantes reativos contêm grupo azo e antraquinona, como cromóforos, e clorotriazinila e sulfatoetilsulfonila, como grupos reativos.

Apesar da classificação formal adotada pelo Colour Index, pode-se ainda dividir os corantes têxteis considerando apenas a estrutura geral, como aniônicos, não iônicos e catiônicos (GUARATINI; ZANONI, 2000; KYZAS et al., 2013; ZAHARIA; SUTEU, 2012).

\subsubsection{Corantes reativos}

Dentre os vários tipos de corantes têxteis existentes, a classe dos reativos apresenta aplicação expressiva no mercado mundial, devido principalmente à ampla gama de tonalidades de cores, facilidade de aplicação e baixo consumo de energia no processo. De forma semelhante, a indústria têxtil brasileira emprega, predominantemente, corantes reativos para fibras celulósicas, que respondem por 57 \% do mercado (ASSOCIAÇÃO BRASILEIRA DA INDÚSTRIA QUÍMICA, 2016).

Estruturalmente, a maioria dos corantes reativos contém grupamentos azo e antraquinônicos. Funcionalmente, esses corantes formam ligação química covalente com a fibra têxtil, o que proporciona estabilidade química para o tingimento. No entanto, os corantes reativos estão dentre os principais corantes aniônicos, que correspondem também aos mais problemáticos, por serem altamente solúveis em água e não serem removidos pelo tratamento convencional dos efluentes têxteis (KYZAS et al., 2013; PEREIRA; ALVES, 2012; ZAHARIA; SUTEU, 2012).

Os corantes reativos possuem estrutura geral composta por um grupo reativo eletrofílico, os quais contêm um grupo de saída nucleófugo (grupo de saída que leva embora o par de elétrons de ligação) e um grupo de ligação. O grupo cromóforo e os grupos de solubilização em água estão ligados em sequência a partir do grupo de ligação. Alguns corantes que contêm dois ou mais grupos reativos são denominados bifuncionais, podendo ser iguais (homofuncionais) ou diferentes (heterofuncionais), conferindo à molécula a capacidade de coesão, uma vez que quanto maior a diversidade desses grupos reativos em uma molécula, mais recalcitrante esta se torna. Os grupos reativos podem ser classificados de acordo com seu mecanismo de fixação. São eles: a) substituição nucleofílica heteroaromática, onde um grupo funcional nucleofílico ionizado da fibra é transferido para o centro eletrofílico do centro do grupo reativo; b) adição 
nucleofílica, que ocorre quando é eliminado o grupo nucleofúgico do grupo reativo da molécula, seguido pela adição de um grupo funcional da fibra têxtil; e $c$ ) formação de fosfonato, caracterizada pela formação de um éster entre a função nucleofílica da fibra e um fósforo-grupo ligado a um carbono aromático ou alifático do corante (GUARATINI; ZANONI, 2000; KYZAS et al., 2013; ZAHARIA; SUTEU, 2012; ZOLLINGER, 2003).

Os corantes reativos podem conter função sulfoxietilsulfonil, as quais formam grupos vinil-sulfona $\left(-\mathrm{SO}_{2}-\mathrm{CH}=\mathrm{CH}_{2}\right)$, que durante o tingimento se ligam à fibra têxtil. Embora essas ligações já estejam formadas, o grupo vinil-sulfona sofre hidrólise espontânea e, como os produtos dessa hidrólise não apresentam qualquer afinidade com as fibras, não formam ligação covalente, ficando dissolvidos no efluente de saída dessa etapa do processo (GUARATINI; ZANONI, 2000; KYZAS et al., 2013; ZAHARIA; SUTEU, 2012). Ainda segundo Zollinger (2003) cerca de 80\% dos corantes reativos são azo. Afirmação confirmada por Zaharia e Suteu (2012) onze anos mais tarde, incluindo ainda dentro dessa classe os ftalocianina, formazan e antraquinônicos.

\subsection{Corantes azo}

Metade dos corantes sintéticos conhecidos são azo, que são compostos contendo grupo azo (-N=N-), com alta polaridade e recalcitrância, caracterizados por propriedades anfotéricas, quando suas moléculas contêm grupos ácidos adicionas (hidroxila, carboxila ou sulfoxila). Tais compostos aceitam prótons para o par de elétrons do nitrogênio, e ainda esses mesmos elétrons interagem com o sistema $\pi$-orbital deslocado. O aceptor substituinte do anel aromático (-Cl ou - $\mathrm{NO}_{2}$ ) causa decréscimo no caráter básico dos grupos amino. Já os grupos doadores $\left(-\mathrm{CH}_{3}\right.$ ou OR), nas posições meta e para, levam a um aumento da basicidade em grupos amínicos, embora doadores substituintes na posição orto podem impedir a protonação e, consequentemente, diminuir a basicidade dos grupos amínicos. A presença de grupos amino na molécula aumenta o ponto de ebulição e sua solubilidade em água (GUARATINI; ZANONI, 2000; KYZAS et al., 2013; ZAHARIA; SUTEU, 2012).

Dependendo do valor de $\mathrm{pH}$, o corante azo pode ser aniônico, por consequência da desprotonação do grupo ácido, pode ser catiônico, por consequência da protonação do grupo amino, ou ainda não iônico (GUARATINI; ZANONI, 2000; KYZAS et al., 2013; ZAHARIA; SUTEU, 2012). 


\subsection{Efluentes têxteis: características e tratamento}

A descarga de efluentes coloridos no ambiente, além de indesejável, é proibida em território nacional e regulamentada pela Resolução do Conselho Nacional do Meio Ambiente n 357, de 17 de março de 2005, não só pela presença de cor, mas também porque muitos dos corantes liberados, e seus produtos de degradação são tóxicos, carcinogênicos ou até mesmo mutagênicos. Além disso, sem o tratamento adequado, estes compostos podem permanecer no ambiente por longos períodos, acarretando ainda mais problemas ao ambiente (AGUIAR; FERRAZ, 2011; GUARATINI; ZANONI, 2000; KUNZ et al., 2002; ZAHARIA; SUTEU, 2012).

Os efluentes altamente coloridos ou efluentes contendo corantes têm sido identificados especialmente pelo banho de tingimento de fibras de celulose, perfazendo, apenas o algodão, o equivalente a $50 \%$ do mercado mundial de fibras celulósicas. Em particular, com uso de corantes reativos nos banhos de tingimento observa-se perdas para o efluente de 10 a $50 \%$, levando para o setor industrial a preocupação com as questões ambientais associadas com teor de corante residual ou a cor residual nos efluentes têxteis tratados. Assim sendo, os corantes orgânicos têxteis devem ser separados e eliminados da água residuária, por meio de métodos eficazes e viáveis, em estações de tratamento de esgoto municipal ou na própria planta industrial, após atender dois conceitos básicos do tratamento: i) separação de poluentes orgânicos de fase líquida do efluente, e ii) retirada e mineralização ou decomposição desses poluentes orgânicos, de forma parcial ou completa (ZAHARIA; SUTEU, 2012).

Processos de separação tem base na mecânica dos fluídos (sedimentação, centrifugação, filtração e flutuação) ou nas membranas sintéticas (micro, ultra e nanofiltração, osmose reversa). Adicionalmente, processos fisico-químicos, tais como adsorção, precipitação química e coagulação-floculação, podem ser usados para separar o dissolvido ou emulsionado (CHEQUER et al., 2013; ZAHARIA; SUTEU, 2012). Outras diferentes técnicas para o tratamento físico e químico desses efluentes foram desenvolvidas, sendo objeto de estudo de recentes pesquisas, que buscam a remoção dos corantes desses resíduos líquidos (ARGUN et al., 2013; EL-GHENYMY et al., 2014; FERNADES RÊGO et al., 2014; FERNANDEZ et al., 2010; FERNANDO et al., 2014; HASSAN; HAMEED, 2011; KAVITHA et al., 2014; LAU et al., 2014; MOREIRA et al., 2013; NABIL et al., 2013; PAJOOTAN et al., 2014; SIDDIQUE et al., 2013; THOMAS et al., 2014; WENG et al., 2013).

Esses processos foram classificados por Fernández e colaboradores. (2010) em i) nãodestrutivos, constituído por todos aqueles que apenas transferem o poluente de fase, sem 
destruí-lo (adsorção, sedimentação, filtração, coagulação e eletrocoagulação) e ii) destrutivos, composto pelas técnicas que destroem a molécula do poluente, por biodegradação ou por processos oxidativos avançados. Ainda outras revisões, como Chacko e Subramanian (2011) e Zaharia e Suteu (2012), apresentam resumidamente os tratamentos mais empregados, suas vantagens e desvantagens, apresentados na Tabela 1, com destaque para as limitações de cada tratamento físico-químico.

Tabela 1 - Algumas das principais técnicas físico-químicas de tratamento de efluentes têxteis, coloridos por corantes orgânicos e suas limitações.

\begin{tabular}{l|l}
\hline \multicolumn{1}{c|}{ Tratamento } & \multicolumn{1}{c}{ Limitações } \\
\hline $\begin{array}{l}\text { Precipitação, coagulação- } \\
\text { floculação }\end{array}$ & $\begin{array}{l}\text { Separação e tratamento de aglomerados; condição seletiva de } \\
\text { operações }\end{array}$ \\
\hline Coagulação eletrocinética & Grande produção de lodo \\
\hline Processo de Fenton & Geração de lodo; problemas com a disposição do lodo \\
\hline Ozonização & $\begin{array}{l}\text { Não aplicável para corantes dispersos; curta meia-vida do } \\
\text { ozônio; produz corantes aromáticos }\end{array}$ \\
\hline Oxidação por NaOCl & Alto custo; produz aminas aromáticas \\
\hline Carvão ativado & Alto custo, elevado custo pra regeneração \\
\hline Processo fotoquímico & Formação de coprodutos \\
\hline Oxidação eletroquímica & Alto custo de processo, principalmente eletricidade \\
\hline Membrana de filtração & $\begin{array}{l}\text { Alto custo de corrida; produção de lodo concentrado; sólidos } \\
\text { dissolvidos não são separados }\end{array}$ \\
\hline Fontes - Chacko e Subramanian & (2011); Zaharia e Suteu (2012).
\end{tabular}

Fontes - Chacko e Subramanian (2011); Zaharia e Suteu (2012).

Embora ineficientes como processos unitários, devido principalmente à diversidade de tipos e classes de corantes, que contêm grupamentos funcionais diferentes, a inviabilização da aplicação de um procedimento único no tratamento desse tipo de efluente, consideram-se esses processos como uma opção quando em associação a tratamentos biológicos, os quais vêm se mostrando uma alternativa promissora para a remoção de corantes dos efluentes do banho de tingimento (ALMEIDA; CORSO, 2014; ÁLVAREZ et al., 2013; BASHA et al., 2011; KIRAN et al., 2013; KUNZ et al., 2001; OLIVEIRA et al., 2010; SABA et al., 2013; SENTHILKUMAR et al., 2012; VANHULLE et al., 2008). Entretanto, os tratamentos biológicos convencionais não se mostraram apropriados para tratar efluentes têxteis, que apresentam alta salinidade e elevado $\mathrm{pH}$. Além disso, esses tratamentos apresentam baixo rendimento na biodegradação de corantes têxteis, que foram sintetizados para resistir à degradação. Adicionalmente, esses tratamentos dispendem de extensos tempos de retenção hidráulica, associados à geração de compostos tóxicos, no caso de processos anaeróbios, podendo ainda formar resíduos de lodo colorido no fundo dos tanques de tratamento, características que os torna também ineficientes, quando aplicados isoladamente. Assim sendo, vários micro-organismos, incluindo fungos, bactérias e algas, vem sendo avaliados na 
descoloração e na degradação de corantes sintéticos. Tais micro-organismos apresentam diferentes capacidades, alguns com vantagens específicas em detrimento de outros (ALI, 2010; CHEQUER et al., 2013; DONLON et al., 1995; DOS SANTOS et al., 2005; HAROUN; IDRIS, 2009; IŞIK; SPONZA, 2007; ZAHARIA; SUTEU, 2012).

\subsection{Biodegradação de corantes}

A biodegradação de corantes é caracterizada pela quebra do grupo cromóforo, que está associada à descoloração, podendo promover o deslocamento do comprimento de onda de máxima absorção desse composto (ALI, 2010; KAUSHIK; MALIK, 2009).

\subsubsection{Fungos ligninolíticos}

Os fungos de podridão branca apresentam vantagem para a aplicação em tratamentos in vivo, devido à presença de um sistema enzimático ligninolítico extracelular e inespecífico, capaz de catalisar a degradação de diferentes compostos químicos, incluindo corantes (AGUIAR; FERRAZ, 2011; BIBI; BHATTI, 2012; DURÁN; ESPOSITO, 2000; FARACO et al., 2009; KALPANA et al., 2012; MALACHOVA et al., 2013; MOREIRA-NETO et al., 2013; MUKHERJEE et al., 2013; PAKSHIRAJAN; KHERIA, 2012). Outra vantagem apresentada por esses fungos é a eficácia no tratamento em ampla faixa de $\mathrm{pH}$ e de temperatura (MUKHERJEE et al., 2013), o que possibilita aplicação direta, dispensando tratamento químico prévio.

\subsubsection{Mecanismo ligninolítico dos basidiomicetos}

O mecanismo ligninolítico desses fungos inclui três enzimas, consideradas por Wong (2009) como principais: Lignina Peroxidase (LiP, EC 1.11.1.14), capaz de oxidar compostos fenólicos e não fenólicos de alto potencial redox; Peroxidase dependente do Manganês (MnP, EC 1.11.1.13), capaz de oxidar compostos fenólicos na presença de $\mathrm{Mn}^{+2}$, e ainda oxidar um segundo mediador para efetivar a quebra de compostos não fenólicos; e Lacase (EC 1.10.3.2), capaz de oxidar compostos fenólicos simultaneamente à redução do oxigênio molecular a água. Ainda, segundo Aguiar e Ferraz (2011), essas enzimas ligninolíticas podem ser ordenadas de acordo com suas capacidades oxidativas: LiPs > MnPs > Lacases.

A LiP e a MnP são heme peroxidases, capazes de oxidar substratos por transferência de elétrons multi-step, com formação de radical catiônico intermediário. A LiP catalisa a despolimerização oxidativa $\mathrm{H}_{2} \mathrm{O}_{2}$-dependente, de forma relativamente inespecífica quanto aos substratos, 
fenólicos e não fenólicos, sendo que os mais rapidamente catalisados são os fenólicos. MnP é capaz de abstrair elétrons apenas de estruturas fenólicas, diferentemente da LiP, que é capaz de oxidar fenólicos e não fenólicos, indistintamente. Nos dois casos, a enzima é ativada pela oxidação por peróxido de hidrogênio, formando um oxo-complexo deficiente em dois elétrons. A redução desse complexo até a enzima nativa ocorre em duas etapas, com a abstração de um elétron de cada vez. No caso da LiP, a redução dos compostos intermediários pode ocorrer por meio da oxidação dos substratos, fenólicos e não fenólicos, levando à formação de radicais cátion. Nessa enzima existe um resíduo de triptofano na cadeia protéica, o qual atua como elo de transferência de elétrons com substratos aromáticos que não podem ter um contato direto com o grupo heme oxidado da enzima. Já a $\mathrm{MnP}$ depende do $\mathrm{Mn}^{2+}$ para a redução de um dos compostos intermediários, oxidando o $\mathrm{Mn}^{+2}$ para $\mathrm{Mn}^{+3}$. Já o outro composto intermediário pode ser reduzido pela oxidação direta de uma estrutura fenólica ou de um átomo de $\mathrm{Mn}^{2+}$, sendo esse íon o elo preferencial de transferência de elétrons, visto que a MnP não possui o resíduo de triptofano, comumente encontrado na $\mathrm{LiP}$, sendo essa a principal diferença entre as duas enzimas (AGUIAR; FERRAZ, 2011; CHACKO; SUBRAMANIAM, 2011; WONG, 2009).

$\mathrm{O} \mathrm{Mn}^{+3}$ formado é então dissociado da enzima e estabilizado pela formação de complexos com $\alpha$-hidroxiácidos, como oxalato e malonato, os quais são ótimos quelantes e são secretados naturalmente pelo fungo. Outras funções fisiológicas estão associadas a estes quelantes, incluindo o aumento da atividade enzimática, pela sua capacidade de facilitar a dissociação de $\mathrm{Mn}^{+3}$ a partir da enzima. A oxidação do ácido oxálico por $\mathrm{Mn}^{+3}$ produz um radical formato $\left(\mathrm{HCO}^{-2}\right)$, que reage com dioxigênio para formar superóxido $\mathrm{O}^{-2}$ e, subsequentemente, $\mathrm{H}_{2} \mathrm{O}_{2}$. O complexo $\mathrm{Mn}^{+3}$-quelante atua como um oxidante difusível de substratos fenólicos, oxidando um elétron do substrato para produzir um radical fenoxila intermediário, o qual sofre rearranjos, clivagens de ligações e degradação não enzimática, produzindo assim vários outros produtos. O quelante $\mathrm{Mn}^{+3}$ gerado pode catalisar a oxidação de substratos fenólicos, incluindo fenóis simples, aminas e corantes, contudo é um oxidante suave sob condições fisiológicas, tendo seu espectro de ação limitado a oxidação de estruturas fenólicas e, por si só, não é capaz de oxidar compostos não fenólicos. Para esses substratos, a oxidação de $\mathrm{Mn}^{+3}$ envolve a formação de radicais reativos na presença de um segundo mediador. $\mathrm{O} \mathrm{Mn}^{+3}$ também participa da peroxidação de lipídeos, para catalisar a clivagem da ligação $\mathrm{C}_{\alpha}-\mathrm{C}_{\beta}$ e de estruturas não-fenólicas da lignina, respectivamente. O mecanismo envolve a captação de hidrogênio a partir do carbono benzílico $\left(\mathrm{C}_{\alpha}\right)$, através de radicais peroxilipídicos, 
seguido da adição de $\mathrm{O}_{2}$ para formar radical peroxi e subsequente degradação não enzimática (WONG, 2009).

As lacases são enzimas oxidoredutases multicobre, contendo quatro átomos de cobre, que abstraem elétrons de fenóis, em função da redução do $\mathrm{Cu}^{+2} \mathrm{a} \mathrm{Cu}^{+1}$, reduzindo $\mathrm{O}_{2} \mathrm{a} \mathrm{H}_{2} \mathrm{O}$. A estequiometria é de quatro moléculas de substrato redutor para cada oxigênio molecular, envolvendo a transferência total de quatro elétrons. O primeiro passo da redução é a catálise do substrato pela redução de um cobre, Tipo 1 (T1), que é o receptor primário, transferindo os elétrons para os demais cobres, T2 e T3, resultando na redução total da enzima. As lacases catalisam a subtração de um elétron a partir de grupos hidroxifenólicos para formar radicais fenoxi, que geralmente sofrem polimerização por acoplamento. Essa reação é acompanhada por desmetilação e formação de quinona, resultando em clivagem do anel aromático (POLAK; JAROSZ-WILKOLAZKA, 2012; SINGH et al., 2015; WONG, 2009).

Sistemas mediados por LiP e MnP são capazes de oxidar não fenólicos; no entanto, alguns fungos de podridão branca não produzem essas duas enzimas, mas produzem lacase como a enzima predominante e ainda são capazes de degradar lignina de forma eficiente. Isso porque a lacase é capaz de oxidar compostos não fenólicos, porém na presença de um mediador, que pode ser sintético, como o caso do ABTS (2,2'-azinobis- (3-etilbenzotiazolino6-sulfonato)) ou natural, como são o ácido benzóico e o íon $\mathrm{Mn}^{+2}$ (AGUIAR; FERRAZ, 2011; SINGH et al., 2015; WONG, 2009). Esses mediadores, conhecidos como compostos de baixa massa molar, podem ser empregados conjuntamente na mesma reação catalisada por lacase, uma vez que tal combinação pode aumentar as taxas de oxidação, comparado com as taxas obtidas separadamente com cada sistema mediador. Segundo Arantes e Milagres (2009) um mediador é uma molécula de baixa massa molar, que atua como carreador de elétrons, e sua oxidação pode ocorrer pela transferência de elétrons via direta ou via transferência de átomos de hidrogênio, sendo que essa última via é imprescindível para que a peroxidação lipídica com lacase ocorra (CAÑAS; CAMARERO, 2010; POLAK; JAROSZ-WILKOLAZKA, 2012).

Ainda em sua revisão, Cañas e Camarero (2010) comentam que o mediador redox ideal deve ser pequeno, capaz de gerar radicais estáveis, na sua forma oxidada, que não inativem a enzima, e ainda ser capaz de ser reciclado sem degenerar. Adicionalmente, do ponto de vista ambiental e industrial, deve ser menos agressivo e de baixo custo. 


\subsubsection{Peroxidação lipídica e reação de Fenton}

A peroxidação lipídica consiste na incorporação do oxigênio molecular a um ácido graxo insaturado para produzir um hidroperóxido $(\mathrm{R}-\mathrm{OOH})$, como produto primário inicial. Tal mecanismo gerador de radicais livres tem como principal produto o radical peroxila (-OOR), o qual apresenta potencial de oxidação suficientemente elevado para oxidar compostos não fenólicos. Durante a biodegradação, a peroxidação lipídica pode ser mediada por radicais hidroxila ( $\left.{ }^{-} \mathrm{OH}\right)$ e hidroperoxila (־OH), e ainda metais de transição $\mathrm{Fe}^{+2} \mathrm{e} \mathrm{Cu}^{+2}$. Contudo $\mathrm{Fe}^{+3}$ e $\mathrm{Fe}^{+3}$-complexado podem iniciar a peroxidação lipídica, desde que um agente redutor esteja presente para reduzir $\mathrm{Fe}^{+3}$ para $\mathrm{Fe}^{+2}$. $\mathrm{O}$ íon $\mathrm{Mn}^{+3}$ gerado pela $\mathrm{MnP}$ também pode mediar a peroxidação lipídica, quando complexado com ácidos orgânicos, possibilitando um aumento da taxa de peroxidação. Ainda lacases podem mediar esse processo, quando em um complexo Lacase-Fenol- $\mathrm{Mn}^{+2}$. Ficam assim evidentes as diferenças na mediação desse processo por essas duas enzimas, uma vez que lacase não requer a presença de peróxido de hidrogênio, nem de ácidos orgânicos para completar sua ação mediadora, diferente da MnP (AGUIAR; FERRAZ, 2011; ARANTES; MILAGRES, 2007; HAMMEL et al., 2002; SREBOTNIK; BOISSON, 2005; TEN HAVE; TEUNISSEN, 2001).

Um processo iniciador da peroxidação de lipídeos é a reação de Fenton, que é baseada na reação entre $\mathrm{H}_{2} \mathrm{O}_{2}$ e Fe $\mathrm{Fe}^{+2}$, em meio ácido, para formar espécies reativas de oxigênio (ROS), principalmente ${ }^{-} \mathrm{OH}$, que é o mais forte oxidante que pode ocorrer em meio aquoso. Dessa forma, fica evidente a importância do íon ferro para os fungos de podridão branca, uma vez que, além de estar diretamente envolvido na produção de ROS, faz parte do sítio ativo das peroxidases. Esse íon é geralmente retirado do substrato ligninocelulósico pelo fungo, sendo encontrado predominantemente na forma oxidada e insolúvel $\left(\mathrm{Fe}^{+3}\right)$, o que gera demanda por quelantes para solubilizá-lo e reduzi-lo. Tais quelantes podem ainda mediar a reação de Fenton, juntamente com o sistema mediado por lacase, o que amplia a oxidação do composto alvo na biodegradação (AGUIAR; FERRAZ, 2011; ARANTES; MILAGRES, 2007; HAMMEL et al., 2002; SREBOTNIK; BOISSON, 2005; TEN HAVE; TEUNISSEN, 2001).

\subsubsection{Compostos de Baixa Massa Molar}

Os compostos de baixa massa molar (CBMM), produzidos naturalmente por fungos de podridão branca, identificados e relacionados à degradação dos componentes da madeira, foram descritos em estudos recentes (ARANTES et al., 2011; ARANTES; MILAGRES, 2009; 
2010; HAMMEL et al., 2002; HORTA et al., 2011; KAPICH. et al., 2010; MOLDES et al., 2012). São eles:

a) ácido 3-hidroxi-antranílico: é um metabólito produzido por Pycnoporus cinnabarinus, que sob forma de radical, é capaz de mediar a atividade de lacase na degradação de não fenólicos;

b)ácidos carboxílicos: dentre as inúmeras funções listadas para o ácido oxálico, um ácido dicarboxílico metabólito fúngico, é capaz de reduzir intermediários para início da degradação não enzimática da madeira, quelar $\mathrm{Ca}^{+2}$ e $\mathrm{Mn}^{+3}$, e ainda mediar naturalmente a atividade de $\mathrm{MnP}$, na presença de $\mathrm{Mn}^{+3}$, e LiP, na presença de álcool veratrílico;

c) ácidos graxos insaturados: a peroxidação de ácidos graxos insaturados produz radicais livres, principalmente radical peroxila, que são capazes de oxidar estruturas não fenólicas da lignina;

d)álcool veratrílico (álcool 3,4-dimetoxibenzílico): metabólito secundário produzido e acumulado no meio de cultura de fungos de podridão branca produtores de LiP, capaz de mediar essa atividade enzimática;

e) compostos aromáticos clorados: podem ser produzidos por fungos, como é o caso do 2-cloro-1,4-dimetoxibenzeno, e atuar na mediação de LiP. Contudo, na ausência dessa enzima, esses compostos podem atuar como substratos de outra enzima oxidase, para produzir peróxido de hidrogênio;

f) espécies reativas de oxigênio (ROS): são aos radicais hidroxila (־H), peroxila (־OOR) e hidroperoxila (־OH). Hidroxila é produzido pela reação de Fenton e é considerado o mais forte oxidante que pode ocorrer nos sistemas aquosos. Já os radicais peroxila e hidroperoxila são resultantes da oxidação de polímeros da madeira pelo radical hidroxila, e também da peroxidação lipídica por MnP. Esses dois últimos são oxidantes mais seletivos;

g)compostos quelantes e redutores de $\mathrm{Fe}^{+3}$ : são compostos aromáticos, por exemplo ácido hidroxifenilacético, ácido hidroxibenzóico e hidroxibenzeno, ou ainda quinonas, capazes de reduzir $\mathrm{Fe}^{+3}$, concomitantemente com a geração de radicais hidroxila, sendo assim considerados mediadores da reação de Fenton;

h) peptídeos: são glicopeptídeos, e também peptídeos, capazes de quelar $\mathrm{Fe}^{+3}$ para reduzir a $\mathrm{Fe}^{+2}$, seguindo a reação de Fenton. Possuem afinidade com $\mathrm{Fe}^{+2}$, formando um complexo capaz de catalisar reações oxidoredutivas, produzindo peróxido de 
hidrogênio, além de também serem capazes de reduzir o peróxido formado a radicais hidroxila, via reação de Fenton.

O modo de ação desses compostos na biodegradação da madeira, segundo Aguiar e Ferraz (2011) consiste em atuar diretamente na oxidação da parede celular vegetal ou ainda como mediadores das enzimas oxidativas, viabilizando assim o acesso das enzimas ao substrato Apesar de haver relatos da importância do papel desses compostos de baixa massa molar na degradação da lignina desde a década de 1980, como mencionado nos estudos de Evans et al. (1994) e de Kirk e Farrell (1987) que esses compostos receberam maior atenção em estudos relacionados à degradação (AGUIAR; FERRAZ, 2011; ARANTES et al., 2009; HAMMEL et al., 2002; MOLDES et al., 2012; TEN HAVE; TEUNISSEN, 2001) o entanto tais estudos não mencionam a sinergia existente entre as enzimas ligninolíticas e a ação oxidativas desses compostos, assunto discutido por Arantes e Milagres (2007), em estudo de degradação de Azure B por fungos de podridão branca., em estudo de degradação de Azure B por fungos de podridão branca.

\subsection{Fatores importantes de tratamentos de descoloração empregando basidiomicetos}

O desenvolvimento de biotecnologia eficiente requer a aplicação de espécies selecionadas cuidadosamente e de condições favoráveis ao processo. Valores significativos de biomassa e componentes celulares podem ser obtidos por otimização de condições de cultivo, por isso em planejamento de sistemas de tratamento é importante estimular a produção das enzimas ligninolíticas, adicionando compostos considerados indutores e/ou estimuladores ao cultivo dos fungos. Uma vez que estudos relatam que a presença de co-substratos, como fontes de carbono e nitrogênio, favorece a descoloração e ainda estimula a produção enzimática (ALI, 2010; ANDRADE et al., 2013; FUKUDA et al., 2009; GAHLOUT et al., 2013; LEVIN et al., 2010; SARAYU; SANDHYA, 2012). Nesse contexto, uma variedade de substratos é avaliada como fonte de carbono e nitrogênio, visando a minimização dos custos dos processos, como por exemplo, amido, glicerol, farelo de arroz e de trigo, licor de maceração de milho, extrato de levedura, glúten de milho, oxalato de amônio, entre outros, variando os melhores substratos e suas concentrações, de acordo com os espécimes estudados. Outros indutores são os metais, uma vez que participam do ciclo catalítico dessas enzimas, como é o caso do cobre e do manganês, amplamente estudados em sistemas de cultivo de basidiomicetos (AKDOGAN et al., 2014; BALDRIAN; GABRIEL, 2002; FONSECA et al., 2010; LORENZO et al., 2006; 
KARP et al., 2012; KAUSHIK; MALIK, 2009; KIRAN et al., 2012; KOYANI et al., 2013; MOREIRA et al., 2000; TINOCO et al., 2011; WONG, 2009). Além disso, é sabido que MnP tem sua expressão regulada pela presença de $\mathrm{Mn}^{+2}$ no meio de cultivo, e ainda a presença de ácidos orgânicos e de $\mathrm{Mn}^{+2}$ têm efeito estimulatório na produção de MnP (BONNARME; JEFFRIES, 1990; MESTER; FIELD, 1997).

Contudo, mesmo diante de tão amplo espectro de ação degradativa e ainda da inespecificidade do sistema ligninocelulolítico, nem todos os fungos são capazes de produzir todas as enzimas do mecanismo enzimático supracitado em sistemas de tratamento biológicos, havendo predominância das lacases na maioria das vezes (BARRASA et al., 2009; BIBI; BHATTI, 2012; MOREIRA et al., 2014; PAPADOPOULOU et al., 2013). Dessa forma, fica comprometida a eficiência do tratamento já que muitos corantes com grupo funcional azo não são substratos de lacase, demonstrando recalcitrância, mesmo em condições otimizadas, o que ainda mostra a necessidade do uso de mediadores, para proporcionar o ataque enzimático nesses casos (CAÑAS; CAMARERO, 2010; KUMAR et al., 2012; HU et al., 2009; NOUSIAINEN et al., 2014; SHANKAR; SHIKHA, 2015).

Outro fator importante na otimização desses sistemas de tratamento é o uso de substrato ligninocelulósico no cultivo, não só devido à indução das enzimas ligninolíticas, mas também porque os substratos ligninocelulósicos podem favorecer a produção de lacases amarelas, capazes de oxidar estruturas não fenólicas diretamente, ampliando assim o espectro de ação do sistema de tratamento (AGUIAR; FERRAZ, 2011; CHEN et al., 2014; IQBAL; EDYVEAN, 2005; LI et al., 2014; MAZMANCI; UNYAYAR, 2005; SAAB et al., 2013; SARATALE et al., 2011).

Deve-se também considerar sistemas in vitro e in vivo, que é objetivo de estudo de vários pesquisadores (HADIBARATA et al., 2012a; OSMA et al., 2010; ZHAO et al., 2007; ZILLE et al., 2003). Contudo, é importante lembrar que sistemas in vivo oferecem vantagens em relação aos sistemas in vitro, uma vez que in vivo ocorre a peroxidação lipídica, via importante da biodegradação, além de apresentar baixo custo (AGUIAR; FERRAZ, 2011; CAÑAS; CAMARERO, 2010).

Existem ainda os fatores que podem afetar a biodegradação dos corantes, como por exemplo as condições ambientais de $\mathrm{pH}$ e temperatura. Além disso, é importante lembrar que estabelecer as condições ótimas para o processo deve anteceder sua caracterização, uma vez que nas condições otimizadas o processo atinge a máxima eficiência. De forma a completar estudos desse tipo, deve-se ainda verificar a presença de produtos da degradação, para 
confirmar a quebra da molécula tratada e também obter informações sobre a toxicidade de seus produtos (ALI, 2010).

\subsubsection{Os gêneros de basidiomicetos: Pleurotus, Peniophora e Trametes}

Os gêneros de basidiomicetos Peniophora, Trametes e Pleurotus vem sendo avaliados em tratamentos com corantes de grupo funcional azo. Shankar e Shikha (2015) estudando a descoloração com Peniophora sp., avaliou o efeito dos metais $\mathrm{Cd}^{+2}, \mathrm{Co}^{+2}, \mathrm{Ca}^{+2}, \mathrm{Cu}^{+2}, \mathrm{Mn}^{+2}$, $\mathrm{Ni}^{+2}, \mathrm{Na}^{+}$e dos mediadores de lacase, 1-hidroxibenzotriazol (HBT) e ABTS, na descoloração de corantes nitro e azo. Seus resultados mostraram que $1 \mathrm{mM}$ de ABTS foi a melhor condição para a descoloração desses corantes, onde Metil Orange, um corante monoazo, apresentou um máximo de descoloração de 42 \% e Amido Black, um corante diazo, atingiu um máximo de 25 \% de descoloração. Em outro estudo empregando P. cinerea CCIBt 2541, Moreira et al. (2014) avaliaram o sistema lacase-siringaldeído- $\mathrm{Mn}^{+2}$-oxalato na descoloração dos corantes têxteis CI Reactive Blue 19 e Red 271, mostrando ser esse um sistema promissor para tratamentos desse tipo. Em 2016, Bonugli-Santos et al. em estudo envolvendo esse mesmo gênero de basidiomiceto, aplicado na descoloração de corante azo, mostraram que MnP tem papel fundamental na descoloração e biodegradação de Reactive Black 5. Contudo, apesar da eficiência de Peniophora na descoloração de corantes sintéticos, tal potencialidade não está bem documentada para diferentes espécies desse gênero (SHANKAR; SHIKHA, 2015).

Basidiomicetos do gênero Trametes vem sendo bastante estudados e os resultados estão bem documentados pela literatura, como é o caso do estudo de Bibi e Bhatti (2012), que avaliaram a descoloração de corantes de função azo e antraquinona, empregando Trametes hirsuta, Pycnoporus sp. e Irpex sp., sob diferentes condições de cultivo. Esses autores observaram que, sob condições estacionárias, T. hirsuta descoloriu o corante antraquinônico em 50 \% após 24 horas, atingindo 80 \% após 5 dias de incubação, mostrando taxas 2 a 5 vezes maior do que aquelas observadas com os demais fungos avaliados. Contudo, como é sabido da dificuldade em se degradar corantes azo, os corantes azo avaliados não descoloriram mais que 40 \% e Trametes apresentou maior descoloração do corante monoazo Reactive Orange 16 em relação aos demais fungos estudados, confirmando assim sua potencial capacidade oxidativa. Em outro estudo com várias espécies de Trametes, Chenaux et al. (2014) avaliaram a descoloração de corante Acid Red 27, corante fenólico monoazo, sob períodos prolongados (acima de 24 horas) e os resultados confirmam a capacidade oxidativa desse gênero de basidiomicetos, indicando ainda a lacase como a principal enzima envolvida na descoloração. 
Si et al. (2013), em estudo de descoloração de corante diazo não fenólico Congo Red, observaram que dentre as 42 espécies testadas, Trametes pubescens apresentou os melhores resultados, confirmando ainda a degradação por identificação de metabólitos. Essa mesma capacidade biodegradativa foi confirmada por Adnan et al. (2014) em estudo com Trametes gibbosa sp. na descoloração de Reactive Black 5. Adicionalmente, lacase purificada de Trametes polyzona foi eficiente em descolorir corantes de função azo, com e sem estruturas fenólicas na molécula do corante, confirmando assim a capacidade desse gênero de basidiomiceto em tratamentos desse tipo (CHAIRIN et al., 2013).

Uma espécie de Pleurotus ( $P$. eryngii) foi avaliada por Hadibarata et al. (2013) na descoloração de Reactive Black 5, um corante reativo diazo contendo estrutura fenólica, em diferentes condições, onde foi observada descoloração acima de 90 \%. Outros pesquisadores, como Papadopoulou et al. (2013), também avaliaram Pleurotus, juntamente com outros fungos, na descoloração de diferentes corantes de função azo e antraquinona, e observaram que as melhores taxas de descoloração foram obtidas pelas espécies desse gênero, contudo os resultados mostram recalcitrância nos tratamentos contendo corantes de função azo. Ainda Kiran et al. (2012), em estudo comparativo de descoloração de Reactive Blue 222 por P. ostreatus e Phanerochaete chrysosporim, mostraram que Pleurotus apresentou melhores resultados de descoloração. Já Barreto et al. (2012) avaliaram a cinética de descoloração de três corantes azo, empregando P. ostreatus, e observaram baixas taxas de descoloração para esses corantes considerados recalcitrantes.

Recentemente Moreira Neto et al. (2011) e Moreira Neto et al. (2013) avaliaram a capacidade de espécies desses gêneros de basidiomicetos em descolorir o corante reativo antraquinônico CI Reactive Blue 19, onde Peniophora cinerea, Pleurotus ostreatus e Trametes villosa foram selecionadas por apresentarem potencial biotecnológico para degradação desse corante têxtil em alta salinidade, pH elevado, associado a um tempo de retenção hidráulica reduzido. Em continuidade, Santos (2016) avaliou tratamentos de descoloração de corantes reativos de função azo, não fenólicos, em misturas no banho de tingimento, empregando esses três basidiomicetos imobilizados em biorreatores, a tentativa de estabelecer um processo biotecnológico. Contudo, ainda é necessário caracterizar o processo, visto que parte dos estudos não comprova a degradação, comprometendo-se apenas com a diminuição da cor no efluente. É nesse contexto que o presente estudo avaliou parâmetros que interferem no processo de descoloração de um corante reativo diazo, de uso frequente pela indústria têxtil, procurando 
inferir os componentes envolvidos nos diferentes mecanismos de degradação do corante pelas espécies estudadas. 


\section{OBJETIVOS}

Na busca pelo aprimoramento do tratamento de efluentes têxteis empregando basidiomicetos, esse trabalho teve por objetivo caracterizar o processo de descoloração de um corante reativo diazo, por fungos ligninolíticos, avaliando as características fisiológicas, concomitantemente ao tratamento de descoloração, além de identificar a possível biodegradação desse corante. Os objetivos específicos foram:

a) determinar atividades enzimáticas ligninolíticas e detectar compostos de baixa massa molar, quelantes e redutores de ferro, presentes em sistemas de cultivo de basidiomicetos, na presença e ausência de corante;

b) identificar a melhor idade fisiológica dos sistemas de cultivo para aplicação em tratamento de descoloração;

c) avaliar concentração de corante para aplicação nos sistemas de tratamento;

d) avaliar a influência de diferentes concentrações de sulfato de cobre e de manganês, adicionados ao meio de cultivo, na produção das enzimas ligninolíticas e na descoloração;

e) avaliar concentração de fonte de ácido graxo conhecida que favoreça não apenas a produção das enzimas ligninolíticas, mas também a descoloração;

f) avaliar o papel de diferentes concentrações e combinações de dois mediadores das atividades enzimáticas na descoloração do corante;

g) avaliar o emprego de ferramentas estatísticas para delineamento experimental e análises de dados em processos de otimização;

h) avaliar método de baixo custo para a detecção de metabólitos formados durante o processo de descoloração;

i) correlacionar os componentes envolvidos no processo de descoloração, a fim de estabelecer possíveis rotas metabólicas. 


\section{MATERIAL E MÉTODOS}

Foram utilizados os fungos Peniophora cinerea (CCIBt 2541), Pleurotus ostreatus (CCIBt 2347) e Trametes villosa (CCIBt 2628), coletados nas América Central e América do Sul, em regiões caracterizadas como tropicais, pertencentes à Coleção de Culturas de Algas, Cianobactérias e Fungos do Instituto de Botânica (CCIBt), selecionados previamente por Moreira Neto et al. (2011). As culturas fúngicas foram mantidas em meio sólido BDA (Batata Dextrose Agar), sob refrigeração a $5 \pm 0,2{ }^{\circ} \mathrm{C}$.

O corante têxtil utilizado foi CI Reactive Blue 222 (RB222) (Golden Tecnologia, São Paulo, SP, Brasil), da classe dos reativos. Esse corante foi avaliado em solução aquosa, denominada nesse estudo como efluente sintético, o qual foi preparado em temperatura ambiente com água deionizada. A estrutura química do corante estudado está apresentada na Figura 1.

Figura 1 - Estrutura química de CI Reactive Blue 222.

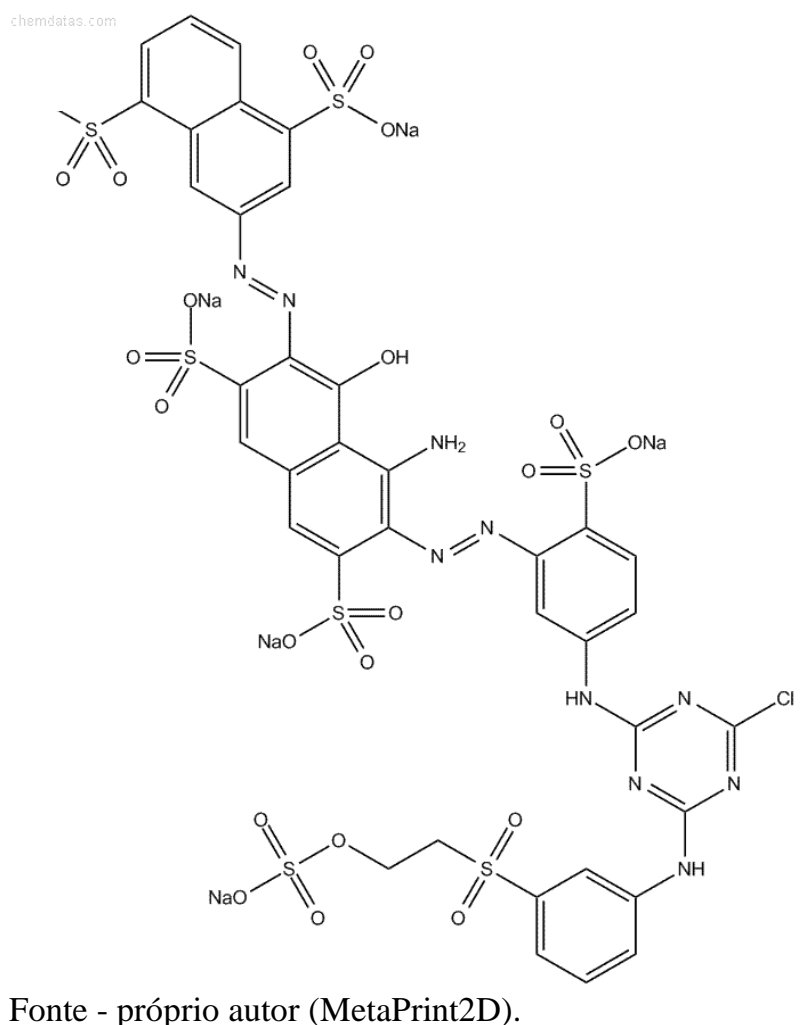

Todos os dados foram analisados por programa estatístico (MINITAB, 2016), onde valores porcentuais foram transformados previamente às análises estatísticas, empregando a equação descrita a seguir (VIEIRA; HOFFMANN, 1989). 
Valor transformado $=\operatorname{arcsen}($ raiz $(\% / 100))$

Onde:

arcsen $=$ arco seno

$\%$ = valor de descoloração porcentual

As médias obtidas nos experimentos 1, 2 e 5 foram comparadas pelo teste de Tukey, sempre protegidas por análise de variância (ANOVA), onde $\alpha \leq 0,1$.

Foi feita análise de correlação entre as atividades enzimáticas e a descoloração, nos experimentos 2, 3, 4 e 5, empregando o coeficiente de correlação de Pearson (p), onde a interpretação se deu com base nos valores obtidos, sendo que positivos corresponderam a correlação positiva e negativos à correlação negativa, de acordo com as faixas: de 0,00 a 0,19 = correlação bem fraca; de 0,20 a 0,39 = correlação fraca; de 0,40 a 0,69= correlação moderada; de 0,70 a 0,89 = correlação forte; de 0,90 a 1,00 = correlação muito forte.

Os experimentos 3 e 4 tiveram planejamento experimental baseado no Delineamento Central Composto Rotacional (DCCR), para avaliação das variáveis e seus fatores. Os blocos experimentais foram compostos por tratamentos fatoriais (+1 e -1), pontos axiais $(+\alpha e-\alpha)$ e um ponto central, avaliado em replicatas. Os valores de $\alpha$ foram calculados pelo programa estatístico e a partir dos dados reais obtidos foi feita análise de superfície de resposta, originando equações quadráticas para predizer valores para as variáveis que apresentaram apoio de seus modelos matemáticos pela análise de variância. Tais equações foram constituídas por uma constante, os coeficientes dos termos lineares e dos termos quadráticos, mais a interação dos coeficientes (CUNICO et al., 2008; PRATHEEBAA et al., 2013; RODRIGUES; IEMMA, 2014), expressas pela equação geral: $[$ Resposta predita $=$ constante $+\Sigma$ coeficientes lineares . fatores $+\Sigma$ coeficientes quadráticos . fatores $+\Sigma$ interação dos coeficientes . fatores]. Foi também empregado o Otimizador de Resposta do programa estatístico, visando identificar as configurações de variáveis que otimizassem uma resposta desejada. 


\subsection{Experimento 1 - Crescimento fúngico, tamponamento do meio $e$ atividades enzimáticas ligninolíticas durante descoloração de RB222 por Pleurotus ostreatus}

Pleurotus ostreatus foi avaliado como basidiomiceto modelo na descoloração in vivo de RB222, onde os sistemas de cultivo líquido que respeitaram uma relação fase líquida:ar de 1:6,6 (v/v).

\subsubsection{Sistemas de cultivo}

Foram preparados frascos contendo meio basal (MB), previamente esterilizado por via úmida a $121{ }^{\circ} \mathrm{C}, 1,5$ atm de pressão, durante 20 minutos. O MB foi constituído de 0,049 g/L CuSO 4 , 0,2 g/L K2 $\mathrm{HPO}_{4}$, 0,05 g/L MgSO 4 , 0,016 g/L MnSO 4 , 12 g/L sacarose e 0,56 g/L ureia (0,056 \%), em água ultra pura (comunicação pessoal) ${ }^{1}$, onde 10 discos de inóculo ( $\varnothing=0,7 \mathrm{~cm} ; \approx 3,9 \mathrm{~cm}^{2}$ ), constituído de micélio fúngico em crescimento exponencial, cultivado em Batata Dextrose Ágar (BDA), foram introduzidos. Os frascos foram incubados a $28 \pm 2{ }^{\circ} \mathrm{C}$, por 10 dias.

\subsubsection{Sistema de tratamento}

Foram constituídos pelos sistemas de cultivo, com 10 dias de idade fisiológica, acrescidos de 25 mL de efluente sintético com RB222, atingindo concentração final de $0,03 \%$. Foram preparados frascos individuais para cada tempo, avaliados em triplicata. Os controles bióticos, onde o efluente sintético foi substituído por água, e controles abióticos, sistemas não inoculados, foram avaliados em duplicata. Os frascos permaneceram incubados a $28 \pm 2{ }^{\circ} \mathrm{C}$ por até 72 horas.

\subsubsection{Parâmetros avaliados}

Foram determinados no tempo inicial, antes da adição do corante, o aumento de biomassa, o pH e as atividades enzimáticas ligninolíticas. Após a adição do corante foram avaliados os mesmos parâmetros descritos acima e também a descoloração a $610 \mathrm{~nm}$ ( $\lambda_{\text {máx }}$ de RB222), em 6, 12, 24, 48 e 72 horas de contato in vivo com o corante.

\footnotetext{
${ }^{1}$ Informação fornecida por Vera Maria Valle Vitali, no Instituto de Botânica da Secretaria do Meio Ambiente do Estado de São Paulo, em janeiro de 2016
} 


\subsection{Biomassa}

A biomassa foi separada da fase líquida por filtração, em membrana de Nylon 0,45 $\mu \mathrm{m}$, previamente seca e pesada, até peso constante. A quantidade (g) foi dada pela diferença de peso entre a biomassa úmida e seca, até obtenção de peso constante. A secagem se deu em estufa de secagem (Mod 320- SE, Fanem Ltda., Brasil) a $105^{\circ} \mathrm{C}$, por 24 horas. Todos os demais parâmetros foram avaliados no filtrado.

\subsubsection{2. $\mathrm{pH}$}

Foi determinado em alíquotas de $15 \mathrm{~mL}$, em temperatura ambiente, empregando pH-metro previamente calibrado (Docu-pHmeter, Sartorius AG, Germany).

\subsection{Atividades enzimáticas}

Foram determinadas as atividades oxidativas de:

a) fenoloxidases: determinada pela oxidação do ABTS (A420nm, $\varepsilon=36.000 \mathrm{M}^{-1}$. $\mathrm{cm}^{-1}$ ) em tampão acetato de sódio $0,1 \mathrm{M}, \mathrm{pH} 4,8$, na presença de $\mathrm{H}_{2} \mathrm{O}_{2}$ na mistura reacional, de acordo com Ballaminut e Matheus (2007), onde uma unidade enzimática correspondeu à quantidade de enzima capaz de oxidar 1 $\mu \mathrm{Mol}$ de ABTS por minuto;

b) lacases: determinada pela oxidação do ABTS (A420nm, $\varepsilon=36.000 \mathrm{M}^{-1} \cdot \mathrm{cm}^{-1}$ ) em tampão acetato de sódio 0,1 M, pH 4,8, na ausência de $\mathrm{H}_{2} \mathrm{O}_{2}$, eliminado da mistura reacional pela adição de $6000 \mathrm{U} / \mathrm{mL}$ de catalase bovina, de acordo com Ballaminut e Matheus (2007), onde uma unidade enzimática correspondeu à quantidade de enzima capaz de oxidar $1 \mu \mathrm{Mol}$ de ABTS por minuto;

c) peroxidases totais: dada pela diferença entre as atividades de fenoloxidases e lacases, conforme Eggert et al. (1996);

d) peroxidase dependente do manganês ( $\mathrm{MnP})$ : dada pela oxidação do vermelho de fenol em $610 \mathrm{~nm}\left(\mathrm{~A}_{610 \mathrm{~nm}}, \varepsilon=65.000 \mathrm{M}^{-1}\right.$. $\left.\mathrm{cm}^{-1}\right)$, em tampão succinato de sódio 0,02 M, pH 4,5, de acordo com Kuwahara et al. (1984), onde uma unidade enzimática correspondeu à quantidade de enzima capaz de oxidar 1 $\mu \mathrm{Mol}$ de substrato por minuto;

e) lignina peroxidase ( $\mathrm{LiP})$ : dada pela oxidação do álcool veratrílico, na presença de $\mathrm{H}_{2} \mathrm{O}_{2}$ a $310 \mathrm{~nm}\left(\mathrm{~A}_{310 \mathrm{~nm}}, \varepsilon=9.300 \mathrm{M}^{-1}\right.$. $\left.\mathrm{cm}^{-1}\right)$ em tampão tartarato de sódio 0,25 M, pH 3,0, de acordo com Kirk e Farrel (1987), onde uma unidade 
enzimática correspondeu à quantidade de enzima capaz de oxidar $1 \mu \mathrm{Mol}$ de substrato por minuto;

f) peroxidase versátil (VP): dada pela oxidação do sulfato de manganês, na presença $\mathrm{H}_{2} \mathrm{O}_{2}$ a $238 \mathrm{~nm}\left(\mathrm{~A}_{238 \mathrm{~nm}}, \varepsilon=6.500 \mathrm{M}^{-1}\right.$. $\left.\mathrm{cm}^{-1}\right)$, segundo o descrito por Rodriguez et al. (2004), onde uma unidade enzimática correspondeu à quantidade de enzima capaz de oxidar $1 \mu \mathrm{Mol}$ de substrato por minuto;

g) atividade total de descoloração (ATD): avaliada pela oxidação do corante RB222, em 526 nm. O cálculo foi feito empregando a equação descrita por Zeraik et al. (2008).

$$
\mathrm{U} / \mathrm{L}=\text { Absorbância } / \varepsilon \cdot 1 / \mathrm{V}_{\text {extrato(mL) }} \text {. diluição } \cdot 1 / \mathrm{t}_{(\min )} \cdot 10^{6}
$$

\subsection{Descoloração}

A avaliação da descoloração do corante foi calculada a partir da leitura das absorbâncias no comprimento de onda de máxima absorção ( $\left.\lambda_{\text {máx }}\right)$ do corante de estudo, 610nm (Espectrofotômetro 600S, FEMTO, Brasil) e calculada empregando a equação descrita por Moreira Neto et al. (2013).

$$
\mathrm{D} \%=\left(\left(\mathrm{A}_{0}-\mathrm{A}\right) \cdot 100\right) / \mathrm{A}_{0}
$$

Sendo:

$\mathrm{D} \%$ = descoloração porcentual

$\mathrm{A}_{0}=$ absorbância no tempo inicial de análise

A = absorbância no tempo final de análise

A partir da observação de descoloração, foram feitas leituras de todas as absorbâncias do espectro entre 100 e 1100nm, a fim de compor o espetro de absorção de cada amostra desejada.

\subsubsection{Coeficiente de Extinção Molar ( $\varepsilon$ ) de RB222 em 526nm}

O Coeficiente de extinção molar $\left(\varepsilon_{526 \mathrm{~nm}}\right)$ do corante RB222 foi obtido experimentalmente pela quantificação do corante no efluente sintético por cromatografia líquida de alta eficiência (HPLC DAD Série 20AT, Shimadzu Corporation, Japão). Os efluentes testados tinham concentração entre 0,01 \% e 0,05 \% e as absorbâncias empregadas foram aquelas observadas em $526 \mathrm{~nm}$. As condições cromatográficas foram: 
coluna analítica C18; eluição isocrática; fase móvel constituída de tampão fosfato de sódio monobásico 25 mM, pH 3,0 e metanol, na proporção de 2:3 (v/v); temperatura do forno de $30{ }^{\circ} \mathrm{C}$; fluxo de $1 \mathrm{~mL} / \mathrm{min}$; volume de injeção de $10 \mu \mathrm{L}$ e tempo de análise de 8 minutos. O coeficiente angular da reta, obtida por regressão linear, correspondeu ao coeficiente de extinção molar.

\subsection{Experimento 2 - Influência da idade fisiológica de basidiomicetos $e$ da concentração de RB222 na descoloração}

Foram avaliados os três basidiomicetos, Pleurotus ostreatus, Peniophora cinerea e Trametes villosa, na descoloração in vitro de diferentes concentrações de corante $(0,03 \%$ $=3,0 \mathrm{E}-02 \%, 0,0003=3,0 \mathrm{E}-04 \% \%$ e 0,00003 \% = 3,0E-05\%), a fim de padronizar a concentração de estudo, que permitisse promover maiores taxas de descoloração de RB222, pelo sistema enzimático extracelular produzido pelos basidiomicetos em diferentes idades fisiológicas. Ainda, com vistas a estimular a peroxidação lipídica e a formação de espécies reativas, foi adicionada ao meio de cultivo uma fonte conhecida de ácido graxo insaturado.

\subsubsection{Obtenção do extrato enzimático}

Na tentativa de favorecer o processo de descoloração de RB222, foi substituída a fonte de nitrogênio (ureia), previamente padronizada por Vitali (comunicação pessoal) ${ }^{2}$. Essa substituição se deu devido à a) possibilidade de interferência da ureia no processo de degradação de corantes de função azo, uma vez que esse composto é utilizado na diazonização, etapa do processo de síntese desses corantes; e à b) facilitação da atividade catalítica da $\mathrm{MnP}$, que emprega oxalato como quelante de $\mathrm{Mn}^{+2}$, uma vez que essa enzima reage com o complexo oxalato- $\mathrm{Mn}^{+2}$ em vez de reagir com $\mathrm{Mn}^{+2}$ livre, visando assim promover a produção dessa atividade enzimática nos cultivos avaliados (WONG, 2009; ZOLLINGER, 2003).

Foram então preparados cultivos, respeitando uma relação fase líquida:ar de 1:5 (v/v), onde o meio líquido continha 2\% de extrato de malte, acrescido dos mesmos sais e fonte de carbono descritos para o MB descrito acima, 0,1 \% de oxalato de amônio, como fonte de nitrogênio, de acordo com Kiran et al. (2012), e 2,5 \% de emulsão de óleo de soja : Tween 20 (9:1, v/v), como fonte de ácido graxo, conforme Matheus e Bononi

\footnotetext{
${ }^{2}$ Informação fornecida por Vera Maria Valle Vitali, no Instituto de Botânica da Secretaria do Meio Ambiente do Estado de São Paulo, em janeiro de 2016
} 
(2002). Esse meio líquido foi previamente esterilizado por via úmida, após resfriamento 5 discos $(\varnothing=0,9 \mathrm{~cm})$ de crescimento micelial com 7 dias foram introduzidos. Esse inóculo foi preparado com adição de 1 \% de pó de serragem de leguminosa em meio BDA, visando estimular o sistema ligninolítico (Ballaminut et al., 2014a).

Os frascos de cultivo, preparados em triplicata, foram então incubados a $28 \pm 2{ }^{\circ} \mathrm{C}$, por até 30 dias, com monitoramento periódico durante incubação, onde o extrato bruto do cultivo foi separado por filtração a vácuo, seguido de centrifugação a 10.000 rpm por 10 minutos, a $20^{\circ} \mathrm{C}$ (Centrifuga Mod. 5804 R, Eppendorf AG, Hamburg), conforme descrito por Ballaminut et al. (2009).

\subsubsection{Parâmetros avaliados}

Foram determinados no tempo inicial, antes da adição de corante, e nos tempos 3, 7, 10, 14, 21 e 30 dias de incubação, os seguintes parâmetros:

\subsubsection{1. $\mathrm{pH}$}

Determinado no extrato bruto, de acordo com o descrito no Experimento 1.

\subsubsection{Biomassa}

Determinada por peso seco em termobalança (ID50, Marte Científica, Brasil) à105 ${ }^{\circ} \mathrm{C}$ por 40 minutos.

\subsubsection{Determinações enzimáticas}

Foram determinadas fenoloxidases, lacase, peroxidases totais, MnP, LiP e VP de acordo com o descrito no Experimento 1.

\subsection{Atividade Ligninolítica Total in vitro}

Os basidiomicetos foram avaliados individualmente, empregando tubos de ensaio, contendo $990 \mu \mathrm{L}$ de extrato bruto do cultivo, onde cada concentração foi avaliada por um tubo Teste e um tubo Controle. Os Controles tiveram as enzimas desativadas por calor (banho-maria a $100{ }^{\circ} \mathrm{C}$, por 10 minutos), antes da adição de corante. Então todos os tubos receberam solução de corante $(10 \mu \mathrm{L})$, atingindo concentrações finais de 0,03\%, 0,0003\% e 0,00003\%, cada dupla de tubos. Os tubos foram então incubados por 2 horas, a $28 \pm 2$ ${ }^{\circ} \mathrm{C}$, em seguida os Testes tiveram suas enzimas também desativadas por calor. Após resfriamento, foi determinada a absorbância, a 610nm, de cada tubo (Spectrophotometer Genesys 10S UV-Vis, Thermo Fisher Scientific Inc., USA) e a descoloração foi calculada 
empregando a equação Descoloração \% = ((Absorbância ${ }_{\text {Controle }}$ - Absorbância $\left.{ }_{\text {Teste }}\right)$ . 100) / Absorbânciacontrole.

\subsection{Experimento 3: Efeito da concentração de cobre e manganês, no meio de cultivo, e da idade fisiológica do cultivo na descoloração in vivo de RB222 por basidiomicetos}

Foram avaliadas diferentes concentrações de cobre $\left(\mathrm{CuSO}_{4}\right)$ e de manganês $\left(\mathrm{MnSO}_{4}\right)$, no estímulo das atividades enzimáticas ligninolíticas e da descoloração do corante RB222, pelos três basidiomicetos. Concentrações mínimas e máximas foram estabelecidas com base na literatura recente (AKPINAR; UREK, 2012; KARP et al., 2012; KIRAN et al., 2012). Concomitantemente, diferentes tempos de incubação do inóculo fúngico foram avaliados, empregando as três espécies de basidiomicetos isoladamente.

\subsubsection{Delineamento experimental}

O planejamento experimental foi feito com base no Delineamento Central Composto Rotacional (DCCR) $2^{3}$, para avaliação das variáveis e seus fatores (Tabela 2). O bloco experimental foi composto por 8 tratamentos fatoriais $(+1$ e -1$), 6$ pontos axiais ( $+\alpha$ e $-\alpha$ em um dos eixos e zero para os outros 2 fatores) e um ponto central, avaliado em triplicata. Os valores de $\alpha$ do DCCR foram calculados pelo programa estatístico.

Tabela 2 - Variáveis avaliadas por DCCR $2^{3}$ para avaliação de concentrações de sulfato de cobre e sulfato de manganês, no meio de cultivo de basidiomicetos, e do tempo de incubação do cultivo desses fungos para descoloração de RB222.

\begin{tabular}{cccc}
$\mathrm{CuSO}_{4}[\mathrm{mM}]$ & $\mathrm{MnSO}_{4}[\mathrm{mM}]$ & $\begin{array}{c}\text { Idade Fisiológica } \\
\text { [dias] }\end{array}$ & Valor $\alpha$ \\
\hline $0,307 *$ & 0,106 & 7 & $-1,68$ \\
0,446 & $0,285 *$ & 11 & -1 \\
0,654 & 0,553 & 18 & 0 \\
0,861 & 0,821 & 25 & 1 \\
1 & 1 & 29 & 1,68 \\
\hline
\end{tabular}

* = valores empregados no meio basal previamente padronizado por Moreira Neto et al. (2011).

As combinações de variáveis originaram 17 tratamentos, apresentados na Tabela 3, onde cada tratamento foi avaliado em um único frasco, e os dados foram analisados por programa estatístico. 
Tabela 3 - Bloco experimental DCCR $2^{3}$ para avaliação das variáveis: concentrações de sulfato de cobre e de sulfato de manganês no meio, e idade fisiológica do cultivo.

\begin{tabular}{|c|c|c|c|}
\hline \multirow{2}{*}{ Tratamento } & \multicolumn{3}{|c|}{ Valor $\alpha$} \\
\hline & $\mathrm{CuSO}_{4}$ & $\mathrm{MnSO}_{4}$ & Idade Fisiológica \\
\hline 1 & -1 & -1 & $\begin{array}{ll}-1 & \\
\end{array}$ \\
\hline 2 & 1 & -1 & -1 \\
\hline 3 & -1 & 1 & -1 \\
\hline 4 & 1 & 1 & -1 \\
\hline 5 & -1 & -1 & 1 \\
\hline 6 & 1 & -1 & 1 \\
\hline 7 & -1 & 1 & 1 \\
\hline 8 & 1 & 1 & 1 \\
\hline 9 & $-1,68$ & 0 & 0 \\
\hline 10 & 1,68 & 0 & 0 \\
\hline 11 & 0 & $-1,68$ & 0 \\
\hline 12 & 0 & 1,68 & 0 \\
\hline 13 & 0 & 0 & $-1,68$ \\
\hline 14 & 0 & 0 & 1,68 \\
\hline $15 a$ & 0 & 0 & 0 \\
\hline $15 b$ & 0 & 0 & 0 \\
\hline $15 c$ & 0 & 0 & 0 \\
\hline
\end{tabular}

\subsubsection{Inóculo}

O inóculo foi preparado em culturas sólidas, conforme descrito anteriormente no Experimento 2 e as culturas foram incubadas a $28 \pm 2{ }^{\circ} \mathrm{C}$, durante 7 dias.

\subsubsection{Sistema de cultivo}

Foram preparados frascos de cultivo respeitando uma relação fase líquida: ar de 1:5 (v/v), onde dez discos de inóculo $(\varnothing=0,9 \mathrm{~cm})$ foram introduzidos no meio líquido, de constituição descrita no Experimento 2, variando as concentrações de sulfato de cobre e sulfato de manganês, conforme apresentado na Tabela 2. Os frascos foram então incubados a $28 \pm 2{ }^{\circ} \mathrm{C}$, por diferentes tempos (Tabela 2) e a configuração de fatores para cada tratamento está apresentada na Tabela 3. 


\subsubsection{Sistema de tratamento}

O efluente sintético com RB222 foi adicionado aos tratamentos, atingindo concentração final de $0,03 \%$. Os tratamentos permaneceram incubados a $28 \pm 2{ }^{\circ} \mathrm{C}$ por 24 horas.

\subsubsection{Parâmetros avaliados}

Os tratamentos foram monitorados no tempo inicial, imediatamente após a adição de corante, e após 24 horas de contato in vivo, a partir da determinação das atividades enzimáticas e da descoloração, conforme descrito no Experimento 1.

\subsection{Experimento 4: Influência de diferentes concentrações de fonte de ácido graxo conhecida e de dois mediadores do sistema enzimático ligninolítico na descoloração in vivo de RB222 por basidiomicetos}

Foram avaliados os três basidiomicetos, onde diferentes concentrações da fonte de ácido graxo utilizada nos experimentos anteriores foram avaliadas, com objetivo de selecionar a concentração que favorecesse a máxima descoloração in vivo. Ao efluente sintético com RB222, foram introduzidas diferentes concentrações de ABTS e de Remazol Brilliant Blue R (RBBR) em diferentes combinações. A seleção das concentrações da fonte de ácido graxo e dos mediadores foi feita com base na literatura (AGUIAR et al., 2010; RODRÍGUEZ COUTO et al., 2005; SHANKAR; SHIKHA, 2015; TAVARES et al., 2008; WONG; YU, 1999)

Para o delineamento experimental dos sistemas contendo $P$. ostreatus e $P$. cinerea foi utilizado DCCR $2^{3}$ (Tabela 4), composto por 8 tratamentos fatoriais ( +1 e -1 ), 6 pontos axiais ( $+\alpha$ e $-\alpha$ em um dos eixos e zero para os outros 2 fatores) e um ponto central, avaliado em triplicata (Tabela 6). Para T. villosa foram avaliadas as mesmas variáveis citadas acima, incluindo concentrações de sulfato de manganês, uma vez que o experimento anterior não mostrou uma resposta precisa para a presença desse metal no meio de cultivo. Foi empregado o DCCR $2^{4}$ (Tabela 5), composto por 16 tratamentos fatoriais $(+1$ e -1$), 8$ pontos axiais $(+\alpha$ e $-\alpha)$ e um ponto central, avaliado em quatruplicata (Tabela 7). Todos os valores de $\alpha$ foram calculados pelo programa estatístico. 
Tabela 4 - Variáveis avaliadas por DCCR $2^{3}$ para diferentes concentrações da fonte de ácido graxo, no meio de cultivo, e dos mediadores das atividades enzimáticas, ABTS e RBBR, nos tratamentos de descoloração in vivo de RB222 por Pleurotus ostreatus e Peniophora cinerea.

\begin{tabular}{cccc}
\hline ABTS $[\mathrm{mM}]$ & $\mathrm{RBBR}[\mu \mathrm{M}]$ & $\begin{array}{c}\text { Fonte de Ácido } \\
\text { Graxo [\%] }\end{array}$ & $\begin{array}{c}\text { Valor } \\
\alpha\end{array}$ \\
\hline 0 & 0 & 0 & $-1,68$ \\
0,4 & 0,04 & 1 & -1 \\
1 & 0,1 & 2,5 & 0 \\
1,6 & 0,16 & 4 & 1 \\
2 & 0,2 & 5 & 1,68 \\
\hline
\end{tabular}

Tabela 5 - Variáveis avaliadas por DCCR $2^{4}$ para diferentes concentrações da fonte de ácido graxo, no meio de cultivo, e dos mediadores das atividades enzimáticas, ABTS e RBBR, nos tratamentos de descoloração in vivo de RB222 por Trametes villosa.

\begin{tabular}{ccccc}
\hline ABTS $[\mathrm{mM}]$ & RBBR $[\mu \mathrm{M}]$ & $\begin{array}{c}\text { Fonte de } \\
\text { Ácido Graxo } \\
{[\%]}\end{array}$ & $\begin{array}{c}\mathrm{MnSO}_{4} \\
{[\mathrm{mM}]}\end{array}$ & $\begin{array}{c}\text { Valor } \\
\alpha\end{array}$ \\
\hline 0 & 0 & 0 & 0,5 & -2 \\
0,5 & 0,05 & 1,25 & 0,75 & -1 \\
1 & 0,1 & 2,5 & 1 & 0 \\
1,5 & 0,15 & 3,75 & 1,25 & 1 \\
2 & 0,2 & 5 & 1,5 & 2 \\
\hline
\end{tabular}


Tabela 6 - Bloco experimental DCCR $2^{3}$ para avaliação das variáveis: concentrações de ABTS, RBBR e da fonte de ácido graxo.

\begin{tabular}{cccc}
\hline Frasco & ABTS $[\mathrm{mM}]$ & RBBR $[\mu \mathrm{M}]$ & $\begin{array}{c}\text { Fonte de Ácido } \\
\text { Graxo [\%] }\end{array}$ \\
\hline 1 & -1 & -1 & -1 \\
2 & 1 & -1 & -1 \\
3 & -1 & 1 & -1 \\
4 & 1 & 1 & -1 \\
5 & -1 & -1 & 1 \\
6 & 1 & -1 & 1 \\
7 & -1 & 1 & 1 \\
8 & 1 & 1 & 1 \\
9 & $-1,68$ & 0 & 0 \\
10 & 1,68 & 0 & 0 \\
11 & 0 & $-1,68$ & 0 \\
12 & 0 & 1,68 & 0 \\
13 & 0 & 0 & $-1,68$ \\
14 & 0 & 0 & 1,68 \\
$15 \mathrm{a}$ & 0 & 0 & 0 \\
$15 \mathrm{~b}$ & 0 & 0 & 0 \\
$15 \mathrm{c}$ & 0 & 0 & 0 \\
\hline
\end{tabular}


Tabela 7 - Bloco experimental DCCR $2^{4}$ para avaliação das variáveis: concentrações de ABTS, RBBR, da fonte de ácido graxo e de $\mathrm{MnSO}_{4}$.

\begin{tabular}{|c|c|c|c|c|}
\hline Frasco & ABTS [mM] & RBBR [pM] & Ácido Graxo [\%] & $\mathrm{MnSO}_{4}[\mathrm{mM}]$ \\
\hline 1 & -1 & -1 & -1 & -1 \\
\hline 2 & 1 & -1 & -1 & -1 \\
\hline 3 & -1 & 1 & -1 & -1 \\
\hline 4 & 1 & 1 & -1 & -1 \\
\hline 5 & -1 & -1 & 1 & -1 \\
\hline 6 & 1 & -1 & 1 & -1 \\
\hline 7 & -1 & 1 & 1 & -1 \\
\hline 8 & 1 & 1 & 1 & -1 \\
\hline 9 & -1 & -1 & -1 & 1 \\
\hline 10 & 1 & -1 & -1 & 1 \\
\hline 11 & -1 & 1 & -1 & -1 \\
\hline 12 & 1 & 1 & -1 & 1 \\
\hline 13 & -1 & -1 & 1 & 1 \\
\hline 14 & 1 & -1 & 1 & -1 \\
\hline 15 & -1 & 1 & 1 & 1 \\
\hline 16 & 1 & 1 & 1 & 1 \\
\hline 17 & -2 & 0 & 0 & 0 \\
\hline 18 & 2 & 0 & 0 & 0 \\
\hline 19 & 0 & -2 & 0 & 0 \\
\hline 20 & 0 & 2 & 0 & 0 \\
\hline 21 & 0 & 0 & -2 & 0 \\
\hline 22 & 0 & 0 & 2 & 0 \\
\hline 23 & 0 & 0 & 0 & -2 \\
\hline 24 & 0 & 0 & 0 & 2 \\
\hline $25 a$ & 0 & 0 & 0 & 0 \\
\hline $25 b$ & 0 & 0 & 0 & 0 \\
\hline $25 c$ & 0 & 0 & 0 & 0 \\
\hline $25 \mathrm{~d}$ & 0 & 0 & 0 & 0 \\
\hline
\end{tabular}

\subsubsection{Inóculo}

O inóculo foi preparado em culturas sólidas, conforme descrito no Experimento 2 e as culturas foram incubadas a $28 \pm 2{ }^{\circ} \mathrm{C}$, durante 7 dias.

\subsubsection{Sistema de cultivo}

Foram preparados conforme descrito no Experimento 2, onde frascos de cultivo respeitaram uma relação fase líquida: ar de 1:5 (v/v) e as quantidades de $\mathrm{CuSO}_{4}$ e de 
$\mathrm{MnSO}_{4}$ foram definidas: $P$. ostreatus recebeu $0,446 \mathrm{mM}$ de $\mathrm{CuSO}_{4}$ e $0,821 \mathrm{mM}$ de $\mathrm{MnSO}_{4} ; P$. cinerea recebeu $1 \mathrm{mM}$ de $\mathrm{CuSO}_{4}$ e 0,106 $\mathrm{mM}$ de $\mathrm{MnSO}_{4}$. T. villosa recebeu 1 $\mathrm{mM}$ de $\mathrm{CuSO}_{4}$ e quantidades variáveis de $\mathrm{MnSO}_{4}$ (Tabela 5). Todos os sistemas de cultivo foram incubados a $28 \pm 2{ }^{\circ} \mathrm{C}$, por intervalos de tempos diferentes: P. ostreatus 25 dias; P. cinerea 18 dias; T. villosa 25 dias.

\subsubsection{Sistema de tratamento}

Após tempos de incubação específicos, os sistemas de cultivo receberam efluente sintético com RB222, atingindo concentração final de 0,03\%, contendo os mediadores descritos, em diferentes combinações de concentrações (Tabela 4 e Tabela 5).

\subsubsection{Parâmetros avaliados}

Os sistemas de tratamento foram monitorados no tempo inicial, após 24 e 48 horas de contato in vivo, pelas atividades enzimáticas de fenoloxidases, lacase e MnP, e pela descoloração in vivo, a $526 \mathrm{~nm}$ e 610 nm, conforme descritos no Experimento 1.

A partir da observação da descoloração, foram feitas leituras de todas as absorbâncias do espectro entre 100 e 1100nm, a fim de compor o espetro de absorção das amostras desejadas.

\subsection{Experimento 5: Caracterização do processo de descoloração de RB222 por basidiomicetos}

Foram avaliados sistemas de tratamento, em fatorial completo com triplicatas para cada condição, os quais foram preparados utilizando os três basidiomicetos, avaliados individualmente.

\subsubsection{Sistema de cultivo}

Os cultivos foram preparados respeitando uma relação fase líquida:ar de 1:3,3 (v/v), onde o meio líquido foi constituído pelos sais e nutrientes descritos na Tabela 8. O meio foi esterilizado por via úmida a $121^{\circ} \mathrm{C}, 1,5$ atm de pressão, durante 20 minutos. Após resfriamento discos de inóculo $(\varnothing=0,9 \mathrm{~cm})$, preparado conforme descrito no Experimento 2, foram introduzidos na proporção 1 disco/10 mL de meio. As culturas de P. cinerea foram incubadas por 18 dias, já $P$. ostreatus e T. villosa permaneceram incubados por 25 dias, a $28 \pm 2{ }^{\circ} \mathrm{C}$. 
Tabela 8 - Sais e nutrientes constituintes do meio líquido, utilizado para cultivo de basidiomicetos a serem empregados em tratamentos de descoloração de RB222 in vivo.

\begin{tabular}{|c|c|c|c|c|}
\hline Componente & $\begin{array}{c}\text { Pleurotus } \\
\text { ostreatus } \\
\text { (quantidade/unidade) }\end{array}$ & $\begin{array}{c}\text { Peniophora } \\
\text { cinerea } \\
\text { (quantidade/unidade) }\end{array}$ & $\begin{array}{c}\text { Trametes } \\
\text { villosa } \\
\text { (quantidade/unidade) }\end{array}$ & Referência \\
\hline $\begin{array}{l}\text { Sulfato de cobre } \\
\left(\mathrm{CuSO}_{4}\right)\end{array}$ & $0,071 \mathrm{~g} / \mathrm{L}$ & $0,160 \quad \mathrm{~g} / \mathrm{L}$ & $0,160 \quad \mathrm{~g} / \mathrm{L}$ & $\begin{array}{l}\text { Dados não } \\
\text { publicados }\end{array}$ \\
\hline $\begin{array}{l}\text { Fosfato básico de } \\
\text { potássio }\left(\mathrm{K}_{2} \mathrm{HPO}_{4}\right)\end{array}$ & $0,2 \quad \mathrm{~g} / \mathrm{L}$ & $\mathrm{g} / \mathrm{L}$ & $0,2 \quad \mathrm{~g} / \mathrm{L}$ & $\begin{array}{l}\text { Moreira Neto } \\
\text { et al., } 2011\end{array}$ \\
\hline $\begin{array}{l}\text { Sulfato de magnésio } \\
\left(\mathrm{MgSO}_{4}\right)\end{array}$ & $0,05 \quad \mathrm{~g} / \mathrm{L}$ & $0,05 \quad \mathrm{~g} / \mathrm{L}$ & 0,05 & $\begin{array}{l}\text { Moreira Neto } \\
\text { et al., } 2011\end{array}$ \\
\hline $\begin{array}{l}\text { Sulfato de manganês } \\
\left(\mathrm{MnSO}_{4}\right)\end{array}$ & $0,143 \mathrm{~g} / \mathrm{L}$ & $0,018 \mathrm{~g} / \mathrm{L}$ & $0,087 \mathrm{~g} / \mathrm{L}$ & $\begin{array}{l}\text { Dados não } \\
\text { publicados }\end{array}$ \\
\hline $\begin{array}{l}\text { Sacarose } \\
\left(\mathrm{C}_{12} \mathrm{H}_{22} \mathrm{O}_{11}\right)\end{array}$ & $\mathrm{g} / \mathrm{L}$ & $\mathrm{g} / \mathrm{L}$ & $\mathrm{g} / \mathrm{L}$ & $\begin{array}{c}\text { Vitali } \\
\text { (comunicação }^{\text {pessoal) })^{3}} \\
\end{array}$ \\
\hline $\begin{array}{l}\text { Oxalato de amônio } \\
\left.\left(\mathrm{NH}_{4}\right)_{2} \mathrm{C}_{2} \mathrm{O}_{4}\right)\end{array}$ & $\mathrm{g} / \mathrm{L}$ & $\mathrm{g} / \mathrm{L}$ & $\mathrm{g} / \mathrm{L}$ & $\begin{array}{l}\text { Kiran et al., } \\
2012\end{array}$ \\
\hline Extrato de malte & $\mathrm{g} / \mathrm{L}$ & $\mathrm{g} / \mathrm{L}$ & $\mathrm{g} / \mathrm{L}$ & $\begin{array}{l}\text { Dados não } \\
\text { publicados }\end{array}$ \\
\hline Emulsão óleo:Tween 20 & na & $\%$ & 3,75 & $\begin{array}{l}\text { Dados não } \\
\text { publicados }\end{array}$ \\
\hline
\end{tabular}

na = não se aplica.

\subsubsection{Sistema de tratamento}

Após incubação, os sistemas de cultivo receberam efluente com RB222, atingindo concentração final de $0,03 \%$. O efluente sintético foi preparado com adição dos mediadores, em concentrações específicas para cada basidiomiceto: 2 mM de ABTS para os três basidiomicetos, mais $0,2 \mu \mathrm{M}$ de RBBR para $P$. ostreatus e $P$. cinerea.

Foram preparados i) controles bióticos, onde o corante foi substituído por água; ii) controles abióticos com fungo morto, onde a biomassa crescida foi morta por esterilização por via úmida a $121{ }^{\circ} \mathrm{C}, 1,5 \mathrm{~atm}$ de pressão, por 30 minutos, antes de receber o efluente sintético; e iii) controles abióticos, sistemas não inoculados ${ }^{4}$.

\subsubsection{Parâmetros avaliados}

Foram determinados as atividades enzimáticas e os CBMM quelantes e redutores de $\mathrm{Fe}^{+3}$ antes da adição de efluente sintético, e após adição de efluente sintético, foram determinadas as atividades enzimáticas e a descoloração de RB222 in vivo.

\footnotetext{
${ }^{3}$ Informação fornecida por Vera Maria Valle Vitali, no Instituto de Botânica da Secretaria do Meio Ambiente do Estado de São Paulo, em janeiro de 2016

${ }^{4}$ Apenas P. ostreatus e T. villosa tiveram controle abiótico com fungo morto em avaliação.
} 


\subsection{Atividades enzimáticas}

Foram determinadas as atividades de fenoloxidases, lacase e de MnP, de acordo com o descrito nos experimentos anteriores.

\subsection{Compostos de Baixa Massa Molar (CBMM)}

Para a separação dos CBMM, o extrato bruto foi filtrado e congelado, em seguida foi liofilizado (Liofilizador Thermo Savant, Modelo Micro Modulo, Thermo Electron Corporation, USA). Após liofilização os extratos foram ressuspensos em água ultrapura, concentrando-os 10 vezes. Os extratos foram então purificados parcialmente por ultrafiltração, empregando membranas de corte de 5 kDa (VIVASPIN 15, Sartorius AG, Germany), em centrífuga (Centrifuga Mod. 5804 R, Eppendorf AG, Hamburg) por 30 minutos, a $10.000 \mathrm{rpm}$, a $10{ }^{\circ} \mathrm{C}$ (ARANTES; MILAGRES, 2007).

Todo material de laboratório empregado nesse ensaio foi tratado com imersão em HCl 6 N por 12 horas, seguida por enxágue com água deionizada, para remoção de traços de ferro.

Para a detecção da presença de compostos com atividade quelante de $\mathrm{Fe}^{3+}$ foi utilizado o Método universal CAS (Cromo Azurol S), descrito por Schwyn e Neilands (1987), que é baseado na competição por ferro entre o complexo férrico do corante indicador CAS e do quelante produzido pelos fungos. Esse método consistiu-se no preparo de um corante complexo indicador, composto por $6 \mathrm{~mL}$ de uma solução de brometo de hexa-deciltrimetilamônio (HDTMA) 10 mM, 1,5 mL de solução de cloreto férrico (1 mM FeCl${ }_{3} \cdot 6 \mathrm{H}_{2} \mathrm{O}$ em $10 \mathrm{mM} \mathrm{HCl}$ ) mais 7,5 mL de solução CAS (Cromo Azurol S) 2 mM. A essa solução foram adicionados 4,307 g de piperazina anidra dissolvida em água deionizada e o pH foi ajustado para 5,6 pela adição de $\mathrm{HCl}$ concentrado, então o volume foi completado para $100 \mathrm{~mL}$ com água ultrapura. O reagente CAS complexado com $\mathrm{Fe}^{3+}$ na solução possui uma intensa cor azul, com absortividade molar $\varepsilon_{630 \mathrm{~nm}}=100.000 \mathrm{M}^{-1} \mathrm{~cm}^{-1}$.

O ensaio foi avaliado por espectrofotometria, com leituras pontuais da absorbância, em 630 nm. A mistura de reação continha $500 \mu \mathrm{L}$ de amostra e $500 \mu \mathrm{L}$ de reagente CAS. O branco substituiu a amostra por meio de cultura não-inoculado e o aparelho foi zerado com água deionizada. A mistura de reação permaneceu em repouso por uma hora, antes da leitura da absorbância, e os resultados foram expressos como porcentagem de compostos quelantes, presentes na amostra capazes de complexar $\mathrm{Fe}^{3+}$ em relação ao 
branco. A porcentagem de quelantes produzidas foi calculada de acordo com a Equação 4:

\% CAS = [(Absorbânciabranco - Absorbância $\left.{ }_{a m o s t r a) ~}\right) /$ Absorbânciabranco $]$. 100

Os ensaios para verificação da presença de atividade redutora de ferro foram avaliados por espectrofotometria, onde a mistura de reação foi constituída por $375 \mu \mathrm{L}$ de amostra ultrafiltrada, $400 \mu \mathrm{L}$ de solução tampão acetato de sódio 50 mM pH 4,5 e $50 \mu \mathrm{L}$ de $\mathrm{FeCl}_{3} 20 \mathrm{mM}$. Após 30 minutos, no escuro, foram adicionados $100 \mu \mathrm{L}$ de NaF $50 \mathrm{mM}$ para paralisar a reação e, em seguida $125 \mu \mathrm{L}$ de ferrozina $10 \mathrm{mM}$. A absorbância foi avaliada em $562 \mathrm{~nm}$. Os resultados foram expressos pela quantidade de $\mathrm{Fe}^{2+}$ formado $\left(\varepsilon_{562 \mathrm{~nm}}=27.900 \mathrm{M}^{-1} \mathrm{~cm}^{-1}\right)$ do aparelho, substituiu- se a amostra e a ferrozina por água deionizada. Um controle, contendo água no lugar da amostra, foi preparado, para descontar a quantidade de íons $\mathrm{Fe}^{2+}$ formados durante o equilíbrio natural $\mathrm{Fe}^{2+} / \mathrm{Fe}^{3+}$ em água (ARANTES et al., 2011; ARANTES; MILAGRES, 2007; MILAGRES et al., 1999; STOOKEY, 1970).

\subsection{Teste de inibição enzimática}

Foram realizados com adição de azida sódica, como inibidor da atividade de lacase, de acordo com Johannes e Majcherczyk (2000), em concentrações de 0,1 a 3 mM, dependendo de cada espécie, até que a atividade enzimática não pudesse mais ser detectada. A inibição de MnP foi feita pela adição de cloreto de cádmio, de acordo com Sundaramoorthy et al. (2005), em concentrações de 1 a 4,7 mM, dependendo de cada espécie fúngica, até que a atividade enzimática não pudesse mais ser detectada. As inibições foram testadas combinadas e isoladamente.

Apenas após a inibição das atividades enzimáticas o efluente sintético com RB222 e mediadores foi introduzido nos sistemas de tratamento.

\subsection{Descoloração}

Avaliada a $610 \mathrm{~nm}$ e $526 \mathrm{~nm}$, de acordo com o descrito nos experimentos anteriores. 
3.5.2.1.5. Detecção de metabólitos por cromatografia de camada delgada (Thin Layer Chromatography - TLC)

Foi padronizado um método TLC, empregando placas de sílica gel G em alumínio $\mathrm{UV}_{254}, 20 x 20 \mathrm{~cm}$ (Boeco, Merck Millipore Corporation, Alemanha), onde as fases móveis testadas foram constituídas por diferentes combinações:

- álcool metílico PA e água ultra pura 3:2 (v/v);

- álcool metílico PA e tampão fosfato de sódio monobásico 25 mM, pH 3,0 $3: 2(\mathrm{v} / \mathrm{v})$

- acetato de etila PA e álcool metílico PA 1:1 (v/v);

- acetato de etila PA e álcool metílico PA 1:1,5 (v/v);

- acetato de etila PA e álcool metílico PA 2:1 (v/v);

- acetato de etila PA e álcool metílico PA 2:3 (v/v);

- acetato de etila PA e álcool etílico PA 2:3 (v/v);

- ácido acético e álcool metílico PA 2:3 (v/v);

- acetato de etila PA, álcool metílico PA e álcool etílico 2:1:1 (v/v/v);

- acetato de etila PA, álcool metílico PA e ácido acético glacial 1:1:0,5 $(\mathrm{v} / \mathrm{v} / \mathrm{v})$;

- acetato de etila PA, álcool metílico PA e ácido acético glacial 1:1,5:0,5 $(\mathrm{v} / \mathrm{v} / \mathrm{v})$.

As demais condições foram selecionadas empregando a fase móvel selecionada e a visualização das corridas nas placas foi feita em Câmara Escura Transiluminadora (SPPencer SP930-35, Hipperquímica Comercial Científica Ltda, Brasil) em 254 nm e 365 nm (KURADE et al., 2015; WATHARKAR et al., 2013).

\subsubsection{Previsão de metabólitos}

Os possíveis metabólitos foram simulados por programa de predição de metabólitos (METAPRINT2D. 2010). 


\section{RESULTADOS E DISCUSSÕES}

Os resultados de cada ensaio desse estudo foram apresentados na mesma sequência experimental descrita anteriormente, no Material e Métodos, identificados pelo número de cada experimento.

\subsection{Experimento 1}

O aumento da biomassa durante contato in vivo com o corante (Figura 2) não apresentou diferença estatística entre os sistemas com e sem corante ( $p=0,367$; APÊNDICE A), nem entre os tempos de incubação ( $p=0,464$; APÊNDICE A), mostrando que nesse intervalo não há grande variação de biomassa, sem interferência da presença do corante.

Figura 2 - Biomassa de Pleurotus ostreatus monitorada durante contato in vivo com RB222 (•) e no cultivo sem corante (O).

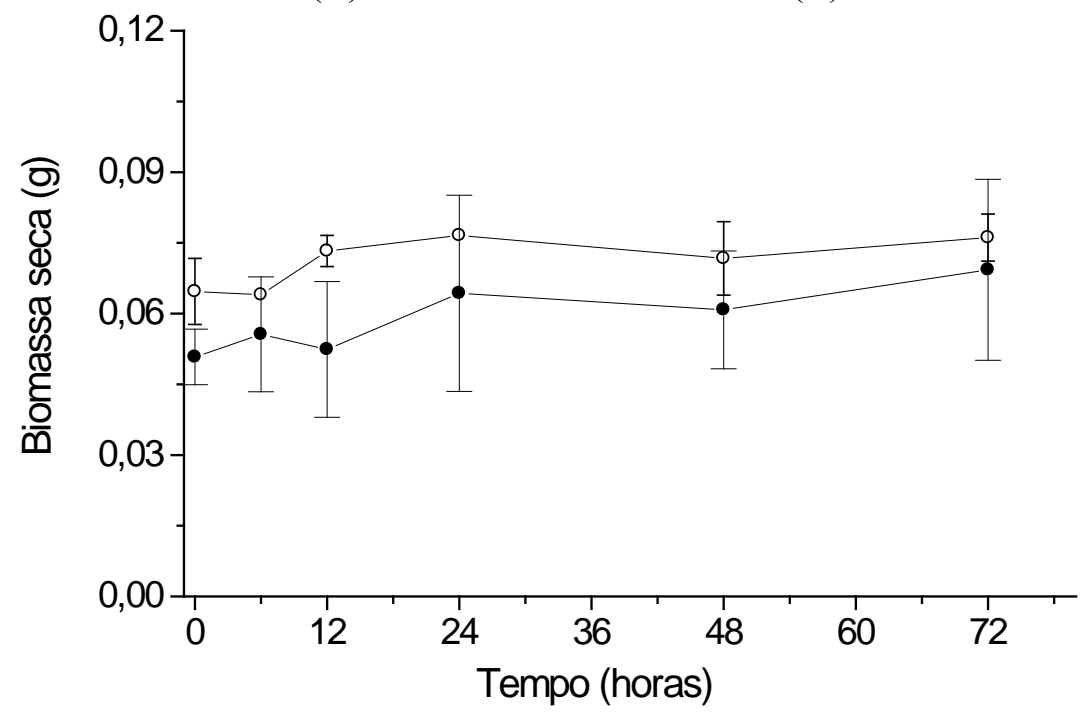

O monitoramento do $\mathrm{pH}$ dos filtrados apresentou pequena diminuição na presença de meio basal, tanto nos sistemas sem corante quanto em combinação com RB222, diferindo significativamente dos sistemas com corante em água sem fungo ( $p=0,002$, APÊNDICE A), com valor máximo de 6,74 (Figura 3). Já os sistemas com corante em meio basal com e sem fungo atingiram valor máximo de 6,16, embora não tenha sido observada diferença estatística entre os tempos avaliados ( $p=0,390$; APÊNDICE A). O pH ficou mantido na faixa de 4,10 a 6,86, corroborando com os valores de pH ótimos observados para descoloração de diferentes corantes por fungos em outros trabalhos (BIBI; BHATTI, 2012; KAUSHIK; MALIK, 2009; MIELGO et al., 2003). Kiran et al. (2012) em estudo de descoloração desse mesmo corante observou que tanto P. ostreatus 
como Phanerochaete chrysosporium apresentaram pH ótimo para descoloração de 4,5. Dessa forma, fica entendido que não há necessidade de tamponamento do $\mathrm{pH}$ dos sistemas durante processo de descoloração, já que o fungo é capaz de mantê-lo dentro de uma faixa específica de $\mathrm{pH}$.

Figura 3 - (A) pH dos sistemas com Pleurotus ostreatus CCIBt 2347 e corante ( $\mathbf{\Delta})$ e sem corante $(\Delta)$; (B) sistemas com corante em água ( $($ ) e em meio basal $(\bullet)$, ambos sem fungo.

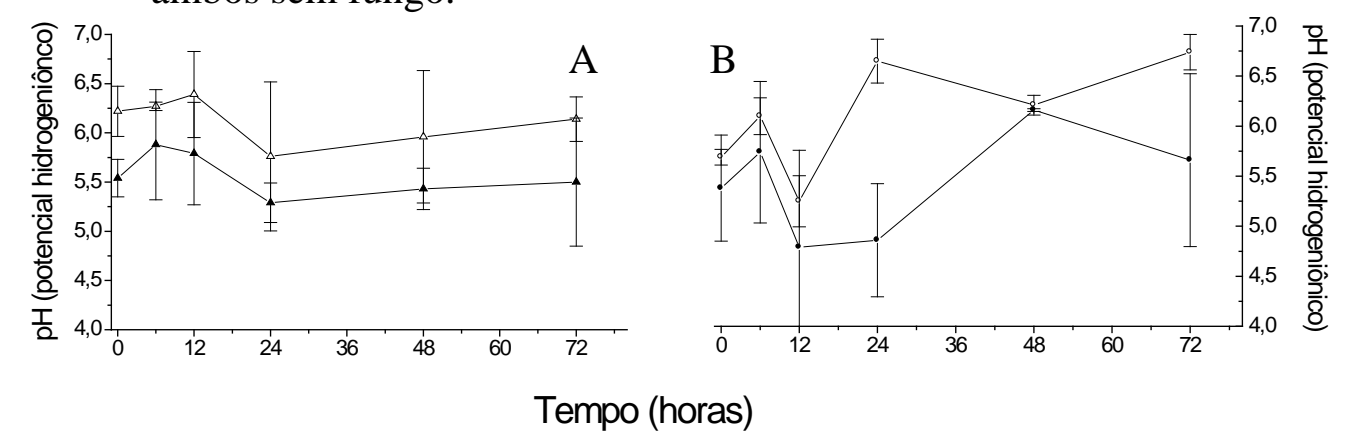

As atividades enzimáticas, apresentadas na Tabela 9, podem ter sido inibidas pela presença do corante, uma vez que apresentaram diferença significativa dos sistemas com fungo sem corante ( $p<0,01$; APÊNDICE A), que apresentaram maiores valores. Entretanto, não foi observada diferença estatística entre os tempos avaliados para fenoloxidases $(p=0,726)$, lacase $(p=0,592)$ nem para peroxidases totais $(p=0,762)$ (APÊNDICE A).

As fenoloxidases observadas nos sistemas sem corante foram em média 4,5 vezes maior que aquela observada nos sistemas com corante, bem como as lacases e as peroxidases totais foram em média 2,5 e 15,5 vezes maior nos sistemas sem cor, respectivamente, sendo que os valores máximos ocorreram após 48 horas. Os sistemas com corante apresentaram maior produção de enzimas no tempo inicial, diminuindo nos demais tempos, embora com boa recuperação após 72 horas (Tabela 9). Não foram detectadas MnP, VP e LiP em nenhum dos extratos avaliados. 
Tabela 9 - Atividades enzimáticas (U/L) produzidas por Pleurotus ostreatus CCIBt 2347 durante contato in vivo com RB222.

\begin{tabular}{|c|c|c|c|c|c|}
\hline \multirow{3}{*}{$\begin{array}{l}\text { Tempo de contato } \\
\text { in vivo (horas) }\end{array}$} & \multicolumn{4}{|c|}{ Sistemas } & \multirow{3}{*}{ Atividade Enzimática } \\
\hline & \multicolumn{2}{|c|}{ Com corante } & \multicolumn{2}{|c|}{ Sem corante } & \\
\hline & Média & DP & Média & DP & \\
\hline 0 & 20,295 & 9,289 & 33,336 & 20,298 & \multirow{6}{*}{ Fenoloxidases } \\
\hline 6 & 20,166 & 10,275 & 34,339 & 7,530 & \\
\hline 12 & 13,863 & 7,009 & 22,456 & 4,583 & \\
\hline 24 & 5,023 & 8,361 & 23,829 & 31,342 & \\
\hline 48 & 3,071 & 0,985 & 53,245 & 35,795 & \\
\hline 72 & 18,880 & 22,589 & 32,564 & 7,203 & \\
\hline 0 & 10,577 & 6,172 & 23,999 & 11,131 & \multirow{6}{*}{ Lacases } \\
\hline 6 & 13,684 & 6,182 & 23,382 & 5,784 & \\
\hline 12 & 13,991 & 5,557 & 12,516 & 3,034 & \\
\hline 24 & 5,387 & 7,214 & 10,263 & 12,986 & \\
\hline 48 & 4,316 & 2,868 & 29,632 & 16,697 & \\
\hline 72 & 11,133 & 14,182 & 17,633 & 3,765 & \\
\hline 0 & 9,718 & 4,329 & 9,337 & 9,167 & \multirow{6}{*}{ Peroxidases Totais } \\
\hline 6 & 6,482 & 4,201 & 10,958 & 1,746 & \\
\hline 12 & 0,611 & 0,530 & 9,939 & 1,550 & \\
\hline 24 & 0,379 & 0,618 & 13,566 & 18,356 & \\
\hline 48 & 0,628 & 0,585 & 23,613 & 19,098 & \\
\hline 72 & 7,748 & 8,447 & 14,932 & 3,438 & \\
\hline
\end{tabular}

DP = desvio padrão; áreas em destaque representam maiores valores.

A descoloração observada nos sistemas com fungo foi maior que aquela observada nos seus sistemas sem fungo, com diferença altamente significativa ( $p=0,000$; APÊNDICE A). Os maiores valores foram observados após 48 horas, atingindo $90 \%$, sendo que os sistemas coloridos sem fungo não ultrapassaram 10 \% de descoloração. Houve também diferença altamente significativa entre os tempos avaliados ( $p=0,001$; APÊNDICE A), sendo maior após 24 horas (Figura 4). Apesar da descoloração não ter atingido 100 \% a 610 nm, tal resultado apresentou vantagens em relação a outros estudos semelhantes, como é o caso do trabalho de Osma et al. (2010), que avaliando a biodegradação do corante RBBR por lacase de Trametes pubescens imobilizada, observaram apenas 44 \% de descoloração após 42 horas de contato. Kiran et al. (2013) em tratamento químico conjugado ao biológico de RB222, testando $P$. ostreatus e Phanerochaete chrysosporium também não obtiveram descoloração maior que 60 \% em 24 horas de tratamento. 
Figura 4 - Descoloração do RB222 a $610 \mathrm{~nm}$ durante tratamento in vivo por Pleurotus ostreatus CCIBt 2347 ( ( ), nos seus controles abióticos com corante em água $(\circ)$ e em meio basal $(\bullet)$.

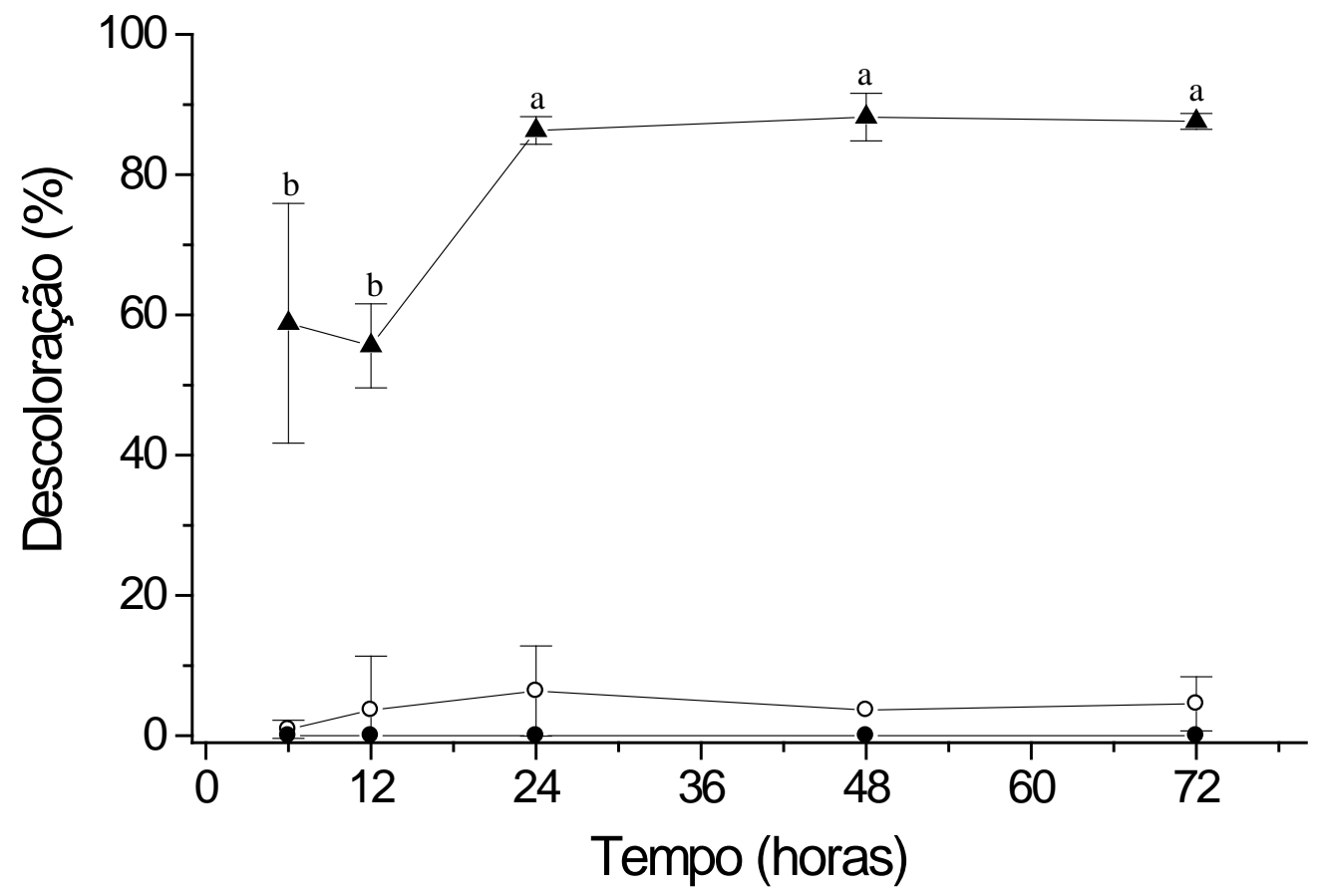

Letras iguais significam igualdade estatística; controles sem diferença estatística.

A descoloração a $610 \mathrm{~nm}$ mostrou-se eficiente e parece ter sido resultado de biossorção, uma vez que o micélio fúngico tornou-se colorido, mas também parece estar associada à transformação da molécula do corante, já que houve mudança de cor da fase líquida. Após 12 horas a fase líquida tornou-se arroxeada e após 24 horas tornou-se rubra, conforme mostra a Figura 5. Zaharia et al. (2012) comentam que corantes sintéticos possuem estruturas aceptoras de elétrons e doadoras de elétrons, sendo assim ionizáveis, portanto diante de moléculas tão reativas, possivelmente, a oxidação do corante, provocada pelo mecanismo ligninolítico do fungo, pode ter dado origem a uma conformação diferente daquela observada na molécula inicial do corante, a qual resultou na mudança da cor na região do visível, revelando um novo $\lambda_{\text {máx, a }} 526 \mathrm{~nm}$, região de absorção do vermelho. 
Figura 5 - Sistemas de tratamento de CI Reactive Blue 222 por Pleurotus ostreatus CCIBt 2347, onde (A) controle abiótico no tempo inicial e (B) sistemas com fungo e corante após 6 horas, (C) após 12 horas e (D) após 24 horas de contato.

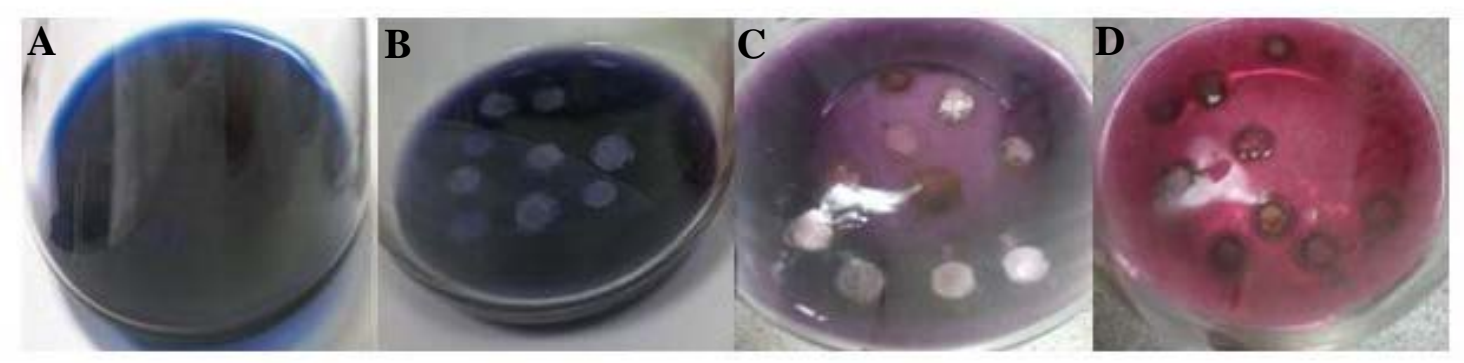

Foi feita varredura das absorbâncias dos filtrados a cada tempo avaliado, possibilitando a construção dos seus espectros de absorção. Na Figura 6 estão apresentados os espectros dos sistemas com e sem fungo, em todos os tempos testados, onde observou-se mudança do $\lambda_{\text {máx, }}$ confirmando deslocamento hipsocrômico no espectro de absorção do corante.

Figura 6 - Espectros de absorção de RB222 tratado com Pleurotus ostreatus CCIBt 2347e seus controles abióticos.

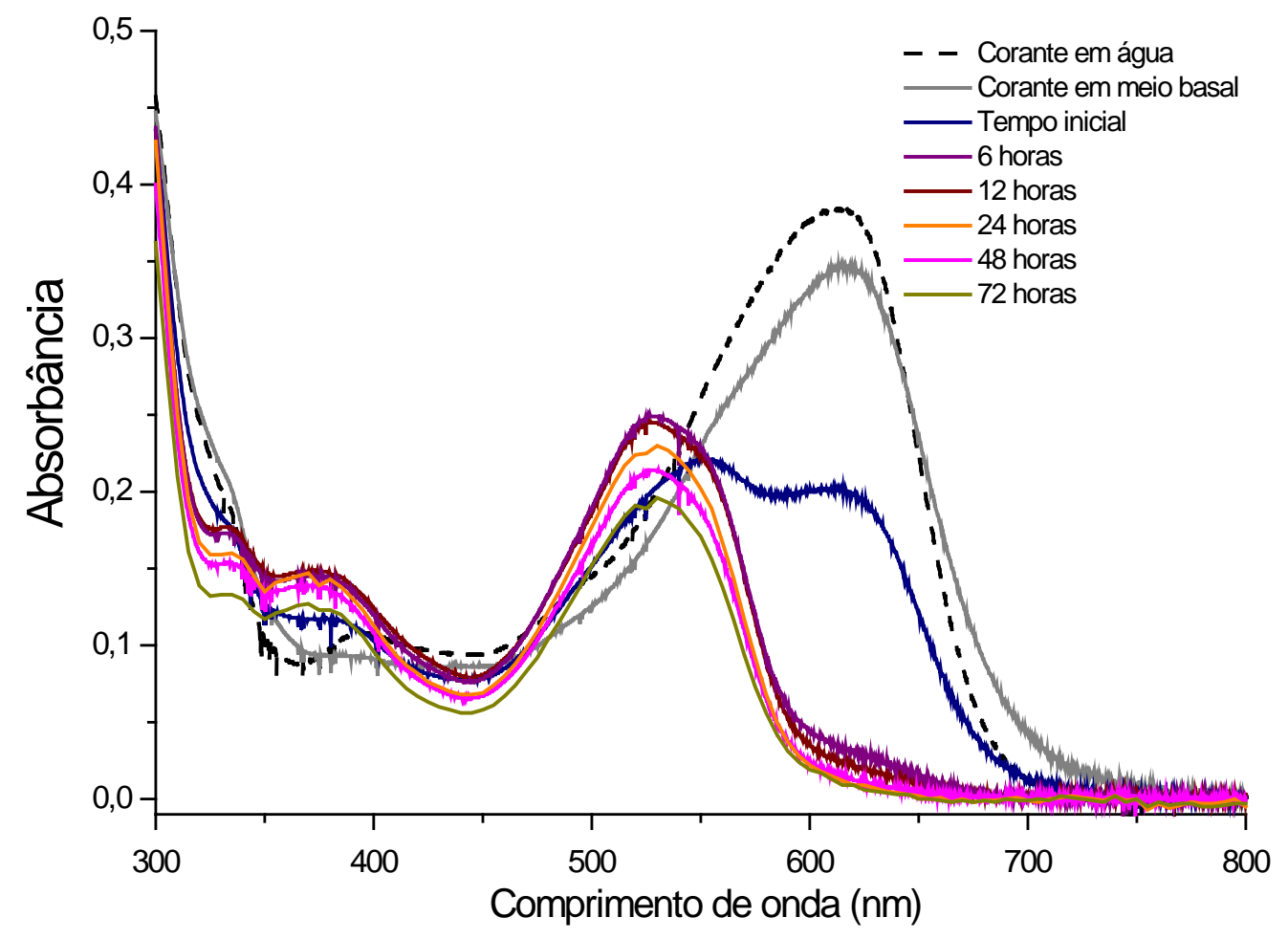

Os sistemas de tratamento avaliados apresentaram deslocamento hipsocrômico nas primeiras 6 horas de contato (Figura 6). Outros estudos de descoloração também

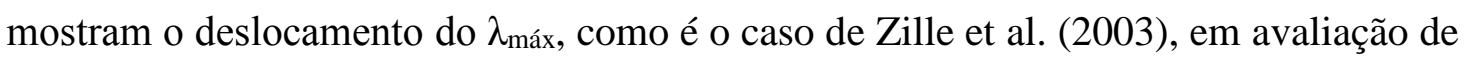
lacase de $T$. villosa na descoloração de corantes ácidos observaram o deslocamento do 


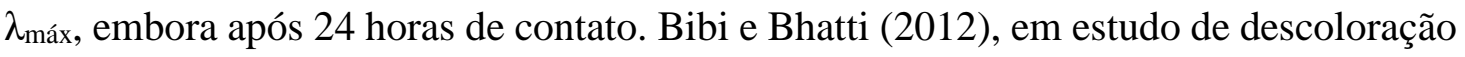
de corantes diversos por fungos, observaram que o corante RBBR, após tratamento com Trametes hirsuta também apresentou deslocamento hipsocrômico do $\lambda_{\text {máx. De acordo }}$ com Kaushik e Malik (2009) a descoloração do corante ocorre quando o centro cromóforo do corante é clivado, podendo provocar assim o deslocamento do $\lambda_{\text {máx. }}$.

Com a constatação de que o $\lambda_{\text {máx }}$ do corante passou a ser $526 \mathrm{~nm}$, esse comprimento de onda foi utilizado para obtenção do coeficiente de extinção molar $(\varepsilon)$ de RB222, proporcionando assim o uso desse coeficiente para complementar o entendimento do processo. O cálculo foi feito a partir da construção de curva de calibração com as absorbâncias em função da concentração do corante, em mol/L, onde o coeficiente angular da reta, obtida por regressão linear, correspondeu ao coeficiente de extinção molar $\left(\varepsilon=853.541 \mathrm{M}^{-1} \mathrm{~cm}^{-1}\right)$ (Figura 7).

Figura 7 - Curva - concentração de RB222 versus absorbância a 526 nm.

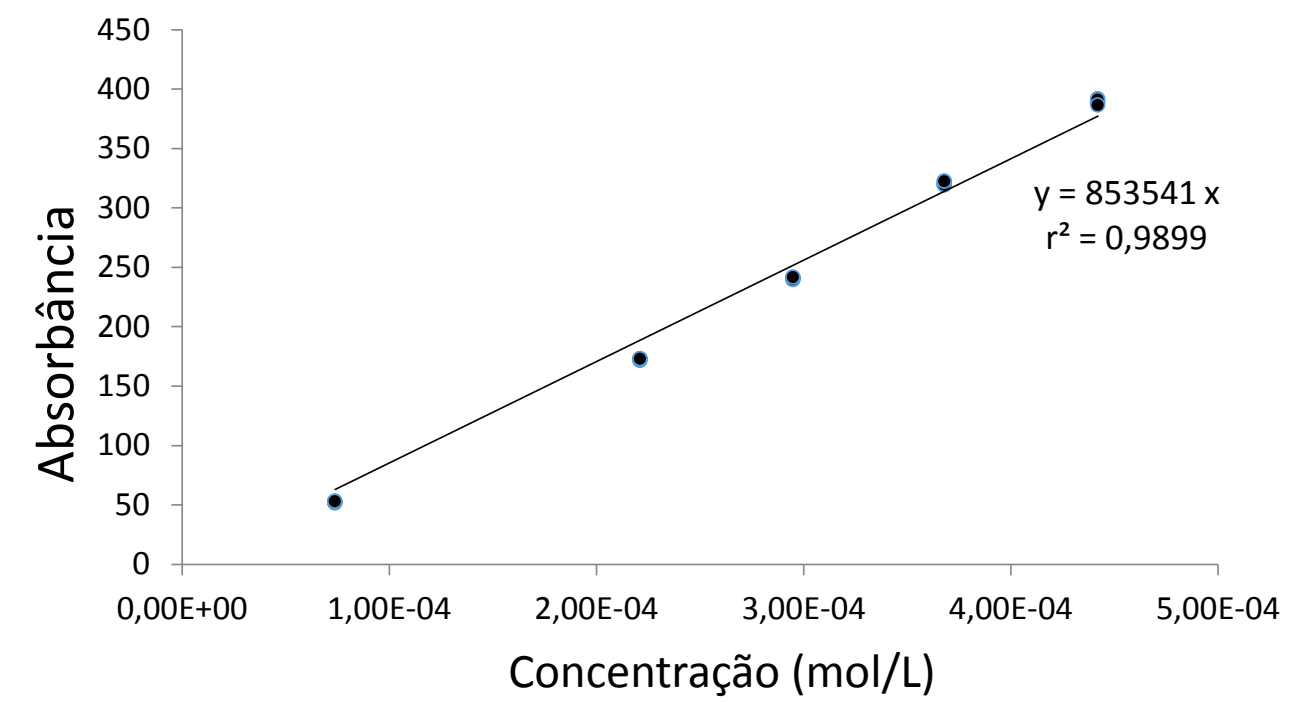

Corante preparado em água ultra pura; dados obtidos por HPLC-DAD.

A atividade total de descoloração (ATD) manteve-se constante durante todo período de incubação, sem diferença significativa entre os tempos avaliados, cerca de 0,8 U/L, entretanto após 72 horas foi observada tendência a um aumento, mostrando que o processo de descoloração in vivo poderia ter continuidade após esse período.

P. ostreatus mostrou-se promissor em aplicações biotecnológicas desse tipo, corroborando com os resultados do estudo de Zhao et al. (2007), que confirmaram a capacidade de biodegradação de corantes azo por uma espécie P. ostreatus, e ainda outros estudos, que empregando também a espécie $P$. ostreatus e suas enzimas comprovam a capacidade desse basidiomiceto em biodegradar diversos corantes 
(KUMAR et al., 2012; LU et al., 2008; ZHAO et al., 2006). Sugere-se ainda que os demais ensaios desse estudo utilizem controles abióticos meio de cultivo ao invés de água.

\subsection{Experimento 2}

A biomassa produzida nos cultivos aumentou a partir do $7^{\circ}$ dia de incubação (Figura 15), sendo maior aos 21 dias para $P$. cinerea e 30 dias para $P$. ostreatus e $T$. villosa, com diferença significativa entre os tempos, para os três fungos ( $p \leq 0,03$; APÊNDICE B). Foram T. villosa e P. cinerea que apresentaram maiores quantidades de biomassa, com mais de $30 \mathrm{~g} / \mathrm{L}$, já $P$. ostreatus produziu o máximo de 23 g de biomassa por litro de cultivo. Tais dados mostram que os metabolismos de crescimento desses basidiomicetos, nas condições aqui avaliadas, permaneceram ativos durante todo tempo de incubação. Em outro estudo Moreira Neto et al. (2013) com meio mínimo para o cultivo dessas mesmas linhagens de basidiomicetos, foi observada biomassa, aos 7 dias de incubação, de 0,778 g/L para $P$. ostreatus, 0,96 g/L para $T$. villosa e 1,35 g/L para $P$. cinerea, bem como essa mesma linhagem de $P$. cinerea produziu 2,26 g/L de biomassa no estudo de Silvério et al. (2013). Entretanto, no estudo aqui apresentado, nessa mesma idade fisiológica, essas mesmas linhagens produziram 14, 26 e 21 g/L, respectivamente, mostrando melhor capacidade de crescimento que o observado pelos autores supracitados, em virtude das condições terem favorecido maior crescimento.

Figura 8 - Biomassa seca por litro de cultivo de Pleurotus ostreatus CCIBt 2347 (ロ), Peniophora cinerea CCIBt 2541 ( $\square$ ) e Trametes villosa CCIBt $2628(\square)$.

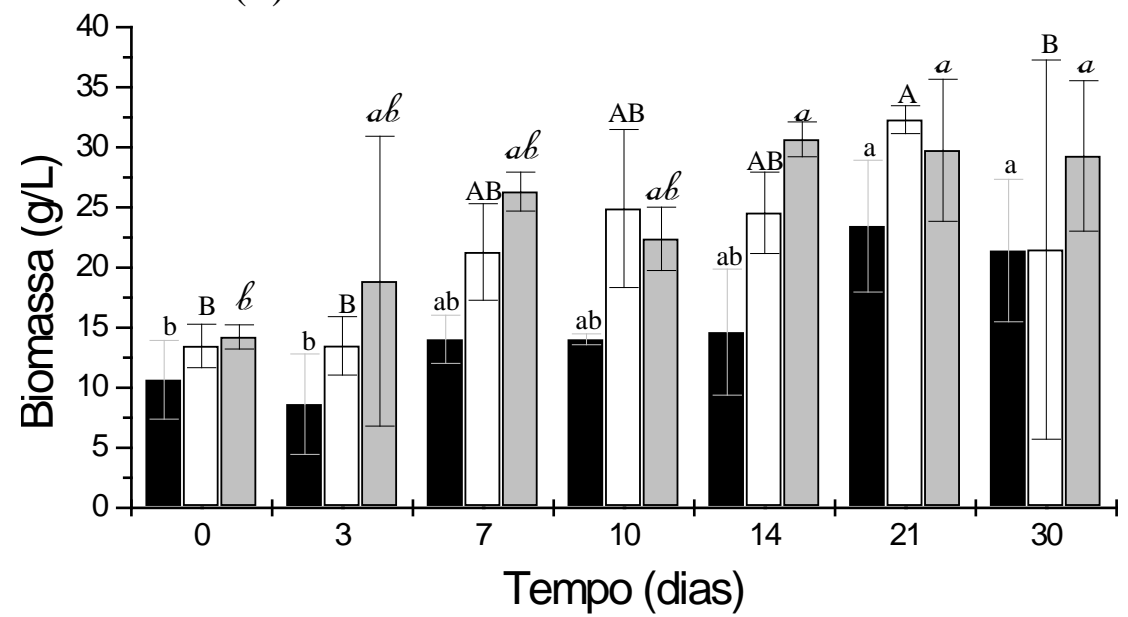

Letras iguais significam igualdade estatística. 
A descoloração, avaliada in vitro pela aplicação de extrato bruto, não foi significativa para nenhuma das concentrações de corante testadas com P. ostreatus ( $p$ > 0,1; APÊNDICE B). P. cinerea apresentou descoloração significativa apenas na menor concentração ( $p=0,000$; APÊNDICE B), sendo máxima quando extratos de 30 dias foram empregados. T. villosa apresentou descoloração significativa (APÊNDICE B) nas três concentrações avaliadas, sendo máxima com extratos de 30 dias (Tabela 10).

Tabela 10 - Descoloração in vitro de RB222 por extrato bruto de basidiomicetos com diferentes idades fisiológicas, em diferentes concentrações de corante.

\begin{tabular}{|c|c|c|c|c|c|c|c|c|c|c|}
\hline \multirow{3}{*}{ Fungo } & \multicolumn{9}{|c|}{ Concentração de corante (\%) } & \multirow{3}{*}{$\begin{array}{c}\text { Tempo } \\
\text { (dias) }\end{array}$} \\
\hline & \multicolumn{3}{|c|}{0,03} & \multicolumn{3}{|c|}{0,003} & \multicolumn{3}{|c|}{0,00003} & \\
\hline & Média & DP & Tukey & Média & DP & Tukey & Média & DP & Tukey & \\
\hline \multirow{7}{*}{ 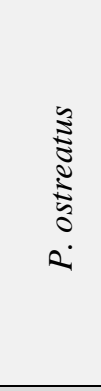 } & 5,35 & 4,68 & a & 8,24 & 5,91 & a & 5,15 & 7,28 & a & 0 \\
\hline & 0,00 & 0,00 & a & 2,80 & 1,30 & a & 0,00 & 0,00 & $\mathrm{a}$ & 3 \\
\hline & 2,11 & 11,35 & a & 4,79 & 2,85 & a & 0,00 & 0,00 & a & 7 \\
\hline & 0,00 & 0,00 & a & 1,26 & 9,89 & a & 4,14 & 7,07 & a & 10 \\
\hline & 0,00 & 0,00 & a & 9,36 & 3,88 & a & 0,00 & 0,00 & a & 14 \\
\hline & 0,00 & 0,00 & a & 10,31 & 10,70 & a & 17,30 & 7,30 & $\mathrm{a}$ & 21 \\
\hline & 96,61 & 34,18 & $\mathrm{a}$ & 13,20 & 41,57 & $\mathrm{a}$ & 15,67 & 39,62 & $\mathrm{a}$ & 30 \\
\hline \multirow{7}{*}{ 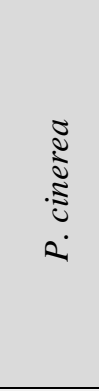 } & 20,49 & 18,59 & $\mathrm{a}$ & 7,26 & 4,37 & a & 12,59 & 1,64 & $\mathrm{ab}$ & 0 \\
\hline & 15,23 & 29,99 & a & 0,00 & 0,00 & a & 4,21 & 3,43 & bc & 3 \\
\hline & 1,67 & 22,52 & a & 0,87 & 11,67 & a & 0,00 & 0,00 & c & 7 \\
\hline & 19,52 & 23,81 & a & 11,35 & 27,59 & $\mathrm{a}$ & 5,77 & 7,01 & bc & 10 \\
\hline & 0,00 & 0,00 & $\mathrm{a}$ & 3,65 & 3,22 & $\mathrm{a}$ & 4,91 & 2,88 & bc & 14 \\
\hline & 9,59 & 70,49 & a & 3,86 & 2,15 & $\mathrm{a}$ & 0,00 & 00,00 & c & 21 \\
\hline & 0,00 & 0,00 & $\mathrm{a}$ & 0,29 & 44,04 & $\mathrm{a}$ & 25,29 & 12,21 & $\mathrm{a}$ & 30 \\
\hline \multirow{7}{*}{ 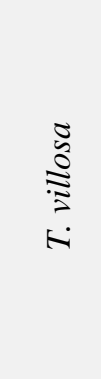 } & 0,00 & 0,00 & $\mathrm{ab}$ & 9,83 & 8,31 & $a b$ & 25,74 & 19,43 & $\mathrm{a}$ & 0 \\
\hline & 0,00 & 0,00 & $\mathrm{ab}$ & 0,98 & 14,70 & $\mathrm{ab}$ & 7,27 & 3,10 & $\mathrm{ab}$ & 3 \\
\hline & 0,00 & 0,00 & $\mathrm{ab}$ & 0,00 & 0,00 & b & 0,00 & 0,00 & b & 7 \\
\hline & 0,00 & 0,00 & b & 3,19 & 13,22 & $\mathrm{ab}$ & 10,63 & 9,30 & $\mathrm{ab}$ & 10 \\
\hline & 0,35 & 13,95 & $\mathrm{ab}$ & 7,66 & 6,66 & $a b$ & 5,36 & 3,42 & $\mathrm{ab}$ & 14 \\
\hline & 0,00 & 0,00 & b & 6,46 & 3,90 & $\mathrm{ab}$ & 5,08 & 8,53 & $\mathrm{ab}$ & 21 \\
\hline & 27,66 & 13,52 & $\mathrm{a}$ & 17,04 & 3,72 & $\mathrm{a}$ & 14,82 & 4,23 & $\mathrm{ab}$ & 30 \\
\hline
\end{tabular}

Letras iguais significam igualdade estatística na comparação dos três basidiomicetos simultaneamente, em cada concentração avaliada; DP = desvio padrão; Tukey = comparação de médias por Tukey; áreas em destaque representam maiores valores.

$\mathrm{O}$ pH dos extratos dos três fungos apresentou pequeno aumento no $30^{\circ}$ dia de incubação, com diferença altamente significativa entre os tempos ( $p=0,000$; APÊNDICE B), sendo que os maiores valores atingiram 5,96 $( \pm 0,13)$ em extratos de $P$. ostreatus, 5,49 $( \pm 0,10)$ em $P$. cinerea e 5,46 $( \pm 0,11)$ em $T$. villosa. Contudo, a faixa de 
pH manteve-se entre 3,87 e 5,96 para os três fungos, assim sendo, pode-se afirmar que o pH nesses sistemas de cultivo permanece na faixa entre 4,0 e 6,0, durante os 30 dias avaliados, corroborando assim com os demais dados aqui apresentados e confirmando o tamponamento do sistema pelo próprio sistema biológico.

Pleurotus ostreatus apresentou as maiores atividades de fenoloxidases (248 U/L), lacases (223 U/L) e MnP (142 U/L) em extratos de 30 dias, com diferença altamente significativa entre os tempos $(p=0,000)$, já suas peroxidases totais não apresentaram diferença estatística (APÊNDICE B). P. cinerea produziu os máximos de fenoloxidases (656 U/L) e de lacases (821 U/L) após 14 dias de incubação, com diferença significativa entre os tempos $(p<0,05)$, embora não tenha apesentado diferença estatística para suas peroxidases totais ou MnP (APÊNDICE B). T. villosa produziu o máximo de fenoloxidases (509 U/L), lacases (474 U/L) e MnP (16 U/L) em extratos de 30 dias, com diferença estatística entre os tempos ( $p \leq 0,05)$, embora sem diferir estatisticamente para as peroxidases totais (APÊNDICE B) (Tabela 11). Não foram detectadas LiP e VP em nenhum dos extratos avaliados.

Shankar e Shikha (2012) em estudo com Peniophora sp. também observaram que a maior produção de lacase ocorreu após 22 dias de incubação, corroborando assim com os dados aqui apresentados, os quais mostraram maiores valores dessa atividade enzimática em períodos de incubação a partir dos 14 dias. Alberts et al. (2009) em estudo de descoloração de corante Poly-R 478 observou que P. ostreatus e Peniophora sp. apresentaram as maiores atividades de lacase em comparação com outros basidiomicetos, do mesmo modo que o aqui observado.

Aguiar et al. (2010) comentam em seu estudo com Ceriporiopsis subvermispora, que 2,6 \% de óleo de soja nas culturas possibilitou aumento da atividade de MnP, bem como no presente estudo foi confirmado o favorecimento da produção de $\mathrm{MnP}$, detectada em todos os extratos. Outros estudos, avaliando sistemas de cultivo com os mesmos gêneros de basidiomicetos observaram altas quantidades de $\mathrm{MnP}$ em extratos de Peniophora sp., por Bonugli-Santos et al. (2012), bem como P. ostreatus, por Salame et al. (2013), e ainda nesse último os autores observaram a capacidade de descoloração de corante monoazo pela MnP testada.

Em mini revisão recente, Knop et al. (2015) comenta a potencialidade de aplicações das peroxidases de $P$. ostreatus, confirmando assim a ampla gama de usos para essas enzima, incluindo degradação de moléculas orgânicas. Moreira Neto et al. (2013) em estudo semelhante, empregando meio mínimo para o crescimento dos 
basidiomicetos, observou que apenas essa mesma linhagem de T. villosa CCIBt 2628 produziu MnP, diferente do que foi aqui observado, onde as condições de cultivo favoreceram a expressão dessa enzima pelos três basidiomicetos. Já outro estudo realizado com essas mesmas linhagens de Peniophora cinerea CCIBt 2541 e Trametes villosa CCIBt 2628, em fermentação sólida, Machado et al. (2005) observaram que esses dois basidiomicetos são capazes de produzir MnP durante descoloração de CI Reactive Blue 19, desde que em condições favoráveis. Martinez et al. (1996) comentam ainda que, em meio líquido, o tipo de fonte de nitrogênio pode favorecer ou não a produção dessa enzima, uma vez que Pleurotus eryngii cultivado na presença de tartarato de amônio não produziu MnP, mas na presença de peptona produziu $3 \mathrm{U} / \mathrm{mL}$ dessa enzima. Já Kiran et al. (2012) em estudo com P. ostreatus observaram que em meio líquido, na presença de 10 \% de Tween 80 associado a 0,1 \% de oxalato de amônio, esse basidiomiceto foi capaz de produzir cerca de $100 \mathrm{U} / \mathrm{mL}$ de $\mathrm{MnP}$, corroborando com o estímulo para produção dessa enzima, igualmente ao aqui observado. 
Tabela 11 - Atividades enzimáticas produzidas por basidiomicetos, durante cultivo líquido em meio enriquecido, para aplicação na descoloração in vitro.

\begin{tabular}{|c|c|c|c|c|c|c|c|c|c|c|}
\hline \multirow{2}{*}{$\underset{\text { (dias) }}{\text { Tempo }}$} & \multicolumn{2}{|c|}{ P. ostreatus } & \multirow{2}{*}{ Tukey } & \multicolumn{2}{|c|}{ P. cinerea } & \multirow{2}{*}{ Tukey } & \multicolumn{2}{|c|}{ T. villosa } & \multirow{2}{*}{ Tukey } & \multirow{2}{*}{$\begin{array}{c}\text { Atividade } \\
\text { Enzimática } \\
\text { [U/L] }\end{array}$} \\
\hline & Média & DP & & Média & DP & & Média & DP & & \\
\hline 0 & 0,00 & 0,00 & c & 0,00 & 0,00 & $\mathrm{~b}$ & 0,00 & 0,00 & $\mathrm{~b}$ & \multirow{7}{*}{ 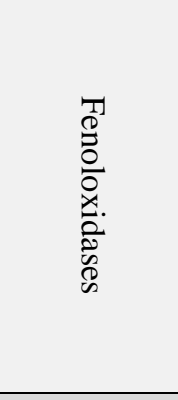 } \\
\hline 3 & 0,00 & 0,00 & c & 25,21 & 23,54 & \multirow{3}{*}{$\begin{array}{l}\mathrm{ab} \\
\mathrm{ab}\end{array}$} & 60,34 & 28,13 & $\mathrm{ab}$ & \\
\hline 7 & 0,00 & 0,00 & c & 263,04 & 109,09 & & 203,05 & 23,38 & $\mathrm{ab}$ & \\
\hline 10 & 0,00 & 0,00 & c & 467,63 & 118,84 & & 158,24 & 197,29 & $\mathrm{ab}$ & \\
\hline 14 & 45,91 & 47,08 & c & 656,23 & 315,71 & a & 397,56 & 264,99 & $\mathrm{ab}$ & \\
\hline 21 & 172,60 & 31,67 & $\mathrm{~b}$ & 595,73 & 114,83 & $\mathrm{a}$ & 41,05 & 42,68 & $\mathrm{~b}$ & \\
\hline 30 & 248,17 & 18,52 & $\mathrm{a}$ & 579,88 & 388,13 & $\mathrm{a}$ & 509,81 & 353,84 & $\mathrm{a}$ & \\
\hline 0 & 0,00 & 0,00 & c & 0,00 & 0,00 & b & 0,00 & 0,00 & b & \\
\hline 3 & 0,00 & 0,00 & c & 75,93 & 32,50 & $\mathrm{~b}$ & 48,46 & 24,04 & $a b$ & \\
\hline 7 & 0,00 & 0,00 & c & 294,47 & 48,82 & ab & 161,95 & 129,62 & $\mathrm{ab}$ & 5 \\
\hline 10 & 0,00 & 0,00 & c & 426,27 & 148,32 & $\mathrm{ab}$ & 211,08 & 162,44 & $\mathrm{ab}$ & ڤ્ڤి \\
\hline 14 & 26,93 & 16,16 & c & 821,67 & 417,40 & $\mathrm{a}$ & 407,44 & 319,31 & $\mathrm{ab}$ & \\
\hline 21 & 136,33 & 24,09 & $\mathrm{~b}$ & 466,86 & 45,44 & $\mathrm{ab}$ & 68,68 & 78,45 & $a b$ & \\
\hline 30 & 223,47 & 39,56 & a & 627,83 & 385,39 & $\mathrm{a}$ & 474,83 & 323,53 & $\mathrm{a}$ & \\
\hline 0 & 0,00 & 0,00 & a & 0,00 & 0,00 & a & 0,00 & 0,00 & a & \\
\hline 3 & 0,00 & 0,00 & a & 0,00 & 0,00 & a & 11,88 & 4,09 & a & Dי \\
\hline 7 & 0,00 & 0,00 & a & 0,00 & 0,00 & a & 41,10 & 117,63 & a & . \\
\hline 10 & 0,00 & 0,00 & a & 41,36 & 71,85 & $\mathrm{a}$ & 0,00 & 0,00 & a & 芯 \\
\hline 14 & 18,98 & 63,14 & a & 0,00 & 0,00 & $\mathrm{a}$ & 0,00 & 0,00 & a & 욤 \\
\hline 21 & 36,27 & 12,42 & a & 128,87 & 76,79 & a & 0,00 & 0,00 & a & 己. \\
\hline 30 & 24,69 & 27,86 & $\mathrm{a}$ & 0,00 & 0,00 & $\mathrm{a}$ & 34,98 & 83,42 & a & \\
\hline 0 & 0,00 & 0,00 & b & 0,00 & 0,00 & a & 0,00 & 0,00 & $\mathrm{~b}$ & \\
\hline 3 & 0,00 & 0,00 & b & 0,00 & 0,00 & a & 0,00 & 0,00 & $\mathrm{~b}$ & \\
\hline 7 & 0,00 & 0,00 & b & 0,23 & 0,40 & a & 0,00 & 0,00 & $\mathrm{~b}$ & \\
\hline 10 & 0,00 & 0,00 & b & 1,73 & 2,99 & a & 0,00 & 0,00 & $\mathrm{~b}$ & $\exists$ \\
\hline 14 & 7,14 & 5,26 & $\mathrm{~b}$ & 10,76 & 7,67 & a & 1,41 & 2,45 & $\mathrm{~b}$ & \\
\hline 21 & 82,12 & 62,47 & a & 21,05 & 7,51 & a & 0,00 & 0,00 & $\mathrm{~b}$ & \\
\hline 30 & 142,73 & 37,93 & $\mathrm{a}$ & 56,65 & 79,67 & $\mathrm{a}$ & 16,37 & 9,70 & $\mathrm{a}$ & \\
\hline
\end{tabular}

Letras iguais significam igualdade estatística; $\mathrm{DP}=$ desvio padrão; Tukey $=$ medias comparadas por Tukey; áreas em destaque representam maiores valores.

Foi feita análise de correlação entre as atividades enzimáticas (U/g de biomassa) em função da descoloração do corante RB222 (\% de descoloração/g de biomassa . L ${ }^{-1}$ ), onde foram obtidos o coeficiente de Pearson (p) e sua a probabilidade ( $p$ ) (APÊNDICE B), tais dados estão apresentados na Tabela 12. A descoloração de 0,03\% de corante apresentou correlação positiva forte $(\mathrm{p}=0,719)$ com lacases de $P$. ostreatus e correlação positiva moderada $(\mathrm{p}=0,691)$ com as $\mathrm{MnP}$ de $P$. ostreatus. A descoloração da 
concentração mais baixa de corante $(0,00003 \%)$ apresentou correlação positiva moderada $(\mathrm{p}=0,534)$ com as lacases desse mesmo basidiomiceto. $T$. villosa apresentou correlação positiva fraca $(\mathrm{p}=0,377)$ entre suas $\mathrm{MnP}$ e a descoloração de 0,03 \% de RB222. Da mesma forma, Ballaminut et al. (2014b) em estudo com Lentinus crinitus na degradação de pentaclorofenol em solo, com adição de 2,5 \% dessa mesma fonte de ácido graxo, observaram que lacase e MnP foram produzidas durante cultivo desse basidiomiceto, sendo que seus máximos coincidiram com as máximas degradações observadas, sugerindo que essas atividades enzimáticas podem estar diretamente envolvidas no processo degradativo, embora não tenham feito análise de correlação.

A descoloração de 0,03 \% de corante apresentou correlação negativa moderada com lacases de $P$. cinerea $(\mathrm{p}=-0,400)$ e a descoloração nas concentrações mais baixas apresentaram correlação com as MnP de $P$. cinerea: negativa moderada $(\mathrm{p}=-0,650)$ com a descoloração de $0,0003 \%$ e positiva moderada $(\mathrm{p}=0,413)$ com 0,00003 \%. Tais dados sugerem inibição das atividades enzimáticas pela presença de corante, uma vez que foi observada correlação negativa nas mais altas concentrações testadas, sendo esse efeito inibitório um fator já mencionado em revisões recentes que falam de processos de descoloração por micro-organismos (ALI, 2010; KAUSHIK; MALIK, 2009). 
Tabela 12 - Correlação entre atividades enzimáticas nos extratos brutos de basidiomicetos e descoloração in vitro de RB222, por grama de biomassa seca, durante cultivo líquido.

\begin{tabular}{|c|c|c|c|c|}
\hline Fungo & $\begin{array}{c}\text { Atividade } \\
\text { Enzimática }\end{array}$ & $\begin{array}{l}\text { Coeficiente de } \\
\text { Pearson }\end{array}$ & Valor $\mathbf{P}$ & Correlação \\
\hline \multicolumn{5}{|c|}{$0,03 \%$ RB222 } \\
\hline \multirow{2}{*}{ P. ostreatus } & Lacase & 0,719 & 0,000 & positiva forte \\
\hline & $\mathrm{MnP}$ & 0,691 & 0,001 & positiva moderada \\
\hline \multirow{2}{*}{ P. cinerea } & Lacase & $-0,400$ & 0,081 & negativa moderada \\
\hline & $\mathrm{MnP}$ & $-0,217$ & 0,359 & sem correlação \\
\hline \multirow{2}{*}{ T. villosa } & Lacase & 0,200 & 0,384 & sem correlação \\
\hline & $\mathrm{MnP}$ & 0,377 & 0,092 & positiva fraca \\
\hline \multicolumn{5}{|c|}{$0,0003 \%$ RB222 } \\
\hline \multirow{2}{*}{ P. ostreatus } & Lacase & 0,314 & 0,165 & sem correlação \\
\hline & $\mathrm{MnP}$ & 0,204 & 0,376 & sem correlação \\
\hline \multirow{2}{*}{ P. cinerea } & Lacase & $-0,301$ & 0,196 & sem correlação \\
\hline & $\mathrm{MnP}$ & $-0,650$ & 0,002 & negativa moderada \\
\hline \multirow{2}{*}{ T. villosa } & Lacase & $-0,131$ & 0,572 & sem correlação \\
\hline & $\mathrm{MnP}$ & 0,200 & 0,385 & sem correlação \\
\hline \multicolumn{5}{|c|}{$0,00003 \%$ RB222 } \\
\hline \multirow{2}{*}{ P. ostreatus } & Lacase & 0,534 & 0,013 & positiva moderada \\
\hline & $\mathrm{MnP}$ & 0,264 & 0,247 & sem correlação \\
\hline \multirow{2}{*}{ P. cinerea } & Lacase & 0,005 & 0,984 & sem correlação \\
\hline & $\mathrm{MnP}$ & 0,413 & 0,070 & positiva moderada \\
\hline \multirow{2}{*}{ T. villosa } & Lacase & $-0,334$ & 0,139 & sem correlação \\
\hline & $\mathrm{MnP}$ & $-0,038$ & 0,872 & sem correlação \\
\hline
\end{tabular}

Áreas em destaque representam correlação significativa.

A caracterização do inóculo fúngico aqui descrita possibilita uso dos resultados para aplicação em estudos de descoloração in vivo, embora seja necessário avaliar ainda outras atividades enzimáticas, uma vez que há evidências de que existem enzimas associadas ao micélio fúngico, que podem interferir no processo biotecnológico e que pela remoção da biomassa, no estudo aqui apresentado, não puderam ser avaliadas. Li et al. (2014) em estudo de descoloração de corantes, incluindo Congo Red, um corante diazo, observaram pequena diferença entre a descoloração in vitro e in vivo, comentando entretanto a vantagem no tratamento in vivo, principalmente quanto a mediação enzimática de forma eficiente. Ainda outros autores comentam a possibilidade desse mecanismo de mediação (RODRIGUEZ et al., 1999; SVOBODOVA et al., 2008).

Confirmando essa premissa Hadibarata et al. (2013) observaram que Pleurotus eryngii foi capaz de descolorir 0,003 \% CI Reactive Black 5 in vivo na presença de Tween 80, sendo essa a maior concentração de corante testada por esses autores. Ainda 
é importante lembrar que estudos semelhantes empregam concentrações menores de 0,03 \% de corantes (MOREIRA NETO et al., 2011; SHAHID et al., 2013; CHAIRIN et al., 2013; HADIBARATA et al., 2012b; JIANG et al., 2013; MOREIRA NETO et al., 2014; SI, et al., 2013; SVOBODOVA et al., 2008), sendo esse um diferencial do presente estudo.

\subsection{Experimento 3}

Os tratamentos empregando $P$. ostreatus apresentaram alta descoloração associada a produção de atividades enzimáticas, onde os dados observados em 24 horas estão descritos na Tabela 13. A máxima descoloração observada foi de 92,62 \%, quando as máximas atividades de fenoloxidases $(395,09 \mathrm{U} / \mathrm{L})$ e de lacases $(422,87 \mathrm{U} / \mathrm{L})$ foram observadas. Contudo quando ocorreu a máxima atividade de MnP (134,39 U/L) a descoloração foi de apenas 7,27 \%. Não foi detectada LiP nem VP em nenhum dos extratos avaliados.

Tabela 13 - Descoloração a 610nm e atividades enzimáticas produzidas pelos tratamentos avaliados empregando Pleurotus ostreatus CCIBt 2347, apresentados com os fatores não codificados e codificados (entre parênteses).

\begin{tabular}{|c|c|c|c|c|c|c|c|}
\hline \multirow{2}{*}{ Tratamento } & \multicolumn{3}{|c|}{ Fatores } & \multirow{2}{*}{$\begin{array}{c}\text { Descoloração } \\
(\%)\end{array}$} & \multirow{2}{*}{$\begin{array}{c}\text { Fenoloxidases } \\
\text { (U/L.dia }{ }^{-1} \text { ) }\end{array}$} & \multirow{2}{*}{$\begin{array}{c}\text { Lacases } \\
\left(\mathbf{U}^{-L . d i a}{ }^{-1}\right)\end{array}$} & \multirow{2}{*}{$\begin{array}{c}\text { MnP } \\
\left(\mathbf{U} / \mathbf{L} . \text { dia }^{-1}\right)\end{array}$} \\
\hline & $\mathrm{Cu}^{+2}(\mathrm{mM})$ & $\mathbf{M n}^{+2}(\mathrm{mM})$ & Idade (dias) & & & & \\
\hline 1 & $0,446(-1)$ & $0,285(-1)$ & $11(-1)$ & 2,00 & 0,00 & 0,00 & 0,00 \\
\hline 2 & $0,861(+1)$ & $0,285(-1)$ & $11(-1)$ & 2,56 & 44,68 & 29,40 & 0,00 \\
\hline 3 & $0,446(-1)$ & $0,821(+1)$ & $11(-1)$ & 0,00 & 4,21 & 9,72 & 0,00 \\
\hline 4 & $0,861(+1)$ & $0,821(+1)$ & $11(-1)$ & 0,58 & 0,00 & 0,00 & 0,00 \\
\hline 5 & $0,446(-1)$ & $0,285(-1)$ & $25(+1)$ & 0,00 & 297,09 & 225,33 & 13,26 \\
\hline 6 & $0,861(+1)$ & $0,285(-1)$ & $25(+1)$ & 0,00 & 324,87 & 215,30 & 6,82 \\
\hline 7 & $0,446(-1)$ & $0,821(+1)$ & $25(+1)$ & 63,63 & 332,59 & 223,78 & 9,83 \\
\hline 8 & $0,861(+1)$ & $0,821(+1)$ & $25(+1)$ & 47,70 & 334,90 & 213,75 & 8,79 \\
\hline 9 & $0,307(-1,68)$ & $0,553(0)$ & $18(0)$ & 4,83 & 169,92 & 136,35 & 128,64 \\
\hline 10 & $1(+1,68)$ & $0,553(0)$ & $18(0)$ & 5,05 & 165,29 & 138,90 & 8,56 \\
\hline 11 & $0,654(0)$ & $0,106(-1,68)$ & $18(0)$ & 7,27 & 155,11 & 130,80 & 134,39 \\
\hline 12 & $0,654(0)$ & $1(+1,68)$ & $18(0)$ & 50,75 & 364,38 & 220,39 & 47,27 \\
\hline 13 & $0,654(0)$ & $0,553(0)$ & $7(-1,68)$ & 2,57 & 0,00 & 0,00 & 0,00 \\
\hline 14 & $0,654(0)$ & $0,553(0)$ & $29(+1,68)$ & 92,62 & 395,09 & 422,87 & 19,56 \\
\hline $15 a$ & $0,654(0)$ & $0,553(0)$ & $18(0)$ & 5,05 & 236,36 & 207,19 & 50,29 \\
\hline $15 b$ & $0,654(0)$ & $0,553(0)$ & $18(0)$ & 7,44 & 179,10 & 135,58 & 34,32 \\
\hline $15 c$ & $0,654(0)$ & $0,553(0)$ & $18(0)$ & 3,10 & 194,69 & 159,81 & 36,82 \\
\hline
\end{tabular}

Áreas em destaque representam os maiores valores.

A partir dos dados reais obtidos foi feita análise de superfície de resposta (APÊNDICE C), originando equações quadráticas para cada variável avaliada. Os 
coeficientes de regressão obtidos para os tratamentos com $P$. ostreatus estão listados na

Tabela 14, onde manganês mostrou efeito significativo no termo linear para descoloração, fenoloxidases e lacases e no termo quadrático para fenoloxidases e lacases $(\mathrm{p}<0,1)$.

A idade fisiológica mostrou efeito significativo no termo linear para a descoloração, fenoloxidases e lacases $(p<0,05)$ e no termo quadrático apenas para a descoloração e fenoloxidases $(p<0,1)$. Houve efeito significativo apenas para a interação entre manganês e a idade fisiológica na descoloração $(p=0,016)$. Os modelos matemáticos obtidos se ajustam para a predição de valores para os fatores significativos.

Tabela 14 - Coeficiente de regressão para descoloração a $610 \mathrm{~nm}$, atividade de fenoloxidases, de lacase e MnP de Pleurotus ostreatus CCIBt 2347.

\begin{tabular}{|c|c|c|c|c|c|c|c|c|}
\hline \multirow[b]{2}{*}{ Fator } & \multicolumn{2}{|c|}{ Descoloração } & \multicolumn{2}{|c|}{ Fenoloxidases } & \multicolumn{2}{|c|}{ Lacase } & \multicolumn{2}{|c|}{ MnP } \\
\hline & $\begin{array}{c}\text { Coeficiente } \\
\text { de } \\
\text { Regressão }\end{array}$ & Valor $p$ & $\begin{array}{c}\text { Coeficiente } \\
\text { de } \\
\text { Regressão }\end{array}$ & Valor $p$ & $\begin{array}{c}\text { Coeficiente } \\
\text { de } \\
\text { Regressão }\end{array}$ & Valor $p$ & $\begin{array}{c}\text { Coeficiente } \\
\text { de } \\
\text { Regressão }\end{array}$ & Valor $p$ \\
\hline Constante & 0,82 & $0,088 *$ & $-333,725$ & $0,004 * * *$ & $-626,156$ & $0,002 * * *$ & 254,373 & 0,817 \\
\hline $\mathrm{Cu}^{+2}(\mathrm{~L})$ & 2,31 & 0,944 & 420,735 & 0,894 & 919,287 & 0,824 & $-619,067$ & 0,247 \\
\hline $\mathrm{Cu}^{+2}(\mathrm{Q})$ & $-1,35$ & 0,396 & $-330,06$ & 0,154 & $-499,968$ & 0,084 & 399,294 & 0,413 \\
\hline $\mathrm{Mn}^{+2}(\mathrm{~L})$ & $-2,48$ & $0,021 * *$ & 239,819 & $0,089 * *$ & 681,38 & $0,054 * *$ & $-406,761$ & 0,192 \\
\hline $\mathrm{Mn}^{+2}(\mathrm{Q})$ & 0,732 & 0,442 & $-304,92$ & $0,044 * *$ & $-413,967$ & $0,027 * *$ & 269,845 & 0,360 \\
\hline Idade (L) & $-0,1261$ & $0,005 * * *$ & 21,5579 & $0,047 * *$ & 23,5901 & $0,019 * *$ & 13,7686 & 0,766 \\
\hline Idade (Q) & 0,00282 & $0,099 *$ & $-0,392552$ & $0,097 *$ & $-0,299032$ & 0,264 & $-0,330861$ & 0,491 \\
\hline $\mathrm{Cu}^{+2} \times \mathrm{Mn}^{+2}$ & $-0,2$ & 0,869 & 146,066 & 0,467 & $-256,274$ & 0,298 & 24,5894 & 0,955 \\
\hline $\mathrm{Cu}^{+2} \mathrm{x}$ Idade & $-0,0237$ & 0,684 & $-4,19276$ & 0,604 & $-6,29986$ & 0,518 & $-1,38491$ & 0,938 \\
\hline $\mathrm{Mn}^{+2} \mathrm{x}$ Idade & 0,1372 & $0,016 * *$ & $-3,17258$ & 0,612 & $-7,74043$ & 0,317 & $-0,209255$ & 0,988 \\
\hline
\end{tabular}

$(\mathrm{L})=$ fator linear; $(\mathrm{Q})$ = fator quadrático; * = diferença estatística com probabilidade de $90 \%$; ** = diferença estatística com probabilidade de 95\%; *** = diferença estatística com probabilidade de 99\%.

A análise de variância dos modelos matemáticos obtidos para cada variável apoiou a capacidade de predizer resultados para a descoloração $(p=0,027)$ e para a produção de lacases $(p=0,082)$, no entanto não apoiou a predição de dados para fenoloxidases ( $p$ $=0,171)$ e para MnP $(p=0,672)$, indicando que esses fatores não apresentaram efeito significativo para a descoloração. Assim sendo, foram estimados os dados para as variáveis que apresentaram significância. Os valores estimados para P. ostreatus mostraram descoloração máxima (acima de 90 \%) quando a concentração de manganês estava acima de 0,821 mM, combinada com qualquer concentração de cobre e empregando cultivos de 25 e 29 dias. A máxima atividade de lacases foi de cerca de 120 U/L empregando cultivos de 25 e 29 dias, quando 0,654 $\mathrm{mM}$ de cobre e 0,285 $\mathrm{mM}$ de manganês estavam presentes no meio de cultivo (Tabela 15). 
Tabela 15 - Valores estimados para a descoloração a $610 \mathrm{~nm}$ in vivo de RB222 e lacase produzida por Pleurotus ostreatus CCIBt 2347 durante contato in vivo.

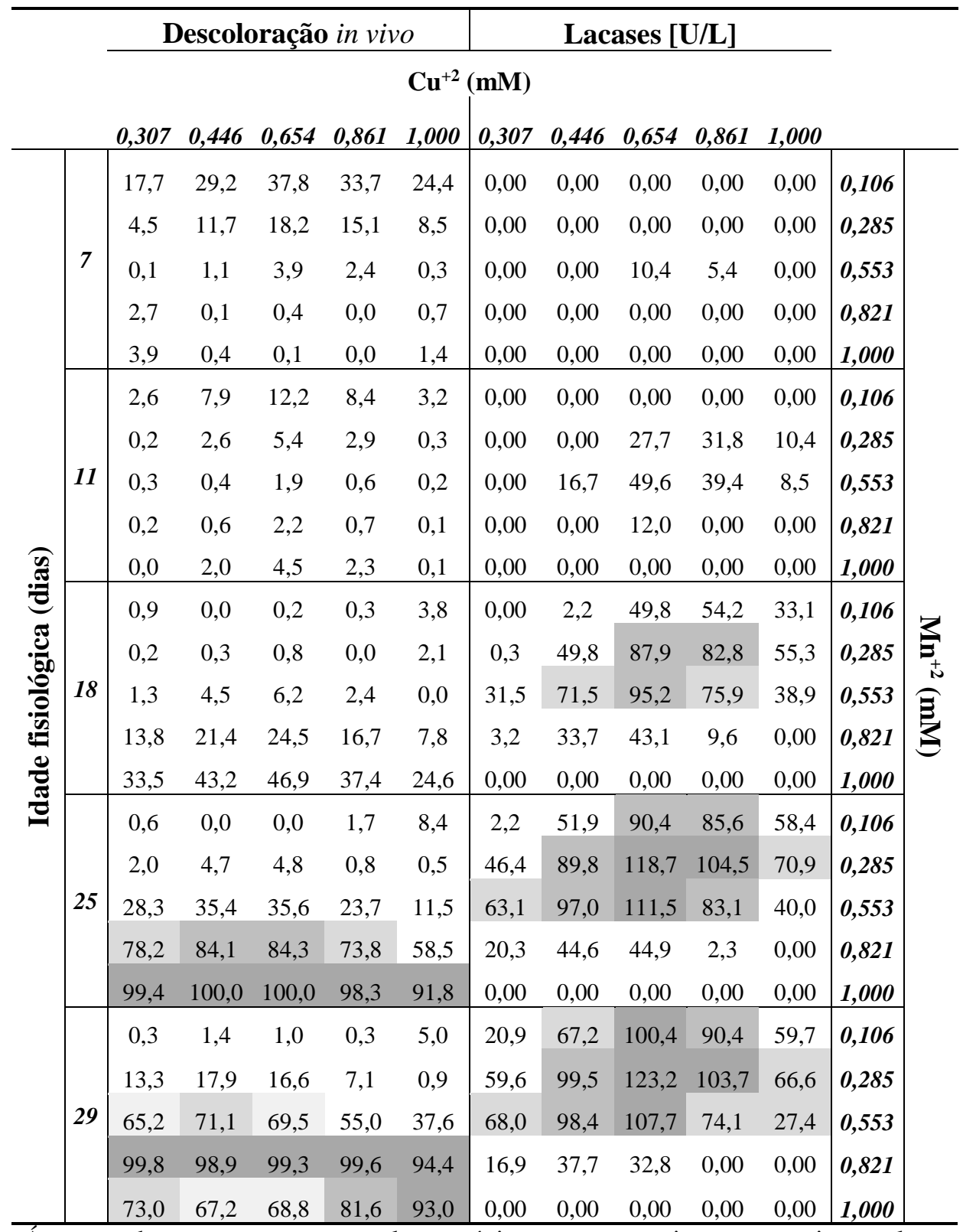

Áreas em destaque representam valores máximos, quanto mais escuros maior o valor.

Na análise de correlação entre a descoloração e as enzimas produzidas por $P$. ostreatus, o coeficiente de Pearson para fenoloxidases foi de 0,516 ( $p=0,034$ ), apresentando correlação positiva moderada significante. Para lacase o coeficiente foi de 0,571 ( $p=0,017)$, apresentando também correlação positiva moderada significante. Já MnP apresentou coeficiente de $-0,006$ ( $p=0,983)$, mostrando não ter correlação com a descoloração observada. Com base nos dados preditos, exibidos na Tabela 15, e a análise de correlação, é possível observar que quando ocorrem as maiores taxas de descoloração pode não haver produção de lacase, confirmando que, apesar dessa enzima 
estar correlacionada com a descoloração de RB222 por esse fungo, é sabido que o processo de descoloração é promovido por um mecanismo ligninolítico complexo, contendo enzimas e compostos de baixa massa molar, não sendo possível atribuir apenas à lacase a responsabilidade pela descoloração observada, embora a correlação observada nos permita inferir que esta enzima tem importante participação na descoloração do corante.

A análise pelo otimizador de resposta visando maximizar a descoloração, sugeriu a seguinte configuração ótima: 0,51 mM de cobre empregando cultivos de 29 dias de incubação. Embora a ferramenta sugira usar a concentração de $1 \mathrm{mM}$ de manganês, este elemento não mostrou ter efeito significativo na descoloração dentro do intervalo de concentração analisado, podendo se utilizar qualquer concentração entre 0,106 e $1 \mathrm{mM}$ de $\mathrm{Mn}^{+2}$. Foi feita também a otimização de resposta para a atividade de lacases, uma vez que a descoloração mostrou correlação com a produção dessa enzima, e a configuração sugerida foi de 0,65 mM de cobre empregando cultivo de 27,89 dias de incubação, para qualquer concentração de manganês. Da mesma forma, Karp et al. (2012), em estudo de caracterização de lacases de $P$. ostreatus, comentam a indução da atividade de lacase pela presença de $150 \mu \mathrm{M}$ de sulfato de cobre, associado a outros componentes testados. Kiran et al. (2012) estudando a descoloração de RB222 por P. ostreatus, também observaram que $1 \mathrm{mM}$ de sulfato de cobre favoreceu não apenas a produção de lacase (38,2 U/mL), mas também a descoloração (96,16 \%), sendo observados os maiores valores na presença desse sal. Fica evidente ainda que uma característica importante do processo é a dinâmica, uma vez que as condições que favorecem a máxima descoloração a $610 \mathrm{~nm}$ nem sempre coincidem com as condições que favorecem as máximas produções das enzimas ligninolíticas.

Os tratamentos constituintes do bloco experimental empregando T. villosa apresentaram descoloração associada a produção de atividades enzimáticas, e os dados observados em 24 horas de contato in vivo estão apresentados na Tabela 16. A máxima descoloração observada foi de 38,41 \%, quando havia pouca atividade de lacase (36,11 U/L) e nenhuma atividade de MnP. Também não foram detectadas atividades de LiP e VP em nenhum dos extratos avaliados. 
Tabela 16 - Descoloração a $610 \mathrm{~nm}$ e atividades enzimáticas produzidas pelos tratamentos com Trametes villosa CCIBt 2628, apresentados com os fatores não codificados e codificados (entre parênteses).

\begin{tabular}{|c|c|c|c|c|c|c|c|}
\hline \multirow{2}{*}{ Tratamento } & \multicolumn{3}{|c|}{ Fatores } & \multirow{2}{*}{ Descoloração (\%) } & \multirow{2}{*}{$\begin{array}{c}\text { Fenoloxidases } \\
\left.\text { (U/L.dia }{ }^{-1}\right)\end{array}$} & \multirow{2}{*}{$\begin{array}{c}\text { Lacases } \\
\left.\text { (U/L.dia }{ }^{-1}\right)\end{array}$} & \multirow{2}{*}{$\begin{array}{c}\text { MnP } \\
\left(\text { U/L.dia }^{-1}\right)\end{array}$} \\
\hline & $\mathrm{Cu}^{+2}(\mathrm{mM})$ & $\mathbf{M n}^{+2}(\mathbf{m M})$ & Idade (dias) & & & & \\
\hline 1 & $0,446(-1)$ & $0,285(-1)$ & $11(-1)$ & 0,10 & 11,96 & 62,43 & 1,82 \\
\hline 2 & $0,861(+1)$ & $0,285(-1)$ & $11(-1)$ & 5,34 & 396,79 & 217,61 & 0,00 \\
\hline 3 & $0,446(-1)$ & $0,821(+1)$ & $11(-1)$ & 13,07 & 150,17 & 135,35 & 0,00 \\
\hline 4 & $0,861(+1)$ & $0,821(+1)$ & $11(-1)$ & 9,48 & 115,29 & 261,60 & 0,85 \\
\hline 5 & $0,446(-1)$ & $0,285(-1)$ & $25(+1)$ & 0,00 & 140,75 & 77,32 & 0,00 \\
\hline 6 & $0,861(+1)$ & $0,285(-1)$ & $25(+1)$ & 0,00 & 195,39 & 195,39 & 0,00 \\
\hline 7 & $0,446(-1)$ & $0,821(+1)$ & $25(+1)$ & 0,00 & 311,60 & 251,41 & 0,00 \\
\hline 8 & $0,861(+1)$ & $0,821(+1)$ & $25(+1)$ & 38,41 & 411,14 & 36,11 & 0,00 \\
\hline 9 & $0,307(-1,68)$ & $0,553(0)$ & $18(0)$ & 1,21 & 855,62 & 516,40 & 8,03 \\
\hline 10 & $1(+1,68)$ & $0,553(0)$ & $18(0)$ & 20,48 & 357,44 & 355,43 & 6,29 \\
\hline 11 & $0,645(0)$ & $0,106(-1,68)$ & $18(0)$ & 11,57 & 645,27 & 598,35 & 12,05 \\
\hline 12 & $0,654(0)$ & $1(+1,68)$ & $18(0)$ & 9,91 & 761,79 & 562,85 & 0,00 \\
\hline 13 & $0,654(0)$ & $0,553(0)$ & $7(-1,68)$ & 7,54 & 54,63 & 37,12 & 0,00 \\
\hline 14 & $0,654(0)$ & $0,553(0)$ & $29(+1,68)$ & 0,00 & 14,04 & 181,73 & 0,00 \\
\hline $15 a$ & 0,654 (0) & $0,553(0)$ & $18(0)$ & 10,53 & 734,32 & 515,16 & 6,97 \\
\hline $15 b$ & $0,654(0)$ & $0,553(0)$ & $18(0)$ & 14,72 & 625,51 & 475,04 & 0,00 \\
\hline $15 c$ & $0,654(0)$ & $0,553(0)$ & $18(0)$ & 15,50 & 121,92 & 103,40 & 0,00 \\
\hline
\end{tabular}

Áreas em destaque representam valores máximos, quanto mais escuros maior o valor.

A partir dos dados reais obtidos foi feita análise de superfície de resposta (APÊNDICE C), os coeficientes de regressão obtidos para os tratamentos com Trametes villosa estão listados na Tabela 17, onde observou-se efeito significativo das concentrações de cobre no termo linear $(p=0,054)$, bem como a idade fisiológica no termo linear $(p=0,100)$ para descoloração, não se ajustando para os demais fatores, nem tampouco para as atividades de fenoloxidases, lacases e MnP, exceto a concentração de manganês que mostrou alguma significância no termo quadrático para $\operatorname{MnP}(p=0,113)$. 
Tabela 17 - Coeficiente de regressão para descoloração a $610 \mathrm{~nm}$, atividade de fenoloxidases, de lacase e de MnP produzidas por Trametes villosa CCIBt 2628.

\begin{tabular}{c|cc|cc|cc|cc}
\hline \multirow{2}{*}{ Fator } & \multicolumn{2}{|c|}{ Descoloração } & \multicolumn{2}{c|}{ Fenoloxidases } & \multicolumn{2}{c|}{ Lacase } & \multicolumn{2}{c}{ MnP } \\
\cline { 2 - 10 } & $\begin{array}{c}\text { Coeficiente } \\
\text { de } \\
\text { Regressão }\end{array}$ & Valor $p$ & $\begin{array}{c}\text { Coeficiente } \\
\text { de } \\
\text { Regressão }\end{array}$ & Valor $p$ & $\begin{array}{c}\text { Coeficiente } \\
\text { de } \\
\text { Regressão }\end{array}$ & Valor $p$ & $\begin{array}{c}\text { Coeficiente } \\
\text { de } \\
\text { Regressão }\end{array}$ & Valor $p$ \\
\hline Constante & $-0,1$ & $0,005 * * *$ & $-25,6938$ & 0,131 & $-1391,49$ & 0,146 & 4,82002 & 0,437 \\
$\mathrm{Cu}^{+2}(\mathrm{~L})$ & 0,3 & $0,054 * *$ & $-1005,13$ & 0,484 & 1709,37 & 0,998 & 27,3965 & 0,160 \\
$\mathrm{Cu}^{+2}(\mathrm{Q})$ & $-0,95$ & 0,440 & 1059,52 & 0,395 & $-283,221$ & 0,833 & 2,24054 & 0,973 \\
$\mathrm{Mn}^{+2}(\mathrm{~L})$ & $-0,26$ & 0,133 & 475,473 & 0,758 & 571,048 & 0,205 & $-77,7132$ & 0,336 \\
$\mathrm{Mn}^{+2}(\mathrm{Q})$ & $-0,354$ & 0,628 & $-172,057$ & 0,814 & 3,60795 & 0,996 & 70,3525 & $0,113 *$ \\
$\left.\mathrm{Idade}^{2} \mathrm{~L}\right)$ & 0,0289 & 0,263 & 41,9507 & 0,472 & 103,536 & 0,885 & $-0,0418314$ & 0,956 \\
$\mathrm{Idade}^{(\mathrm{Q})}$ & $-0,00219$ & $0,100 *$ & $-1,17186$ & 0,346 & $-3,11897$ & 0,046 & 0,0166236 & 0,803 \\
$\mathrm{Cu}^{+2} \mathrm{x}$ Mn+2 & 0,93 & 0,411 & $-802,571$ & 0,479 & $-2040,7$ & 0,130 & $-4,40028$ & 0,943 \\
$\mathrm{Cu}^{+2} \mathrm{x}$ Idade & 0,0485 & 0,301 & $-5,41417$ & 0,905 & $-11,6712$ & 0,816 & $-0,494374$ & 0,843 \\
$\mathrm{Mn}^{+2} \mathrm{x}$ Idade & 0,018 & 0,611 & 16,3114 & 0,645 & 27,54 & 0,487 & $-0,383222$ & 0,843 \\
\hline
\end{tabular}

$(\mathrm{L})$ = fator linear; $(\mathrm{Q})$ = fator quadrático; $(\mathrm{Q})$ = fator quadrático; * = diferença estatística com probabilidade de $90 \%$; ** = diferença estatística com probabilidade de $95 \%$; *** = diferença estatística com probabilidade de $99 \%$.

As equações de regressão para estimar os dados das variáveis avaliadas para $T$. villosa não predizem resultados com níveis de confiança significativo, uma vez que a análise de variância não apoia os modelos matemáticos para descoloração $(p=0,238)$, para fenoloxidases $(p=0,821)$, lacase $(p=0,356)$ e MnP $(p=0,629)$. No entanto, a solução apresentada pelo otimizador de resposta, para maximizar a descoloração nos tratamentos empregando esse fungo, mostrou a seguinte configuração de fatores: $1 \mathrm{mM}$ de cobre, $1 \mathrm{mM}$ de manganês e 21,6667 dias.

Foi feita análise de correlação entre a descoloração e as atividades enzimáticas produzidas por esse basidiomiceto, onde o coeficiente de Pearson (p) para fenoloxidases foi de 0,241 ( $p=0,351)$, para lacase foi de 0,036 $(p=0,892)$ e para MnP 0,091 ( $p=$ 0,729), sem mostrar correlação dessas atividades com a descoloração observada.

Diante da impossibilidade em se estimar dados para os tratamentos com esse basidiomiceto, considerou-se a configuração onde ocorreu a maior descoloração real (38,41 \%), onde 0,861 mM de cobre e 0,821 mM de manganês estavam presentes, com 25 dias.

A Tabela 18 apresenta a descoloração e produção de atividades enzimáticas, em 24 horas, observadas nos tratamentos com P. cinerea. A máxima descoloração foi de 31,65 \%, quando 961,34 U/L de fenoloxidases, 491,86 U/L de lacases e 8,68 U/L de 
MnP estavam presentes nos sistemas. LiP e VP não foram detectadas em nenhum dos extratos avaliados.

Tabela 18 - Descoloração a $610 \mathrm{~nm}$ e atividades enzimáticas produzidas pelos tratamentos com Peniophora cinerea CCIBt 2541, apresentados com os fatores não codificados e codificados (entre parênteses).

\begin{tabular}{|c|c|c|c|c|c|c|c|}
\hline \multirow{2}{*}{ Tratamento } & \multicolumn{3}{|c|}{ Fatores } & \multirow{2}{*}{$\begin{array}{c}\text { Descoloração } \\
\text { (\%) }\end{array}$} & \multirow{2}{*}{$\begin{array}{c}\text { Fenoloxidases } \\
\text { (U/L.dia' }\end{array}$} & \multirow{2}{*}{$\begin{array}{c}\text { Lacases } \\
\left.\text { (U/L.dia }{ }^{-1}\right)\end{array}$} & \multirow{2}{*}{$\begin{array}{c}\text { MnP } \\
\left(\text { U/L.dia }^{-1}\right)\end{array}$} \\
\hline & $\mathrm{Cu}^{+2}(\mathrm{mM})$ & $\mathbf{M n}^{+2}(\mathrm{mM})$ & Idade (dias) & & & & \\
\hline 1 & $0,446(-1)$ & $0,285(-1)$ & $11(-1)$ & 0,00 & 395,48 & 186,74 & 3,09 \\
\hline 2 & $0,861(+1)$ & $0,285(-1)$ & $11(-1)$ & 10,55 & 649,13 & 532,91 & 2,38 \\
\hline 3 & $0,446(-1)$ & $0,821(+1)$ & $11(-1)$ & 8,70 & 853,31 & 639,87 & 4,65 \\
\hline 4 & $0,861(+1)$ & $0,821(+1)$ & $11(-1)$ & 10,46 & 769,04 & 596,81 & 8,18 \\
\hline 5 & $0,446(-1)$ & $0,285(-1)$ & $25(+1)$ & 0,00 & 1147,93 & 893,59 & 33,94 \\
\hline 6 & $0,861(+1)$ & $0,285(-1)$ & $25(+1)$ & 0,00 & 1466,78 & 825,07 & 30,89 \\
\hline 7 & $0,446(-1)$ & $0,821(+1)$ & $25(+1)$ & 0,00 & 753,53 & 773,21 & 10,53 \\
\hline 8 & $0,861(+1)$ & $0,821(+1)$ & $25(+1)$ & 7,73 & 658,39 & 466,70 & 8,79 \\
\hline 9 & $0,307(-1,68)$ & $0,553(0)$ & $18(0)$ & 31,65 & 961,34 & 491,86 & 8,68 \\
\hline 10 & $1(+1,68)$ & $0,553(0)$ & $18(0)$ & 16,19 & 993,91 & 810,25 & 20,17 \\
\hline 11 & $0,645(0)$ & $0,106(-1,68)$ & $18(0)$ & 13,45 & 895,60 & 932,17 & 55,15 \\
\hline 12 & $0,645(0)$ & $1(+1,68)$ & $18(0)$ & 25,42 & 776,14 & 659,00 & 3,35 \\
\hline 13 & $0,645(0)$ & $0,553(0)$ & $7(-1,68)$ & 5,66 & 588,70 & 409,99 & 0,00 \\
\hline 14 & $0,645(0)$ & $0,553(0)$ & $29(+1,68)$ & 16,23 & 624,59 & 600,36 & 8,94 \\
\hline $15 a$ & $0,645(0)$ & $0,553(0)$ & $18(0)$ & 14,57 & 1125,55 & 753,92 & 21,34 \\
\hline $15 b$ & $0,645(0)$ & $0,553(0)$ & $18(0)$ & 22,80 & 686,78 & 749,67 & 9,85 \\
\hline $15 \mathrm{c}$ & $0,645(0)$ & $0,553(0)$ & $18(0)$ & 25,25 & 1152,41 & 958,41 & 7,27 \\
\hline
\end{tabular}

Os coeficientes de regressão (APÊNDICE C) para os fatores testados com $P$. cinerea estão apresentados na Tabela 19, onde o manganês no termo quadrático ( $p=$ $0,103)$ e as interações com esse metal $(p<0,05)$ apresentaram significância para fenoloxidases, bem como manganês no termo linear também apresentou significância para lacases $(p=0,082)$. No entanto, os modelos matemáticos para todas as variáveis avaliadas com esse basidiomiceto não apresentaram efeito significativo, não podendo ser empregados para estimar dados, uma vez que não foram apoiados pela análise de variância $(p>0,1)$. 
Tabela 19 - Coeficiente de regressão para descoloração a $610 \mathrm{~nm}$, atividade de fenoloxidases, de lacase e MnP produzidas por Peniophora cinerea CCIBt 2541.

\begin{tabular}{|c|c|c|c|c|c|c|c|c|}
\hline \multirow[b]{2}{*}{ Fator } & \multicolumn{2}{|c|}{ Descoloração } & \multicolumn{2}{|c|}{ Fenoloxidases } & \multicolumn{2}{|c|}{ Lacase } & \multicolumn{2}{|c|}{ MnP } \\
\hline & $\begin{array}{c}\text { Coeficiente } \\
\text { de } \\
\text { Regressão }\end{array}$ & Valor $p$ & $\begin{array}{c}\text { Coeficiente } \\
\text { de } \\
\text { Regressão }\end{array}$ & Valor $p$ & $\begin{array}{c}\text { Coeficiente } \\
\text { de } \\
\text { Regressão }\end{array}$ & Valor $p$ & $\begin{array}{l}\text { Coeficiente } \\
\text { de } \\
\text { Regressão }\end{array}$ & Valor $p$ \\
\hline Constante & $-1,37$ & $0,010 * * *$ & $-2717,44$ & $0,007 * * *$ & $-966,411$ & 0,517 & $-21,2818$ & 0,608 \\
\hline $\mathrm{Cu}^{+2}(\mathrm{~L})$ & 1,76 & 0,719 & 4151,5 & 0,395 & 3251,32 & 0,831 & 62,8981 & 0,605 \\
\hline $\mathrm{Cu}^{+2}(\mathrm{Q})$ & $-1,14$ & 0,524 & $-2666,04$ & 0,115 & $-1841,29$ & 0,367 & $-74,6597$ & 0,588 \\
\hline $\mathrm{Mn}^{+2}(\mathrm{~L})$ & 1,33 & 0,380 & 6052,41 & 0,374 & $-889,132$ & $0,082 * *$ & $-187,645$ & 0,219 \\
\hline $\mathrm{Mn}^{+2}(\mathrm{Q})$ & $-0,95$ & 0,381 & $-1667,4$ & $0,103 *$ & $-205,005$ & 0,863 & 82,5701 & 0,331 \\
\hline Idade (L) & 0,948 & 0,680 & 32,9622 & 0,946 & 57,4278 & 0,464 & 6,7005 & 0,902 \\
\hline Idade (Q) & $-0,0026$ & 0,166 & $-0,697079$ & 0,650 & $-0,596813$ & 0,762 & $-0,126458$ & 0,365 \\
\hline $\mathrm{Cu}^{+2} \times \mathrm{Mn}+2$ & $-0,04$ & 0,979 & $-3994,93$ & $0,022 * *$ & 700,272 & 0,702 & 148,416 & 0,259 \\
\hline $\mathrm{Cu}^{+2} \mathrm{x}$ Idade & $-0,0073$ & 0,911 & 71,7127 & 0,236 & $-72,8555$ & 0,341 & $-1,89178$ & 0,712 \\
\hline $\mathrm{Mn}^{+2} \mathrm{x}$ Idade & $-0,0012$ & 0,982 & $-100,083$ & $0,052 * *$ & 5,31532 & 0,926 & $-1,46969$ & 0,711 \\
\hline
\end{tabular}

$(\mathrm{L})$ = fator linear; $(\mathrm{Q})$ = fator quadrático; $(\mathrm{Q})=$ fator quadrático; * = diferença estatística com probabilidade de $90 \%$; ** = diferença estatística com probabilidade de $95 \%$; *** = diferença estatística com probabilidade de $99 \%$.

A análise de correlação entre a descoloração e as atividades enzimáticas não apresentou significância para fenoloxidases (Pearson $=-0,122 ; p=0,641$ ), nem para lacases $($ Pearson $=-0,087 ; p=0,74)$ ou para MnP (Pearson $=-0,265 ; p=0,304$ ). Contudo, a análise otimização de resposta foi feita apenas para a descoloração, a qual sugeriu a seguinte configuração de fatores: 0,706 mM de cobre, 0,6749 mM de manganês, empregando cultivo de 17 dias. Diferentemente, a máxima descoloração real (31,65 \%) foi observada na presença de 0,307 mM de cobre e 0,553 mM de manganês, coincidindo contudo com a idade fisiológica (18 dias). Shankar e Shikha (2015) avaliaram lacase bruta de Peniophora sp. na descoloração de corantes sintéticos e observaram maiores atividades de lacases quando $1 \mathrm{mM}$ de cobre e de manganês estavam presentes. No entanto, esses mesmos autores observaram maiores descolorações quando 0,5 a $1 \mathrm{mM}$ de cobre, com 0,5 ou $10 \mathrm{mM}$ de manganês estavam presentes no meio.

A literatura confirma que os metais diretamente envolvidos no ciclo catalítico das principais enzimas ligninolíticas podem regular sua expressão, quando adicionados ao meio de cultivo, como é o caso do $\mathrm{Mn}^{+2}$ e do $\mathrm{Cu}^{+2}$, podendo ainda maximizar suas produções (AKPINAR; UREK, 2012; HU et al., 2009; LORENZO et al., 2006; PALMIERI et al., 2000; TEN HAVE; TEUNISSEN, 2001; WONG, 2009). Baldrian e Gabriel (2002) acrescentam ainda que a presença de $\mathrm{Cu}^{+2}$ pode afetar positivamente a 
atividade e a estabilidade da lacase de $P$. ostreatus. Outros estudos também mostraram indução e/ou favorecimento da descoloração de diferentes corantes na presença desses metais (KAUSHIK; MALIK, 2009; KIRAN et al., 2012; MOREIRA et al., 2000). O manganês $\left(\mathrm{Mn}^{+2}\right)$ também apresenta funções múltiplas no cultivo de fungos, tendo seu papel como indutor de MnP bem fundamentado na literatura (KAUSHIK; MALIK, 2009; TEN HAVE; TEUNISSEN, 2001; WONG 2009), bem como mediador do processo de descoloração de RB222 por $P$. ostreatus e por Phanerochaete chrysosporium, favorecendo maiores taxas de descoloração e maior produção enzimática (KIRAN et al., 2012). Lorenzo et al. (2006) em outro estudo comenta que 3,5 $\mathrm{mM}$ de $\mathrm{Cu}^{+2}$ favoreceram a atividade de lacases (8277 U/L), bem como a presença de $\mathrm{Mn}^{+2}$ (1 mM) favoreceu a produção de 938U/L dessa mesma enzima, por Trametes versicolor em avaliação de descoloração de índigo carmine, sendo a produção de lacase e suas isoenzimas um fator importante do processo.

Outro fator importante avaliado aqui é o efeito da idade fisiológica do cultivo para aplicação em processos biotecnológicos, uma vez que diferentes estudos vem mostrando que os fungos respondem diferentemente a cada situação (BALLAMINUT; MATHEUS, 2007; MAZMANCI; UNYAYAR, 2005). Ballaminut et al. (2014b) comentam que a melhor idade fisiológica para a degradação do poluente em fermentação sólida de Lentinus crinitus não está vinculada à máxima colonização do substrato, nem à maior produção enzimática, mas sim ao melhor momento favorável a promover a degradação do poluente de interesse, associado à presença das enzimas ligninolíticas, não necessariamente seus máximos valores. Moreira Neto et al. (2011) estudando as mesmas espécies aqui estudadas, avaliaram sistemas de descoloração de CI Reactive Blue 19, empregando cultivo de 7 e 9 dias de incubação, onde ambos foram considerados aptos para uso nos tratamentos. Entretanto, os cultivos foram avaliados somente até os nove dias de incubação, momento em que os maiores valores de descoloração ocorreram, evidenciando assim a necessidade em se obter mais detalhes sobre o momento ótimo para início do tratamento in vivo, além dos 9 dias de incubação. Foi nesse contexto, e frente aos dados obtidos, considerando os dados reais e preditos, além da análise de correlação, que foram selecionadas as configurações consideradas ótimas para os fatores:

a) $\quad P$. ostreatus emprega cultivo com 25 dias, contendo 0,446 $\mathrm{mM}$ de cobre e 0,821 mM de manganês; 
b) T. villosa emprega cultivo com 25 dias, contendo $1 \mathrm{mM}$ de cobre e de manganês;

c) P. cinerea emprega cultivo com 18 dias, contendo $1 \mathrm{mM}$ de cobre e 0,106 mM de manganês.

\subsection{Experimento 4}

As descolorações e as atividades enzimáticas produzidas por $P$. ostreatus estão apresentadas na Tabela 20, onde a máxima descoloração a $610 \mathrm{~nm}$ foi de 92,98 \%, em 24 horas, juntamente com 28,90 \% de descoloração a $526 \mathrm{~nm}$, quando foram produzidas 348,02 U/L de fenoloxidases, 4,91 U/L de MnP e 331,05 U/L de lacases, sendo esse o máximo de lacases observado nos tratamentos. Nessa mesma condição ocorreu a máxima descoloração a 610 nm após 48 horas (99,79 \%), acompanhada de 59,82 \% de descoloração a $526 \mathrm{~nm}$, quando 333,36 U/L de fenoloxidases, 4,91 U/L de MnP e 319,62 $\mathrm{U} / \mathrm{L}$ de lacases foram produzidos. 
Tabela 20 - Descoloração e atividades enzimáticas (U/L.dia ${ }^{-1}$ ) produzidas por Pleurotus ostreatus CCIBt 2347, seus fatores não codificados e codificados (entre parênteses). Áreas em destaque representam maiores valores.

\begin{tabular}{|c|c|}
\hline & 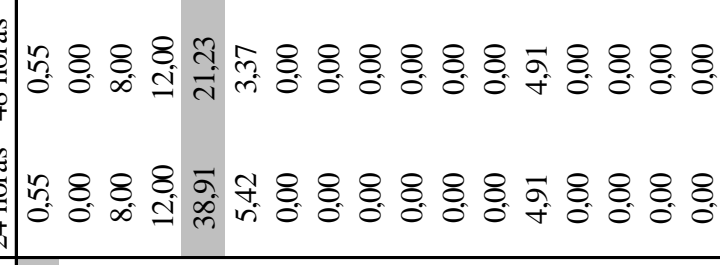 \\
\hline & 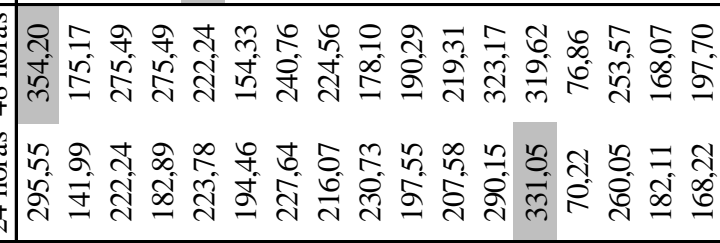 \\
\hline 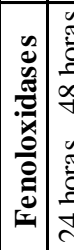 & 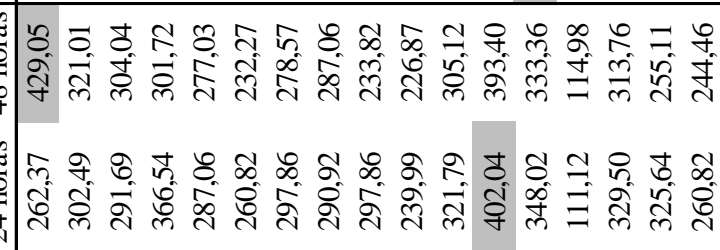 \\
\hline 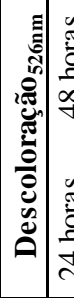 & 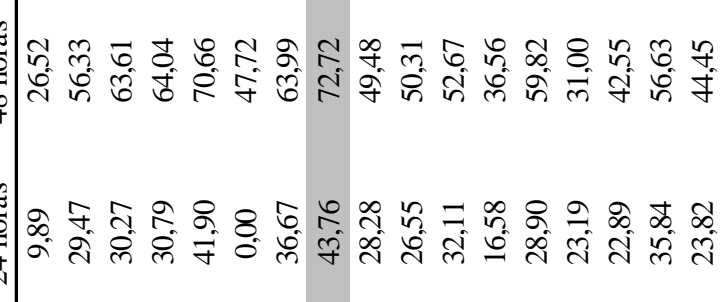 \\
\hline 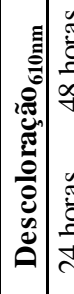 & 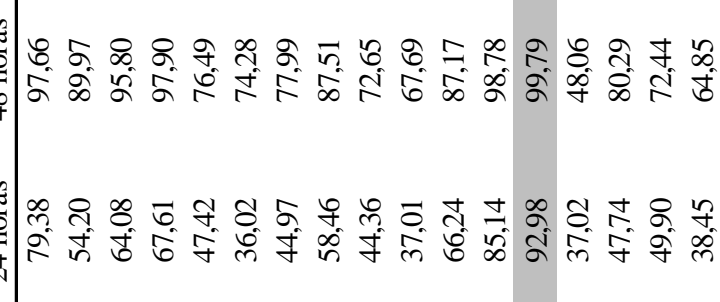 \\
\hline 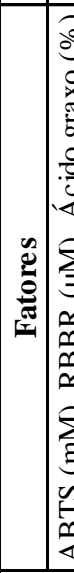 & 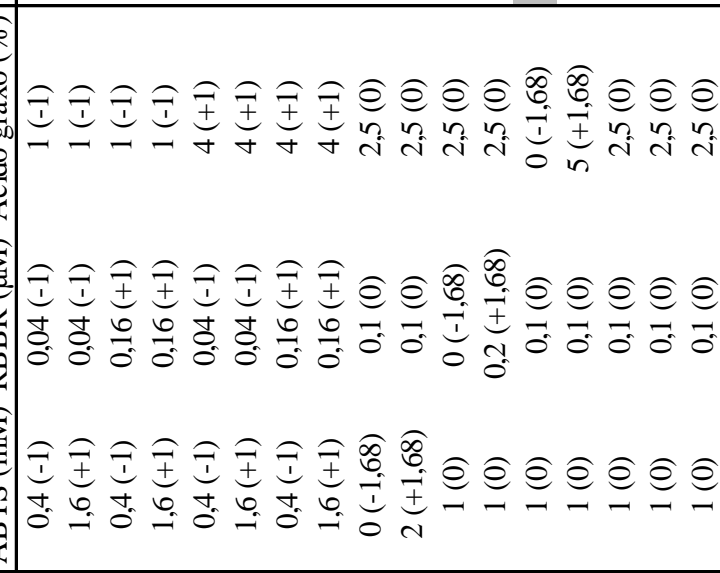 \\
\hline 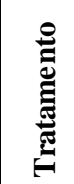 & 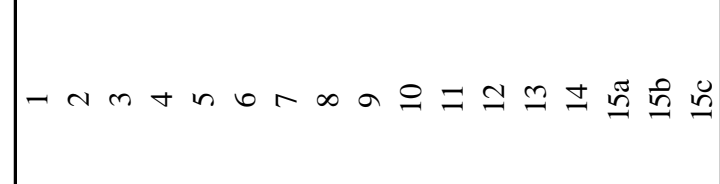 \\
\hline
\end{tabular}


Kaushik e Malik (2009) comentam que a descoloração de corante ocorre quando

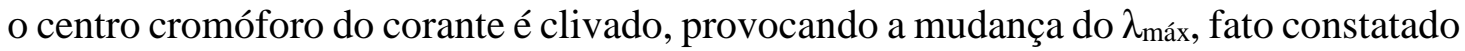
já no Experimento inicial desse estudo. Sugere-se então que, após clivagem do primeiro grupo azo, o $\lambda_{\text {máx }}$ passou a ser em $526 \mathrm{~nm}$, conforme mostra a o espectro de absorção dos tratamentos (Figura 9).

Zhao et al. (2007), avaliando a descoloração de corantes azo, também por $P$. ostreatus, comentam que a quebra da ligação azo $(\mathrm{N}=\mathrm{N})$ dos corantes ocorre pelo mecanismo oxidativo, formando os primeiros metabólitos identificados como sulfonatos aromáticos, sulfonatos hidroxi-aromáticos e quinonas. Adicionalmente, Lu et al. (2008) comentam que corantes azo sulfonados podem sofrer a quebra oxidativa do grupo cromóforo logo no início do processo de descoloração com $P$. ostreatus. Nesse contexto pode-se inferir que RB222 parece ter sofrido quebra da ligação azo nas primeiras 24 horas de contato, resultante da ação das lacases de $P$. ostreatus CCIBt 2347, o que conferiu mudança de cor de azul para o vermelho (526 nm). Contudo, foi observada também descoloração a 526 nm (Tabela 20), podendo ser esse fenômeno resultante da quebra do segundo grupo azo da molécula do corante.

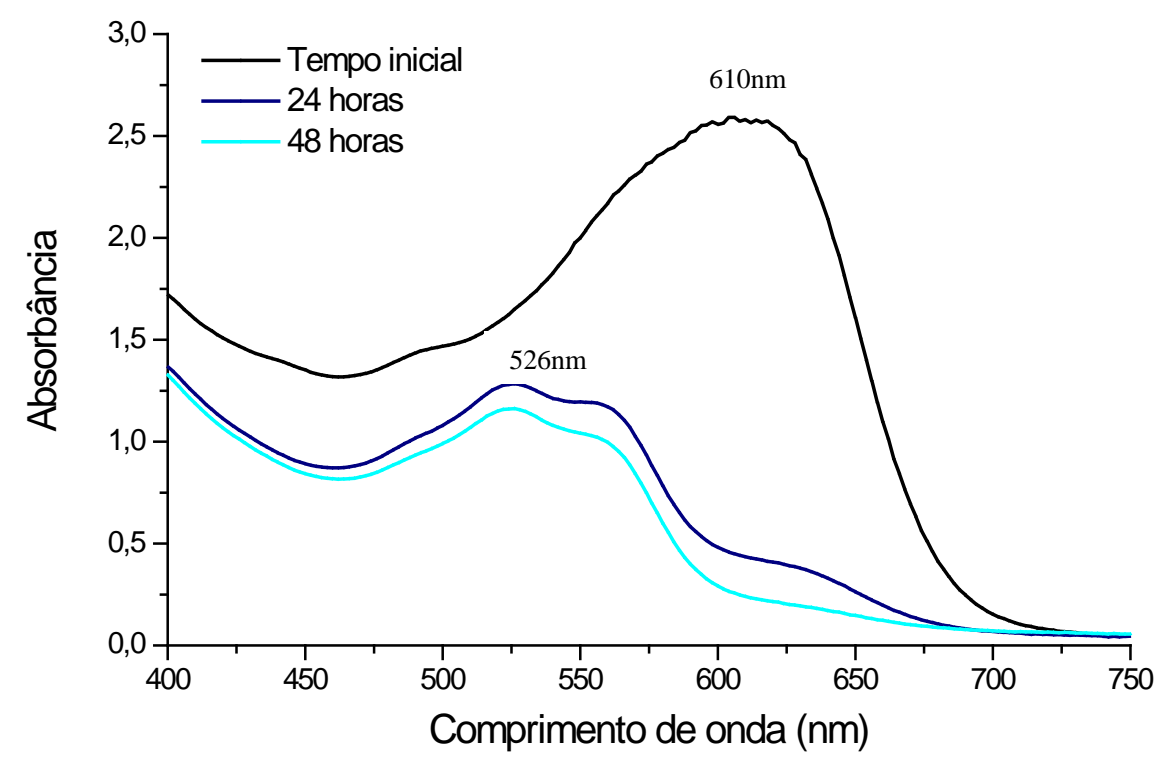

Figura 9 - Espectros de absorção da fase líquida dos tratamentos de RB222 com Pleurotus ostreatus CCIBt 2347.

A análise de variância (APÊNDICE D) apoiou os modelos matemáticos para a descoloração a 610nm ( $p=0,008)$, bem como para as atividades de $\operatorname{MnP}(p=0,044)$ e de fenoloxidases $(p=0,069)$ após 24 horas. Houve efeito significativo também para a descoloração a $610 \mathrm{~nm}(p=0,022)$ e para lacases $(p=0,091)$, após 48 horas. Os 
coeficientes de regressão para os fatores cujos modelos matemáticos foram significativos estão apresentados na Tabela 21, onde foi observado efeito significativo do RBBR e do ácido graxo sobre a descoloração, indicando ainda haver interação ABTS $\mathrm{x}$ RBBR. Os mesmos fatores interferiam de maneiras desiguais nas atividades enzimáticas.

Tabela 21 - Coeficiente de regressão para descoloração a $610 \mathrm{~nm}$ e atividades enzimáticas para Pleurotus ostreatus CCIBt 2347.

\begin{tabular}{|c|c|c|c|c|c|c|c|c|c|c|}
\hline \multirow[b]{3}{*}{ Fator } & \multicolumn{6}{|c|}{ Tempo 24 horas } & \multicolumn{4}{|c|}{ Tempo 48 horas } \\
\hline & \multicolumn{2}{|c|}{ Descoloração $_{610 \mathrm{~nm}}$} & \multicolumn{2}{|c|}{ Fenoloxidases } & \multicolumn{2}{|c|}{ MnP } & \multicolumn{2}{|c|}{ Descoloração $_{610 \mathrm{~nm}}$} & \multicolumn{2}{|c|}{ Lacase } \\
\hline & $\begin{array}{c}\text { Coeficiente } \\
\text { de } \\
\text { Regressão }\end{array}$ & Valor $p$ & $\begin{array}{c}\text { Coeficiente } \\
\text { de } \\
\text { Regressão }\end{array}$ & Valor $p$ & $\begin{array}{c}\text { Coeficiente } \\
\text { de } \\
\text { Regressão }\end{array}$ & Valor $p$ & $\begin{array}{c}\text { Coeficiente } \\
\text { de } \\
\text { Regressão }\end{array}$ & Valor $p$ & $\begin{array}{c}\text { Coeficiente } \\
\text { de } \\
\text { Regressão }\end{array}$ & Valor $p$ \\
\hline Constante & 1,711 & $0,000 * * *$ & 298,000 & $0,000 * * *$ & $-0,500$ & 0,892 & 1,802 & $0,000 * * *$ & 579,000 & $0,001 * * *$ \\
\hline ABTS (L) & $-0,149$ & 0,342 & 82,800 & 0,357 & $-11,700$ & 0,365 & $-0,306$ & 0,908 & $-109,000$ & 0,789 \\
\hline $\operatorname{ABTS}(Q)$ & $-0,090$ & 0,276 & $-53,900$ & 0,187 & 4,250 & 0,394 & 0,070 & 0,578 & $-5,700$ & 0,902 \\
\hline RBBR (L) & $-7,760$ & 0,147 & $-1529,000$ & 0,130 & 35,000 & 0,575 & $-7,150$ & $0,097 *$ & $-3751,000$ & 0,529 \\
\hline RBBR (Q) & 28,130 & $0,008 * * *$ & 3634,000 & 0,357 & 425,000 & 0,394 & 38,000 & $0,016 * *$ & 14985,000 & $0,012 * * *$ \\
\hline Ácido Graxo (L) & $-0,320$ & $0,001 * * *$ & 57,000 & $0,049 * *$ & 5,190 & 0,178 & $-0,322$ & $0,001 * * *$ & $-95,500$ & $0,017 * *$ \\
\hline Ácido Graxo (Q) & 0,032 & $0,036 * *$ & $-18,510$ & $0,016 * * *$ & 1,466 & 0,091 & 0,032 & 0,135 & 5,310 & 0,483 \\
\hline ABTS x RBBR & 1,977 & $0,065 * *$ & 392,000 & 0,399 & 126,700 & $0,056 * *$ & 1,030 & 0,490 & 539,000 & 0,344 \\
\hline ABTS x Ácido Graxo & 0,036 & 0,354 & $-13,500$ & 0,465 & $-4,760$ & $0,069 * *$ & 0,028 & 0,632 & 23,700 & 0,301 \\
\hline RBBR x Ácido Graxo & 0,332 & 0,388 & 301,000 & 0,129 & $-92,800$ & $0,004 * * *$ & $-0,100$ & 0,866 & 150,000 & 0,502 \\
\hline
\end{tabular}

$(\mathrm{L})=$ fator linear; $(\mathrm{Q})=$ fator quadrático; * = diferença estatística com probabilidade de $90 \%$; ** = diferença estatística com probabilidade de $95 \%$; *** = diferença estatística com probabilidade de $99 \%$.

Aplicando a equação de regressão originada, com os coeficientes de regressão e os fatores não codificados, foi possível estimar valores para a descoloração a $610 \mathrm{~nm}$, nos dois tempos avaliados, bem como atividades enzimáticas que apresentaram efeito significativo (Tabela 22 e Tabela 23). 
Tabela 22 - Descoloração a $610 \mathrm{~nm}$, fenoloxidases e MnP estimados para sistemas de tratamento com Pleurotus ostreatus CCIBt 2347 com 24 horas de contato in vivo.

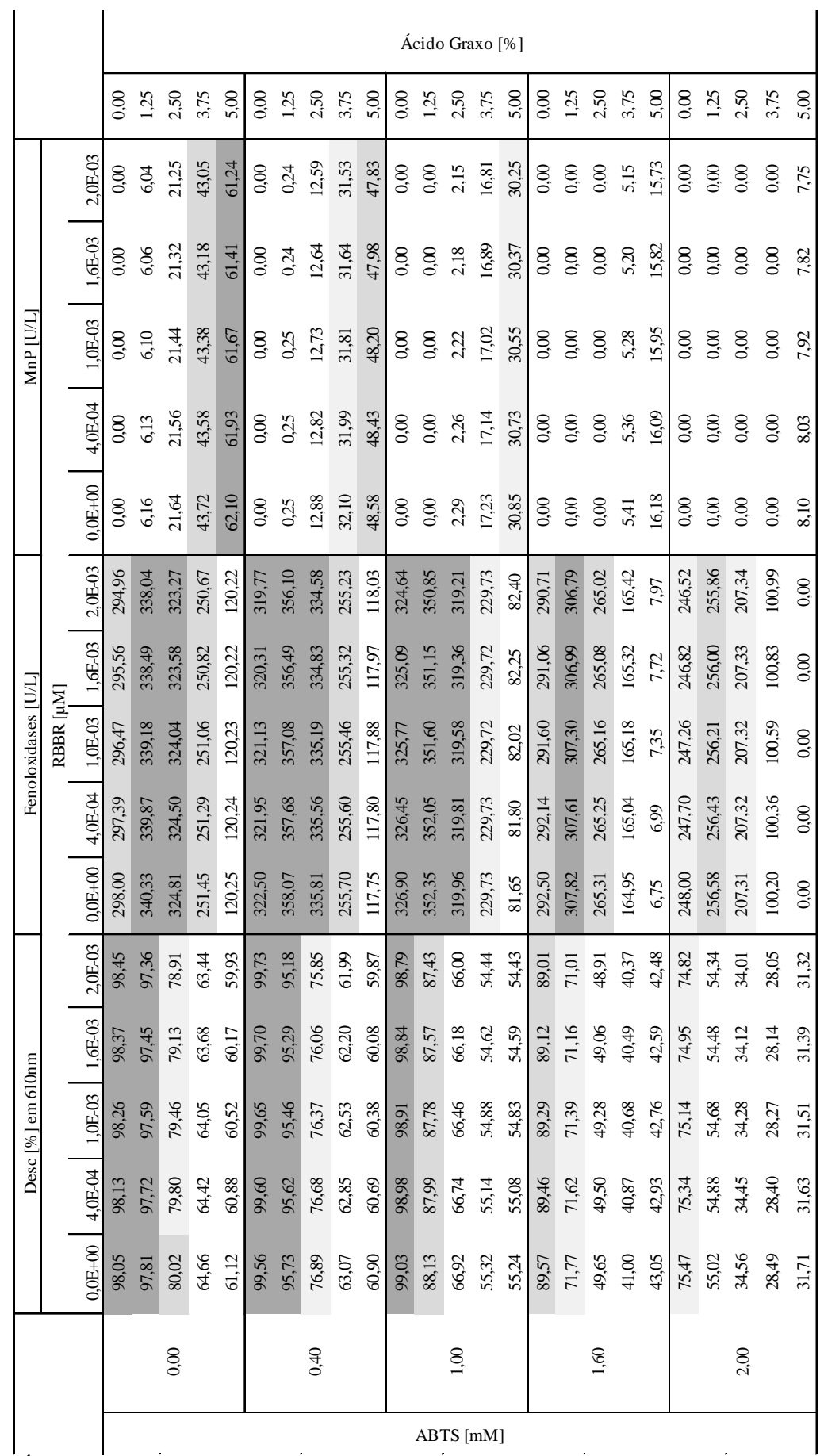

Áreas em realçadas destacam valores máximos, quanto mais escuro maior o valor. 
Tabela 23 - Descoloração a $610 \mathrm{~nm}$, fenoloxidases e MnP estimados para sistemas de tratamento com Pleurotus ostreatus CCIBt 2347 com 48 horas de contato in vivo.

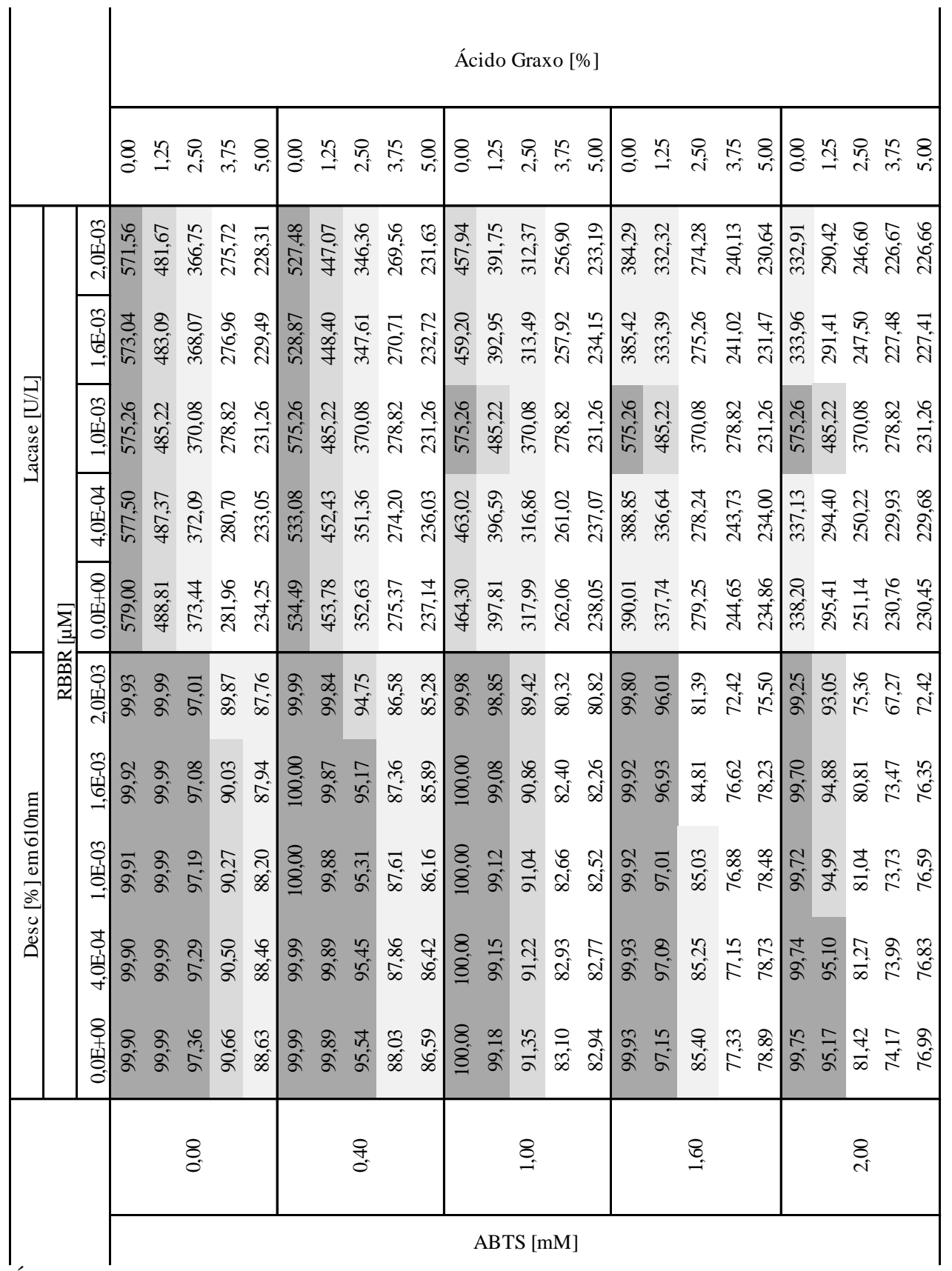

Áreas em destaque representam valores máximos, quanto mais escuro maior o valor.

A descoloração a $610 \mathrm{~nm}$ mostrou correlação positiva forte com a atividade de lacases, tanto em 24 horas (Pearson $=0,691$, valor $p=0,002$ ) quanto em 48 horas (Pearson $=0,835$, valor $p=0,000$ ), bem como mostrou correlação positiva moderada (Pearson $=0,537$, valor $p=0,026$ ) com as fenoloxidases, em 24 horas, e correlação positiva forte (Pearson $=0,824$, valor $p=0,000$ ) com as fenoloxidases, em 48 horas (APÊNDICE D). A descoloração a 526 nm não apresentou correlação com nenhuma das 
enzimas testadas ( $p \geq 0,136)$ e MnP não apresentou correlação com a descoloração ( $p$ > 0,1), em nenhum dos comprimentos de onda ou tempos avaliados.

Diante da correlação entre a descoloração de RB222 e as lacases de Pleurotus ostreatus CCIBt 2347, e com base no estudo de Bourbonnais e Paice (1990), pode-se afirmar que lacase na presença de mediadores torna-se apta a clivar a ligação $\mathrm{C} \alpha-\mathrm{C} \beta$ também de compostos não fenólicos, uma vez que foi observada descoloração a $526 \mathrm{~nm}$, comprimento de onda possivelmente referente ao metabólito contendo segundo grupo azo, ligado ao radical não fenólico. Tal mecanismo pode ter ocorrido pela presença do ABTS, onde a lacase oxida esse substrato abstraindo 4 elétrons do composto, quando os $\mathrm{Cu}^{+2}$ do seu centro ativo são reduzidos a $\mathrm{Cu}^{+}$. Nesse caminho a lacase retorna ao seu estado original, reduzindo o oxigênio molecular a água, e o composto oxidado, que é um radical cátion ativo, é automaticamente decomposto em produtos mais simples. Se esses radicais catiônicos tiverem tempo de vida longo o suficiente, podem abstrair elétrons de outros compostos ricos em elétrons, como é o caso dos corantes sintéticos. Ou ainda pela presença do RBBR, que apresenta mecanismo um pouco diferente, envolvendo o transporte de elétrons via radical-H, que é capaz de abstrair elétrons dos compostos não fenólicos (ALMANSA et al., 2004; CAÑAS; CAMARERO, 2010; WONG; YU, 1999; WONG 2009).

As configurações dos fatores obtidas pelo otimizador de respostas (APÊNDICE D), onde foram avaliadas as condições ótimas para maximizar a descoloração em 610 nm, após 24 e 48 horas, são: 2 mM de ABTS, 0,2 $\mu \mathrm{M}$ de RBBR, sem adição de ácido graxo. No entanto, não foi avaliada a maximização da produção de lacases, uma vez que é sabido que lacase e MnP possuem isoenzimas, as quais desempenham papéis diferentes, podendo nem sempre coincidir a maior atividade com a maior descoloração, já que possuem diferentes propriedades catalíticas (JIANG et al., 2013; LORENZO et al., 2006; MARTINEZ et al., 1996; MOLDES et al., 2004; MOLDES; SANROMAN, 2006).

Os dados obtidos nos tratamentos com $P$. cinerea estão apresentados na Tabela 24. A máxima descoloração a $610 \mathrm{~nm}$ ocorreu após 48 horas (53,72 \%), acompanhada por 46,40 \% de descoloração a $526 \mathrm{~nm}$, onde estavam presentes 556,37 U/L de fenoloxidases e 422,10 U/L de lacases, sem MnP. 
Tabela 24 - Descoloração e atividades enzimáticas (U/L . dia $^{-1}$ ) produzidas por Peniophora cinerea CCIBt 2541, com seus fatores não codificados e codificados (entre parêneses). Áreas em destaque representam maiores valores.

\begin{tabular}{|c|c|}
\hline & 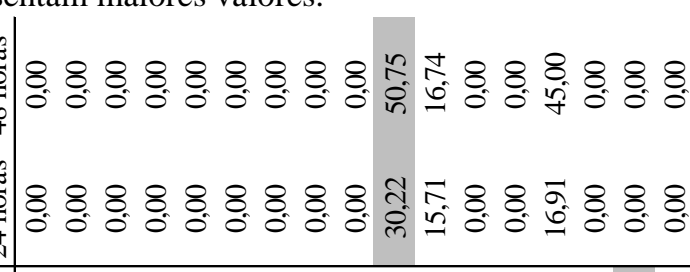 \\
\hline & 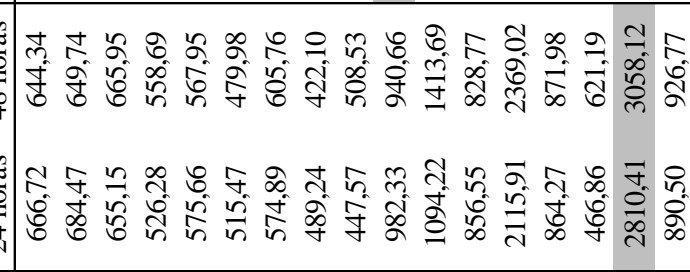 \\
\hline & 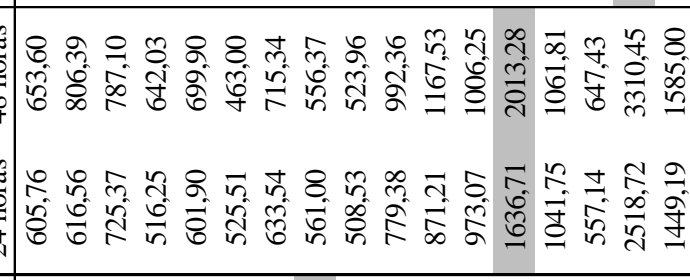 \\
\hline 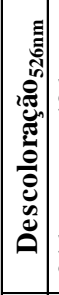 & 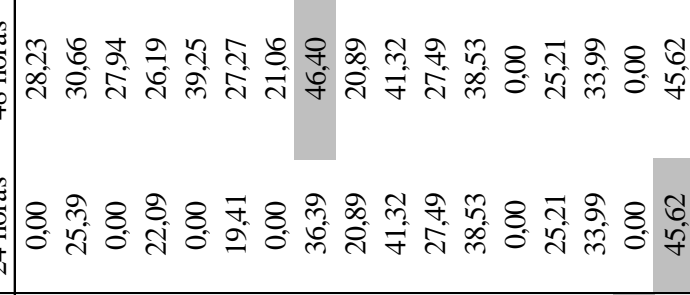 \\
\hline & 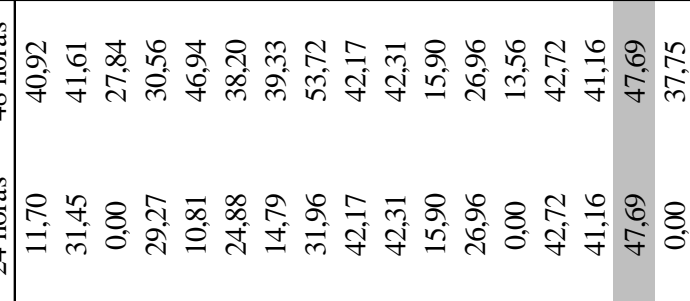 \\
\hline & 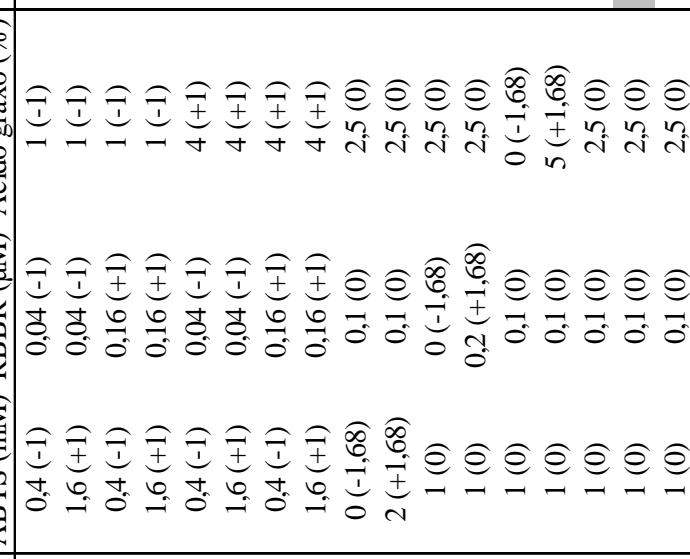 \\
\hline $\bar{z}$ & $\infty の \ominus \exists \cong \cong \unlhd \mathscr{n}$ \\
\hline
\end{tabular}


A análise de variância (APÊNDICE D) não apoiou os modelos matemáticos obtidos para os tratamentos com Peniophora cinerea, assim sendo os coeficientes de regressão obtidos não foram empregados para estimar valores. Contudo, foi possível avaliar a correlação entre a descoloração e as atividades enzimáticas, a partir dos valores reais, onde a descoloração a 526 e a $610 \mathrm{~nm}$ apresentaram correlação negativa moderada tanto com a atividade de fenoloxidases (Pearson $=-0,413, p=0,100$ ), em 24 horas como com a MnP em 48 horas (Pearson $=-0,404, p=0,107$ ), respectivamente. Apresentou também correlação negativa moderada entre a descoloração a $526 \mathrm{~nm}$ e a atividade de fenoloxidases em 48 horas (Pearson $=-0,419, p=0,094$ ), bem como com lacases em 48 horas (Pearson $=-0,459, p=0,064)$.

Em que pese o modelo matemático não suportar significativamente a estimativa de configurações ótimas de descoloração, observando-se os dados reais obtidos, vê-se que a configuração dos fatores capaz de maximizar a descoloração, nos dois comprimentos de onda, é de 1,6 mM de ABTS, 0,16 $\mu \mathrm{M}$ de RBBR e 4,0 \% de fonte de ácido graxo.

Diante de correlações negativas entre descoloração e enzimas ligninolíticas, podese sugerir uma rota metabólica para a descoloração por ação não enzimática, com participação, principalmente, das espécies reativas de oxigênio (ROS) formadas pela peroxidação de ácidos graxos insaturados, ${ }^{-} \mathrm{OH}$, o qual é considerado um dos mais poderosos oxidantes, além de $\mathrm{ROO}^{-}$e ${ }^{-} \mathrm{OOH}$, radicais secundários resultantes da oxidação de polímeros por ${ }^{-} \mathrm{OH}$. Os radicais ${ }^{-} \mathrm{OH}$ atacam moléculas orgânicas por abstração ou adição de um átomo de hidrogênio de duplas ligações, gerando novos intermediários oxidados de baixa massa molar, ou ainda $\mathrm{CO}_{2}$ e $\mathrm{H}_{2} \mathrm{O}$, no caso da mineralização (HAMMEL et al., 2002; WATANABE et al., 2000).

A descoloração e as atividades enzimáticas produzidas pelos tratamentos com $T$. villosa estão apresentados na Tabela 25. A máxima descoloração foi de 88,87 \% a 610 nm, em 48 horas, acompanhada de 70,98 \% de descoloração a $526 \mathrm{~nm}$, na presença de 426,73 U/L de fenoloxidases e 381,98 U/L de lacases, sem produzir MnP. 
Tabela 25 - Descoloração e atividades enzimáticas produzidas por Trametes villosa CCIBt 2628, com seus fatores não codificados e codificados (entre parênteses). Áreas em destaque representam maiores valores.

\begin{tabular}{|c|c|}
\hline & 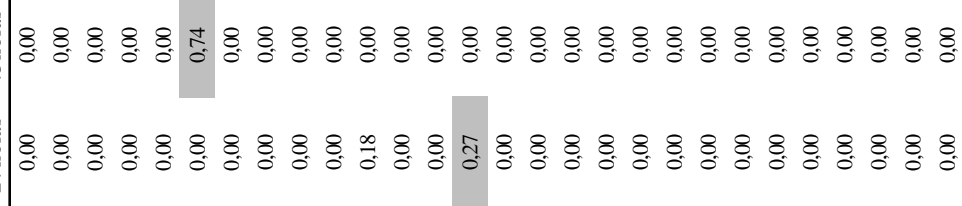 \\
\hline & 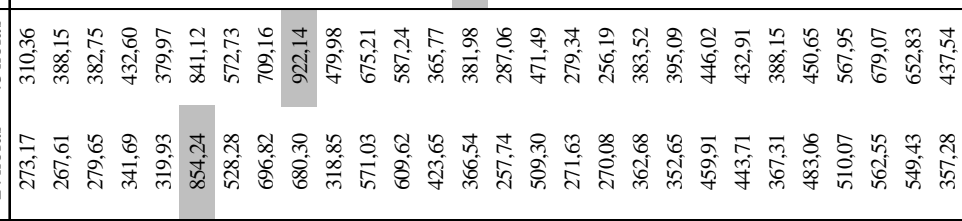 \\
\hline & 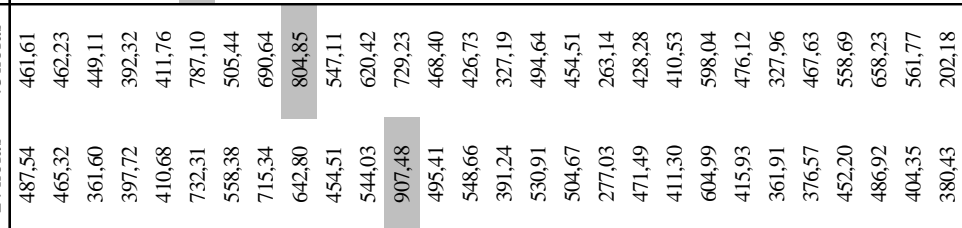 \\
\hline & 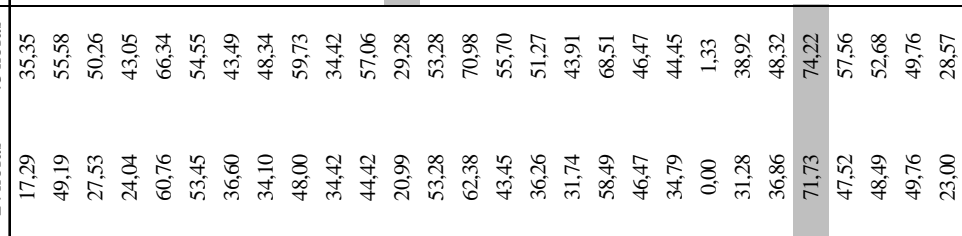 \\
\hline & 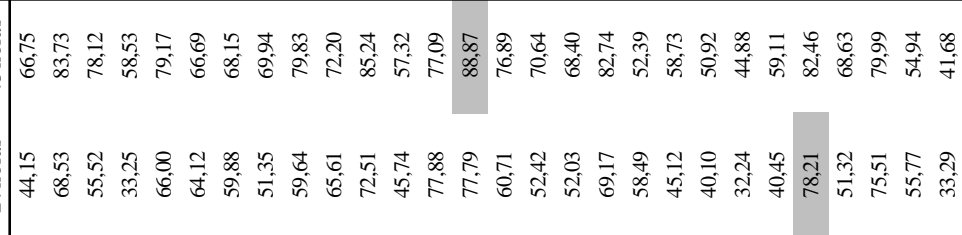 \\
\hline & 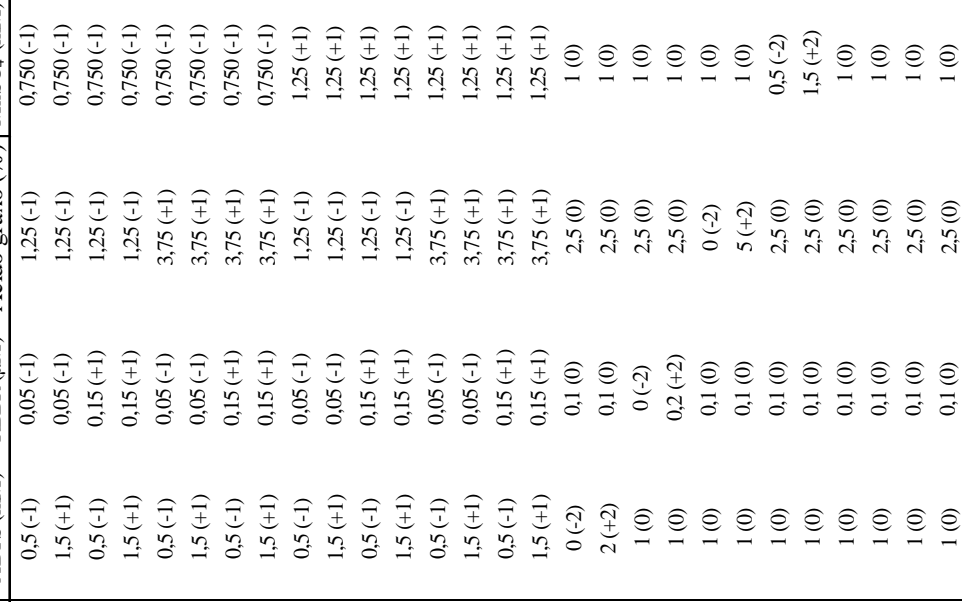 \\
\hline 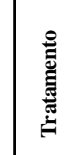 & 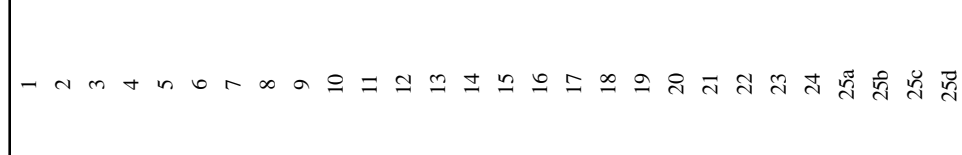 \\
\hline
\end{tabular}

A análise de variância (APÊNDICE D) apoiou apenas o modelo matemático para a lacase $(p=0,028)$ e para a descoloração a $526 \mathrm{~nm}(p=0,021)$, em 24 horas. Os coeficientes de regressão obtidos para esses modelos estão apresentados na Tabela 26. 
Tabela 26 - Coeficiente de regressão para descoloração a $526 \mathrm{~nm}$ e lacases de Trametes villosa CCIBt 2347 em 24 horas de contato in vivo.

\begin{tabular}{|c|c|c|c|c|}
\hline \multirow[b]{2}{*}{ Fator } & \multicolumn{2}{|c|}{ Descoloração $526 \mathrm{~nm}$} & \multicolumn{2}{|c|}{ Lacase } \\
\hline & $\begin{array}{c}\text { Coeficiente } \\
\text { de } \\
\text { Regressão }\end{array}$ & Valor $p$ & $\begin{array}{c}\text { Coeficiente } \\
\text { de } \\
\text { Regressão }\end{array}$ & Valor $p$ \\
\hline Constante & 0,074 & $0,000 * * *$ & -1504 & $0,000 * * *$ \\
\hline ABTS (L) & 0,354 & 0,565 & 459 & 0,739 \\
\hline ABTS (Q) & 0,062 & 0,574 & -193 & $0,085 * *$ \\
\hline RBBR (L) & 1,08 & $0,053 * *$ & 2049 & 0,858 \\
\hline RBBR (Q) & 1,8 & 0,872 & -9155 & 0,392 \\
\hline Ácido Graxo (L) & 0,472 & $0,003 * * *$ & 351 & 0,893 \\
\hline Ácido Graxo (Q) & $-0,0602$ & $0,004 * * *$ & $-2,2$ & 0,897 \\
\hline $\mathrm{Mn}^{+2}(\mathrm{~L})$ & $-0,692$ & $0,097 *$ & 2363 & 0,249 \\
\hline $\mathrm{Mn}^{+2}(\mathrm{Q})$ & 0,634 & 0,163 & -153 & 0,717 \\
\hline ABTS x RBBR & $-1,55$ & 0,258 & 1381 & 0,295 \\
\hline ABTS x Ácido Graxo & 0,0002 & 0,997 & 134,3 & $0,020 * * *$ \\
\hline ABTS x $\mathrm{Mn}^{+2}$ & $-0,291$ & 0,288 & -530 & $0,057 * *$ \\
\hline RBBR x Ácido Graxo & $-0,475$ & 0,383 & 118 & 0,820 \\
\hline $\mathrm{RBBR} \times \mathrm{Mn}^{+2}$ & 0,16 & 0,952 & -1800 & 0,49 \\
\hline Ácido Graxo x Mn² & $-0,044$ & 0,683 & -489 & 0 \\
\hline
\end{tabular}

Os coeficientes e seus fatores não codificados foram empregados para estimar dados para a descoloração a 526 nm, após 24 horas, onde seu máximo (96,90 \%) foi observado quando $2 \mathrm{mM}$ de ABTS, 3,75 \% de ácido graxo e 0,5 mM de manganês estavam presentes. Contudo, sem coincidir com a máxima produção de lacase (Tabela 27), confirmando o resultado da análise estatística, que não correlacionou a descoloração com as atividades enzimáticas ( $p>0,1$; APÊNDICE D). 
Tabela 27 - Dados estimados para descoloração a 526 nm e produção de lacase por Trametes villosa CCIBt 2628 após 24 horas de contato in vivo.

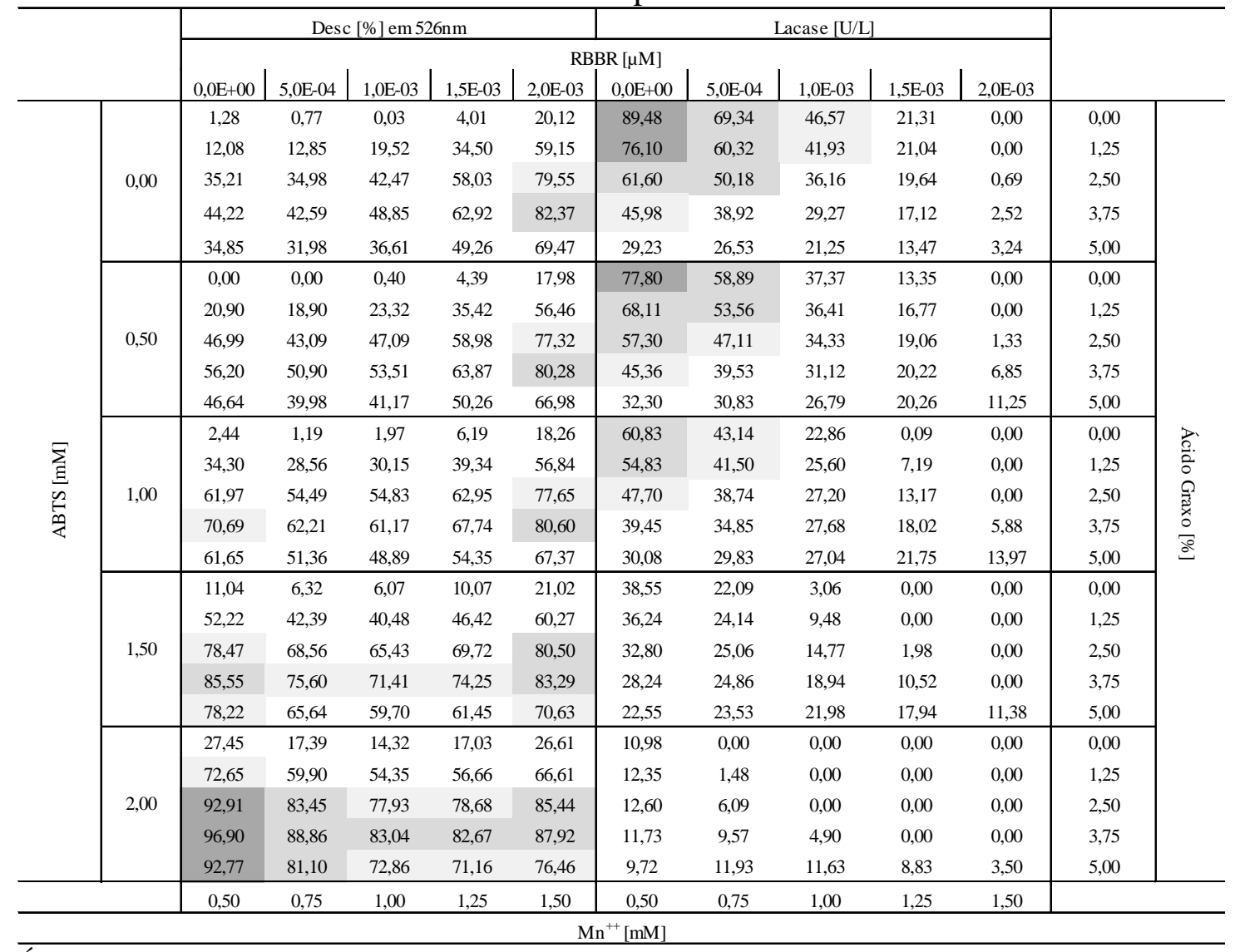

Áreas em destaque representam maiores valores, quanto mais escuro maior o valor.

A partir da análise estatística de otimização de resposta, para as variáveis que apresentaram significância (APÊNDICE D), e dos resultados obtidos pelos tratamentos reais, a configuração de fatores, selecionada para maximizar a descoloração por $T$. villosa, foi de $2 \mathrm{mM}$ de ABTS, 0,5 mM de manganês e 3,75 \% de ácido graxo, na ausência de RBBR.

Apesar de a lacase não apresentar correlação com a descoloração, é importante lembrar o que Böhmer et al. (1998) já comentavam que o sistema mediado por lacase pode participar da degradação de compostos concomitantemente com a peroxidação lipídica. Fato confirmado ainda por Srebotnik e Boisson (2005), que sugerem que lacase/fenol/ $\mathrm{Mn}^{+2}$ funcionam como um sistema mediador natural para a peroxidação lipídica in vivo, em fungos que expressem lacase predominantemente.

Observando os valores máximos de cada variável avaliada, pode-se confirmar que uma única configuração de fatores não irá contemplar a otimização de todas as variáveis, uma vez que o processo é dinâmico, capaz de apresentar necessidades distintas a cada fase do processo, para cada variável, mostrando que estudos posteriores poderão contar 
com intervenções sucessivas, para garantir a otimização do processo em suas diferentes fases.

\subsection{Experimento 5}

A descoloração a $526 \mathrm{~nm}$ promovida por $P$. ostreatus (Figura 10) não apresentou diferença estatística entre os tratamentos ( $p>0,1$; APÊNDICE E), no entanto apresentou as maiores taxas de descoloração a $610 \mathrm{~nm}, 88$ \% nos sistemas com inibidor de MnP e 73 \% nos sistemas com corante sem inibidores, que não diferiram entre si, mas diferiram dos demais tratamentos com inibidores e controles abióticos ( $p=0,049$; APÊNDICE E) em 48 horas. Nestas condições havia de 577 U/L a 752 U/L de lacases presentes nos extratos, contudo, em 24 horas, esses mesmos sistemas de tratamento, juntamente com os sistemas com corante e fungo morto, apresentaram maior descoloração a $610 \mathrm{~nm}$ (de 40 a $74 \%$ ) diferindo estatisticamente dos demais tratamentos ( $p=0,015$; APÊNDICE E). Observando tais dados é possível confirmar que a biossorção pode ser um fenômeno significativo nas primeiras 24 horas de contato. A adição de azida sódica inibiu fenoloxidases e lacases, diminuindo as taxas de descoloração observadas. Houve produção de MnP em todos os sistemas in vivo antes da adição de corante, embora essa atividade tenha sido inibida pela presença do corante no sistema. Por sua vez, Novotný et al. (2004), estudando a biodegradação de corantes diferentes por Irpex lacteus, observaram a inibição da síntese de MnP pela presença de RBBR e azul de bromofenol nos sistemas. 
Figura 10 - Descoloração de RB222, a 526 nm e 610 nm, e atividades enzimáticas produzidas por Pleurotus ostreatus CCIBt 2347 in vivo na presença de inibidores enzimáticos.

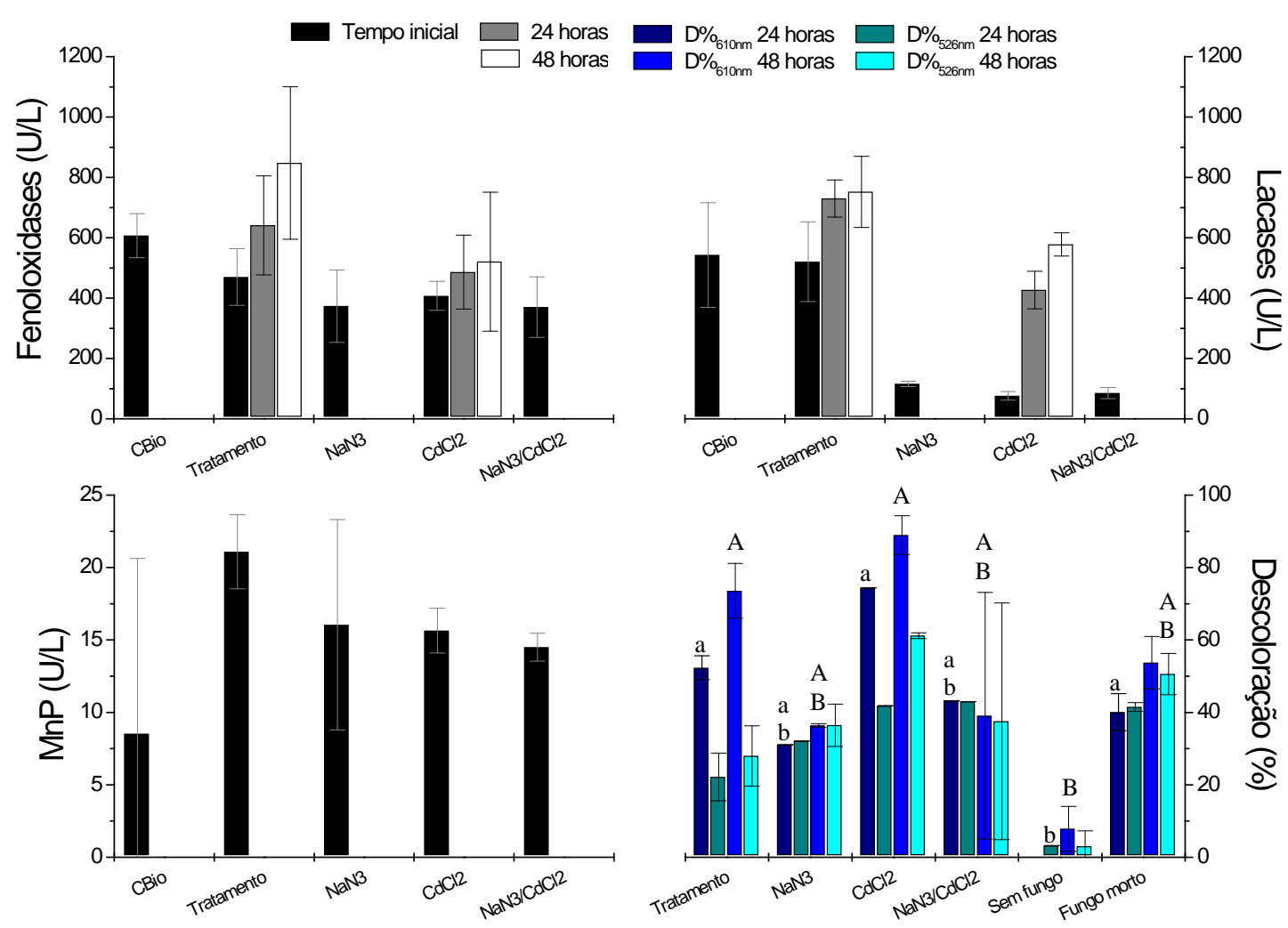

Legenda: CBio = sistemas sem corante; Tratamento = sistemas com corante sem inibidores; NaN3 = sistemas com corante e adição de azida sódica (inibidor de lacase); $\mathrm{CdCl} 2$ = sistemas com corante e adição de cloreto de cádmio (inibidor de $\mathrm{MnP}$ ); $\mathrm{NaN3/CdCl2} \mathrm{=} \mathrm{sistemas} \mathrm{com} \mathrm{corante} \mathrm{e} \mathrm{adição} \mathrm{de}$ inibidores (inibidores de lacase e MnP); Sem fungo = sistemas com corante sem biomassa; Fungo morto = sistemas com corante e biomassa morta. Letras iguais significam igualdade estatística: minúsculas para a descoloração a $610 \mathrm{~nm}$ em 24 horas e maiúsculas para a descoloração a $610 \mathrm{~nm}$ em 48 horas; descoloração a 526 nm sem diferença estatística.

Peniophora cinerea (Figura 11) também apresentou maiores taxas de descoloração a $610 \mathrm{~nm}$ nos sistemas com inibidor de MnP (30 \%), em 48 horas. A 526 nm, a descoloração nesses mesmos sistemas foi de 27 \% em 24 horas de 39 \% e em 48 horas, diferindo dos demais tratamentos ( $p \leq 0,1$; APÊNDICE E). Nesses sistemas haviam de 510 U/L a 705 U/L de lacases, sendo essa a enzima principal produzida por esses tratamentos, embora pareça não estar envolvido na descoloração. A adição de azida sódica não inibiu totalmente a atividade de fenoloxidases e de lacases desse basidiomiceto, após 24 horas, assim sendo a cada coleta foi adicionada solução de inibidor até que a atividade fosse eliminada dos extratos. Contrariamente, a atividade de MnP foi totalmente inibida nos extratos que receberam cloreto de cádmio. Entretanto, a descoloração parece não ter sido afetada pela presença ou ausência dessas enzimas nos extratos. 
Figura 11 - Descoloração de RB222, a 526 nm e 610 nm, e atividades enzimáticas produzidas por Peniophora cinerea CCIBt 2541 in vivo na presença de inibidores enzimáticos.

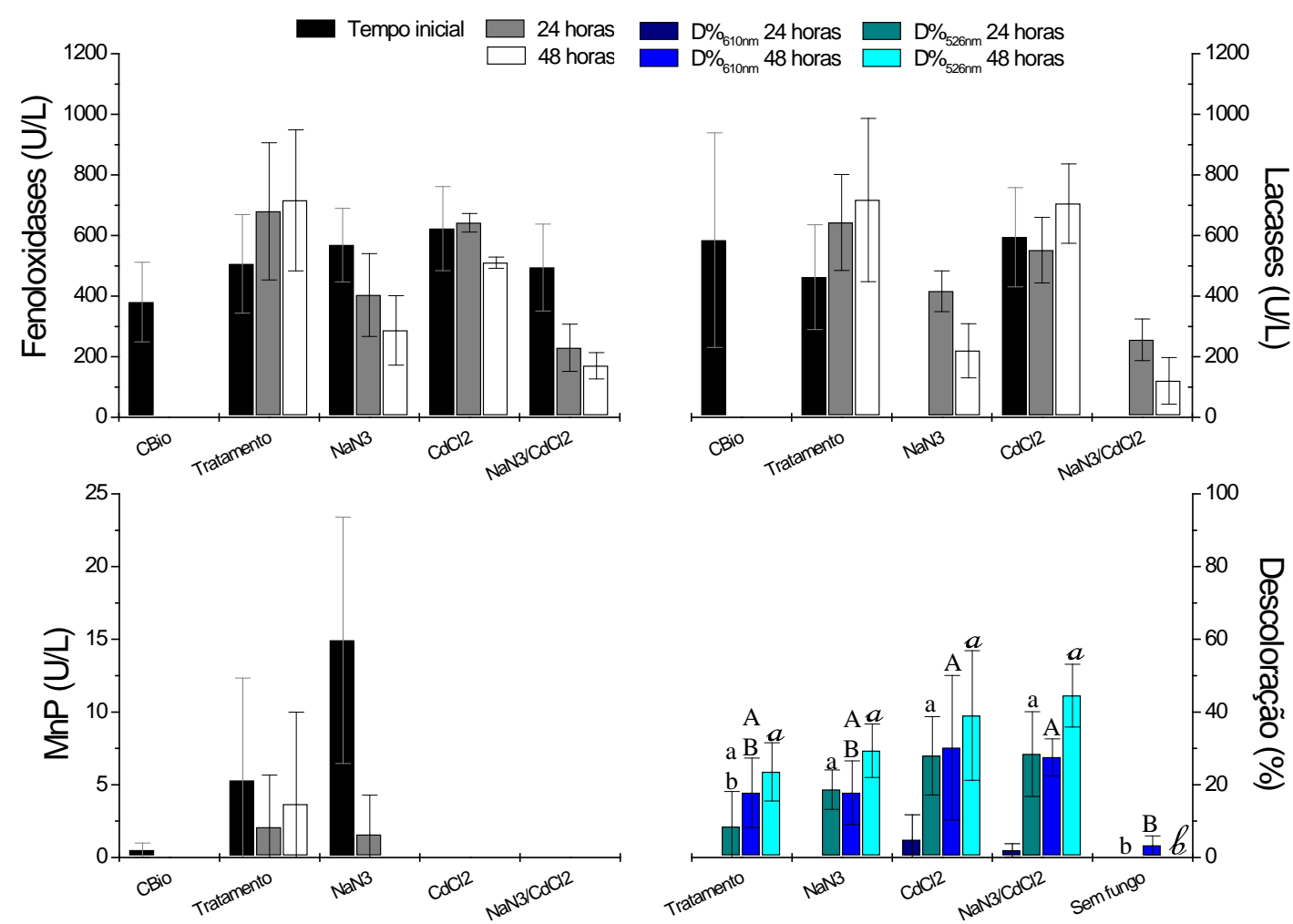

Legenda: CBio = sistemas sem corante; Tratamento = sistemas com corante sem inibidores; NaN3 = sistemas com corante e adição de azida sódica (inibidor de lacase); $\mathrm{CdCl} 2$ = sistemas com corante e adição de cloreto de cádmio (inibidor de $\mathrm{MnP}$ ); $\mathrm{NaN3/CdCl} 2$ = sistemas com corante e adição de inibidores (inibidores de lacase e $\mathrm{MnP}$ ); Sem fungo = sistemas com corante sem biomassa; Fungo morto = sistemas com corante e biomassa morta. Letras iguais significam igualdade estatística: minúsculas para a descoloração a $526 \mathrm{~nm}$ em 48 horas, minúsculas itálicas para a descoloração a 526 nm em 48 horas e maiúsculas para a descoloração a 610 nm em 48 horas; descoloração a 610 nm em 24 horas não apresentaram diferença estatística.

Trametes villosa (Figura 12) não apresentou diferença estatística entre os sistemas avaliados para descoloração, incluindo os controles abióticos, em qualquer comprimento de onda ( $p>0,1$; APÊNDICE E). A principal enzima produzida foi lacase, em média 289 U/L, exceto nos sistemas abióticos, podendo a descoloração nesses últimos ser resultante tanto de fenômeno biossortivo bem como de processos não enzimáticos, promovidos pelos compostos existentes nos extratos contendo biomassa crescida morta. Contudo, nos sistemas in vivo não se pode descartar a hipótese de ação enzimática. A adição de azida sódica foi capaz de inibir eficientemente a atividade de lacases, contudo foi necessária a adição desse inibidor também em 24 horas de incubação, até a eliminação dessa atividade nesses extratos, uma vez que é sabido que lacases apresentam diferentes isoenzimas com características químicas distintas (JIANG et al., 2013; LORENZO et al., 2006; MARTINEZ et al., 1996; MOLDES et al., 2004; 
MOLDES; SANROMAN, 2006), a quais podem ter respondido de forma diferente à presença da azida sódica. Não se observou atividade de $\mathrm{MnP}$ em nenhuma condição avaliada para T. villosa, fato decorrente da aplicação da configuração de fatores ótima para a descoloração, não coincidindo com a configuração favorável a produção dessa enzima, conforme já observado nos Experimentos anteriores.

Figura 12 - Descoloração de RB222, a 526 nm e 610 nm, e atividades enzimáticas e produzidas por Trametes villosa CCIBt 2628 in vivo na presença de inibidores enzimáticos.

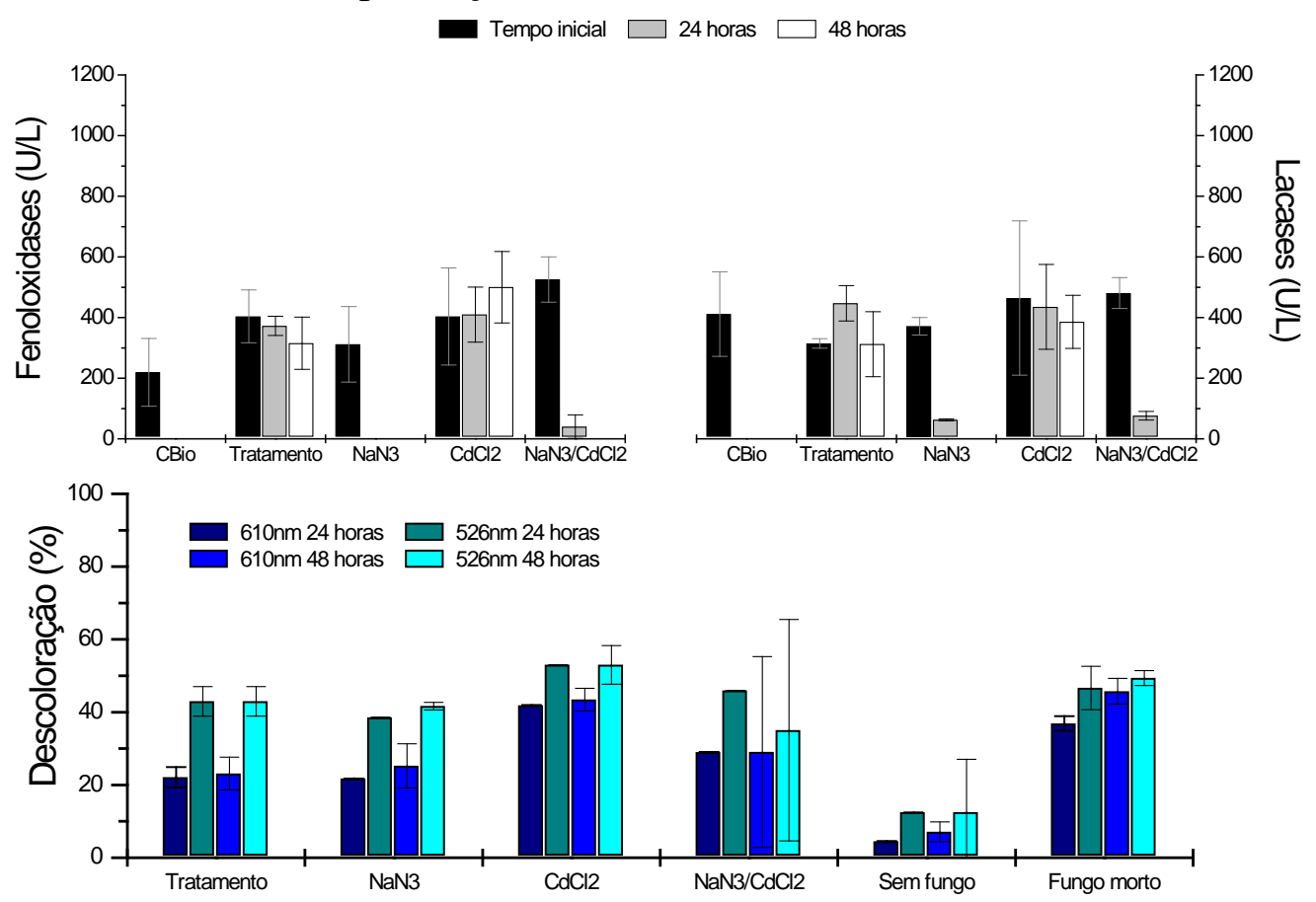

Legenda: $\mathrm{CBio}=$ sistemas sem corante; Tratamento = sistemas com corante sem inibidores; NaN3 = sistemas com corante e adição de azida sódica (inibidor de lacase); $\mathrm{CdCl} 2$ = sistemas com corante e adição de cloreto de cádmio (inibidor de MnP); NaN3/CdCl2 = sistemas com corante e adição de inibidores (inibidores de lacase e MnP); Sem fungo = sistemas com corante sem biomassa; Fungo morto = sistemas com corante e biomassa morta.

Os sistemas com $P$. ostreatus apresentaram mudança de cor na região do visível, já $P$. cinerea e $T$. villosa apresentaram diminuição da absorbância nos $\lambda_{\text {máx, embora os }}$ sistemas tenham permanecido azuis, conforme mostra a Figura 13. 
Figura 13 - Fase líquida dos tratamentos após 48 horas de contato in vivo com basidiomicetos.

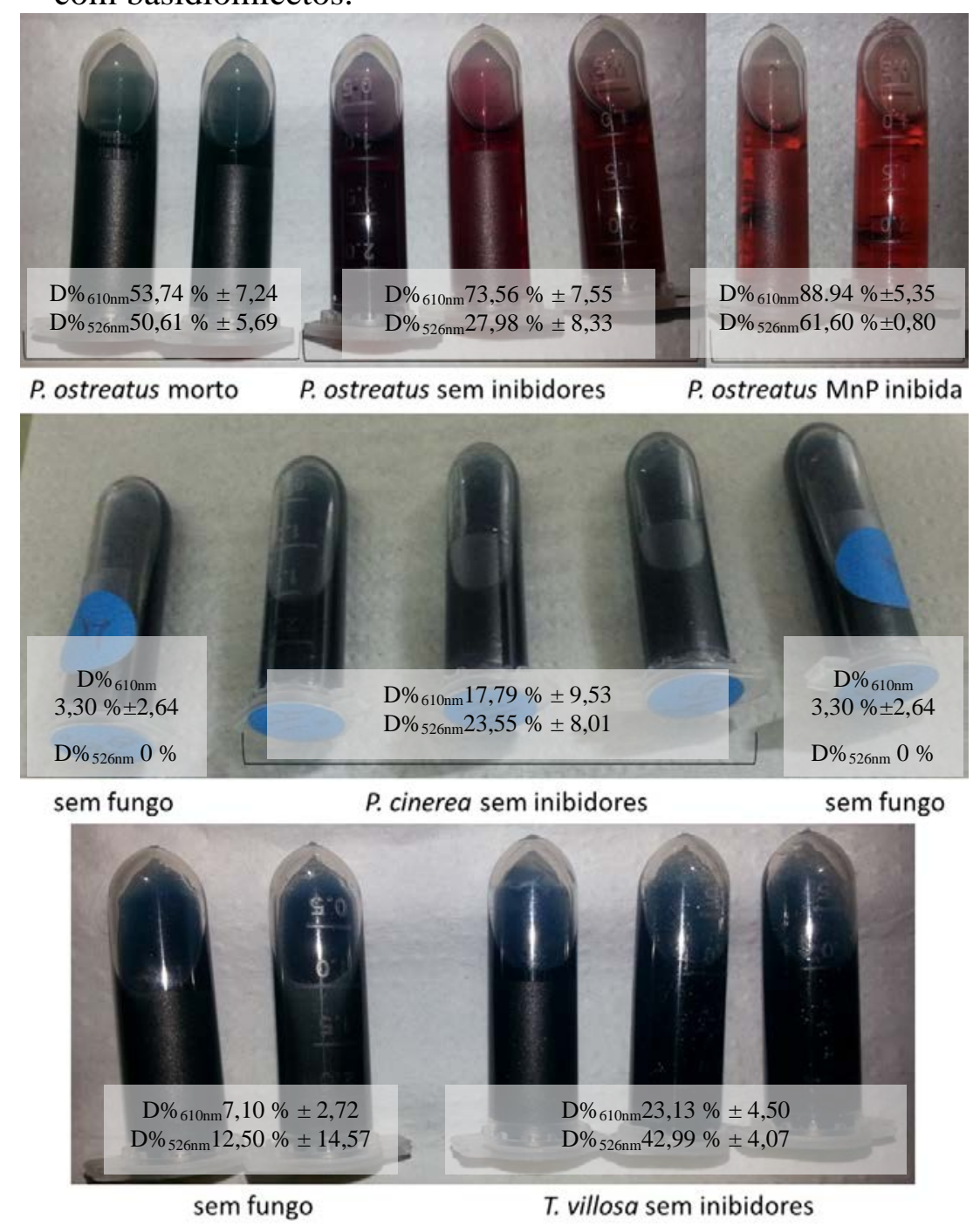

Legenda: $\mathrm{D} \% 610 \mathrm{~nm}=$ descoloração porcentual a $610 \mathrm{~nm}$; D\%526nm = descoloração porcentual a $526 \mathrm{~nm}$.

Para confirmar a biodegradação envolvida no processo, um método TLC empregando fase móvel, majoritariamente constituída por metanol, foi utilizada. Plácido et al. (2016), que em estudo de degradação de corantes azóicos e ftalocianina por Leptospherulina sp., comentam que quando empregado o solvente metanol é possível observar maior número de $\mathrm{R}_{\mathrm{F}}$ nesse tipo análise com corantes.

A fase móvel selecionada foi a que empregou acetato de etila PA : metanol PA (1 :1,5, v/v) (Synth, Labsynth, Brasil), e a corrida se deu sob temperatura controlada, $20 \pm$ $2{ }^{\circ} \mathrm{C}$, com tempo máximo de 40 minutos. 
As placas contendo as corridas de sistemas tratados por $P$. cinerea apresentou dois novos $R_{F}$, sendo um $R_{F}=0,64$ em 48 horas, nos sistemas coloridos com inibidor de lacase e de $\mathrm{MnP}$, e outro $\mathrm{R}_{\mathrm{F}}=0,60$, em 24 e 48 horas, nos sistemas coloridos com inibidor de MnP (Figura 14). Os sistemas com P. ostreatus também apresentaram um novo $\mathrm{R}_{\mathrm{F}}=0,49$, nos sistemas coloridos sem inibidores em 48 horas, bem como os sistemas com $T$. villosa apresentou um novo $\mathrm{R}_{\mathrm{F}}=0,27$, nos sistemas coloridos sem $\mathrm{MnP}$ em 24 horas, contudo, após 48 horas esse metabólito não foi detectado (Figura 15).

Figura 14 - Placa de cromatografia de camada delgada dos tratamentos com Peniophora cinerea CCIBt 2541, sob luz ultravioleta a $365 \mathrm{~nm}$.

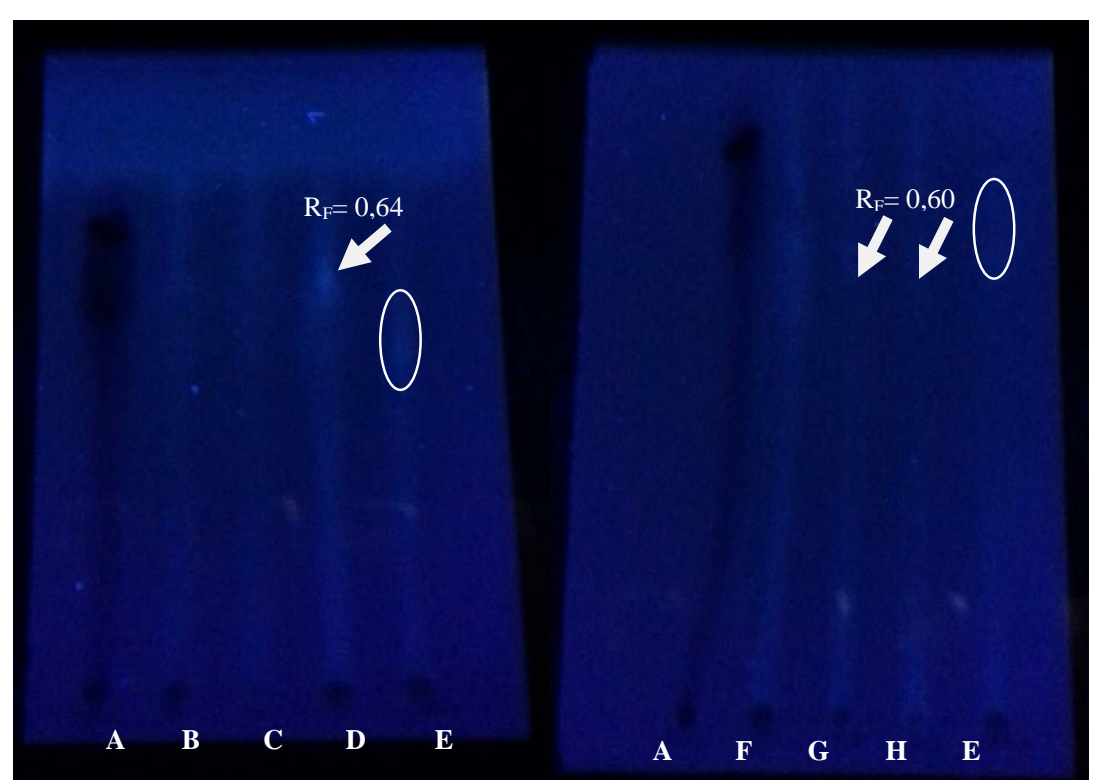

Legenda: Corridas de (A) RB222 [0,3 \%]; (B) tratamentos com Peniophora cinerea CCIBt 2541 com corante e inibição de MnP no tempo inicial, após (C) 24 horas e (D) após 48 horas; (F) sistemas com corante e inibição de lacase e MnP no tempo inicial, após (G) 24 horas e (H) após 48 horas; e (E) meio de cultivo contendo RB222 [0,03\%]; área circulada $\mathrm{R}_{\mathrm{F}}$ do corante RB222. 
Figura 15 - Placas de cromatografia de camada delgada dos tratamentos com Pleurotus ostreatus CCIBt 2347 (à esquerda) e Trametes villosa CCIBt 2628 (à direita), sob luz ultravioleta a 365 nm.

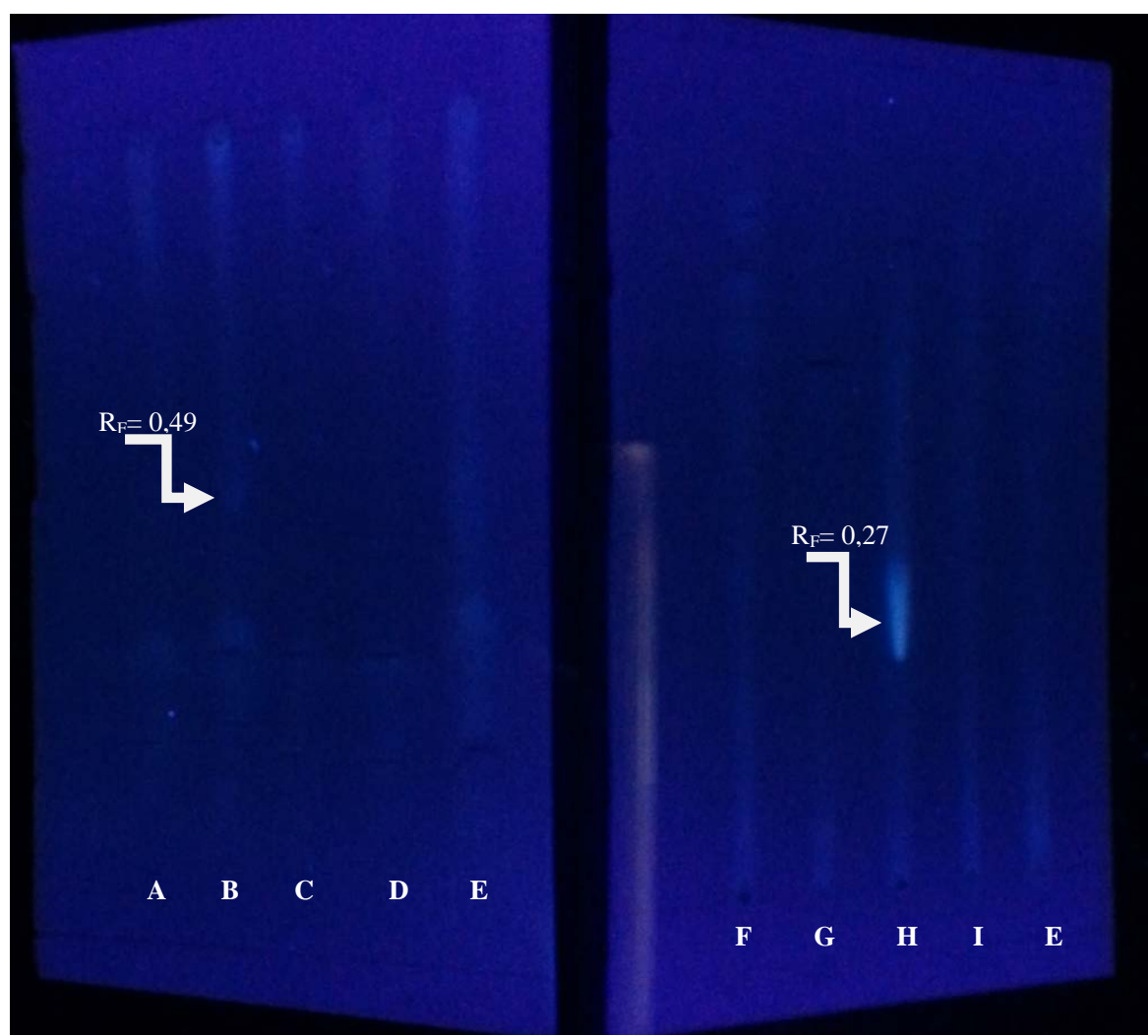

Legenda: P. ostreatus (A) sistemas com corante sem fungo; (B) tratamentos com corante sem inibição enzimática, em 48 horas; (C) com corante e inibição de MnP, em 48 horas; e (D) com corantes e inibição de lacase, em 48 horas; (E) sistemas com corante e fungo morto; $\boldsymbol{T}$. villosa (F) tratamentos com corante sem inibidores em 24 horas e (G) em 48 horas; (H) com corante e inibição de MnP em 24 horas e (I) em 48 horas; (E) sistemas com corante e fungo morto.

Para ampliar a compreensão do mecanismo degradativo desses fungos na degradação do corante avaliado, foram quantificados os compostos de baixa massa molar quelantes e redutores de $\mathrm{Fe}^{+3}$, apresentados na Tabela 28, responsáveis por preconizar vias não enzimáticas importantes.

Tabela 28 - Compostos de baixa massa molar no extrato bruto do cultivo de basidiomicetos antes do contato in vivo com RB222.

\begin{tabular}{|c|c|c|c|c|}
\hline \multirow[t]{2}{*}{ Fungo } & \multicolumn{2}{|c|}{$\begin{array}{l}\text { Atividade Redutora de } \\
\qquad \mathrm{Fe}^{+3} \\
\left(\mu \mathrm{Mol} \mathrm{Fe}^{+2} / \mathrm{L}\right)\end{array}$} & \multicolumn{2}{|c|}{$\begin{array}{c}\text { Compostos Quelantes } \\
\text { de } \mathrm{Fe}^{+3} \\
(\%)\end{array}$} \\
\hline & Média & $D P$ & Média & $D P$ \\
\hline Peniophora cinerea & 1,112 & 0,906 & 5,35 & 0,80 \\
\hline Pleurotus ostreatus & 0,642 & 0,473 & 78,67 & 3,34 \\
\hline Trametes villosa & 1,522 & 1,400 & 21,49 & 30,29 \\
\hline
\end{tabular}


A análise de correlação das atividades enzimáticas e dos CBMM com a descoloração, nos dois comprimentos de onda, está apresentada na Tabela 29. Houve correlação negativa moderada das lacases de $P$. cinerea com a descoloração, em ambos comprimentos de onda $(p<0,09)$. Lacases de $P$. ostreatus apresentou correlação positiva moderada com a descoloração a $610 \mathrm{~nm}(p=0,003)$, bem como os CBMM redutores de $\mathrm{Fe}^{+3}$ de $P$. ostreatus apresentaram correlação negativa muito forte com a descoloração a $526 \mathrm{~nm}(p=0,065)$ e positiva muito forte com CBMM quelantes de $\mathrm{Fe}^{+3}$ $(p=0,008)$. Lacases e CBMM de $T$. villosa não apresentaram correlação com a descoloração (APÊNDICE E).

Tabela 29 - Coeficiente Pearson de correlação entre as atividades enzimáticas e a descoloração, e entre os CBMM e a descoloração, em 610 nm e 526 nm.

\begin{tabular}{|c|c|c|c|c|c|c|c|}
\hline \multirow{2}{*}{$\begin{array}{l}\text { Componente } \\
\text { oxidante }\end{array}$} & \multirow[b]{2}{*}{ Fungo } & \multicolumn{3}{|c|}{ Descoloração610nm } & \multicolumn{3}{|c|}{ Descoloração526nm } \\
\hline & & $\begin{array}{l}\text { Coeficiente } \\
\text { Pearson }\end{array}$ & $\begin{array}{c}\text { Valor } \\
p\end{array}$ & Correlação & $\begin{array}{l}\text { Coeficiente } \\
\text { Pearson }\end{array}$ & $\begin{array}{c}\text { Valor } \\
p\end{array}$ & Correlação \\
\hline Lacases & \multirow{4}{*}{$\begin{array}{l}\text { Peniophora } \\
\text { cinerea }\end{array}$} & $-0,516$ & 0,041 & $\begin{array}{l}\text { negativa } \\
\text { moderada }\end{array}$ & $-0,438$ & 0,090 & $\begin{array}{l}\text { negativa } \\
\text { moderada }\end{array}$ \\
\hline $\mathrm{MnP}$ & & $-0,236$ & 0,378 & sc & $-0,110$ & 0,684 & $\mathrm{sc}$ \\
\hline $\mathrm{CBMM}$ redutores $\mathrm{Fe}^{+3}$ & & SC & sc & sc & $-0,607$ & 0,585 & sc \\
\hline CBMM quelantes $\mathrm{Fe}^{+3}$ & & SC & sc & sc & 0,692 & 0,513 & sc \\
\hline Lacases & \multirow{3}{*}{$\begin{array}{l}\text { Pleurotus } \\
\text { ostreatus }\end{array}$} & 0,658 & 0,003 & $\begin{array}{l}\text { positiva } \\
\text { moderada }\end{array}$ & 0,073 & 0,774 & sc \\
\hline CBMM redutores $\mathrm{Fe}^{+3}$ & & $-0,947$ & 0,207 & sc & $-0,995$ & 0,065 & $\begin{array}{l}\text { negativa } \\
\text { muito forte }\end{array}$ \\
\hline CBMM quelantes $\mathrm{Fe}^{+3}$ & & 0,904 & 0,281 & sc & 1,000 & 0,008 & $\begin{array}{c}\text { positiva } \\
\text { muito forte }\end{array}$ \\
\hline Lacases & \multirow{3}{*}{$\begin{array}{c}\text { Trametes } \\
\text { villosa }\end{array}$} & 0,035 & 0,889 & sc & 0,189 & 0,452 & sc \\
\hline CBMM redutores $\mathrm{Fe}^{+3}$ & & 0,528 & 0,646 & sc & $-0,790$ & 0,420 & sc \\
\hline CBMM quelantes $\mathrm{Fe}^{+3}$ & & $-0,430$ & 0,717 & sc & 0,716 & 0,492 & sc \\
\hline
\end{tabular}

Legenda: sc = sem correlação.

De forma geral, $P$. ostreatus descoloriu o corante por ação predominante de suas lacases, uma vez que apresentou formação de metabólito na presença de lacases e não produziu MnP durante contato in vivo. Houve correlação negativa muito forte da descoloração a $526 \mathrm{~nm}$ com os CBMM redutores de $\mathrm{Fe}^{+3}$ (Pearson = - 0,995, $p=0,065$; APÊNDICE E) e positiva muito forte com os CBMM quelantes de $\mathrm{Fe}^{+3}$ (Pearson = 1,000, $p=0,008$; APÊNDICE E). Assim sendo, é sugerido que lacases podem ter atuado conjuntamente com os CBMM, uma vez que Arantes e Milagres (2007) já comentavam interação da atividade redutora de ferro com lacases e MnP de Lentinula edodes, Trametes versicolor e Perenniporia medullapanis em estudo de descoloração de Azure B. 
Lacases descolorem corantes azo por meio de um mecanismo não específico de radicais livres, onde os $\mathrm{Cu}^{+2}$ do seu centro reativo retiram elétrons dos substratos fenólicos. Após oxidado, esse substrato torna-se um radical cátion ativo, capaz de retirar elétrons de outro composto não fenólico, retornando ao seu estado original em seguida. A partir dessa oxidação, o composto não fenólico passa a ter um radical fenólico, facilitando assim o ataque catalítico. Então, um ataque nucleofílico do carbono do anel fenólico, recém-formado, ligado ao grupo azo, produz sulfonatos aromáticos e quinonas. Os radicais formados pela oxidação de um elétron do corante por lacase podem então reagir com as quinonas formadas, para serem oxidados novamente, podendo ainda ocorrer acoplamento cruzado entre as espécies reativas, formando ligações C-C e C-O entre as moléculas fenólicas, onde um elétron é removido do radical hidroxila, gerando um radical alcoxila (radical lipídico-O). Tais radicais, quando livres formam dímeros nas posições orto e para com o grupo hidroxila. Dessa forma, os radicais fenólicos podem ser oxidados ainda por produtos oligoméricos (CHACKO; SUBRAMANIAM, 2011; MOTA et al., 2015; THOMAS et al., 2014; ZHAO et al., 2007; ZHAO; HARDIN, 2007; WONG; YU, 1999). Todas essas sequências de reações caracterizam o mecanismo degradativo de basidiomicetos com participação predominante de lacases, como é o caso do $P$. ostreatus. O ataque nucleofílico por água no carbono do anel fenólico ligado ao grupo azo produz ácido benzenesulfônico e naftoquinona e esse último pode ainda reagir com a lacase formando naftodiol. Diferentemente, outros corantes, como o diazo não fenólico Congo Red, tem como metabólitos da quebra o naftaleno-amina, bifenilamina, bifenil e diazônio-naftaleno, uma vez que seguem rotas diferentes daquelas observadas na degradação dos corantes fenólicos (MOTA et al., 2015; SI et al., 2013).

Ainda nesse contexto, Gárcia-Montaño et al. (2008) comentam que o ataque oxidativo inicia preferencialmente no grupo azo, ligado ao radical fenólico, liberando $\mathrm{N}^{2}$ para a atmosfera. Assim sendo, uma via hipotética do ataque de RB222 por $P$. ostreatus seria a oxidação do carbono do radical fenólico ligado ao azo, pelo $\mathrm{Cu}^{+2} \mathrm{da}$ lacase. A partir daí forma-se uma quinona ligada ao outro grupo. O segundo ataque pode ter acontecido por hidroxilação do radical cíclico ligado ao grupo azo, permitindo assim o ataque do segundo grupo azo pela lacase, ou até mesmo pela ação da hidroxila no naftaleno ou benzeno ligado ao radical monoclorotriazina (GARCIA-MONTAÑO et al. 2008). 
P. cinerea descolore RB222 sem participação direta de $\mathrm{MnP}$, produzindo metabólito nessa condição, e ainda sua produção de lacases está correlacionada de forma negativa moderada com a descoloração. Assim sendo, é importante ressaltar que Moreira et al. (2014) comprovaram a existência de 8 isoenzimas de lacase, com diferentes propriedades, produzidas por essa mesma linhagem de P. cinerea CCIBt 2541. Os autores comentam a capacidade dessas lacases em oxidar diretamente $\mathrm{Mn}^{+2}$, isoladamente ou quando combinadas com mediador e oxalato. No entanto, apesar desses autores comprovarem a eficiência de sistemas combinados de lacases de $P$. cinerea na descoloração de corante antraquinônico, os resultados não mostraram grande eficiência na descoloração do corante reativo de função azo CI Reactive Red 271. Do mesmo modo, os resultados aqui apresentados não atingiram altas taxas de descoloração, embora tenha sido possível comprovar a degradação pela formação de metabólito, não é possível relacioná-la apenas à ação das enzimas avaliadas, já que os sistemas coloridos com inibição de lacase, conjuntamente com a inibição da $\mathrm{MnP}$, apresentaram descoloração do corante. Ainda nesse contexto, é importante lembrar que os fungos de podridão branca são dotados de mecanismos oxidativos não enzimáticos, mediados pelos CBMM, sendo os compostos redutores de $\mathrm{Fe}^{+3}$, os que desempenham papel chave no processo de degradação, gerando radical hidroxila $\left({ }^{-} \mathrm{OH}\right)$ via reação de Fenton. Essa espécie reativa de oxigênio é um poderoso oxidante, o mais forte em meio aquoso, que reage rapidamente com moléculas orgânicas, seja abstraindo hidrogênio de estruturas alifáticas, ou adicionando-os em aromáticos (AGUIAR et al., 2010; ARANTES; MILAGRES, 2009; HAMMEL et al., 2002). Considerando ainda o estudo de Clarke et al. (2010), esses autores comentam a degradação do corante Acid Orange 7 na presença de excesso de $\mathrm{Mn}^{+3}$, sugerindo uma possível rota oxidativa resultante da redução desse $\mathrm{Mn}^{+3}$, o que gera sucessivamente quinona, capaz de reduzir $\mathrm{Fe}^{+3}$ para $\mathrm{Fe}^{+2}$. A simultânea geração de peróxido de hidrogênio possibilita o início da reação de Fenton, sugere-se aqui então uma possível via metabólica para P. cinerea, onde segundo Garcia-Montaño et al. (2008) o ataque preferencial acontece pelo grupo azo ligado ao radical fenólico, sendo possivelmente essa a primeira quebra da molécula.

Os CBMM quelantes e redutores de $\mathrm{Fe}^{+3}$ nos inóculos de $P$. cinerea foram observados em quantidades muito menores do que o observado em estudos semelhantes com outros fungos (ARANTES et al., 2011; ARANTES; MILAGRES, 2007). Contudo, Paranhos (2011) avaliando essa mesma linhagem de P. cinerea CCIBt 2541 observou 4 $\mu \mathrm{M}$ de $\mathrm{Fe}^{+3}$ reduzido em culturas de 21 dias, confirmando que tal basidiomiceto produz 
poucos redutores de ferro em cultivo líquido. Ainda Nidheesh et al. (2013), em sua revisão sobre processo de Fenton na degradação de corantes, comentam que existe uma concentração de $\mathrm{Fe}^{+2}$, sugerida por Wang et al. (2010) como ótima, de 2 mM. Entretanto, mesmo com essa baixa quantidade de compostos redutores de ferro detectados, quando 5 \% de quelantes de ferro estão presentes, a degradação de RB222 teve início em até 48 horas de contato in vivo (32\% a $610 \mathrm{~nm}$ ). Em estudo semelhante, onde essa mesma linhagem de P. cinerea CCIBt 2541 foi avaliada na descoloração do Azul Brilhante HGR, Paranhos (2011) comentam que a descoloração atingiu um máximo de 38 \% em 72 horas de contato, ainda esse mesmo autor, em 2007, bem como Melo (2009) comentaram que existe predominância dos CBMM na descoloração de corantes reativos por essa linhagem de $P$. cinerea. Fica assim sugerida a ação dos CBMM no processo com $P$. cinerea, tendo o ${ }^{-} \mathrm{OH}$, possivelmente, papel predominante, baseado na afirmativa de Nidheesh et al. (2013) de que esses radicais geram novos intermediários com baixa massa molar. Zhao et al. (2007) no estudo de degradação de Orange II, um corante monoazo fenólico sulfonado, por $P$. ostreatus, comentaram a formação de ácido 4hidroxi-benzosulfônico e 1,2-dihidroxinaftaleno pela oxidação de Fenton. O princípio desse mecanismo inclui a redução de quinona extracelular para hidroquinona, a qual reage com $\mathrm{Fe}^{+3}$ para formar $\mathrm{Fe}^{+2}$ e um radical semiquinona. Essa semiquinona reduz $\mathrm{O}_{2}$ para ${ }^{-} \mathrm{OOH}$ e a quinona original, esse ciclo gera um sistema de Fenton completo, uma vez que ${ }^{-} \mathrm{OOH}$ é uma fonte de $\mathrm{H}_{2} \mathrm{O}_{2}$. Contudo, as hidroquinonas precisam ter potencial de redução suficientemente negativo para reduzir $\mathrm{Fe}^{+3}$ quando complexado com oxalato. É proposto então que catecóis, os quais são produzidos por alguns fungos e agem não somente como redutor de $\mathrm{Fe}^{+3}$, mas também como quelante de $\mathrm{Fe}^{+3}$ (HAMMEL et al., 2002), possam estar entre os CBMM quantificados. No entanto para que seja possível afirmar essa hipótese seriam necessárias análises complementares de caracterização dos CBMM.

A degradação de RB222 por T. villosa foi confirmada pelo surgimento de um metabólito em 24 horas, que foi degradado em 48 horas. De modo análogo, Enayatizamir et al. (2011), em estudo de descoloração de Reactive Black 5 por Phanerochaete chrysosporium, avaliaram a degradação por TLC e seus resultados mostraram o surgimento de um metabólito, que foi degradado após 48 horas. Da mesma forma, Lu et al. (2008), em avaliação da descoloração de CI Mordant Violet 5, CI Acid Orange 7 e CI Acid Orange 8 por $P$. ostreatus, observaram por HPLC e CE-MS que, após 1 dia os corantes CI Mordant Violet 5 e CI Acid Orange 8 desapareceram e 
metabólitos foram formados, sendo um deles o 1,2-naftoquinona, o qual foi degradado no terceiro dia de tratamento. O mesmo foi observado com CI Acid Orange 7, contudo a formação desse metabólito ocorreu no segundo dia de tratamento, desaparecendo no quinto dia. Ainda Kanagaraj et al. (2015), em estudo de degradação do corante diazo não fenólico por lacase bacteriana, avaliam a presença de metabólitos por cromatografia de camada delgada (TLC) e observaram $R_{F}$ maiores do que observados no controle contendo corante não degradado.

T. villosa apresentou uma via metabólica bem diferente das supracitadas, sem correlação direta com as enzimas ligninolíticas determinadas, nem com os CBMM quantificados. No entanto, vale ressaltar o comentado por Arantes e Milagres (2009), que os complexos enzimáticos produzidos por fungos de degradação de madeira incluem sistemas hidrolíticos e oxidativos, abrangendo muitas outras enzimas, não quantificadas nesse estudo. Ainda é importante lembrar, que no estágio inicial da degradação, os fungos secretam glicopeptídeos de baixa massa molar, que reduzem $\mathrm{Fe}^{+3}$ e complexam $\mathrm{Fe}^{+2}$. Esse complexo, segundo Arantes e Milagres (2009), catalisa a oxirredução entre $\mathrm{O}_{2}$ e um doador de elétrons, produzindo peróxido de hidrogênio, que em seguida é reduzido gerando ${ }^{-} \mathrm{OH}$, via reação de Fenton. É sabido também que os sistemas contendo ${ }^{-} \mathrm{OH}$, podem mediar a quebra de ligações monoclorotriazina-HNradical, desestabilizando assim molécula do corante e favorecendo a descoloração, fato mencionado por García-Montaño et al. (2008) em estudo de degradação de corante azo por processos oxidativos avançados. Zille et al. (2005) já comentavam, em estudo de degradação de corantes azo por lacase de T. villosa, que a oxidação química de um corante monoazo fenólico contendo grupo sulfonil inicia pela oxidação do grupo fenólico com a participação de um elétron, gerando um radical fenoxila, seguido pela oxidação de um íon carbônio. Nesse contexto sugere-se aqui uma possível rota metabólica para T. villosa via CBMM, onde o papel predominante pode ter acontecido pela ação de hidroxilas formadas pela reação de Fenton, embora não possa ser negligenciada a ação das suas lacases.

Dessa forma, são sugeridos alguns metabólitos preditos, descritos na Figura 16. O programa simula diferentes reações, no entanto a esquematização ilustra apenas as possíveis reações oxidativas e de hidroxilação. 
Figura 16 - Possíveis metabólitos da degradação de RB222 após tratamentos com basidiomicetos. Metaprint2D.

\section{Reactive Blue 222}

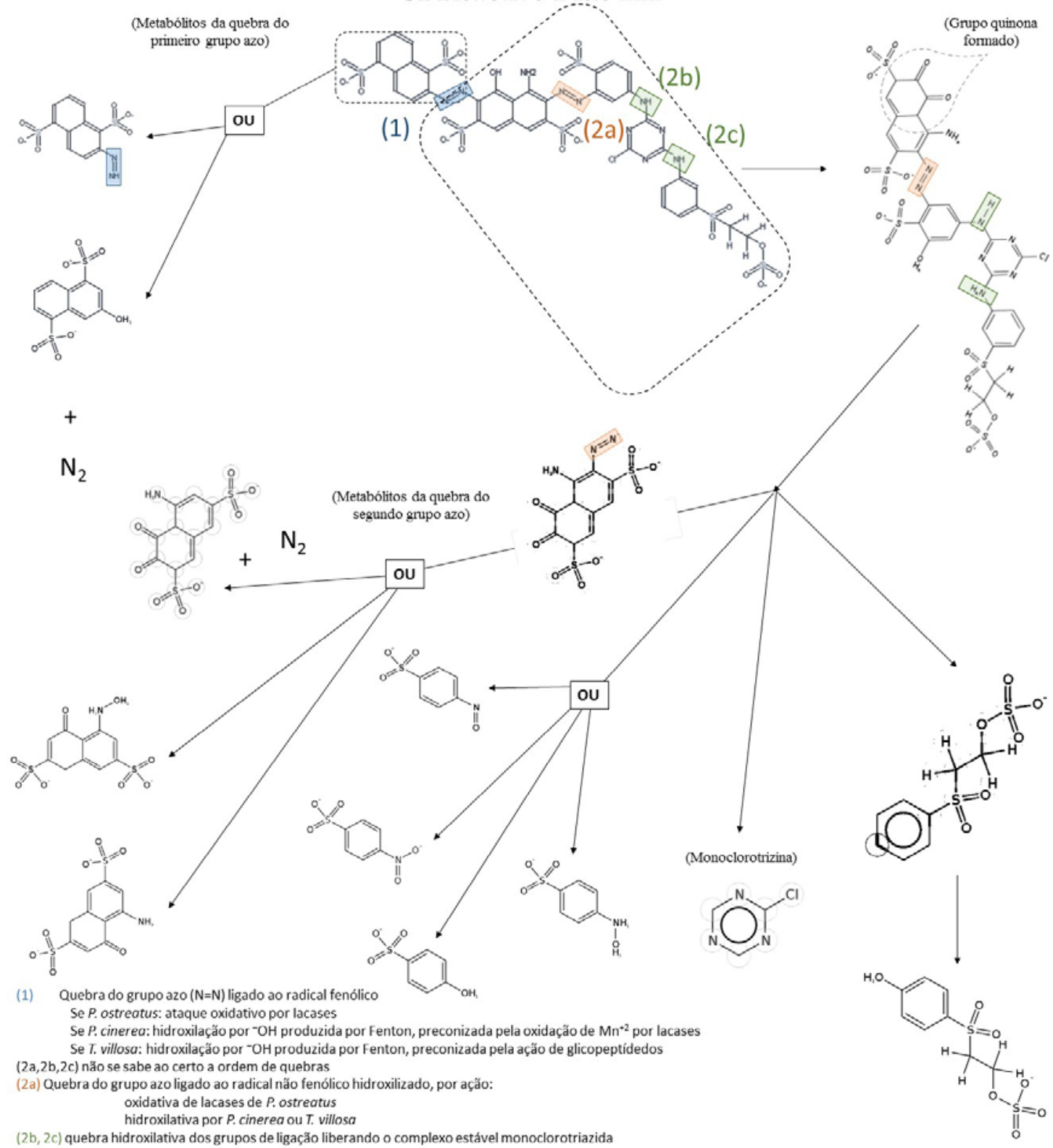

Independente da rota metabólica, sugere-se que a primeira quebra tenha ocorrido no grupo azo ligado ao radical fenólico, uma vez que essa é a ligação mais instável da molécula, a partir daí cada fungo atuou de forma especifica na quebra das demais ligações. 


\section{CONCLUSÕES}

- Conclui-se que os três basidiomicetos estão aptos a participar de processos de descoloração desse corante diazo fenólico, confirmando a inespecificidade de seus mecanismos degradativos. Fica ainda evidente que o processo é dinâmico, capaz de expressar diferentes especificidades durante as etapas do processo, de acordo com i) a espécie de basidiomiceto empregada, ii) o tempo de incubação pré-contato e durante contato in vivo e iii) as condições nutricionais, incluindo mediadores enzimáticos, o que sugere a necessidade de intervenções sucessivas, a fim de maximizar a descoloração em todas as etapas do processo;

- As três espécies de basidiomicetos expressam lacase, como principal enzima ligninolítica, que, juntamente com outras enzimas e compostos quelantes e redutores de ferro, constituem mecanismos degradativos eficientes para descolorir concentração elevada desse corante recalcitrante (0,03 \%);

- Concentrações de sulfato de cobre, sulfato de manganês e fonte de ácido graxo influenciam não apenas a produção das enzimas ligninolíticas, mas também a descoloração, mostrando que esses são fatores importantes para se otimizar, na busca pela eficiência de processos desse tipo. A idade fisiológica do cultivo também mostra-se um importante fator a ser considerado para cultivos empregando esses basidiomicetos;

- $\quad$ P. ostreatus apresenta maior eficiência na descoloração empregando cultivo de 25 dias, contendo 0,446 $\mathrm{mM}$ de sulfato de cobre e 0,821 $\mathrm{mM}$ de sulfato de manganês, sem adição de ácido graxo insaturado. T. villosa também mostra máxima eficiência quando emprega cultivo com 25 dias, contendo $1 \mathrm{mM}$ de sulfato de cobre e de manganês, na presença de 3,75\% de fonte de ácido graxo insaturado. Já $P$. cinerea mostra máxima eficiência empregando cultivo com 18 dias, contendo $1 \mathrm{mM}$ de sulfato de cobre e 0,106 mM de sulfato de manganês, na presença de 4\% de fonte de ácido graxo insaturado;

- A presença de mediadores no efluente sintético influencia positivamente a descoloração, quando $2 \mathrm{mM}$ de ABTS são adicionados, para qualquer um dos basidiomicetos estudados. Já o RBBR influencia positivamente apenas os tratamentos com $P$. ostreatus e $P$. cinerea, na concentração de $0,2 \mu \mathrm{M}$; 
- As ferramentas estatísticas mostram-se apropriadas para analisar a eficiência desse tipo de processo, possibilitando ainda esclarecimentos sobre as vias de processos;

- Cromatografia de Camada Delgada apresenta-se como técnica eficaz para detectar metabólitos, o que pode viabilizar pesquisas biotecnológicas com descobertas importantes minimizando custos de análise;

- P. ostreatus é capaz de degradar RB222 nas primeiras 24 horas de contato in vivo, provocando deslocamento hipsocrômico do comprimento de onda de máxima absorção, com participação ativa das lacases, associadas à ação não enzimática dos CBMM.

- $\quad$. cinerea é capaz de iniciar a descoloração de RB222 sem a ação direta de lacases e MnP, uma vez que os compostos de baixa massa molar presentes em seus extratos de cultivo apresentam participação ativa no processo.

- T. villosa é capaz de iniciar a descoloração de RB222, também fazendo uso de um mecanismo misto, enzimático e não enzimático.

- Por fim, conclui-se que embora a grande maioria dos estudos desse tipo foquem erroneamente em máximas produções enzimáticas, negligenciando a ação de CBMM e vias adjacentes do processo in vivo, fica comprovado que o mecanismo ligninolítico pode atingir sua máxima eficiência em configurações diferentes daquelas preconizadas até então. 


\section{REFERÊNCIAS*}

ADNAN, L. et al. Biodegradation of bis-azo dye Reactive Black 5 by white-rot fungus Trametes gibbosa sp. WRF 3 and its metabolite Characterization. Water Air and Soil Pollution, Cham, v. 225, n. 10, p. 1-11, 2014. ISSN 0049-6979.

AGUIAR, A. et al. Behavior of Ceriporiopsis subvermispora during Pinus taeda biotreatment in soybean-oil-amended cultures. International Biodeterioration and Biodegradation, v. 64, n. 7, p. 588-593, 2010. ISSN 0964-8305.

AGUIAR, A.; FERRAZ, A. Mecanismos envolvidos na biodegradação de materiais lignocelulósicos e aplicações tecnológicas correlatas. Química Nova , v. 34, n. 10, p. 1729-1738, 2011. ISSN 01004042.

AKDOGAN, H. A.; TOPUZ, M. C.; URHAN, A. A. Studies on decolorization of Reactive Blue 19 textile dye by Coprinus plicatilis. Journal of Environmental Health Science Engineering, v. 12, n. 1, 2014. ISSN 2052336X.

AKPINAR, M.; UREK, R. Production of ligninolytic enzymes by solid-state fermentation using Pleurotus eryngii. Preparative Biochemistry and Biotechnology, v. 42, n. 6, p. 582-597, 2012. ISSN 1082-6068.

ALBERTS, J. F. et al. Degradation of aflatoxin B(1) by fungal laccase enzymes. International Journal of Food Microbiology., v. 135, n. 1, p. 47, 2009.

ALI, H. Biodegradation of Synthetic Dyes-A Review. Water Air and Soil Pollution 213: 251-273 p. 2010.

ALMANSA, E. et al. Influence of structure on dye degradation with laccase mediator systems. Biocatalysis and Biotransformation, v. 22, n. 5-6, p. 315-324, 2004. ISSN 1024-2422.

ALMEIDA, E. J. R.; CORSO, C. R. Comparative study of toxicity of azo dye Procion Red MX- 5B following biosorption and biodegradation treatments with the fungi Aspergillus niger and Aspergillus terreus. Chemosphere, 2014. ISSN 0045-6535.

ÁLVAREZ, M. S. et al. Novel physico-biological treatment for the remediation of textile dyes-containing industrial effluents. Bioresource Technology, v. 146, p. 689-95, Oct $\begin{array}{lcccc}2013 . & \text { ISSN } & \text { 1873-2976. } & \text { Disponível } & \text { em: } \\ \text { http://www.ncbi.nlm.nih.gov/pubmed/23985354>. Acesso em: } 15 \text { out. } 2016 .\end{array}$

ANDRADE, M. V. F. et al. Azo Dye Degradation by Phanerochaete chrysosporium in the Medium Enriched with Nitrogen in the Presence of Primary Co-Substrate. Brazilian Archives of Biology and Technology, v. 56, n. 5, p. 867-874, 2013. ISSN 1516-8913.

\footnotetext{
* De acordo com: ASSOCIAÇÃO BRASILEIRA DE NORMAS TÉCNICAS. NBR6023: informação e documentação: referências: elaboração. Rio de Janeiro, 2002.
} 
ARANTES, V. et al. Lignocellulosic polysaccharides and lignin degradation by wood decay fungi: the relevance of nonenzymatic Fenton-based reactions. Journal of Industrial Microbiology and Biotechnology, Berlin/Heidelberg, v. 38, n. 4, p. 541-555, 2011. ISSN 1367-5435.

ARANTES, V.; MILAGRES, A., M. F. Relevância de compostos de baixa massa molar produzidos por fungos e envolvidos na biodegradação da madeira. Química Nova, v. 32, n. 6, p. 1586-1595, 2009. ISSN 0100-4042.

ARANTES, V.; MILAGRES, A. M. F. The synergistic action of ligninolytic enzymes (MnP and Laccase) and $\mathrm{Fe}^{3+}$-reducing activity from white-rot fungi for degradation of Azure B. Enzyme and Microbial Technology, v. 42, n. 1, p. 17-22, 2007. ISSN 01410229.

Effect of $\mathrm{pH}$ and oxalic acid on the reduction of $\mathrm{Fe}^{3+}$ by a biomimetic chelator and on $\mathrm{Fe}^{3+}$ desorption/adsorption onto wood: Implications for brown-rot decay. International Biodeterioration and Biodegradation, v. 63, n. 4, p. 478-483, 2009. ISSN 0964-8305.

ARGUN, M. E.; GÜCLÜ, D.; KARATAS, M. Adsorption of Reactive Blue 114 dye by using a new adsorbent: Pomelo peel. Journal of Industrial and Engineering Chemistry, 2013. ISSN 1226086X.

ASSOCIAÇÃO BRASILEIRA DA INDÚSTRIA QUÍMICA. Usos de corantes, pigmentos a branqueadores ópticos Disponível em <http://abiquim.org.br/corantes/cor_aplicacoes.asp>. Acesso em: 15 out. 2016.

BALDRIAN, P.; GABRIEL, J. Copper and cadmium increase laccase activity in Pleurotus ostreatus. FEMS Microbiology Letters, v. 206, n. 1, p. 69-74, 2002. ISSN 0378-1097.

BALLAMINUT, N. et al. Avaliação de substratos lignolíticos em inóculo de basidiomicetos para descoloração de corantes. In: Congresso Brasileiro de Recursos Genéticos, 3., 2014a, Santos. Resumos. Santos: Mendes Convention Center, 2014a. Área 2, protocolo 643. Disponível em < http://www.cbrg.net.br/cd/areamicroorganismos.html>. Acesso em 15 fev. 2017.

BALLAMINUT, N. et al. Physiological Characterization of fungal inoculum for biotechnological remediation of soils. Brazilian Archives of Biology and Technology, v. 57, n. 4, p. 561-570, 08/2014 2014b. ISSN 1516-8913. Disponível em: $<$ http://www.scielo.br/scielo.php?script=sci_abstract\&pid=S1516-

89132014000400561\&lng=en\&nrm=iso\&tlng=en>. Acesso em 15 out. 2016.

BALLAMINUT, N.; MATHEUS, D. R. Characterization of fungal inoculum used in soil bioremediation. Brazilian Journal of Microbiology, v. 38, n. 2, p. 248-252, 2007. ISSN 1517-8382.

BALLAMINUT, N.; YAMANAKA, R.; MACHADO, K. M. G. Interference of a commercial catalase preparation in laccase and peroxidase activities. Brazilian Archives of Biology and Technology, v. 52, n. 5, p. 1193-1198, 2009. ISSN 1516-8913. 
BARRASA, J.; MARTÍNEZ, A.; MARTÍNEZ, M. Isolation and selection of novel basidiomycetes for decolorization of recalcitrant dyes. Folia Microbiologica, Dordrecht, v. 54, n. 1, p. 59-66, 2009. ISSN 0015-5632.

BARRETO, W. et al. A kinetic study of the biodegradation of textile dye mixtures by Pleurotus ostreatus fungus. Monatshefte für Chemie, Vienna, v. 143, n. 10, p. 13891395, 2012. ISSN 0026-9247.

BASHA, C. A. et al. Degradation studies for textile reactive dye by combined electrochemical, microbial and photocatalytic methods. Separation and Purification Technology, p.303-309. 2011

BIBI, I.; BHATTI, H. N. Enhanced biodecolorization of reactive dyes by basidiomycetes under static conditions. Applied Biochemistry and Biotechology, v. 166, n. 8, p. 20782090, 2012. ISSN 0273-2289.

BONNARME, P.; JEFFRIES, T. W. Mn(II) regulation of lignin peroxidases and manganese-dependent peroxidases from lignin-degrading white rot fungi. Applied and Enviromental Microbiology, v. 56, n. 1, p. 210, 1990. ISSN 0099-2240.

BONUGLI-SANTOS, R.; DURRANT, L.; SETTE, L. The production of ligninolytic enzymes by marine-derived basidiomycetes and their biotechnological potential in the biodegradation of recalcitrant pollutants and the treatment of textile effluents. Water Air and Soil Pollution, Dordrecht, v. 223, n. 5, p. 2333-2345, 2012. ISSN 0049-6979.

BONUGLI-SANTOS, R. et al. Enhanced textile dye decolorization by marine-derived basidiomycete Peniophora sp. CBMAI 1063 using integrated statistical design. Environmental Science and Pollution Research, Berlin/Heidelberg, v. 23, n. 9, p. 86598668, 2016. ISSN 0944-1344.

BOURBONNAIS, R.; PAICE, M. G. Oxidation of non- phenolic substrates. An expanded role for laccase in lignin biodegradation. FEBS Letters, v. 267, n. 1, p. 99-102, 1990. ISSN 00145793.

BÖHMER, S.; MESSNER, K.; SREBOTNIK, E. Oxidation of phenanthrene by a fungal laccase in the presence of 1-hydroxybenzotriazole and unsaturated lipids. Biochemical and Biophysical Research Communications, v. 244, n. 1, p. 233-238, 1998. ISSN 0006-291X.

CAÑAS, A. I.; CAMARERO, S. Laccases and their natural mediators: Biotechnological tools for sustainable eco- friendly processes. Biotechnology advances, v. 28, n. 6, p. 694705, 2010. ISSN 0734-9750.

CHACKO, J. T.; SUBRAMANIAM, K. Enzymatic degradation of azo dyes - a review. International Journal of Environmental Sciences 1: 1250-1260 p. 2011.

CHAIRIN, T. et al. Biodegradation of bisphenol a and decolorization of synthetic dyes by laccase from white rot fungus, Trametes polyzona. (Report). Applied Biochemistry and Biotechnology, v. 169, n. 2, p. 539, 2013. ISSN 0273-2289. 
CHEN, Q. et al. A multiscale study on the structural and mechanical properties of the luffa sponge from Luffa cylindrica plant. Journal of Biomechanics, 47: 1332 p. 2014.

CHENAUX, P.; LALJI, N.; LEFEBVRE, D. Trametes meyenii possesses elevated dye degradation abilities under normal nutritional conditions compared to other white rot fungi. AMB Express, Berlin/Heidelberg, v. 4, n. 1, p. 1-9, 2014.

CHEQUER, F. M. D. et al. Textile dyes: dyeing process and environmental impact. In: GÜNAY, M. (Ed.). Eco-Friendly textile dyeing and finishing: InTech, 2013. DOI: 10.5772/53659. Disponível em: <http://www.intechopen.com/books/eco-friendlytextile-dyeing-and-finishing/textile-dyes-dyeing-process-and-environmental-impact>.

Acesso em: 15 out. 2016.

CLARKE. C. E. et al. Oxidative decolorization of acid azo dyes by a Mn oxide containing waste. Environmental Science and Technology, v. 44, p. 1116-1122, 2010. ISSN 15205851.

CONSELHO NACIONAL DE MEIO AMBIENTE. Resolução no 357, de 2005. Classificação dos corpos de água e diretrizes ambientais. Disponível em: <http://www.mma.gov.br/port/conama/res/res05/res35705.pdf>. Acesso em: 15 out. 2016.

CUNICO, M. W. M. et al. Planejamento fatorial: uma ferramenta estatística valiosa para a definição de parâmetros experimentais empregados na pesquisa científica. Visão Acadêmica. Curitiba, Paraná, v. 9, n. 1, p. 23-32, 2008.

DONLON, B. A. et al. Toxicity of N-substituted aromatics to acetoclastic methanogenic activity in granular sludge. Applied and Environmental Microbiology, v. 61, n. 11, p. 3889-3893, 1995. ISSN 00992240.

DOS SANTOS, A. B. et al. The transformation and toxicity of anthraquinone dyes during thermophilic (55 degrees C) and mesophilic (30 degrees C) anaerobic treatments. Journal of Biotechnology, v. 115, n. 4, p. 345-353, 2005. ISSN 0168-1656.

DURÁN, N.; ESPOSITO, E. Potential applications of oxidative enzymes and phenoloxidase-like compounds in wastewater and soil treatment: A review. Applied Catalysis B: Environmental, v. 28, n. 2, p. 83-99, 2000. ISSN 09263373.

EGGERT, C.; TEMP, U.; ERIKSSON, K. E. L. The ligninolytic system of the white rot fungus Pycnoporus cinnabarinus: Purification and characterization of the laccase. Applied and Environmental Microbiology, v. 62, n. 4, p. 1151-1158, 1996. ISSN 00992240.

EL-GHENYMY, A. et al. Decolorization and mineralization of Orange G azo dye solutions by anodic oxidation with a boron-doped diamond anode in divided and undivided tank reactors. Electrochimica Acta, v. 130, p. 568-576, 2014. ISSN 00134686. 
ENAYATZAMIR, K. et al. Decolouration of azo dyes by Phanerochaete chrysosporium immobilised into alginate beads. Environmental Science and Pollution Research, v. 17, n. 1, p. 145-153, 2010. ISSN 09441344.

EVANS, C. S. et al. Enzymes and small molecular mass agents involved with lignocellulose degradation. FEMS Microbiology Reviews, v. 13, n. 2-3, p. 235-240, 1994. ISSN 01686445.

FARACO, V. et al. Bio- remediation of colored industrial wastewaters by the white- rot fungi Phanerochaete chrysosporium and Pleurotus ostreatus and their enzymes. Biodegradation, v. 20, n. 2, p. 209-220, 2009. ISSN 0923-9820.

FERNADES RÊGO, F. E. et al. Application of electro-Fenton process as alternative for degradation of Novacron Blue dye. Journal of Environmental Chemical Engineering, v. 2, n. 2, p. 875-880, 6// 2014. ISSN 2213-3437. Disponível em: <http://www.sciencedirect.com/science/article/pii/S2213343714000451>. Acesso em: 15 out. 2016.

FERNANDEZ, C.; LARRECHI, M. S.; CALLAO, M. P. An analytical overview of processes for removing organic dyes from wastewater effluents. Trac Trends in Analytical Chemistry, 29: 1202-1211 p. 2010.

FERNANDO, E.; KESHAVARZ, T.; KYAZZE, G. Complete degradation of the azo dye Acid Orange-7 and bioelectricity generation in an integrated microbial fuel cell, aerobic two-stage bioreactor system in continuous flow mode at ambient temperature. Bioresource Technology, v. 156, p. 155-162, 2014. ISSN 0960-8524.

FONSECA, M. I. et al. Copper inducing effect on laccase production of white rot fungi native from Misiones (Argentina). Enzyme and Microbial Technology, v. 46, n. 6, p. 534-539, 2010. ISSN 0141-0229.

FUKUDA, E. et al. Fungal cell wall polysaccharides: purification and characterization. Semina Ciências Agrárias 30: 117-133 p. 2009.

GAHLOUT, M.; GUPTE, S.; GUPTE, A. Optimization of culture condition for enhanced decolorization and degradation of azo dye reactive violet 1 with concomitant production of ligninolytic enzymes by Ganoderma cupreum AG-1. 3 Biotech, Berlin/Heidelberg, v. 3, n. 2, p. 143-152, 2013. ISSN 2190-572X.

GARCÍA-MONTAÑO, J. et al. Degradation pathways of the commercial reactive azo dye Procion Red H-E7B under solar-assisted photo-fenton reaction. Environmental Science and Technology, v. 42, n. 17, p. 6663-6670, 2008. ISSN 0013936X.

GUARATINI, C. C. I.; ZANONI, M. V. B. Corantes têxteis. Química Nova, v. 23, n. 1, p. 71-78, 2000. ISSN 01004042.

HADIBARATA, T. et al. Microbial decolorization of an azo dye reactive black 5 using white-rot fungus Pleurotus eryngii F032. International Journal of Environment and Pollution, Dordrecht, v. 224, n. 6, p. 1-9, 2013. ISSN 0049-6979. 
HADIBARATA, T.; YUSOFF, A.; KRISTANTI, R. Acceleration of anthraquinone-type dye removal by white-rot fungus under optimized environmental conditions. International Journal of Environment and Pollution, Dordrecht, v. 223, n. 8, p. 46694677, 2012a. ISSN 0049-6979.

Decolorization and metabolism of anthraquionone- type dye by laccase of whiterot fungi Polyporus sp. S133. International Journal of Environment and Pollution, Dordrecht, v. 223, n. 2, p. 933-941, 2012b. ISSN 0049-6979.

HAMMEL, K. E. et al. Reactive oxygen species as agents of wood decay by fungi. Enzyme and Microbial Technology, v. 30, n. 4, p. 445-453, 2002. ISSN 01410229.

HAROUN, M.; IDRIS, A. Treatment of textile wastewater with an anaerobic fluidized bed reactor. Desalination, v. 237, n. 1-3, p. 357-366, 2009. ISSN 00119164.

HASSAN, H.; HAMEED, B. H. Oxidative decolorization of Acid Red 1 solutions by Fezeolite Y type catalyst. Desalination, v. 276, n. 1-3, p. 45-52, 2011. ISSN 00119164.

HORTA, M. A. et al. Linoleic acid peroxidation initiated by $\mathrm{Fe}^{3+}$-reducing compounds recovered from Eucalyptus grandis biotreated with Ceriporiopsis subvermispora. International Biodeterioration and Biodegradation, v. 65, n. 1, p. 164-171, 2011. ISSN 0964-8305.

HU, M. et al. Laccase- mediator system in the decolorization of different types of recalcitrant dyes. Journal of Industrial Microbiology and Biotechnology, v. 36, n. 1, p. 45-51, 2009. ISSN 1367-5435.

IQBAL, M.; EDYVEAN, R. G. J. Loofa sponge immobilized fungal biosorbent: A robust system for cadmium and other dissolved metal removal from aqueous solution. Chemosphere, v. 61, n. 4, p. 510-518, 2005. ISSN 0045-6535.

IŞIK, M.; SPONZA, D. T. Fate and toxicity of azo dye metabolites under batch long-term anaerobic incubations. Enzyme and Microbial Technology, v. 40, n. 4, p. 934-939, 2007. ISSN 01410229.

JIANG, M.; TEN, Z.; DING, S. J. Decolorization of synthetic dyes by crude and purified laccases from Coprinus comatus grown under different cultures: the role of major isoenzyme in dyes decolorization. Applied Biochemistry and Biotechnology, v. 169, n. 2, p. 660-672, 2013. ISSN 0273-2289.

JOHANNES, C.; MAJCHERCZYK, A. Laccase activity tests and laccase inhibitors. Journal of Biotechnology, v. 78, n. 2, p. 193-199, 2000. ISSN 0168-1656.

KALPANA, D. et al. Biodecolorization and biodegradation of reactive Levafix Blue ERA granulate dye by the white rot fungus Irpex lacteus. Journal of Environmental Management, 111: 142-149 p. 2012.

KANAGARAJ, J.; SENTHILVELAN, T.; PANDA, R. Biodegradation of azo dyes in industrial effluent: an eco-friendly way toward green technology. Clean Techn Environ Policy, Berlin/Heidelberg, v. 17, n. 2, p. 331-341, 2015. ISSN 1618-954X. 
KAPICH, A. N. et al. Oxidizability of unsaturated fatty acids and of a non- phenolic lignin structure in the manganese peroxidase-dependent lipid peroxidation system. Enzyme and Microbial Technology, v. 46, n. 2, p. 136-140, 2010. ISSN 0141-0229.

KARP, S. G. et al. Characterization of laccase isoforms produced by Pleurotus ostreatus in solid state fermentation of sugarcane bagasse. Bioresource Technology, v. 114, p. 735-739, 2012. ISSN 0960-8524.

KAUSHIK, P.; MALIK, A. Fungal dye decolourization: Recent advances and future potential. Environment International, v. 35, n. 1, p. 127-141, 2009. ISSN 0160-4120.

KAVITHA, S. R. et al. Fluorescence quenching and photocatalytic degradation of textile dyeing waste water by silver nanoparticles. Spectrochimica Acta Part A: Molecular and Biomolecular Spectroscopy, v. 127, p. 115-121, 2014. ISSN 1386-1425.

KIRAN, S.; ALI, S.; ASGHER, M. Degradation and mineralization of azo dye Reactive Blue 222 by sequential Photo-Fenton's oxidation followed by aerobic biological treatment using white rot fungi. Bulletin of Environmental Contamination and Toxicology, v. 90, n. 2, p. 208-15, Feb 2013. ISSN 1432-0800. Disponível em: <http://www.ncbi.nlm.nih.gov/pubmed/23272326>. Acesso em: 15 out. 2016.

KIRAN, S. et al. Comparative study on decolorization of Reactive Dye 222 by white rot fungi Pleurotus ostreatus IBL-02 and Phanerochaete chrysosporium IBL-03: Academic Journals, 6: 3639-3650 p. 2012.

KIRK, T. K.; FARRELL, R. L. Enzymatic combustion: The microbial degradation of lignin. Annual Review of Microbiology, 41: 465-501 p. 1987.

KNOP, D.; YARDEN, O.; HADAR, Y. The ligninolytic peroxidases in the genus Pleurotus : divergence in activities, expression, and potential applications. Applied Microbiology and Biotechnology, Berlin/Heidelberg, v. 99, n. 3, p. 1025-1038, 2015. ISSN 0175-7598.

KOYANI, R. D. et al. Contribution of lignin degrading enzymes in decolourisation and degradation of reactive textile dyes. International Biodeterioration and Biodegradation, v. 77, p. 1-9, 2013. ISSN 09648305.

KUMAR, V. V. et al. Biochemical characterization of three phase partitioned laccase and its application in decolorization and degradation of synthetic dyes. Journal of Molecular Catalysis B: Enzymatic, v. 74, n. 1-2, p. 63-72, 2012. ISSN 1381-1177.

KUNZ, A. et al. Novas tendências no tratamento de efluentes têxteis. Química Nova., 25: 78-82 p. 2002.

KUNZ, A.; REGINATTO, V.; DURAN, N. Combined treatment of textile effluent using the sequence Phanerochaete chrysosporium-ozone. Chemosphere, v. 44, n. 2, p. 281287, 2001. ISSN 0045-6535. 
KURADE, M. B. et al. Bacterial- yeast consortium as an effective biocatalyst for biodegradation of sulphonated azo dye Reactive Red 198. RSC Advances, v. 5, n. 29, p. 23046-23056, 2015. ISSN 20462069.

KUWAHARA, M. et al. Separation and characterization of two extracelluar $\mathrm{H}_{2} \mathrm{O}_{2}$ dependent oxidases from ligninolytic cultures of Phanerochaete chrysosporium. FEBS Letters, v. 169, n. 2, p. 247-250, 1984. ISSN 0014-5793.

KYZAS, G. Z. et al. Decolorization of dyeing wastewater using polymeric absorbents an overview. In: GÜNAY, M. (Ed.). Eco-Friendly textile dyeing and finishing: InTech, 2013. DOI: 10.5772/52817. Disponível em: <http://www.intechopen.com/books/ecofriendly-textile-dyeing-and-finishing/decolorization-of-dyeing-wastewater-usingpolymeric-absorbents-an-overview>. Acesso em: 15 out. 2016.

LAU, Y.-Y. et al. Coagulation- flocculation of azo dye Acid Orange 7 with green refined laterite soil. Chemical Engineering Journal, v. 246, p. 383-390, 2014. ISSN 1385-8947.

LEVIN, L.; MELIGNANI, E.; RAMOS, A. M. Effect of nitrogen sources and vitamins on ligninolytic enzyme production by some white-rot fungi. Dye decolorization by selected culture filtrates. Bioresource Technology, v. 101, n. 12, p. 4554-4563, 2010. ISSN 09608524.

LI, H. et al. In vivo and in vitro decolorization of synthetic dyes by laccase from solid state fermentation with Trametes sp SYBC-L4. Bioprocess and Biosystems Engineering, v. 37, n. 12, p. 2597-2605, 2014. ISSN 1615-7591.

LORENZO, M.; MOLDES, D.; SANROMAN, M. A. Effect of heavy metals on the production of several laccase isoenzymes by Trametes versicolor and on their ability to decolourise dyes. Chemosphere, v. 63, n. 6, p. 912-917, 2006. ISSN 0045-6535.

LU, Y. et al. Determination of the degradation products of selected sulfonated phenylazonaphthol dyes treated by white rot fungus Pleurotus ostreatus by capillary electrophoresis coupled with electrospray ionization ion trap mass spectrometry. Journal of Chromatography A, v. 1208, n. 1-2, p. 223, 2008. ISSN 0021-9673.

MACHADO, K. M. G.; MATHEUS, D. R.; BONONI, V. L. R. Ligninolytic enzymes production and Remazol Brilliant Blue $\mathrm{R}$ decolorization by tropical brazilian basidiomycetes fungi. Brazilian Journal of Microbiology, v. 36, n. 3, p. 246-252, 2005. ISSN 1517-8382.

MALACHOVA, K. et al. Biodegradation and detoxification potential of rotating biological contactor (RBC) with Irpex lacteus for remediation of dye-containing wastewater. Water Research, v. 47, n. 19, p. 7143-8, Dec 2013. ISSN 1879-2448. Disponível em: <http://www.ncbi.nlm.nih.gov/pubmed/24210510>. Acesso em: 15 out. 2016.

MARTINEZ, M. J. et al. Purification and catalytic properties of two manganese peroxidase isoenzymes from Pleurotus eryngii. European Journal of Biochemistry, v. 237, n. 2, p. 424-432, 1996. ISSN 0014-2956. 
MATHEUS, D. R.; BONONI, V. L. R. C/N Ratio and vegetable oil to mineralize 14Chexachlorobenzene by white-rot-fungi. In: Gavaskar, A. R., Chen, A. S. C. (eds.). Remediation of Chlorinated and Recalcitrant Compounds. Monterey, CA, Paper 2B10. 2002.

MAZMANCI, M. A.; UNYAYAR, A. Decolourisation of Reactive Black 5 by Funalia trogii immobilised on Luffa cylindrica sponge. Process Biochemistry, v. 40, n. 1, p. 337342, 2005. ISSN 1359-5113.

MELO, J. P. Avaliação da degradação de corantes têxteis reativos da indústria têxtil por quelantes de ferro produzidos por fungos basidiomicetos. 2009. $134 \mathrm{f}$. Trabalho de Conclusão de Curso (Ciências Biológicas).Universidade Santo Amaro, São Paulo, 2009.

MESTER, T.; FIELD, J. A. Optimization of manganese peroxidase production by the white rot fungus Bjerkandera sp. strain BOS55. FEMS Microbiology Letters, v. 155, n. 2, p. 161-168, 1997. ISSN 0378-1097.

METAPRINT2D. Metabolic site predictor. Sam Adams, Centre for Molecular Science Informatics, University of Camridge. Disponível em <http://wwwmetaprint2d.ch.cam.ac.uk/metaprint2d-react/about.html>. Acesso em 15 out. 2016.

MIELGO, I. et al. Oxidative Degradation of Azo Dyes by Manganese Peroxidase under Optimized Conditions. Biotechnology Progress, USA, v. 19, n. 2, p. 325-331, 2003. ISSN 8756-7938.

MILAGRES, A. M. F.; MACHUCA, A.; NAPOLEÃO, D. Detection of siderophore production from several fungi and bacteria by a modification of chrome azurol S (CAS) agar plate assay. Journal of Microbiological Methods, v. 37, n. 1, p. 1-6, 1999. ISSN 0167-7012.

MINITAB. Windows User. Versão 17.3.1. Minitab Inc. 2016.

MOLDES, D.; FERNÁNDEZ-FERNÁNDEZ, M.; SANROMÁN, M. Á. Role of laccase and low molecular weight metabolites from Trametes versicolor in dye decolorization. The Scientific World Journal, v. 2012, 2012.

MOLDES, D.; LORENZO, M.; SANROMÁN, M. Different proportions of laccase isoenzymes produced by submerged cultures of Trametes versicolor grown on lignocellulosic wastes. Biotechnology Letters, Dordrecht, v. 26, n. 4, p. 327-330, 2004. ISSN 0141-5492.

MOLDES, D.; SANROMAN, M. A. Amelioration of the ability to decolorize dyes by laccase: relationship between redox mediators and laccase isoenzymes in Trametes versicolor. World Journal of Microbiology and Biotechnology, v. 22, n. 11, p. 11971204, 2006. ISSN 0959-3993.

MOREIRA, F. C. et al. Decolorization and mineralization of Sunset Yellow FCF azo dye by anodic oxidation, electro-Fenton, UVA photoelectro-Fenton and solar photoelectro- 
Fenton processes. Applied Catalysis B: Environmental, v. 142, p. 877-890, 2013. ISSN 0926-3373.

MOREIRA, M. T. et al. Evaluation of different fungal strains in the decolourisation of synthetic dyes. Biotechnology Letters, New York, v. 22, n. 18, p. 1499-1503, 2000. ISSN 0141-5492.

MOREIRA NETO, S. L. et al. Decolorization of salt-alkaline effluent with industrial reactive dyes by laccase-producing basidiomycetes strains. Letters in Applied Microbiology, v. 56, n. 4, p. 283-290, 2013. ISSN 0266-8254.

MOREIRA NETO, S. L. et al. Novel salt and alkali tolerant neotropical basidiomycetes for dye decolorisation in simulated textile effluent. World Journal of Microbiology and Biotechnology, v. 27, n. 11, p. 2665-2673, 2011. ISSN 0959-3993.

MOREIRA NETO, S. L.; MILAGRES, A. M. F.; MUSSATTO, S. Reactive dyes and textile effluent decolorization by a mediator system of salt-tolerant laccase from Peniophora cinerea. Separation and Purification Technology, v. 135, p. 183-189, 2014. ISSN 1383-5866.

MOTA, T. et al. Decolourization of Congo Red by Ganoderma lucidum Laccase: Evaluation of Degradation Products and Toxicity. Water Air Soil Pollution, Cham, v. 226, n. 10, p. 1-11, 2015. ISSN 0049-6979.

MUKHERJEE, S. et al. Potential use of polyphenol oxidases (PPO) in the bioremediation of phenolic contaminants containing industrial wastewater. Reviews in Environmental Science and Bio/Technology, 12: 61-73 p. 2013.

NABIL, G. M.; EL-MALLAH, N. M.; MAHMOUD, M. E. Enhanced decolorization of reactive black 5 dye by active carbon sorbent-immobilized-cationic surfactant (AC-CS). Journal of Industrial and Engineering Chemistry, 2013. ISSN 1226086X.

NIDHEESH, P.; GANDHIMATHI, R.; RAMESH, S. Degradation of dyes from aqueous solution by Fenton processes: a review. Environmental Science and Pollution Research, Berlin/Heidelberg, v. 20, n. 4, p. 2099-2132, 2013. ISSN 0944-1344.

NOUSIAINEN, P. et al. Phenolic mediators enhance the manganese peroxidase catalyzed oxidation of recalcitrant lignin model compounds and synthetic lignin. Fungal Genetics and Biology, v. 72, p. 137-149, 2014. ISSN 1087-1845.

NOVOTNÝ, Č. et al. Biodegradation of synthetic dyes by Irpex lacteus under various growth conditions. International Biodeterioration and Biodegradation, p.215-223. 2004

OLIVEIRA, L. H. S. et al. Descoloração de corantes sintéticos por basidiomicetos tropicais brasileiros. Naturalia, p.85-99. 2010

OSMA, J. F.; TOCA-HERRERA, J. L.; RODRIGUEZ-COUTO, S. Transformation pathway of Remazol Brilliant Blue R by immobilised laccase. Bioresource Technology, v. 101, n. 22, p. 8509-8514, 2010. ISSN 0960-8524. 
PAJOOTAN, E.; ARAMI, M.; RAHIMDOKHT, M. Discoloration of wastewater in a continuous electro- Fenton process using modified graphite electrode with multi-walled carbon nanotubes/surfactant. Separation and Purification Technology, v. 130, p. 34, 2014. ISSN 1383-5866.

PAKSHIRAJAN, K.; KHERIA, S. Continuous treatment of coloured industry wastewater using immobilized Phanerochaete chrysosporium in a rotating biological contactor reactor. Journal of Environmental Management, 101: 118-123 p. 2012.

PALMIERI, G. et al. Copper induction of laccase isoenzymes in the ligninolytic fungus Pleurotus ostreatus. Applied and Environmental Microbiology, v. 66, n. 3, p. 920-924, 2000. ISSN

0099-2240.

PAPADOPOULOU, $K$. et al. Optimization of fungal decolorization of azo and anthraquinone dyes via Box-Behnken design. International Biodeterioration and Biodegradation, v. 77, p. 31-38, 2013. ISSN 0964-8305.

PARANHOS, A. P. S. Avaliação da produção de quelantes de ferro por fungos basidiomicetos e degradação de corantes da indústria têxtil. 2007.122 f. Trabalho de Conclusão de Curso (Ciências Biológicas).Universidade Santo Amaro, São Paulo, 2007.

PARANHOS, A. P. S. Estudo dos compostos de baixa massa molar, redutores de ferro, produzidos por basidiomicetos com potencialidade em descolorir corantes da indústria têxtil. 2011. 141 f. Dissertação (Mestado em Botânica). Instituto de Botânica da Secretaria do Estado de Meio Ambiente, São Paulo, 2011.

PEREIRA, L.; ALVES, M. Dyes - Environmental impact and remediation. In: Malik, A.; Grohmann, E. (Ed.). Environmental Protection Strategies for Sustainable Development. Springer, Netherlands, 2012. cap. 4, p.111-162. ISBN 978-94-007-15912. DOI: dx.doi.org/10.1007/978-94-007-1591-2.

PLÁCIDO, J. et al. Degradation and detoxification of synthetic dyes and textile industry effluents by newly isolated Leptosphaerulina sp. from Colombia. Bioresources and Bioprocessing, Berlin/Heidelberg, v. 3, n. 1, p. 1-14, 2016.

POLAK, J.; JAROSZ-WILKOLAZKA, A. Fungal laccases as green catalysts for dye synthesis. Process Biochemistry, v. 47, n. 9, p. 1295-1307, 2012. ISSN 1359-5113.

PRATHEEBAA, P.; PERIASAMY, R.; PALVANNAN, T. Factorial design for optimization of laccase production from Pleurotus ostreatus IMI 395545 and laccase mediated synthetic dye decolorization. Indian Journal of Biotechnology, v. 12, n. 2, p. 236-245, 2013. ISSN 0972-5849.

RODRIGUES, M. I.; IEMMA, A. F. Planejamento de experimentos e otimização de processos. 3. ed. Campinas: Cárita, 2014. 336 p. 
RODRIGUEZ, E. et al. Degradation of phenolic and non- phenolic aromatic pollutants by four Pleurotus species: the role of laccase and versatile peroxidase. Soil Biology and Biochemistry, v. 36, n. 6, p. 909-916, 2004. ISSN 0038-0717.

RODRIGUEZ, E.; PICKARD, M. A.; VAZQUEZ-DUHALT, R. Industrial dye decolorization by laccases from ligninolytic fungi. Current Microbiology, v. 38, n. 1, p. 27-32, 1999. ISSN 0343-8651.

RODRÍGUEZ COUTO, S.; SANROMÁN, M.; GÜBITZ, G. M. Influence of redox mediators and metal ions on synthetic acid dye decolourization by crude laccase from Trametes hirsuta. Chemosphere, v. 58, n. 4, p. 417-422, 2005. ISSN 00456535.

SAAB, H. B. et al. Luffa cylindrica and phytosterols bioconversion: from shake flask to jar bioreactor. Journal of Industrial Microbiology and Biotechnology, 40: 1315-1320 p. 2013.

SABA, B. et al. Reactive black- 5 azo dye treatment in suspended and attach growth sequencing batch bioreactor using different co-substrates. International Biodeterioration and Biodegradation, v. 85, p. 556-562, 2013. ISSN 0964-8305.

SALAME, T. M. et al. Redundancy among manganese peroxidases in Pleurotus ostreatus. Applied and Environmental Microbiology, v. 79, n. 7, p. 2405, 2013.

SANTOS, G. D. O. F. D. Avaliação do tratamento de efluentes do banho de tingimento de indústria têxtil por fungos basidiomicetos em biorreatores. 2016. 174 f. Tese (Doutorado em Biotecnologia). Instituto de Ciências Biomédicas, Universidade de São Paulo, São Paulo, 2016.

SARATALE, G. D. et al. Fixed- bed decolorization of Reactive Blue 172 by Proteus vulgaris NCIM- 2027 immobilized on Luffa cylindrica sponge. International Biodeterioration and Biodegradation, v. 65, n. 3, p. 494-503, 2011. ISSN 0964-8305.

SARAYU, K.; SANDHYA, S. Current technologies for biological treatment of textile wastewater - a review. Applied Biochemistry and Biotechnology, New York, v. 167, n. 3, p. 645-661, 2012. ISSN 0273-2289.

SCHWYN, B.; NEILANDS, J. B. Universal chemical assay for the detection and determination of siderophores. Analytical Biochemistry, v. 160, n. 1, p. 47-56, 1987. ISSN 0003-2697.

SENTHILKUMAR, S. et al. Electrochemical oxidation and aerobic biodegradation with isolated bacterial strains for dye wastewater: Combined and integrated approach. Electrochimica Acta, v. 77, p. 171-178, 2012. ISSN 0013-4686.

SHAHID, A. et al. Biodegradation of textile dyes by fungi isolated from North Indian field soil. Environment Asia, v. 6, n. 2, p. 51-57, 2013. ISSN 1906-1714.

SHANKAR, S.; SHIKHA, S. Laccase Production and Enzymatic Modification of Lignin by a Novel Peniophora sp. Applied Biochemistry and Biotechnology, v. 166, n. 4, p. 1082-1094, 2012. ISSN 0273-2289. 
Effect of Metal Ions and Redox Mediators on Decolorization of Synthetic Dyes by Crude Laccase from a Novel White rot Fungus Peniophora sp. (NFCCI-2131). Applied Biochemistry and Biotechnology, Boston, v. 175, n. 1, p. 635-647, 2015. ISSN 0273-2289. Errata em: Applied Biochemistry and Biotechnology, Boston, v. 175, n. 1, p. 648, 2015.

SI, J.; CUI, B.; DAI, Y. Decolorization of chemically different dyes by white- rot fungi in submerged cultures. Annals of Microbiology, v. 63, n. 3, p. 1099-1108, 2013. ISSN 1590-4261.

SIDDIQUE, M.; FAROOQ, R.; PRICE, G. J. Synergistic effects of combining ultrasound with the Fenton process in the degradation of Reactive Blue 19. Ultrasonics Sonochemistry, v. 21, n. 3, p. 1206-1212, 2013. ISSN 1350-4177.

SILVÉRIO, S. et al. Laccase production by free and immobilized mycelia of Peniophora cinerea and Trametes versicolor : a comparative study. Bioprocess and Biosystems Engineering, Berlin/Heidelberg, v. 36, n. 3, p. 365-373, 2013. ISSN 1615-7591.

SINGH, R. L.; SINGH, P. K.; SINGH, R. P. Enzymatic decolorization and degradation of azo dyes - a review. International Biodeterioration and Biodegradation, v. 104, p. 21-31, 2015. ISSN 0964-8305.

SREBOTNIK, E.; BOISSON, J.-N. Peroxidation of linoleic acid during the oxidation of phenols by fungal laccase. Enzyme and Microbial Technology, v. 36, n. 5, p. 785-789, 2005. ISSN 0141-0229.

STOOKEY, L. L. Ferrozine - A new spectrophotometric reagent for iron. Analytical Chemistry, v. 42, n. 7, p. 779-781, 1970. ISSN 00032700.

SUNDARAMOORTHY, M. et al. High-resolution crystal structure of manganese peroxidase: substrate and inhibitor complexes. Biochemistry, v. 44, n. 17, p. 6463, 2005. ISSN 0006-2960.

SVOBODOVA, K. et al. Implication of mycelium- associated laccase from Irpex lacteus in the decolorization of synthetic dyes. Bioresource Technology, v. 99, n. 3, p. 463-471, 2008. ISSN 0960-8524.

TAVARES, A. et al. Optimisation of reactive textile dyes degradation by laccasemediator system. Journal of Chemical Technology and Biotechnology, v. 83, n. 12, p. 1609-1615, 2008. ISSN 0268-2575.

TEN HAVE, R.; TEUNISSEN, P. J. M. Oxidative mechanisms involved in lignin degradation by white- rot fungi. Chemical Reviews, v. 101, n. 11, p. 3397-3413, 2001. ISSN 00092665.

THOMAS, S. et al. Oxidative degradation of Acid Red 1 in aqueous medium. Chemical Engineering Journal, v. 244, p. 473-482, 2014. ISSN 1385-8947. 
TINOCO, R. et al. Increasing Pleurotus ostreatus laccase production by culture medium optimization and copper/lignin synergistic induction. Journal of Industrial Microbiology and Biotechnology, v. 38, n. 4, p. 531-540, 2011. ISSN 1367-5435.

VANHULLE, S. et al. Decolorization, cytotoxicity, and genotoxicity reduction during a combined ozonation/fungal treatment of dye-contaminated wastewater. Environmental Science and Technology, v. 42, n. 2, p. 584, 2008. ISSN 0013-936X.

WANG, C.-T. et al. COD removal from real dyeing wastewater by electro-Fenton technology using an activated carbon fiber cathode. Desalination, v. 253, n. 1, p. 129134, 2010. ISSN 0011-9164.

WATANABE, T. et al. Formation of acyl radical in lipid peroxidation of linoleic acid by manganese dependent peroxidase from Ceriporiopsis subvermispora and Bjerkandera adusta. European Journal of Biochemistry, v. 267, n. 13, p. 4222-4231, 2000. ISSN 00142956.

WATHARKAR, A. D. et al. Enhanced phytotransformation of Navy Blue RX dye by Petunia grandiflora Juss. with augmentation of rhizospheric Bacillus pumilus strain PgJ and subsequent toxicity analysis. Bioresource Technology, v. 142, p. 246-254, 2013. ISSN 0960-8524.

WENG, C. H. et al. Rapid decoloration of Reactive Black 5 by an advanced Fenton process in conjunction with ultrasound. Separation and Purification Technology, v. 117, p. 75, 2013. ISSN 1383-5866.

WONG, D. W. S. Structure and action mechanism of ligninolytic enzymes. Applied Biochemistry and Biotechnology, 157: 174-209 p. 2009.

WONG, Y.; YU, J. Laccase-catalyzed decolorization of synthetic dyes. Water Research, v. 33, n. 16, p. 3512-3520, 1999. ISSN 0043-1354.

ZAHARIA, C.; SUTEU, D. Textile organic dyes - characteristics, polluting effects and separation/elimination procedures from industrial effluents - a critical overview. In: PUZYN, T. e MOSTRAG-SZLICHTYNG, A. (Ed.). Organic pollutants ten years after the stockholm convention - environmental and analytical update: In Tech, 2012. Disponível em: <http://www.intechopen.com/books/organic-pollutants-ten-years-afterthe-stockholm-convention-environmental-and-analytical-update/textile-organic-dyescharacteristics-polluting-effects-and-separation-elimination-procedures-from-in>. Acesso em: 15 out. 2016.

ZERAIK, A. E. et al. Development of a spot test for peroxidase activity monitoring during a purification procedure. Química Nova, v. 31, n. 4, p. 731-734, 2008. ISSN 0100-4042.

ZHAO, X.; HARDIN, I. R. HPLC and spectrophotometric analysis of biodegradation of azo dyes by Pleurotus ostreatus. Dyes and Pigments, v. 73, n. 3, p. 322-325, 2007. ISSN 0143-7208. 
ZHAO, X. et al. Study of biodegradation products from azo dyes in fungal degradation by capillary electrophoresis/electrospray mass spectrometry. Journal of Chromatography A, v. 1159, n. 1-2, p. 217-224, 2007. ISSN 00219673.

ZHAO, X. H.; HARDIN, I. R.; HWANG, H. M. Biodegradation of a model azo disperse dye by the white rot fungus Pleurotus ostreatus. International Biodeterioration and Biodegradation, v. 57, n. 1, p. 1-6, 2006. ISSN 0964-8305.

ZILLE, A. et al. Immobilized laccase for decolourization of Reactive Black 5 dyeing effluent. Biotechnology Letters, New York, v. 25, n. 17, p. 1473-1477, 2003. ISSN 0141-5492.

ZILLE, A. et al. Degradation of azo dyes by Trametes villosa laccase over long periods of oxidative conditions. Applied and Environmental Microbiology, v. 71, n. 11, p. 6711, 2005. ISSN 0099-2240

ZOLLINGER, H. Colour chemistry: syntheses, propeties and applications of oganic dyes and pigments. 3. ed. Switzeland: Wiley-VHC. 2003. 637p. 


\section{APÊNDICES}




\section{APÊNDICE A - Análise estatística item 4.1}
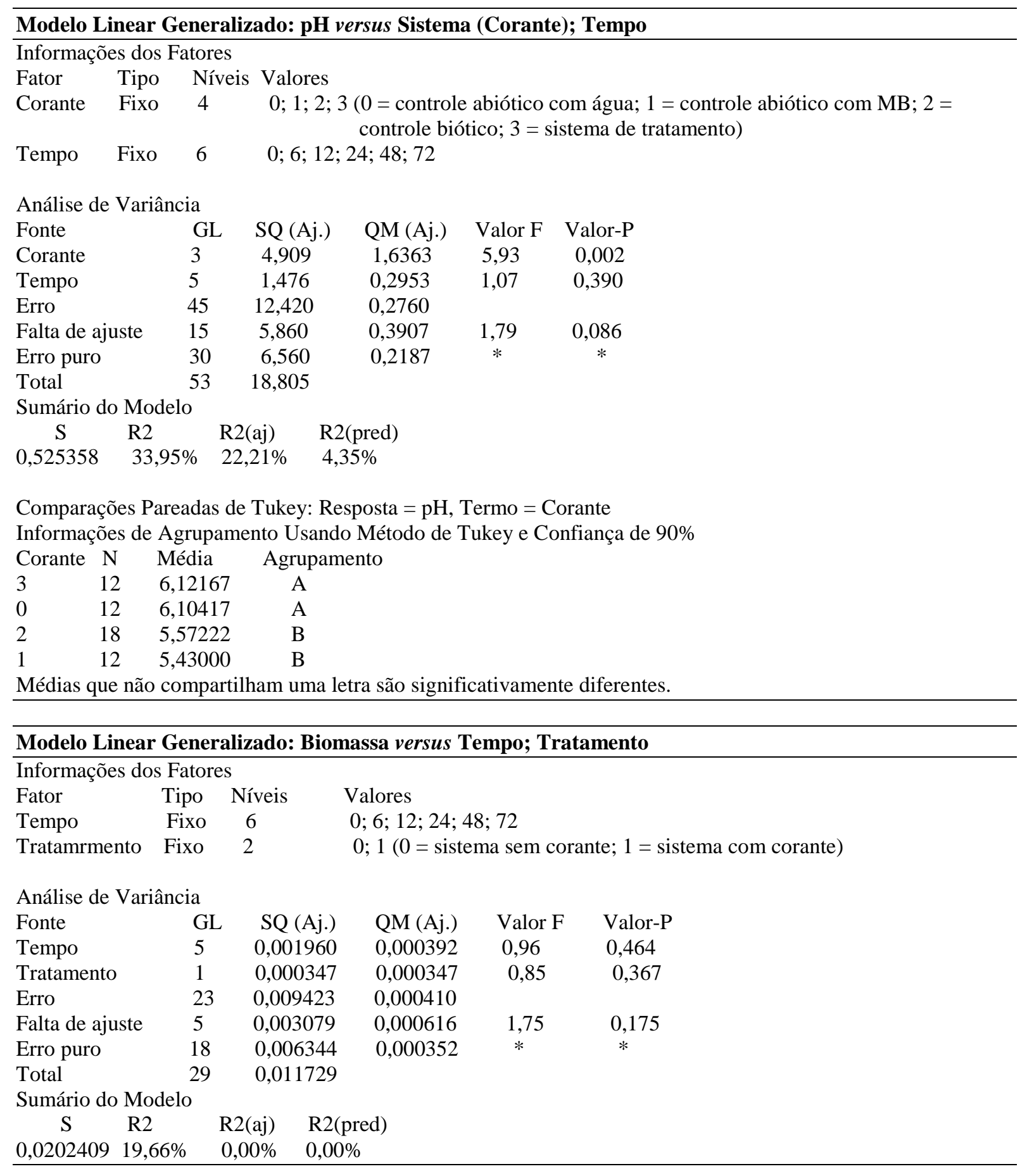

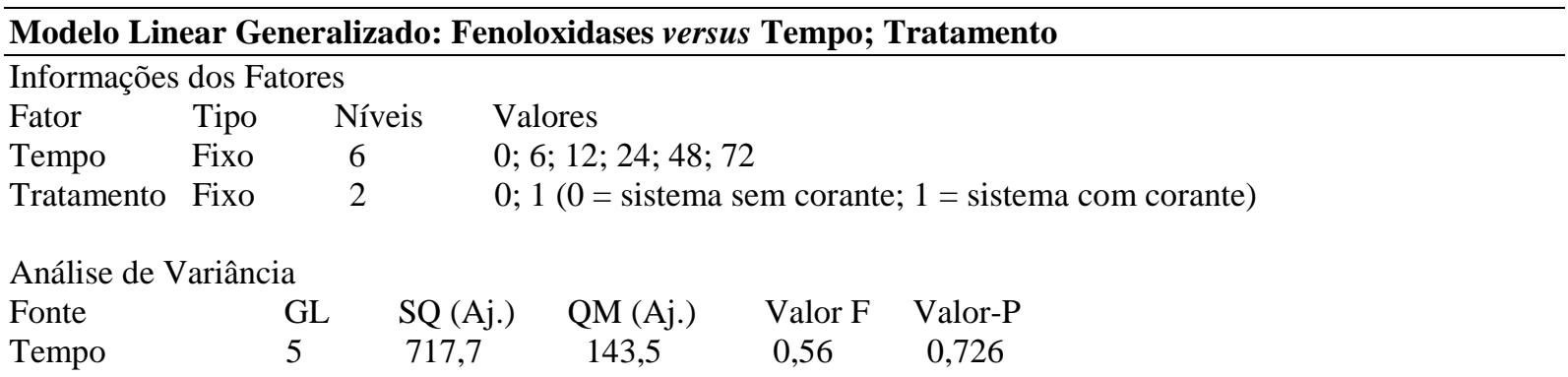




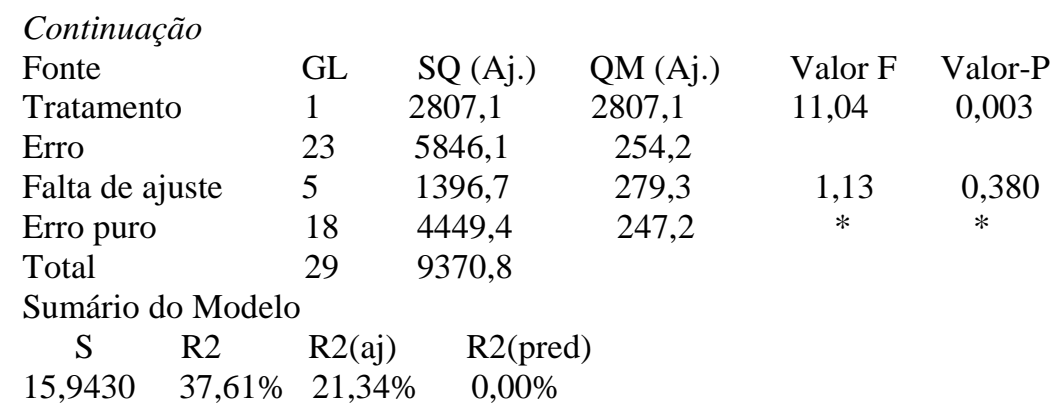

Comparações Pareadas de Tukey: Resposta $=$ Fenoloxidases, Termo $=$ Tratamento Informações de Agrupamento Usando Método de Tukey e Confiança de 90\%

Tratamento N Média Agrupamento

$\begin{array}{llll}0 & 12 & 33,2948 \quad \text { A }\end{array}$

$\begin{array}{llll}1 & 18 & 13,5497 & \text { B }\end{array}$

Médias que não compartilham uma letra são significativamente diferentes.

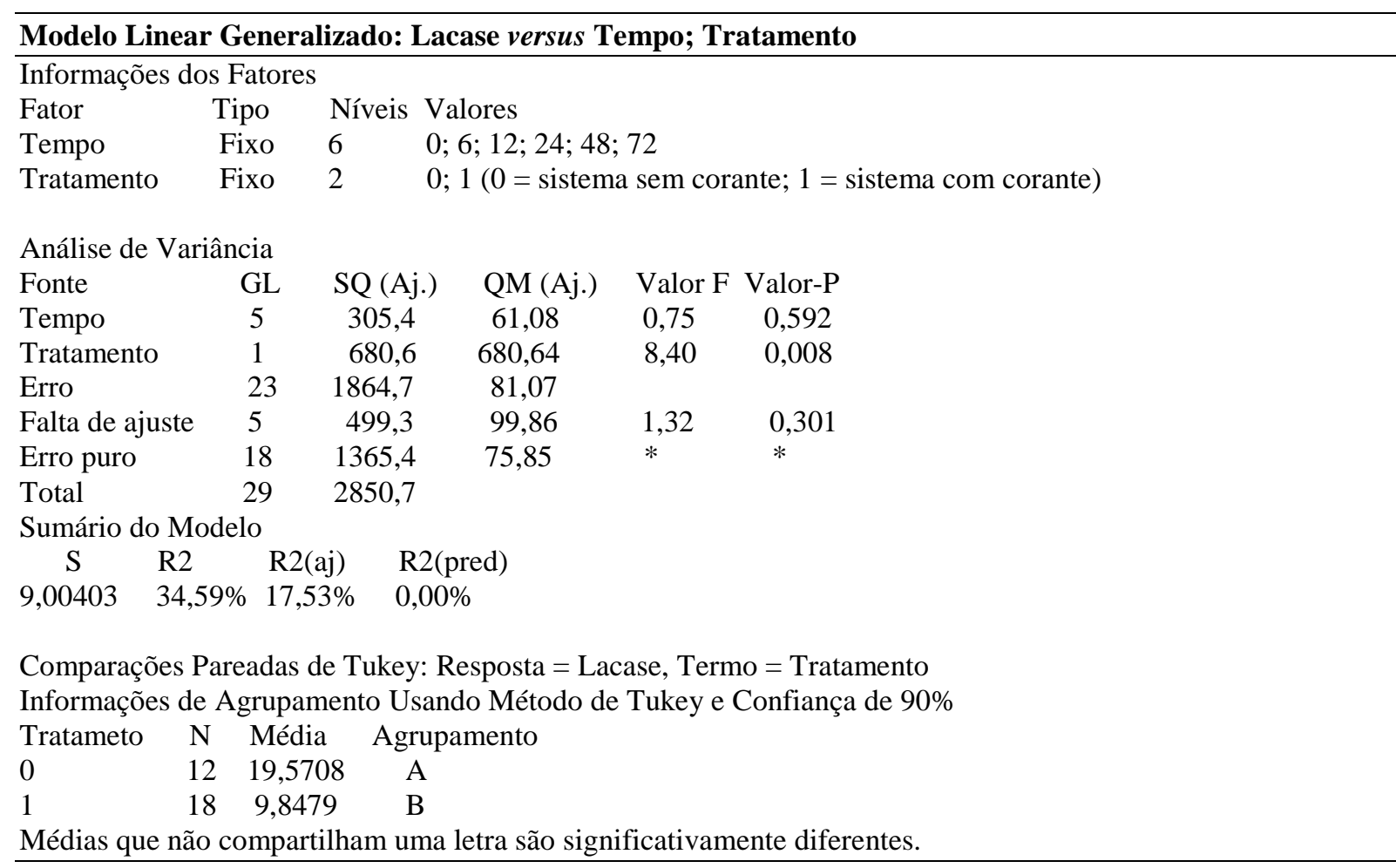

\begin{tabular}{|c|c|c|c|c|c|}
\hline \multicolumn{6}{|c|}{ Modelo Linear Generalizado: Peroxidases Totais versus Tempo; Tratamento } \\
\hline \multicolumn{6}{|c|}{ Informações dos Fatores } \\
\hline Fator & Tipo & \multicolumn{4}{|c|}{ Níveis Valores } \\
\hline Tempo & Fixo & 6 & \multicolumn{3}{|c|}{$0 ; 6 ; 12 ; 24 ; 48 ; 72$} \\
\hline Tratamento & Fixo & 2 & \multicolumn{3}{|c|}{$0 ; 1(0=$ sistema sem corante $1=$ sistema com corante $)$} \\
\hline \multicolumn{6}{|c|}{ Análise de Variância } \\
\hline Fonte & GL & SQ (Aj.) & QM (Aj.) & Valor F & Valor-P \\
\hline Tempo & 5 & 157,9 & 31,59 & 0,52 & 0,762 \\
\hline Tratamento & 1 & 644,8 & 644,78 & 10,53 & 0,004 \\
\hline Erro & 23 & 1408,9 & 61,26 & & \\
\hline Falta de ajuste & 5 & 388,5 & 77,69 & 1,37 & 0,281 \\
\hline Erro puro & 18 & 1020,4 & 56,69 & $*$ & $*$ \\
\hline Total & 29 & 2211,6 & & & \\
\hline
\end{tabular}


Continuação

Sumário do Modelo

$\begin{array}{clll}\text { S } & \text { R2 } & \text { R2(aj) } & \text { R2(pred) } \\ 7,82662 & 36,30 \% & 19,68 \% & 0,00 \%\end{array}$

Comparações Pareadas de Tukey: Resposta $=$ Peroxidases, Termo $=$ Tratamento

Informações de Agrupamento Usando Método de Tukey e Confiança de 90\%

Tratamento N Média Agrupamento

$\begin{array}{llll}0 & 12 & 13,7241 & \text { A } \\ 1 & 18 & 4,2608 & B\end{array}$

Médias que não compartilham uma letra são significativamente diferentes.

\begin{tabular}{|c|c|c|c|c|c|}
\hline Modelo Lir & ear Gene & alizado: A & ATD versus T & & \\
\hline Informaçõe & dos Fator & & & & \\
\hline Fator & Tipo & Níveis V & Valores & & \\
\hline Tempo & Fixo & $\begin{array}{ll}6 & 0\end{array}$ & $0 ; 6 ; 12 ; 24 ; 4$ & & \\
\hline Análise de & ariância & & & & \\
\hline Fonte & GL & SQ (Aj.) & QM (Aj.) & Valor F & Valor-P \\
\hline Tempo & 5 & 0,000080 & 0,000016 & 2,19 & 0,124 \\
\hline Erro & 12 & 0,000087 & 0,000007 & & \\
\hline Total & 17 & 0,000167 & & & \\
\hline Sumário do & Modelo & & & & \\
\hline S & R2 & R2(aj) & R2(pred) & & \\
\hline 0,0026969 & $47,70 \%$ & $25,91 \%$ & $0,00 \%$ & & \\
\hline
\end{tabular}

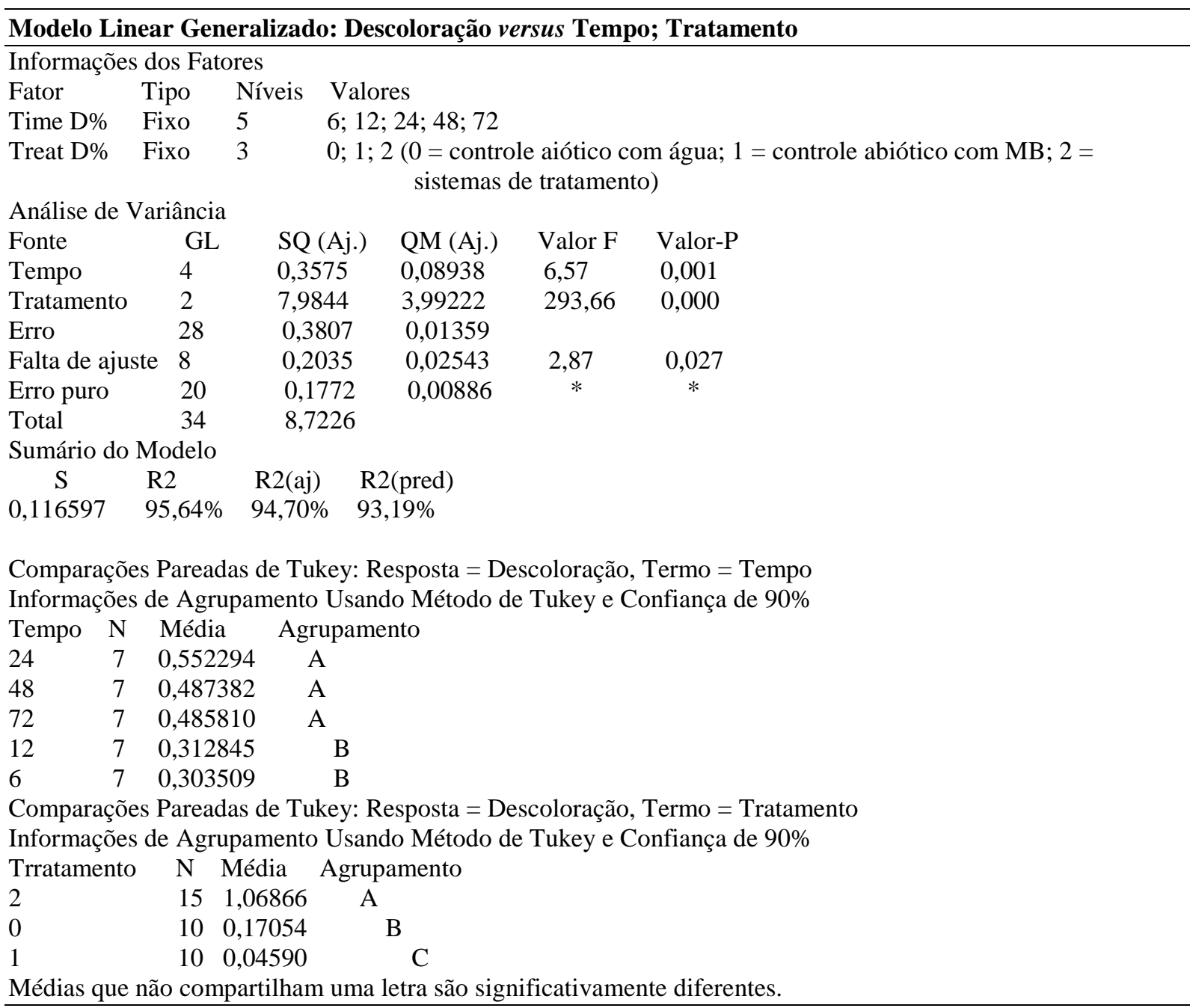




\section{APÊNDICE B - Análise estatística item 4.2}

\section{Modelo Linear Generalizado: Biomassa Pleurotus ostreatus versus Tempo}

Informações dos Fatores

$\begin{array}{llcl}\text { Fator } & \text { Tipo } & \text { Níveis } & \text { Valores } \\ \text { Tempo } & \text { Fixo } & 7 & 0 ; 3 ; 7 ; 10 ; 14 ; 21 ; 30\end{array}$

Análise de Variância

$\begin{array}{lccccc}\text { Fonte } & \text { GL } & \text { SQ (Aj.) } & \text { QM (Aj.) } & \text { Valor F } & \text { Valor-P } \\ \text { Tempo } & 6 & 520,3 & 86,71 & 4,85 & 0,007 \\ \text { Erro } & 14 & 250,1 & 17,86 & & \\ \text { Total } & 20 & 770,3 & & & \end{array}$

Sumário do Modelo

$\begin{array}{clll}\text { S } & \text { R2 } & \text { R2(aj) } & \text { R2(pred) } \\ 4,22628 & 67,54 \% & 53,63 \% & 26,96 \%\end{array}$

Comparações Pareadas de Tukey

Informações de Agrupamento Usando Método de Tukey e Confiança de 90\%

Tempo N Média Agrupamento

$\begin{array}{llll}21 & 3 & 23,4460 & \text { A } \\ 30 & 3 & 21,4113 & \text { A } \\ 14 & 3 & 14,6253 & \text { A B } \\ 7 & 3 & 14,0267 & \text { A B } \\ 10 & 3 & 14,0253 & \text { A B } \\ 0 & 3 & 10,6593 & \text { B } \\ 3 & 3 & 8,6300 & \text { B }\end{array}$

Médias que não compartilham uma letra são significativamente diferentes.

\section{Modelo Linear Generalizado: Biomassa Peniophora cinerea versus Tempo}

\begin{tabular}{|c|c|c|c|c|c|c|}
\hline \multicolumn{7}{|c|}{ Informações dos Fatores } \\
\hline Fator & Tipo & Níveis & \multicolumn{4}{|c|}{ Valores } \\
\hline Tempo & Fixo & 7 & \multicolumn{4}{|c|}{$0 ; 3 ; 7 ; 10 ; 14 ; 21 ; 30$} \\
\hline \multicolumn{7}{|c|}{ Análise de Variância } \\
\hline Fonte & GL & SQ & (Aj.) & QM (Aj.) & Valor F & Valor-P \\
\hline Tempo & 6 & 937 & & 156,26 & 3,31 & 0,030 \\
\hline Erro & 14 & 660 & & 47,17 & & \\
\hline Total & 20 & 159 & & & & \\
\hline
\end{tabular}

Sumário do Modelo

$\begin{array}{clll}\mathrm{S} & \mathrm{R} 2 & \mathrm{R} 2(\mathrm{aj}) & \mathrm{R} 2 \text { (pred) } \\ 6,86795 & 58,67 \% & 40,96 \% & 7,02 \%\end{array}$

Comparações Pareadas de Tukey

Informações de Agrupamento Usando Método de Tukey e Confiança de 90\%

Tempo N Média Agrupamento

$\begin{array}{llll}21 & 3 & 32,3073 \quad \text { A }\end{array}$

$\begin{array}{llll}10 & 3 & 24,9120 & \text { A B }\end{array}$

$14 \quad 3 \quad 24,5560 \quad$ A B

$\begin{array}{llll}7 & 3 & 21,2953 & \text { A B }\end{array}$

$\begin{array}{llll}30 & 3 & 14,3293 & \text { B }\end{array}$

$\begin{array}{llll}3 & 3 & 13,4847 & \text { B }\end{array}$

$\begin{array}{llll}0 & 3 & 13,4733 \quad \text { B }\end{array}$

Médias que não compartilham uma letra são significativamente diferentes. 


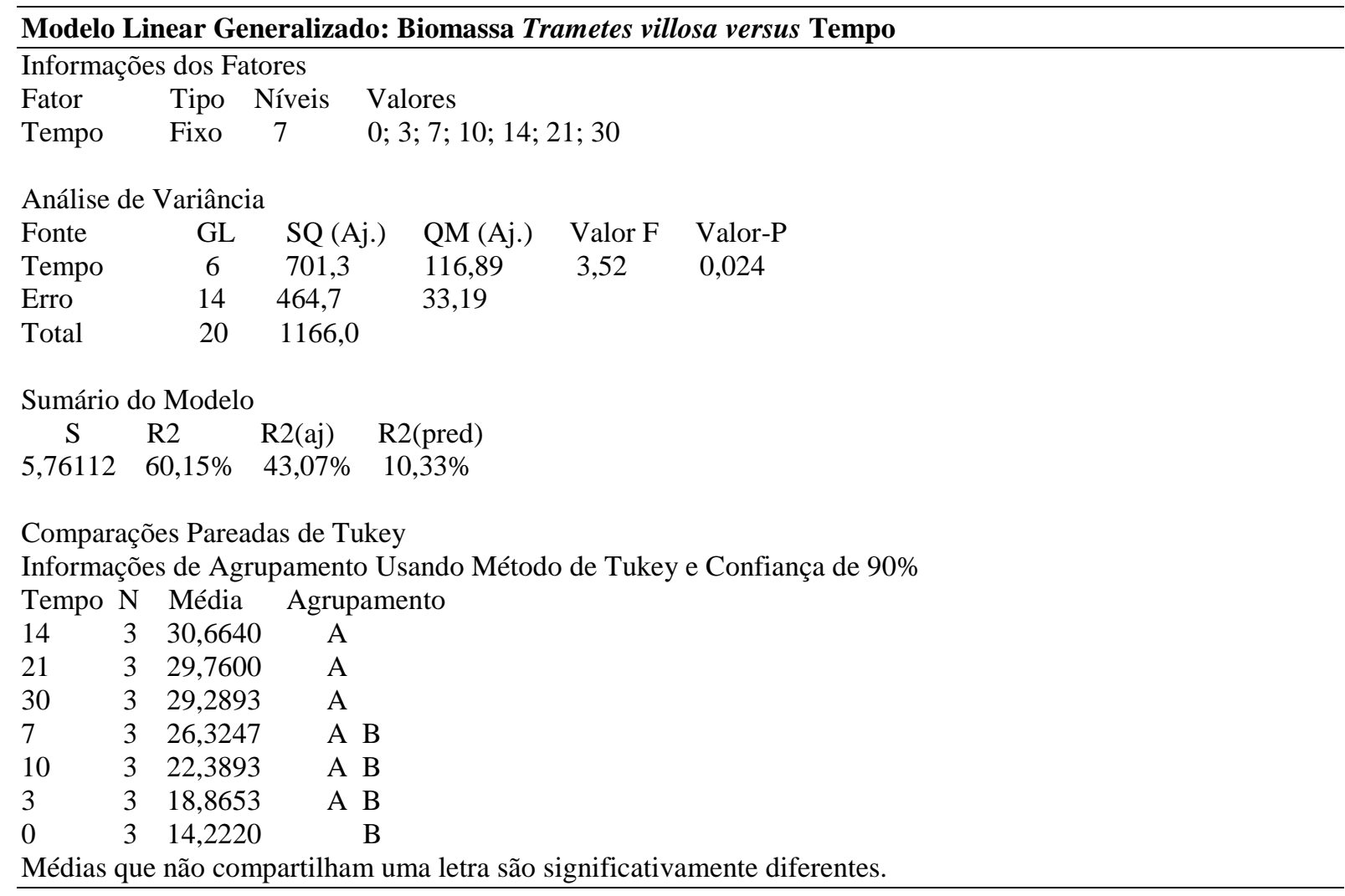

Médias que não compartilham uma letra são significativamente diferentes.

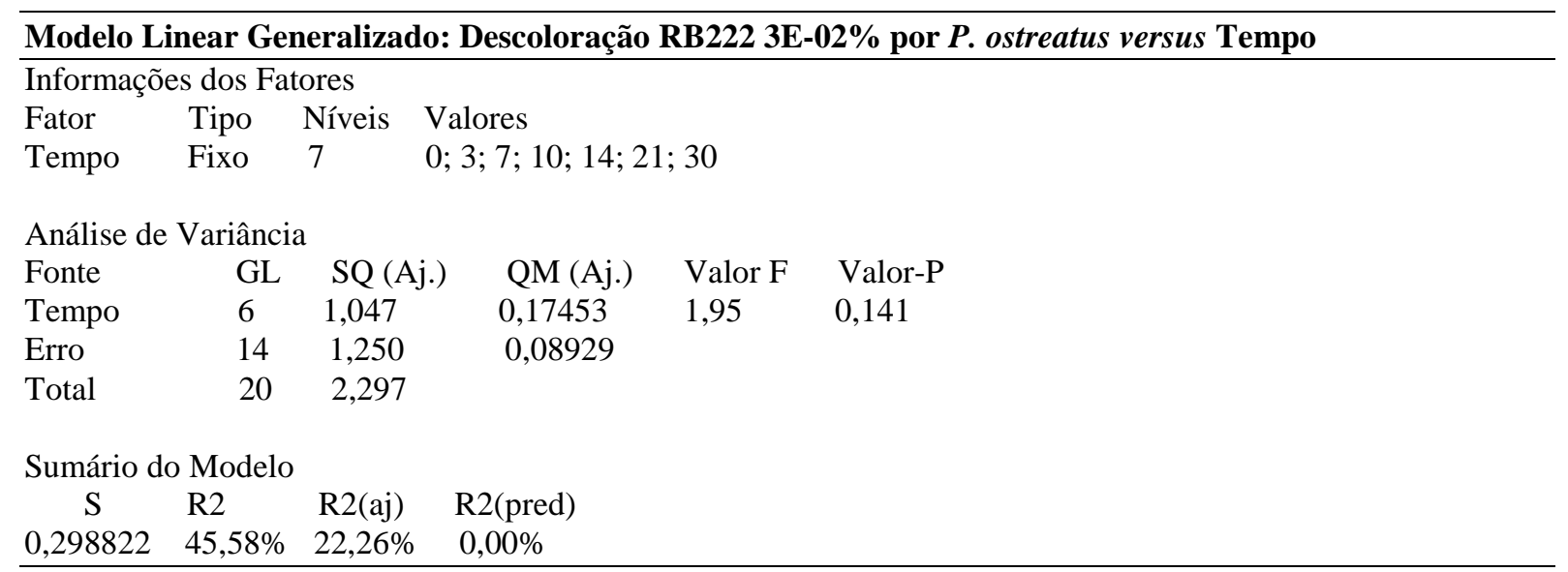

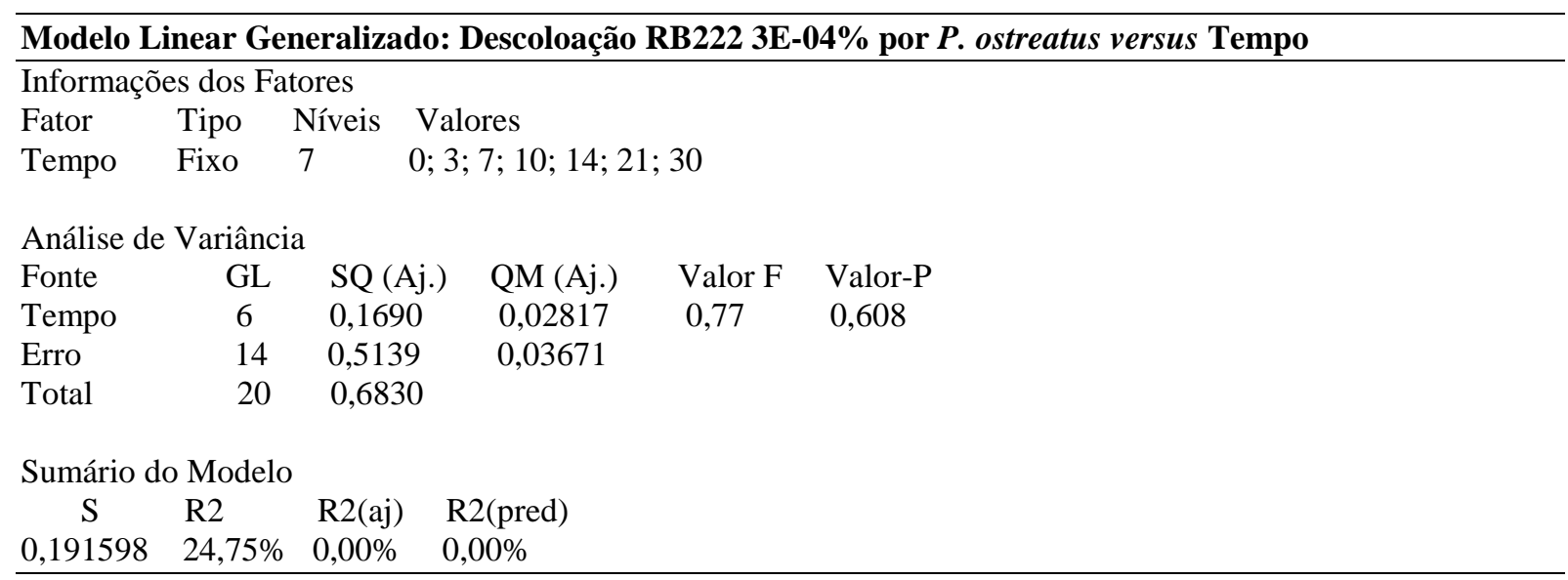




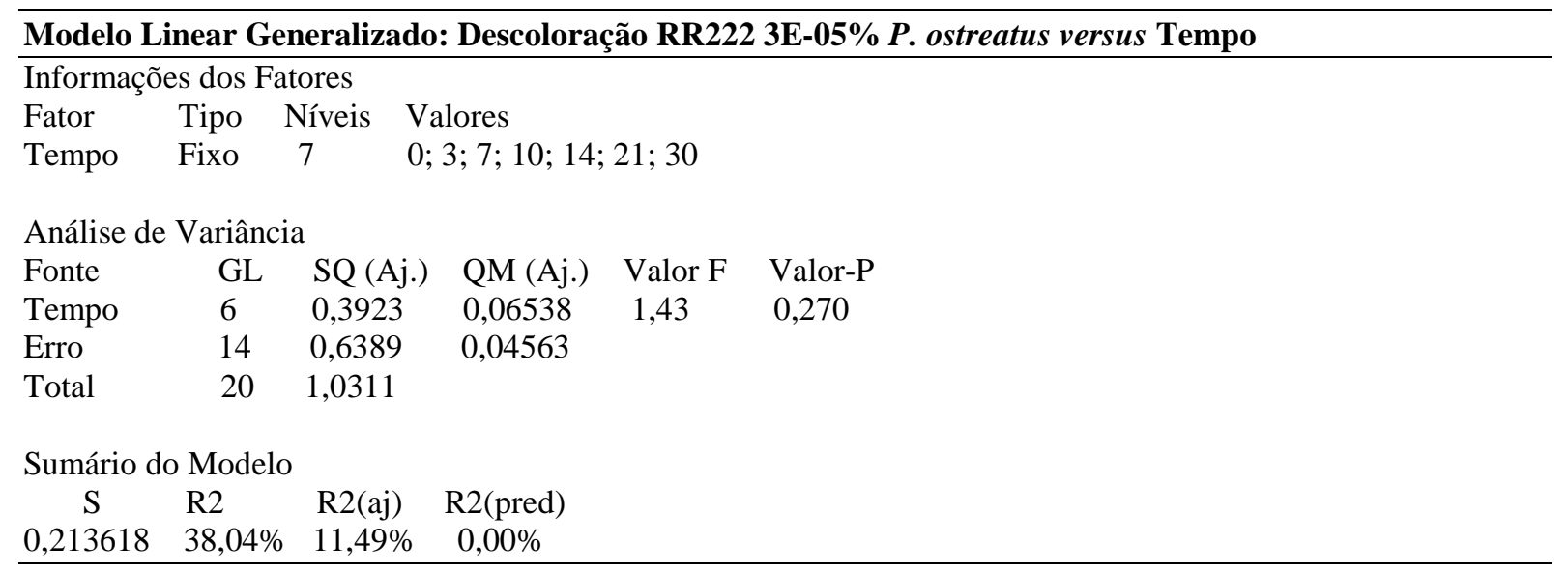

Modelo Linear Generalizado: Descoloração RB222 3E-02\% por P. cinerea versus Tempo

Informações dos Fatores

Fator Tipo Níveis Valores

Tempo Fixo $7 \quad$ 0; $3 ; 7 ; 10 ; 14 ; 21 ; 30$

Análise de Variância

$\begin{array}{lcllll}\text { Fonte } & \text { GL } & \text { SQ (Aj.) } & \text { QM (Aj.) } & \text { Valor F } & \text { Valor-P } \\ \text { Tempo } & 6 & 0,5619 & 0,09365 & 0,71 & 0,649 \\ \text { Erro } & 14 & 1,8535 & 0,13240 & & \\ \text { Total } & 20 & 2,4154 & & & \end{array}$

Sumário do Modelo

\begin{tabular}{cllll}
$\mathrm{S}$ & $\mathrm{R} 2$ & $\mathrm{R} 2(\mathrm{aj})$ & $\mathrm{R} 2(\mathrm{pred})$ \\
0,363863 & $23,26 \%$ & $0,00 \%$ & $0,00 \%$ \\
\hline
\end{tabular}

\section{Modelo Linear Generalizado: Descoloração RB222 3E-04\% por P. cinerea versus Tempo}

Informações dos Fatores

Fator Tipo Níveis Valores

Tempo Fixo $7 \quad 0 ; 3 ; 7 ; 10 ; 14 ; 21 ; 30$

Análise de Variância

$\begin{array}{lcccll}\text { Fonte } & \text { GL } & \text { SQ (Aj.) } & \text { QM (Aj.) } & \text { Valor F } & \text { Valor-P } \\ \text { Tempo } & 6 & 0,09833 & 0,01639 & 0,38 & 0,879 \\ \text { Erro } & 14 & 0,60313 & 0,04308 & & \\ \text { Total } & 20 & 0,70146 & & & \end{array}$

Sumário do Modelo

$\begin{array}{clll}\mathrm{S} & \mathrm{R} 2 & \mathrm{R} 2(\mathrm{aj}) & \mathrm{R} 2 \text { (pred) } \\ 0,207559 & 14,02 \% & 0,00 \% & 0,00 \%\end{array}$

\section{Modelo Linear Generalizado: Descoloração RR222 3E-05\% por P. cinerea versus Tempo}

Informações dos Fatores

Fator Tipo Níveis

Tempo Fixo 7

Valores

$0 ; 3 ; 7 ; 10 ; 14 ; 21 ; 30$

Análise de Variância

$\begin{array}{llllll}\text { Fonte } & \text { GL } & \text { SQ (Aj.) } & \text { QM (Aj.) } & \text { Valor F } & \text { Valor-P } \\ \text { Tempo } & 6 & 0,5689 & 0,09481 & 9,19 & 0,000 \\ \text { Erro } & 14 & 0,1445 & 0,01032 & & \\ \text { Total } & 20 & 0,7134 & & & \end{array}$

Sumário do Modelo

$\begin{array}{clll}\text { S } & \text { R2 } & \text { R2(aj) } & \text { R2(pred) } \\ 0,101588 & 79,75 \% & 71,07 \% & 54,43 \%\end{array}$


Continuação

Comparações Pareadas de Tukey

Informações de Agrupamento Usando Método de Tukey e Confiança de 90\%

Tempo N Média Agrupamento

$\begin{array}{llll}30 & 3 & 0,520221 & \text { A }\end{array}$

$\begin{array}{llll}0 & 3 & 0,362254 & \text { A B }\end{array}$

$\begin{array}{llll}14 & 3 & 0,217677 & \text { B C }\end{array}$

$\begin{array}{llll}10 & 3 & 0,204743 & \text { B C }\end{array}$

$\begin{array}{llll}3 & 3 & 0,194772 & \text { B C }\end{array}$

$\begin{array}{llll}21 & 3 & 0,046830 & \mathrm{C}\end{array}$

$\begin{array}{llll}7 & 3 & 0,000000 & \mathrm{C}\end{array}$

Médias que não compartilham uma letra são significativamente diferentes.

Modelo Linear Generalizado: Descoloração RB222 3E-02\% por T. villosa versus Tempo

Informações dos Fatores

Fator Tipo Níveis Valores

Tempo Fixo $7 \quad 0 ; 3 ; 7 ; 10 ; 14 ; 21 ; 30$

Análise de Variância

$\begin{array}{llllll}\text { Fonte } & \text { GL } & \text { SQ (Aj.) } & \text { QM (Aj.) } & \text { Valor F } & \text { Valor-P } \\ \text { Tempo } & 6 & 0,5587 & 0,09312 & 2,45 & 0,079 \\ \text { Erro } & 14 & 0,5332 & 0,03808 & & \\ \text { Total } & 20 & 1,0919 & & & \end{array}$

Sumário do Modelo

$\begin{array}{cllc}\text { S } & \text { R2 } & \text { R2(aj) } & \text { R2(pred) } \\ 0,195148 & 51,17 \% & 30,24 \% & 0,00 \%\end{array}$

Comparações Pareadas de Tukey

Informações de Agrupamento Usando Método de Tukey e Confiança de 90\%

Tempo N Média Agrupamento

$\begin{array}{llll}30 & 3 & 0,546841 & \text { A }\end{array}$

$\begin{array}{llll}7 & 3 & 0,270012 & \text { A B }\end{array}$

$\begin{array}{llll}3 & 3 & 0,182611 & \text { A B }\end{array}$

$\begin{array}{llll}14 & 3 & 0,177994 & \text { A B }\end{array}$

$\begin{array}{llll}0 & 3 & 0,074025 & \text { A B }\end{array}$

$\begin{array}{llll}10 & 3 & 0,051892 & \text { B }\end{array}$

$\begin{array}{llll}21 & 3 & 0,049090 \quad \text { B }\end{array}$

Médias que não compartilham uma letra são significativamente diferentes.

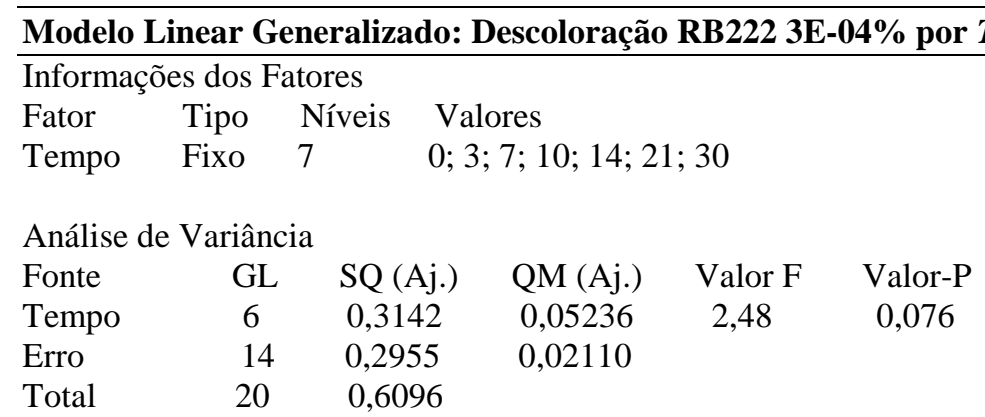

Sumário do Modelo

$\begin{array}{cllc}\text { S } & \text { R2 } & \text { R2(aj) } & \text { R2(pred) } \\ 0,145275 & 51,53 \% & 30,76 \% & 0,00 \%\end{array}$

Comparações Pareadas de Tukey

Informações de Agrupamento Usando Método de Tukey e Confiança de 90\%

Tempo N Média Agrupamento

$\begin{array}{llll}30 & 3 & 0,424064 & \text { A }\end{array}$

$\begin{array}{llll}0 & 3 & 0,301771 & \text { A B }\end{array}$ 


\begin{tabular}{lrcc}
\multicolumn{2}{l}{ Continuação } & \\
Tempo & N & Média & Agrupamento \\
14 & 3 & 0,254780 & A B \\
21 & 3 & 0,246870 & A B \\
10 & 3 & 0,223420 & A B \\
3 & 3 & 0,139876 & A B \\
7 & 3 & 0,000000 & B
\end{tabular}

Médias que não compartilham uma letra são significativamente diferentes.

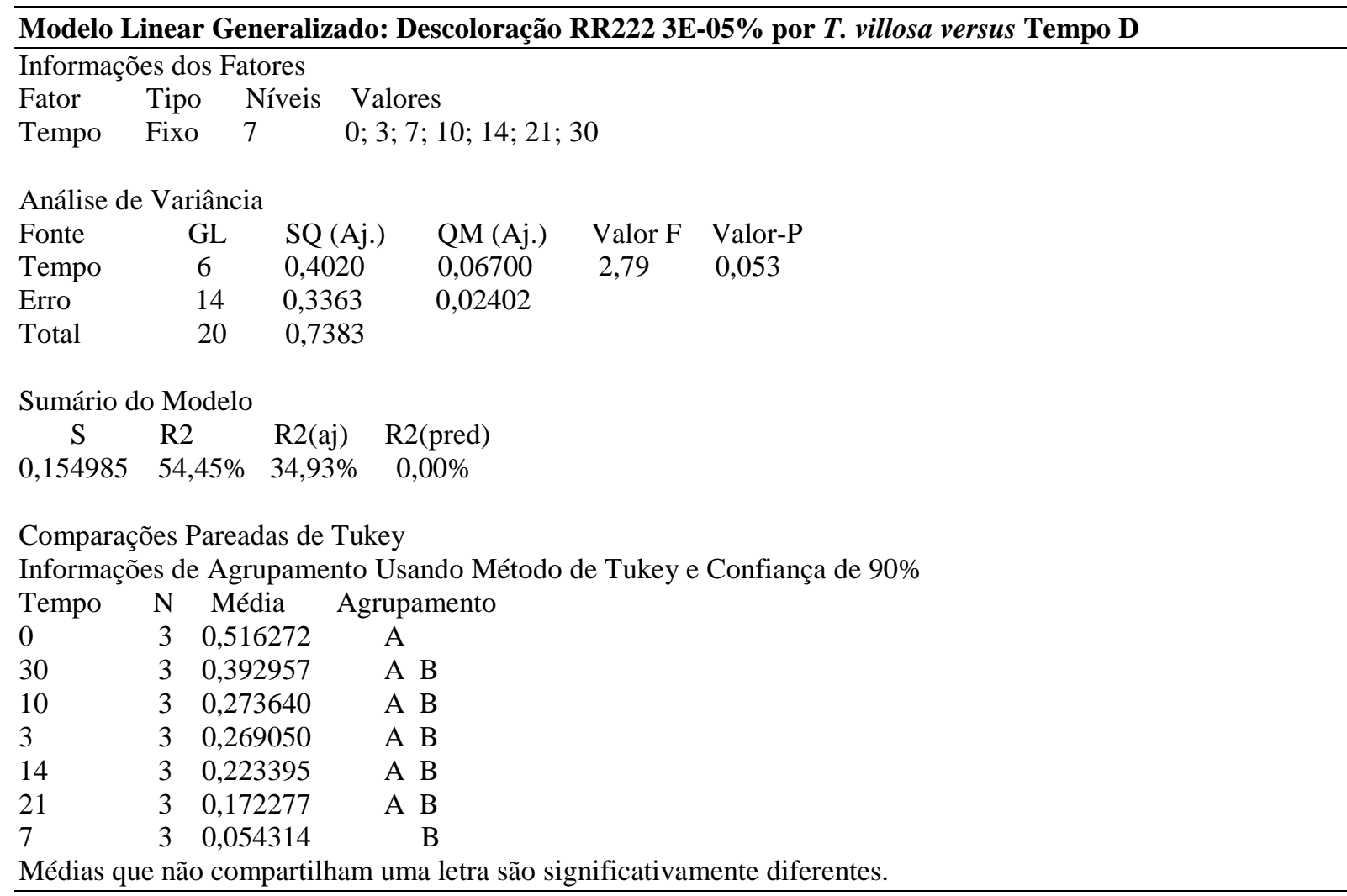

\section{Modelo Linear Generalizado: pH P. ostreatus versus Tempo}

\begin{tabular}{llll}
\hline \multicolumn{4}{l}{ Informações dos Fatores } \\
Fator & Tipo & Níveis & Valores \\
Tempo & Fixo & 7 & $0 ; 3 ; 7 ; 10 ; 14 ; 21 ; 30$
\end{tabular}

Análise de Variância

$\begin{array}{llllll}\text { Fonte } & \text { GL } & \text { SQ (Aj.) } & \text { QM (Aj.) } & \text { Valor F } & \text { Valor-P } \\ \text { Tempo } & 6 & 3,0607 & 0,51011 & 23,12 & 0,000 \\ \text { Erro } & 14 & 0,3089 & 0,02206 & & \\ \text { Total } & 20 & 3,3695 & & & \end{array}$

Sumário do Modelo

$\begin{array}{clll}\text { S } & \text { R2 } & \text { R2(aj) } & \text { R2(pred) } \\ 0,148533 & 90,83 \% & 86,91 \% & 79,38 \%\end{array}$

Comparações Pareadas de Tukey

Informações de Agrupamento Usando Método de Tukey e Confiança de 90\%

Tempo N Média Agrupamento

\begin{tabular}{|c|c|c|}
\hline 30 & 35,95667 A & \\
\hline 14 & $35,68667 \mathrm{~A}$ & B \\
\hline 21 & $35,63000 \mathrm{~A}$ & B \\
\hline 10 & 35,33000 & B C \\
\hline 3 & 34,99333 & C D \\
\hline 7 & 34,97667 & C D \\
\hline
\end{tabular}


Continuação

Tempo N Média Agrupamento

$0 \quad 34,91000 \quad$ D

Médias que não compartilham uma letra são significativamente diferentes.

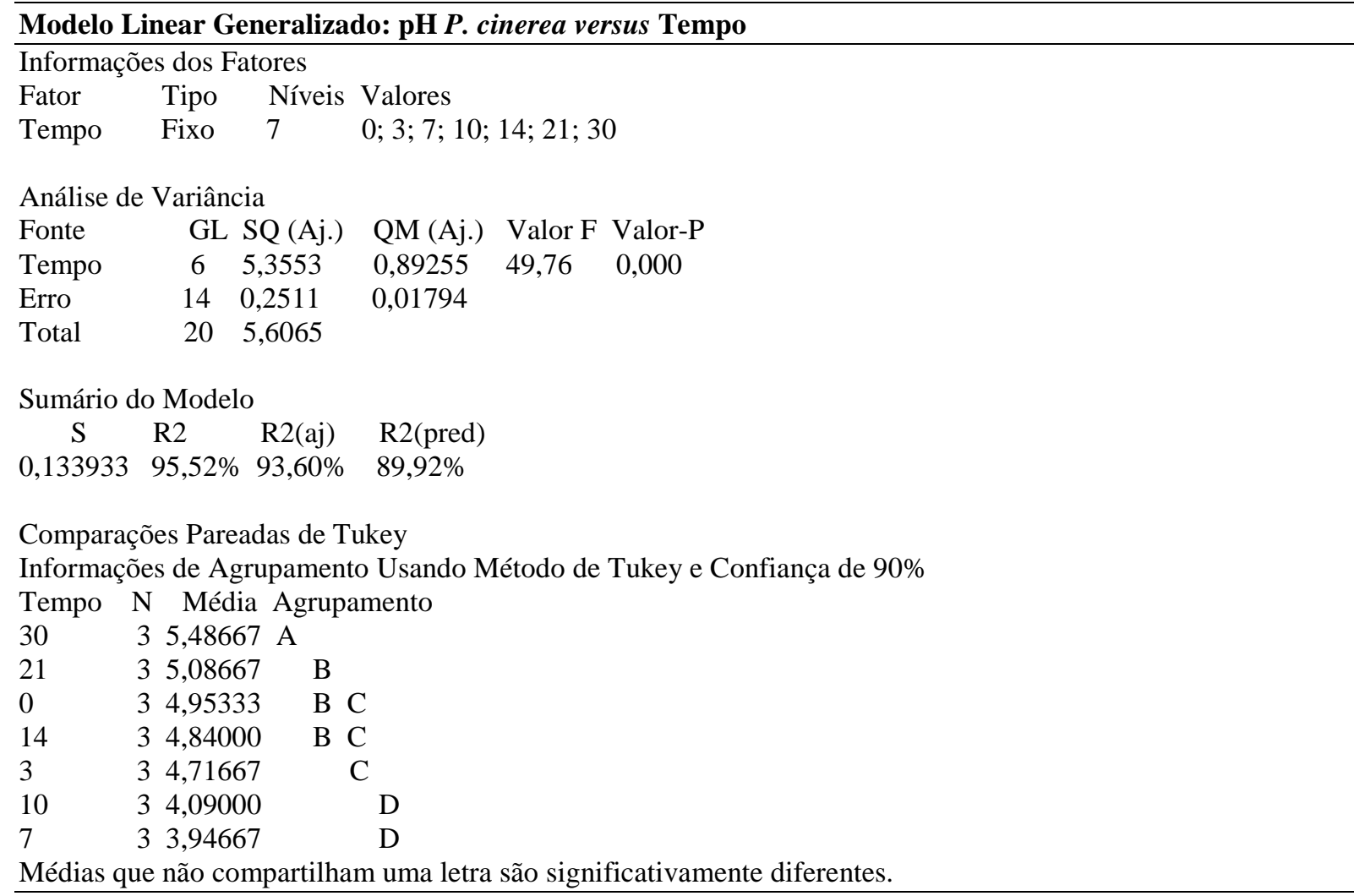

\section{Modelo Linear Generalizado: pH T. villosa versus Tempo}

\begin{tabular}{|c|c|c|c|c|c|}
\hline \multicolumn{6}{|c|}{ Informações dos Fatores } \\
\hline Fator & Tipo & Níveis & \multicolumn{3}{|l|}{ Valores } \\
\hline Tempo & Fixo & 7 & \multicolumn{3}{|c|}{$0 ; 3 ; 7 ; 10 ; 14 ; 21 ; 30$} \\
\hline \multicolumn{6}{|c|}{ Análise de Variância } \\
\hline Fonte & GL & SQ (Aj.) & QM (Aj.) & Valor F & Valor-P \\
\hline Tempo & 6 & 5,1372 & 0,85620 & 29,63 & 0,000 \\
\hline Erro & 14 & 0,4045 & 0,02890 & & \\
\hline Total & 20 & 5,5417 & & & \\
\hline
\end{tabular}

Sumário do Modelo

$$
\text { S R2 R2(aj) R2(pred) }
$$

$0,169986 \quad 92,70 \% \quad 89,57 \% \quad 83,58 \%$

Comparações Pareadas de Tukey:

Informações de Agrupamento Usando Método de Tukey e Confiança de 90\%

Tempo N Média Agrupamento

$\begin{array}{llllll}30 & & 5,46333 & \text { A } & \\ 21 & & 3 & 4,99000 & & \text { B } \\ 14 & & 3 & 4,88000 & & \text { B } \\ 0 & & 3 & 4,87667 & & \text { B } \\ 3 & 3 & 4,70333 & & \text { B } \\ 10 & & 3 & 4,15333 & & \text { C } \\ 7 & & 3 & 3,87333 & & \text { C }\end{array}$

Médias que não compartilham uma letra são significativamente diferentes. 


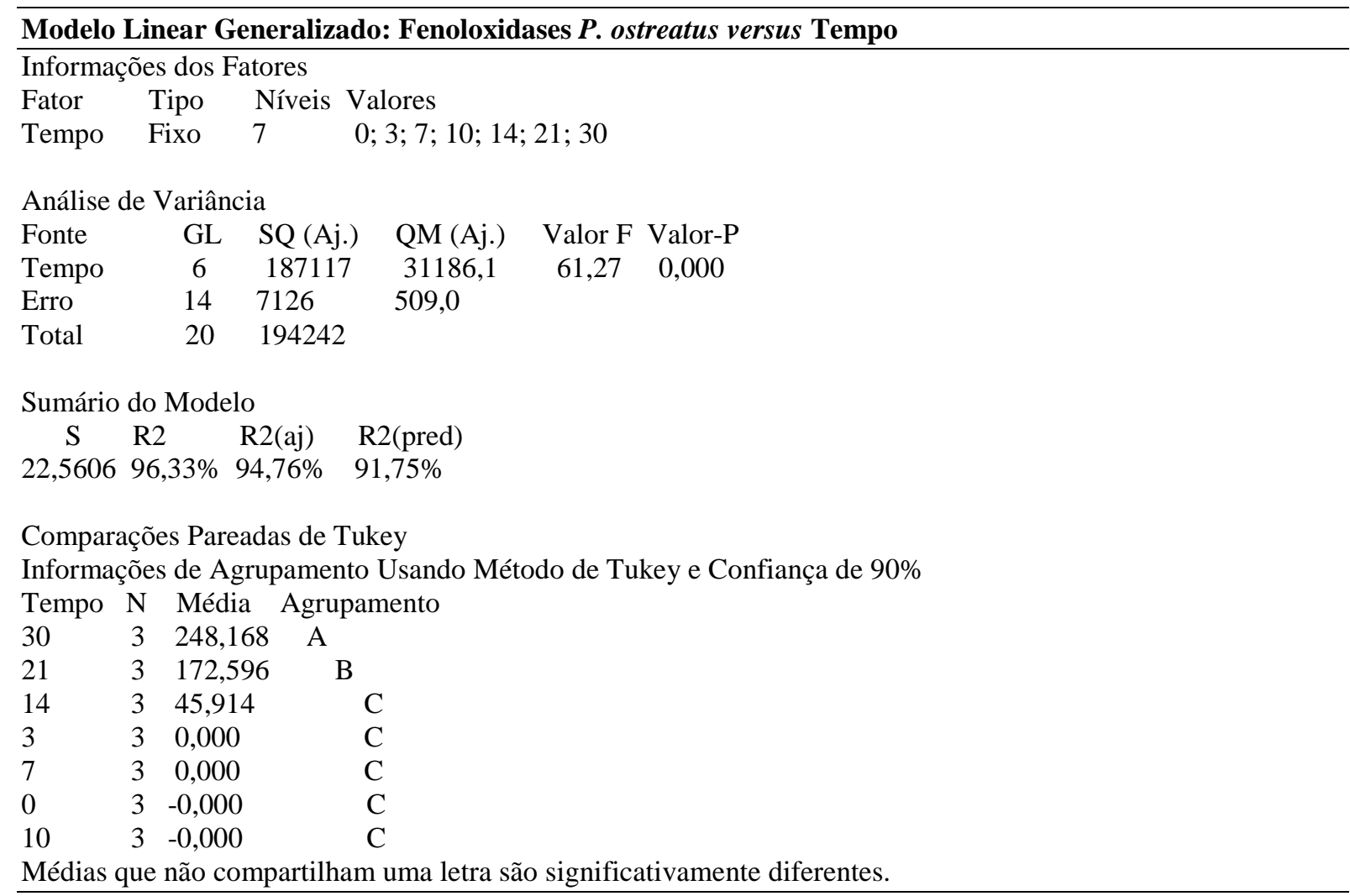

\section{Modelo Linear Generalizado: Lacase P. ostreatus versus Tempo D}

Informações dos Fatores

Fator Tipo Níveis Valores

Tempo Fixo $7 \quad 0 ; 3 ; 7 ; 10 ; 14 ; 21 ; 30$

Análise de Variância

$\begin{array}{lclccc}\text { Fonte } & \text { GL } & \text { SQ (Aj.) } & \text { QM (Aj.) } & \text { Valor F } & \text { Valor-P } \\ \text { Tempo } & 6 & 143656 & 23942,7 & 69,65 & 0,000 \\ \text { Erro } & 14 & 4813 & 343,8 & & \\ \text { Total } & 20 & 148469 & & & \end{array}$

Sumário do Modelo

$\begin{array}{clll}\text { S } & \text { R2 } & \text { R2(aj) } & \text { R2(pred) } \\ 18,5410 & 96,76 \% & 95,37 \% & 92,71 \%\end{array}$

\section{Comparações Pareadas de Tukey: Resposta $=$ Lacase_PO, Termo $=$ Tempo $\mathrm{D}$}

Informações de Agrupamento Usando Método de Tukey e Confiança de $90 \%$

Tempo N Média Agrupamento

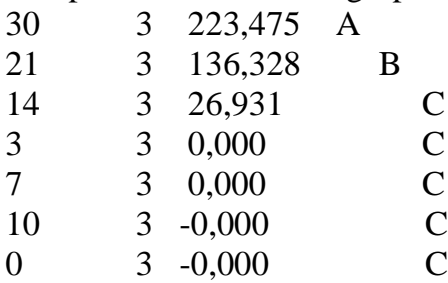

Médias que não compartilham uma letra são significativamente diferentes.

\begin{tabular}{l}
\hline \multicolumn{4}{l}{ Modelo Linear Generalizado: Peroxidases P. ostreatus versus Tempo } \\
\hline Informações dos Fatores \\
$\begin{array}{llll}\text { Fator } & \text { Tipo } & \text { Níveis } & \text { Valores } \\
\text { Tempo } & \text { Fixo } & 7 & 0 ; 3 ; 7 ; 10 ; 14 ; 21 ; 30\end{array}$
\end{tabular}


Continuação

Análise de Variância

$\begin{array}{lcllll}\text { Fonte } & \text { GL } & \text { SQ (Aj.) } & \text { QM (Aj.) } & \text { Valor F } & \text { Valor-P } \\ \text { Tempo } & 6 & 4999 & 833,2 & 1,61 & 0,217 \\ \text { Erro } & 14 & 7255 & 518,2 & & \\ \text { Total } & 20 & 12254 & & & \end{array}$

Sumário do Modelo

$$
\text { S R2 R2(aj) R2(pred) }
$$

$22,7646 \quad 40,80 \% \quad 15,42 \% \quad 0,00 \%$

\section{Modelo Linear Generalizado: MnP P. ostreatus versus Tempo}

Informações dos Fatores

$\begin{array}{llll}\text { Fator } & \text { Tipo } & \text { Níveis } & \text { Valores } \\ \text { Tempo } & \text { Fixo } & 7 & 0 ; 3 ; 7 ; 10 ; 14 ; 21 ; 30\end{array}$

Análise de Variância

$\begin{array}{lcllll}\text { Fonte } & \text { GL } & \text { SQ (Aj.) } & \text { QM (Aj.) } & \text { Valor F } & \text { Valor-P } \\ \text { Tempo } & 6 & 58432 & 9738,7 & 12,70 & 0,000 \\ \text { Erro } & 14 & 10739 & 767,1 & & \\ \text { Total } & 20 & 69171 & & & \end{array}$

Sumário do Modelo

$$
\text { S } \quad \text { R2 } \quad \text { R2(aj) R2(pred) }
$$

$27,6957 \quad 84,48 \% \quad 77,82 \% \quad 65,07 \%$

Comparações Pareadas de Tukey

Informações de Agrupamento Usando Método de Tukey e Confiança de 90\%

Tempo N Média Agrupamento

$\begin{array}{llll}30 & 3 & 142,727 & \text { A } \\ 21 & 3 & 82,122 & \text { A } \\ 14 & 3 & 7,141 & \text { B } \\ 3 & 3 & 0,000 & \text { B } \\ 7 & 3 & 0,000 & \text { B } \\ 10 & 3 & -0,000 & \text { B } \\ 0 & 3 & -0,000 & \text { B }\end{array}$

Médias que não compartilham uma letra são significativamente diferentes.

Modelo Linear Generalizado: Fenoloxidases $P$. cinerea versus Tempo

Informações dos Fatores

Fator Tipo Níveis Valores

Tempo Fixo $7 \quad 0 ; 3 ; 7 ; 10 ; 14 ; 21 ; 30$

Análise de Variância

$\begin{array}{lccccc}\text { Fonte } & \text { GL } & \text { SQ (Aj.) } & \text { QM (Aj.) } & \text { Valor F } & \text { Valor-P } \\ \text { Tempo } & 6 & 1361045 & 226841 & 5,47 & 0,004 \\ \text { Erro } & 14 & 580162 & 41440 & & \\ \text { Total } & 20 & 1941208 & & & \end{array}$

Sumário do Modelo

$$
\text { S R2 R2(aj) R2(pred) }
$$

$203,569 \quad 70,11 \% \quad 57,30 \% \quad 32,75 \%$

Comparações Pareadas de Tukey

Informações de Agrupamento Usando Método de Tukey e Confiança de 90\%

Tempo N Média Agrupamento

$143656,225 \mathrm{~A}$

213595,727 A

303579,882 A

103467,630 A $\quad$ B 
Continuação

Tempo N Média Agrupamento

$\begin{array}{lllll}7 & 3 & 263,035 & \text { A } & \text { B }\end{array}$

$\begin{array}{llll}3 & 3 & 25,208 & B\end{array}$

$\begin{array}{llll}0 & 3 & 0,000 & \text { B }\end{array}$

Médias que não compartilham uma letra são significativamente diferentes.

Modelo Linear Generalizado: Lacase $P$. cinerea versus Tempo

Informações dos Fatores

Fator Tipo Níveis Valores

Tempo Fixo $7 \quad 0 ; 3 ; 7 ; 10 ; 14 ; 21 ; 30$

Análise de Variância

$\begin{array}{lcllll}\text { Fonte } & \text { GL } & \text { SQ (Aj.) } & \text { QM (Aj.) } & \text { Valor F } & \text { Valor-P } \\ \text { Tempo } & 6 & 1529845 & 254974 & 5,10 & 0,006 \\ \text { Erro } & 14 & 700511 & 50037 & & \\ \text { Total } & 20 & 2230356 & & & \end{array}$

Sumário do Modelo

$\begin{array}{llll}\mathrm{S} & \mathrm{R} 2 & \mathrm{R} 2(\mathrm{aj}) & \mathrm{R} 2(\mathrm{pred})\end{array}$

223,688 68,59\% 55,13\% 29,33\%

Comparações Pareadas de Tukey

Informações de Agrupamento Usando Método de Tukey e Confiança de 90\%

Tempo N Média Agrupamento

$\begin{array}{llll}14 & 3 & 821,671 & \mathrm{~A}\end{array}$

$30 \quad 3 \quad 627,828 \quad$ A

$\begin{array}{lllll}21 & 3 & 466,858 & \text { A } & \text { B }\end{array}$

$\begin{array}{lllll}10 & 3 & 426,269 & \text { A } & \text { B }\end{array}$

$\begin{array}{lllll}7 & 3 & 294,468 & \text { A } & \text { B }\end{array}$

$\begin{array}{llll}3 & 3 & 75,932 & \text { B }\end{array}$

$\begin{array}{llll}0 & 3 & 0,000 & B\end{array}$

Médias que não compartilham uma letra são significativamente diferentes.

\section{Modelo Linear Generalizado: Peroxidases $P$. cinerea versus Tempo}

Informações dos Fatores

Fator Tipo Níveis Valores

Tempo Fixo $7 \quad$ 0; 3; 7; 10; 14; 21; 30

Análise de Variância

$\begin{array}{lcclcc}\text { Fonte } & \text { GL } & \text { SQ (Aj.) } & \text { QM (Aj.) } & \text { Valor F } & \text { Valor-P } \\ \text { Tempo } & 6 & 125327 & 20888 & 0,92 & 0,510 \\ \text { Erro } & 14 & 317971 & 22712 & & \\ \text { Total } & 20 & 443298 & & & \end{array}$

Sumário do Modelo

$\begin{array}{clll}\text { S } & \text { R2 } & \text { R2(aj) } & \text { R2(pred) }\end{array}$

\begin{tabular}{|c|c|c|c|c|c|}
\hline \multicolumn{6}{|c|}{ Modelo Linear Generalizado: MnP P. cinerea } \\
\hline \multicolumn{6}{|c|}{ Informações dos Fatores } \\
\hline Fator & Tipo & Níveis Valores & \multicolumn{3}{|c|}{ Valores } \\
\hline Tempo & Fixo & $7 \quad 0$; & \multicolumn{3}{|c|}{$0 ; 3 ; 7 ; 10 ; 14 ; 21 ; 30$} \\
\hline \multicolumn{6}{|c|}{ Análise de Variância } \\
\hline Fonte & GL & SQ (Aj.) & QM (Aj.) & Valor F & Valor-P \\
\hline Tempo & 6 & 7810 & 1301,7 & 1,41 & 0,279 \\
\hline Erro & 14 & 12942 & 924,4 & & \\
\hline Total & 20 & 20752 & & & \\
\hline
\end{tabular}


Continuação

Sumário do Modelo

$\begin{array}{clll}\text { S } & \text { R2 } & \text { R2(aj) } & \text { R2(pred) } \\ 30,4041 & 37,64 \% & 10,91 \% & 0,00 \%\end{array}$

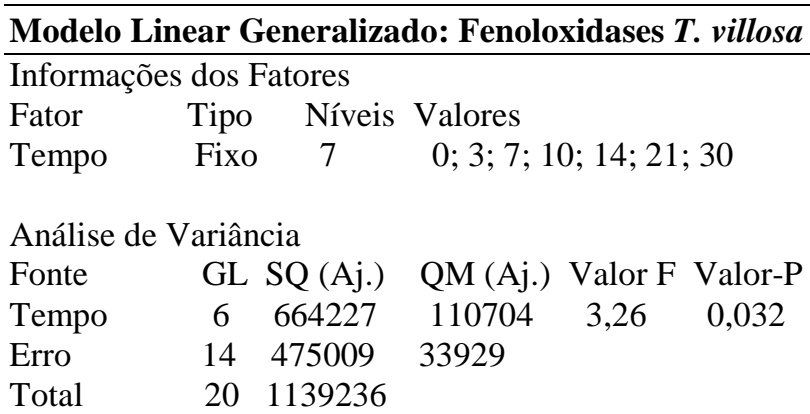

Sumário do Modelo

$\begin{array}{clll}\text { S } & \text { R2 } & \text { R2(aj) } & \text { R2(pred) } \\ 184,199 & 58,30 \% & 40,44 \% & 6,19 \%\end{array}$

Comparações Pareadas de Tukey

Informações de Agrupamento Usando Método de Tukey e Confiança de 90\%

Tempo N Média Agrupamento

$\begin{array}{llll}30 & 3 & 509,814 & \text { A }\end{array}$

$\begin{array}{lllll}14 & 3 & 397,563 & \text { A } & \text { B }\end{array}$

$\begin{array}{lllll}7 & 3 & 203,051 & \text { A } & \text { B }\end{array}$

$10 \quad 3 \quad 158,243 \quad$ A $\quad$ B

$\begin{array}{lllll}3 & 3 & 60,344 & \text { A } & \text { B }\end{array}$

$\begin{array}{llll}21 & 3 & 41,053 & \text { B }\end{array}$

$\begin{array}{llll}0 & 3 & 0,000 & \text { B }\end{array}$

Médias que não compartilham uma letra são significativamente diferentes.

\section{Modelo Linear Generalizado: Lacase T. villosa versus Tempo}

\begin{tabular}{|c|c|c|c|c|c|}
\hline \multicolumn{6}{|c|}{ Informações dos Fatores } \\
\hline Fator & Tipo & \multicolumn{4}{|c|}{ Níveis Valores } \\
\hline Tempo & Fixo & $7 \quad 0$; & \multicolumn{3}{|c|}{$0 ; 3 ; 7 ; 10 ; 14 ; 21 ; 30$} \\
\hline \multicolumn{6}{|c|}{ Análise de Variância } \\
\hline Fonte & GI & SQ (Aj.) & $\mathrm{QM}(\mathrm{Aj})$. & Valor F & Valor-P \\
\hline Tempo & 6 & 600707 & 100118 & 2,73 & 0,057 \\
\hline Erro & 14 & 513105 & 36650 & & \\
\hline Total & 20 & 1113812 & & & \\
\hline
\end{tabular}

Sumário do Modelo

$\begin{array}{clll}\text { S } & \text { R2 } & \text { R2(aj) } & \text { R2(pred) } \\ 191,443 & 53,93 \% & 34,19 \% & 0,00 \%\end{array}$

Comparações Pareadas de Tukey

Informações de Agrupamento Usando Método de Tukey e Confiança de 90\%

Tempo N Média Agrupamento

$\begin{array}{llcll}30 & 3 & 474,832 & \text { A } & \\ 14 & 3 & 407,440 & \text { A } & \text { B } \\ 10 & 3 & 211,077 & \text { A } & \text { B } \\ 7 & 3 & 161,947 & \text { A } & \text { B } \\ 21 & 3 & 68,678 & \text { A } & \text { B } \\ 3 & 3 & 48,461 & \text { A } & \text { B } \\ 0 & 3 & 0,000 & & \text { B }\end{array}$

Médias que não compartilham uma letra são significativamente diferentes. 


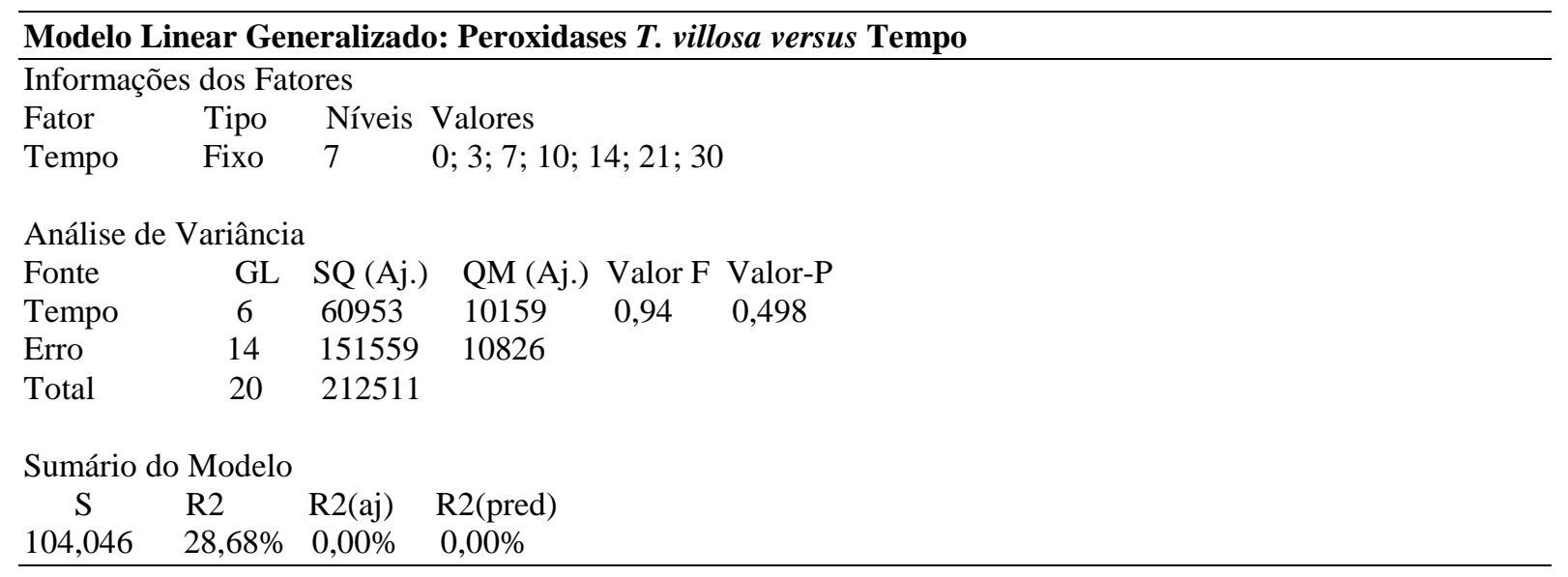

\section{Modelo Linear Generalizado: MnP T. villosa versus Tempo}

Informações dos Fatores

Fator Tipo Níveis Valores

Tempo Fixo $7 \quad 0 ; 3 ; 7 ; 10 ; 14 ; 21 ; 30$

Análise de Variância

$\begin{array}{llllll}\text { Fonte } & \text { GL } & \text { SQ (Aj.) } & \text { QM (Aj.) } & \text { Valor F } & \text { Valor-P } \\ \text { Tempo } & 6 & 674,5 & 112,42 & 7,86 & 0,001 \\ \text { Erro } & 14 & 200,3 & 14,31 & & \\ \text { Total } & 20 & 874,8 & & & \end{array}$

Sumário do Modelo

$\begin{array}{clll}\text { S } & \text { R2 } & \text { R2(aj) } & \text { R2(pred) } \\ 3,78248 & 77,10 \% & 67,29 \% & 48,48 \%\end{array}$

Comparações Pareadas de Tukey

Informações de Agrupamento Usando Método de Tukey e Confiança de 90\%

Tempo N Média Agrupamento

$\begin{array}{llll}30 & 3 & 16,3713 \quad \text { A }\end{array}$

$\begin{array}{llll}14 & 3 & 1,4142 & \text { B }\end{array}$

$\begin{array}{llll}0 & 3 & 0,0000 & \mathrm{~B}\end{array}$

$\begin{array}{llll}3 & 3 & 0,0000 & \mathrm{~B}\end{array}$

$\begin{array}{llll}7 & 3 & 0,0000 & \text { B }\end{array}$

$\begin{array}{llll}10 & 3 & -0,0000 & \text { B }\end{array}$

$\begin{array}{llll}21 & 3 & -0,0000 & \text { B }\end{array}$

Médias que não compartilham uma letra são significativamente diferentes.

Lacase versus descoloração 3E-02\% RB222

Análise de Correlação Pleurotus ostreatus

Correlação de Pearson $=0,719$

Valor-P $=0,000$

Lacase versus descoloração 3E-04\% RB222

Correlação de Pearson $=0,314$

Valor-P = 0,165

Lacase versus descoloração 3E-05\% RB222

Correlação de Pearson $=0,534$

Valor-P $=0,013$

MnP versus descoloração 3E-02\% RB222

Correlação de Pearson $=0,691$

Valor-P $=0,001$ 
Continuação

MnP versus descoloração 3E-04\% RB222

Correlação de Pearson $=0,204$

Valor-P $=0,376$

MnP versus descoloração 3E-05\% RB222

Correlação de Pearson $=0,264$

Valor-P $=0,247$

Lacase versus descoloração 3E-02\% RB222

Correlação de Pearson $=-0,400$

Valor-P $=0,081$

Lacase versus descoloração 3E-04\% RB222

Correlação de Pearson = -0,301

Valor-P = 0,196

Lacase versus descoloração 3E-05\% RB222

Correlação de Pearson $=0,005$

Valor-P $=0,984$

MnP versus descoloração 3E-02\% RB222

Correlação de Pearson $=-0,217$

Valor-P = 0,359

MnP versus descoloração 3E-04\% RB222

Correlação de Pearson $=-0,650$

Valor-P $=0,002$

MnP versus descoloração 3E-05\% RB222

Correlação de Pearson = 0,413

Valor-P = 0,070

Lacase versus descoloração 3E-02\% RB222

Correlação de Pearson $=0,200$

Valor-P $=0,384$

Lacase versus descoloração 3E-04\% RB222

Correlação de Pearson $=-0,131$

Valor-P $=0,572$

Lacase versus descoloração 3E-05\% RB222

Correlação de Pearson $=-0,334$

Valor-P = 0,139

MnP versus descoloração 3E-02\% RB222

Correlação de Pearson $=0,377$

Valor-P $=0,092$

MnP versus descoloração 3E-04\% RB222

Correlação de Pearson $=0,200$

Valor-P $=0,385$

MnP versus descoloração 3E-05\% RB222

Correlação de Pearson $=-0,038$

Valor-P = 0,872 


\section{APÊNDICE C - Análise estatística item 4.3}

Pleurotus ostreatus

\begin{tabular}{lccccc}
\hline \multicolumn{6}{l}{ Regressão de Superfície de Resposta: Descoloração RB222 por P. ostreat } \\
\hline Análise de Variância & GL & SQ (Aj.) & QM (Aj.) & Valor F & Valor-P \\
Fonte & 9 & 1,91224 & 0,212471 & 4,66 & 0,027 \\
Modelo & 3 & 1,15583 & 0,385276 & 8,45 & 0,010 \\
Linear & 1 & 0,00024 & 0,000238 & 0,01 & 0,944 \\
Cu+2 & 1 & 0,39902 & 0,399022 & 8,75 & 0,021 \\
Mn+2 & 1 & 0,75657 & 0,756569 & 16,59 & 0,005 \\
Tempo & 3 & 0,28994 & 0,096647 & 2,12 & 0,186 \\
Quadrado & 1 & 0,03725 & 0,037248 & 0,82 & 0,396 \\
Cu+2*Cu+2 & 1 & 0,03023 & 0,030227 & 0,66 & 0,442 \\
Mn+2*Mn+2 & 1 & 0,16485 & 0,164854 & 3,61 & 0,099 \\
Tempo*Tempo & 3 & 0,46647 & 0,155489 & 3,41 & 0,082 \\
Interação com 2 Fatores & 1 & 0,00133 & 0,001335 & 0,03 & 0,869 \\
Cu+2*Mn+2 & 1 & 0,00821 & 0,008212 & 0,18 & 0,684 \\
Cu+2*Tempo & 1 & 0,45692 & 0,456922 & 10,02 & 0,016 \\
Mn+2*Tempo & 7 & 0,31928 & 0,045611 & & \\
Erro & 5 & 0,31437 & 0,062873 & 25,60 & 0,038 \\
Falta de ajuste & 2 & 0,00491 & 0,002456 & $*$ & $*$ \\
Erro puro & 16 & 2,23152 & & & \\
Total & & & & &
\end{tabular}

Sumário do Modelo

$\begin{array}{clll}\text { S } & \text { R2 } & \text { R2(aj) } & \text { R2(pred) } \\ 0,213568 & 85,69 \% & 67,30 \% & 0,00 \%\end{array}$

Coeficientes Codificados

$\begin{array}{lrrrrrr}\text { Termo } & \text { Efeito } & \text { Coef } & \text { EP de Coef } & \text { Valor T } & \text { Valor-P } & \text { VIF } \\ \text { Constante } & 0,244 & 0,123 & 1,98 & 0,088 & & \\ \mathrm{Cu}+2 & -0,0084 & -0,0042 & 0,0578 & -0,07 & 0,944 & 1,00 \\ \mathrm{Mn}+2 & 0,3420 & 0,1710 & 0,0578 & 2,96 & 0,021 & 1,00 \\ \text { Tempo } & 0,4709 & 0,2355 & 0,0578 & 4,07 & 0,005 & 1,00 \\ \mathrm{Cu}+2 * \mathrm{Cu}+2 & -0,1151 & -0,0576 & 0,0637 & -0,90 & 0,396 & 1,15 \\ \mathrm{Mn}+2 * \mathrm{Mn}+2 & 0,1037 & 0,0519 & 0,0637 & 0,81 & 0,442 & 1,15 \\ \text { Tempo*Tempo } & 0,2422 & 0,1211 & 0,0637 & 1,90 & 0,099 & 1,15 \\ \mathrm{Cu}+2 * \mathrm{Mn}+2 & -0,0258 & -0,0129 & 0,0755 & -0,17 & 0,869 & 1,00 \\ \mathrm{Cu}+2 * \text { Tempo } & -0,0641 & -0,0320 & 0,0755 & -0,42 & 0,684 & 1,00 \\ \mathrm{Mn}+2 * \text { Tempo } & 0,4780 & 0,2390 & 0,0755 & 3,17 & 0,016 & 1,00\end{array}$

Equação de Regressão em Unidades Não codificadas

Descoloração $=0,82+(2,31 * \mathrm{Cu}+2)-(2,48 * \mathrm{Mn}+2)-(0,1261 * \mathrm{Tempo})-(1,35 * \mathrm{Cu}+2 * \mathrm{Cu}+2)+$ $(0,732 * \mathrm{Mn}+2 * \mathrm{Mn}+2)+(0,00282 * \mathrm{Tempo} * \mathrm{Tempo})-(0,2 * \mathrm{Cu}+2 * \mathrm{Mn}+2)-(0,0237 * \mathrm{Cu}+2 * \mathrm{Tempo})+$ $(0,1372 * \mathrm{Mn}+2 *$ Tempo $)$

\begin{tabular}{llllc}
\hline \multicolumn{5}{l}{ Regressão de Superfície de Resposta: Fenoloxidases $P$. } \\
\hline \multicolumn{4}{l}{ Estimated Regression Coefficients for } & Fenoloxidases using \\
Term & Coef & SE Coef & T & P \\
Constant & 72,384 & 16,978 & 4,263 & 0,004 \\
$\mathrm{Cu}+2$ & $-1,103$ & 7,978 & $-0,138$ & 0,894 \\
$\mathrm{Mn}+2$ & $-15,718$ & 7,978 & $-1,970$ & 0,089 \\
Tempo & 19,196 & 7,978 & 2,406 & 0,047 \\
$\mathrm{Cu}+2 * \mathrm{Cu}+2$ & $-14,040$ & 8,789 & $-1,598$ & 0,154 \\
$\mathrm{Mn}+2 * \mathrm{Mn}+2$ & $-21,587$ & 8,789 & $-2,456$ & 0,044 \\
$\mathrm{Tempo}$ Tempo & $-16,829$ & 8,789 & $-1,915$ & 0,097 \\
$\mathrm{Cu}+2 * \mathrm{Mn}+2$ & 8,016 & 10,419 & 0,769 & 0,467 \\
$\mathrm{Cu}+2 * T e m p o$ & $-5,662$ & 10,419 & $-0,543$ & 0,604 \\
$\mathrm{Mn}+2 * T e m p o$ & $-5,527$ & 10,419 & $-0,530$ & 0,612
\end{tabular}


Continuação

$\mathrm{S}=29,4689 \quad$ PRESS $=43829,2$

$\mathrm{R}-\mathrm{Sq}=72,94 \% \mathrm{R}-\mathrm{Sq}($ pred $)=0,00 \% \mathrm{R}-\mathrm{Sq}(\operatorname{adj})=38,15 \%$

Analysis of Variance for Fenoloxidases

$\begin{array}{llllllc}\text { Source } & \text { DF } & \text { Seq SS } & \text { Adj SS } & \text { Adj MS } & \text { F } & \text { P } \\ \text { Regression } & 9 & 16384,8 & 16384,8 & 1820,5 & 2,10 & 0,171 \\ \text { Linear } & 3 & 8415,4 & 8415,4 & 2805,1 & 3,23 & 0,091 \\ \text { Square } & 3 & 6954,6 & 6954,6 & 2318,2 & 2,67 & 0,129 \\ \text { Interaction } & 3 & 1014,9 & 1014,9 & 338,3 & 0,39 & 0,764 \\ \text { Residual Erro } & 7 & 6078,9 & 6078,9 & 868,4 & & \\ \text { Lack-of-Fit } & 5 & 5420,2 & 5420,2 & 1084,0 & 3,29 & 0,249 \\ \text { Pure Error } & 2 & 658,7 & 658,7 & 329,4 & & \\ \text { Total } & 16 & 22463,7 & & & & \end{array}$

Estimated Regression Coefficients for Fenoloxidases using data in uncoded units

$\begin{array}{ll}\text { Term } & \text { Coef } \\ \text { Constant } & -333,725 \\ \mathrm{Cu}+2 & 420,735 \\ \mathrm{Mn}+2 & 239,819 \\ \text { Tempo } & 21,5579 \\ \mathrm{Cu}+2 * \mathrm{Cu}+2 & -330,060 \\ \mathrm{Mn}+2 * \mathrm{Mn}+2 & -304,920 \\ \mathrm{Tempo} \text { Tempo } & -0,392552 \\ \mathrm{Cu}+2 * \mathrm{Mn}+2 & 146,066 \\ \mathrm{Cu}+2 * \text { Tempo } & -4,19276 \\ \mathrm{Mn}+2 * \text { Tempo } & -3,17258\end{array}$

Regressão de Superfície de Resposta: Lacase P. ostreatus versus $\mathrm{Cu}+2$; $\mathrm{Mn+2}$; Tempo

Estimated Regression Coefficients for Lacase using coded units

$\begin{array}{lcccc}\text { Term } & \text { Coef } & \text { SE Coef } & \mathrm{T} & \mathrm{P} \\ \text { Constant } & 95,222 & 20,381 & 4,672 & 0,002 \\ \mathrm{Cu}+2 & 2,209 & 9,577 & 0,231 & 0,824 \\ \mathrm{Mn}+2 & -22,172 & 9,577 & -2,315 & 0,054 \\ \text { Tempo } & 28,990 & 9,577 & 3,027 & 0,019 \\ \mathrm{Cu}+2 * \mathrm{Cu}+2 & -21,268 & 10,551 & -2,016 & 0,084 \\ \mathrm{Mn}+2 * \mathrm{Mn}+ & -29,306 & 10,551 & -2,778 & 0,027 \\ \text { Tempo*Tempo } & -12,820 & 10,551 & -1,215 & 0,264 \\ \mathrm{Cu}+2 * \mathrm{Mn}+2 & -14,064 & 12,507 & -1,124 & 0,298 \\ \mathrm{Cu}+2 * \text { Tempo } & -8,508 & 12,507 & -0,680 & 0,518 \\ \mathrm{Mn}+2 * \text { Tempo } & -13,485 & 12,507 & -1,078 & 0,317\end{array}$

$\mathrm{S}=35,3756 \quad$ PRESS $=42580,1$

$\mathrm{R}-\mathrm{Sq}=79,27 \%$ R-Sq(pred) $=0,00 \% \mathrm{R}-\mathrm{Sq}(\operatorname{adj})=52,62 \%$

Analysis of Variance for Lacase

$\begin{array}{lllllcc}\text { Source } & \text { DF } & \text { Seq SS } & \text { Adj SS } & \text { Adj MS } & \text { F } & \text { P } \\ \text { Regression } & 9 & 33503 & 33503 & 3722,6 & 2,97 & 0,082 \\ \text { Linear } & 3 & 18242 & 18242 & 6080,5 & 4,86 & 0,039 \\ \text { Square } & 3 & 11645 & 11645 & 3881,8 & 3,10 & 0,098 \\ \text { Interaction } & 3 & 3616 & 3616 & 1205,4 & 0,96 & 0,461 \\ \text { Residual Error } & 7 & 8760 & 8760 & 1251,4 & & \\ \text { Lack-of-Fit } & 5 & 4063 & 4063 & 812,6 & 0,35 & 0,853 \\ \text { Pure Error } & 2 & 4697 & 4697 & 2348,4 & & \end{array}$

Total $\quad 16 \quad 42263$

Estimated Regression Coefficients for Lacase using data in uncoded units

$\begin{array}{ll}\text { Term } & \text { Coef } \\ \text { Constant } & -626,156 \\ \mathrm{Cu}+2 & 919,287\end{array}$


Continuação

Estimated Regression Coefficients for Lacase using data in uncoded units

\begin{tabular}{ll}
$\mathrm{Mn}+2$ & 681,318 \\
Tempo & 23,5901 \\
$\mathrm{Cu}+2 * \mathrm{Cu}+2$ & $-499,968$ \\
$\mathrm{Mn}+2 * \mathrm{Mn}+2$ & $-413,967$ \\
$\mathrm{Tempo} * \mathrm{Tempo}$ & $-0,299032$ \\
$\mathrm{Cu}+2 * \mathrm{Mn}+2$ & $-256,274$ \\
$\mathrm{Cu}+2 * \mathrm{Tempo}$ & $-6,29986$ \\
$\mathrm{Mn}+2 *$ Tempo & $-7,74043$ \\
\hline
\end{tabular}

Regressão de Superfície de Resposta: MnP P. ostreatus versus $\mathrm{Cu}+2$; $\mathrm{Mn}+2$; Tempo

Estimated Regression Coefficients for MnP using coded units

$\begin{array}{lllll}\text { Term } & \text { Coef } & \text { SE Coef } & \mathrm{T} & \mathrm{P} \\ \text { Constant } & 9,0695 & 37,69 & 0,241 & 0,817 \\ \mathrm{Cu}+2 & -22,3823 & 17,71 & -1,264 & 0,247 \\ \mathrm{Mn}+2 & -25,5453 & 17,71 & -1,442 & 0,192 \\ \text { Tempo } & 5,4803 & 17,71 & 0,309 & 0,766 \\ \mathrm{Cu}+2 * \mathrm{Cu}+2 & 16,9856 & 19,51 & 0,871 & 0,413 \\ \mathrm{Mn}+2 * \mathrm{Mn}+2 & 19,1034 & 19,51 & 0,979 & 0,360 \\ \text { Tempo*Tempo } & -14,1844 & 19,51 & -0,727 & 0,491 \\ \mathrm{Cu}+2 * \mathrm{Mn}+2 & 1,3494 & 23,13 & 0,058 & 0,955 \\ \mathrm{Cu}+2 * \text { Tempo } & -1,8703 & 23,13 & -0,081 & 0,938 \\ \mathrm{Mn}+2 * \text { Tempo } & -0,3646 & 23,13 & -0,016 & 0,988\end{array}$

$\mathrm{S}=65,4218 \quad$ PRESS $=226811$

$\mathrm{R}-\mathrm{Sq}=48,66 \% \mathrm{R}-\mathrm{Sq}($ pred$)=0,00 \% \mathrm{R}-\mathrm{Sq}(\operatorname{adj})=0,00 \%$

Analysis of Variance for $\mathrm{MnP}$

$\begin{array}{lclllll}\text { Source } & \text { DF } & \text { Seq SS } & \text { Adj SS } & \text { Adj MS } & \text { F } & \text { P } \\ \text { Regression } & 9 & 28392,9 & 28392,9 & 3154,77 & 0,74 & 0,672 \\ \text { Linear } & 3 & 16149,4 & 16149,4 & 5383,15 & 1,26 & 0,360 \\ \text { Square } & 3 & 12199,9 & 12199,9 & 4066,63 & 0,95 & 0,467 \\ \text { Interaction } & 3 & 43,6 & 43,6 & 14,54 & 0,00 & 1,000 \\ \text { Residual Error } & 7 & 29960,1 & 29960,1 & 4280,01 & & \\ \text { Lack-of-Fit } & 5 & 29888,4 & 29888,4 & 5977,68 & 166,83 & 0,006 \\ \text { Pure Error } & 2 & 71,7 & 71,7 & 35,83 & & \\ \text { Total } & 16 & 58353,0 & & & & \end{array}$

Estimated Regression Coefficients for MnP using data in uncoded units

\begin{tabular}{ll} 
Term & Coef \\
Constant & 254,373 \\
$\mathrm{Cu}+2$ & $-619,067$ \\
$\mathrm{Mn}+2$ & $-406,761$ \\
Tempo & 13,7687 \\
$\mathrm{Cu}+2 * \mathrm{Cu}+2$ & 399,294 \\
$\mathrm{Mn}+2 * \mathrm{Mn}+2$ & 269,845 \\
Tempo*Tempo & $-0,330861$ \\
$\mathrm{Cu}+2 * \mathrm{Mn}+2$ & 24,5894 \\
$\mathrm{Cu}+2 *$ Tempo & $-1,38491$ \\
$\mathrm{Mn}+2 *$ Tempo & $-0,209255$ \\
\hline
\end{tabular}

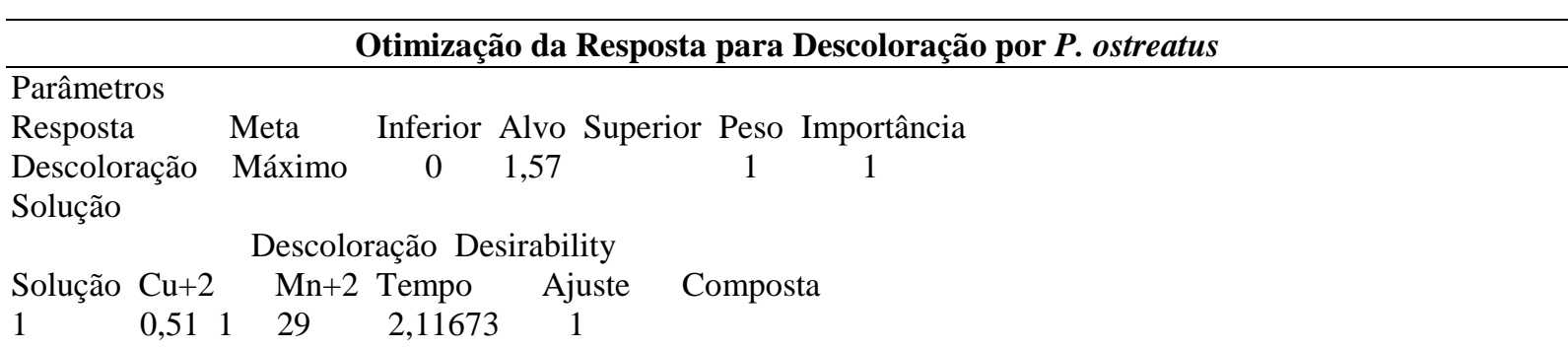


Continuação

Predição de Múltiplas Respostas

Variável Configuração

$\begin{array}{ll}\mathrm{Cu}+2 & \mathbf{0 , 5 1} \\ \mathrm{Mn}+2 & \mathbf{1} \\ \text { Tempo } & \mathbf{2 9}\end{array}$

EP do

Resposta Ajuste Ajustado IC de 95\% IP de 95\%

Descoloração $\quad 2,117 \quad 0,353 \quad(1,283 ; 2,951)(1,142 ; 3,092)$

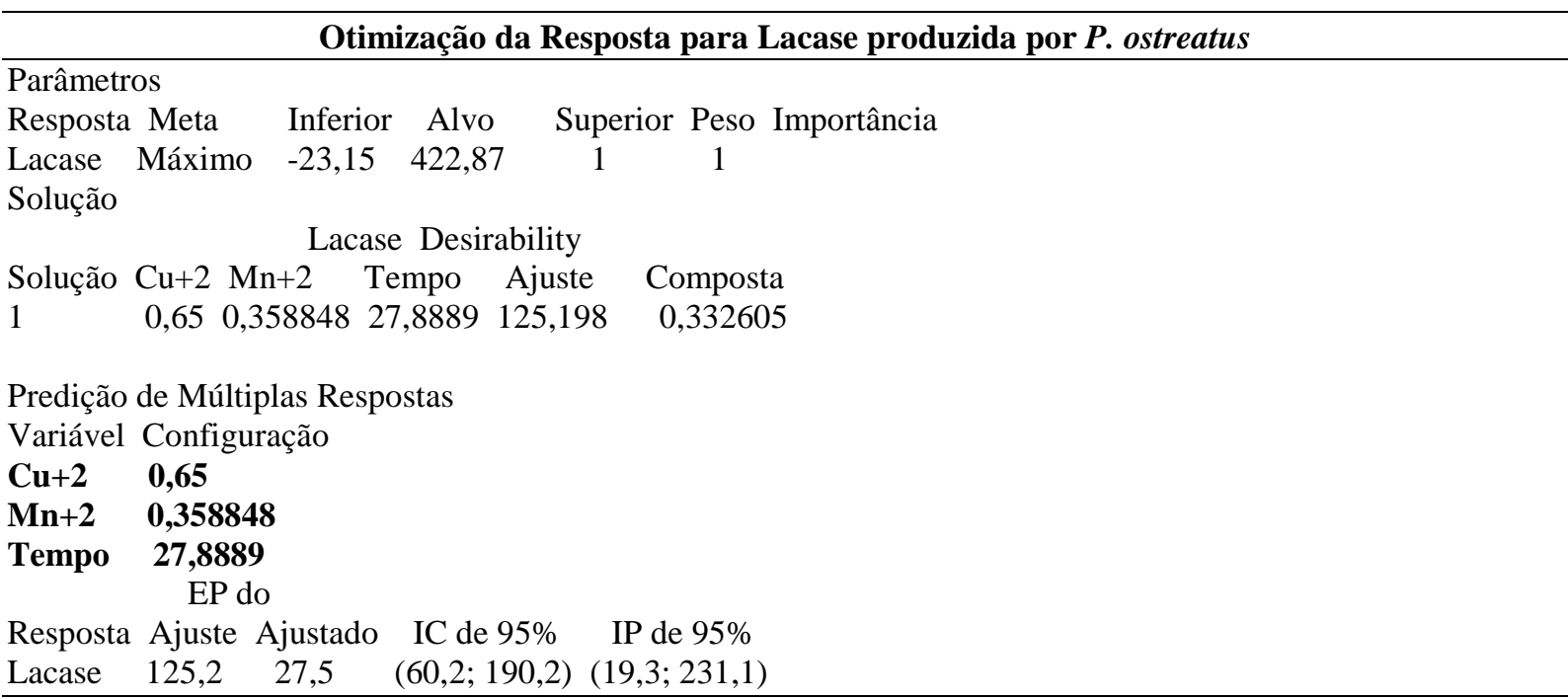

Regressão de Superfície de Resposta: Descoloração RB222 por P. cinerea versus Cu+2; Mn+2; Tempo

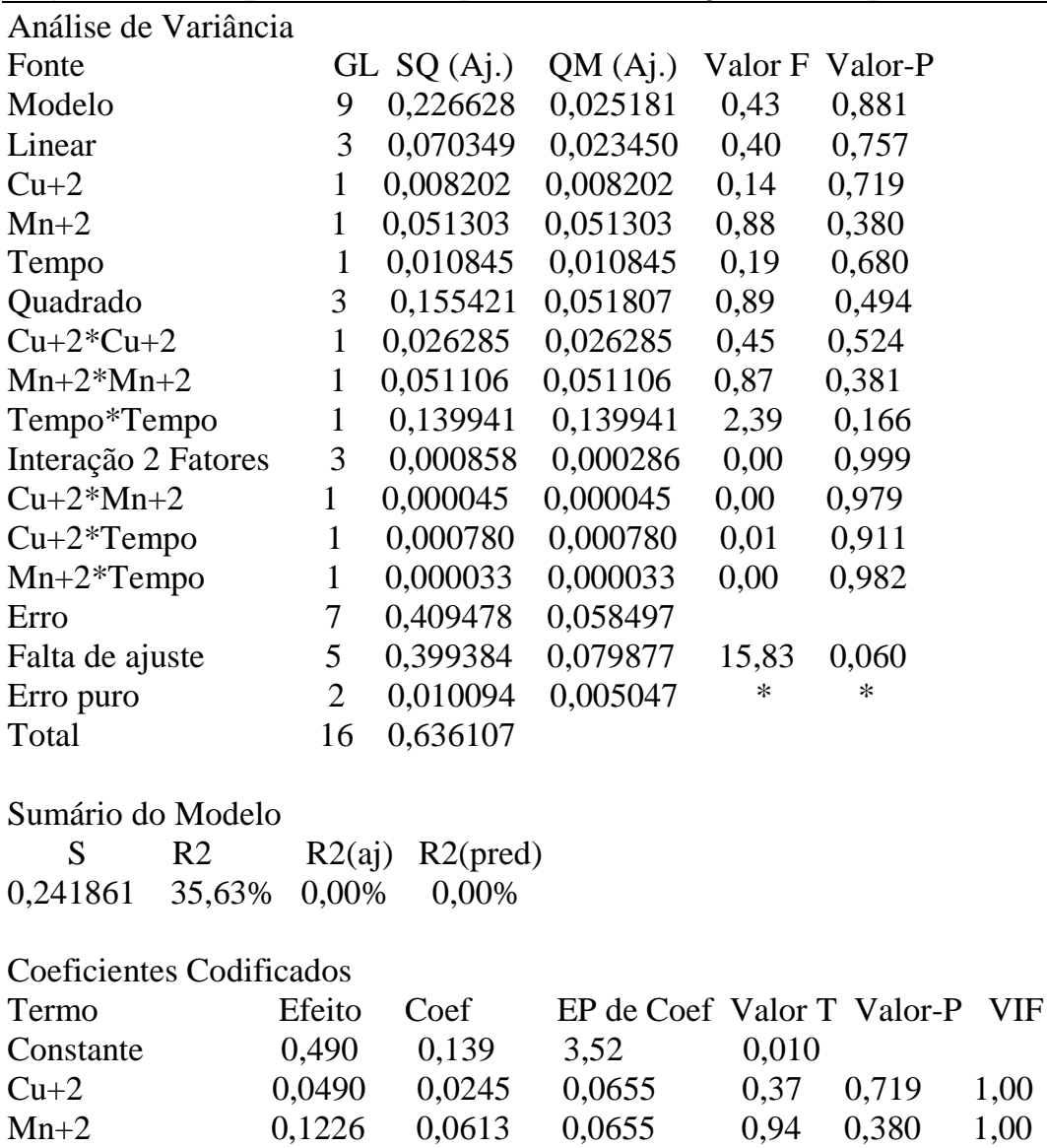


Continuação

$\begin{array}{lcllccc}\text { Termo } & \text { Efeito } & \text { Coef } & \text { EP de Coef } & \text { Valor T } & \text { Valor-P } & \text { VIF } \\ \text { Tempo } & -0,0564 & -0,0282 & 0,0655 & -0,43 & 0,680 & 1,00 \\ \mathrm{Cu}+2 * \mathrm{Cu}+2 & -0,0967 & -0,0484 & 0,0721 & -0,67 & 0,524 & 1,15 \\ \mathrm{Mn}+2 * \mathrm{Mn}+2 & -0,1348 & -0,0674 & 0,0721 & -0,93 & 0,381 & 1,15 \\ \text { Tempo*Tempo } & -0,2231 & -0,1116 & 0,0721 & -1,55 & 0,166 & 1,15 \\ \mathrm{Cu}+2 * \mathrm{Mn}+2 & -0,0047 & -0,0024 & 0,0855 & -0,03 & 0,979 & 1,00 \\ \mathrm{Cu}+2 * \text { Tempo } & -0,0198 & -0,0099 & 0,0855 & -0,12 & 0,911 & 1,00 \\ \mathrm{Mn}+2 * \text { Tempo } & -0,0041 & -0,0020 & 0,0855 & -0,02 & 0,982 & 1,00\end{array}$

Equação de Regressão em Unidades Não codificadas Descoloração $=-1,37+(1,76 * \mathrm{Cu}+2)+(1,33 * \mathrm{Mn}+2)+(0,0948 * \mathrm{Tempo})-(1,14 * \mathrm{Cu}+2 * \mathrm{Cu}+2)-$ $(0,95 * \mathrm{Mn}+2 * \mathrm{Mn}+2) \quad-(0,00260 * \mathrm{Tempo} * \mathrm{Tempo}) \quad-(0,04 * \mathrm{Cu}+2 * \mathrm{Mn}+2) \quad-\quad(0,0073 * \mathrm{Cu}+2 * \mathrm{Tempo}) \quad-$ $(0,0012 * \mathrm{Mn}+2 *$ Tempo $)$

\begin{tabular}{|c|c|c|c|c|c|}
\hline \multicolumn{6}{|c|}{ Regressão de Superfície de Resposta: Fenoloxidases $P$. ciner } \\
\hline \multicolumn{6}{|c|}{ Estimated Regression Coefficients for Fenoloxidases using code } \\
\hline Term & Coef & SE Coef & $\mathrm{T}$ & $\mathrm{P}$ & \\
\hline Constant & 465,103 & 121,80 & 3,818 & 0,007 & $* * *$ \\
\hline $\mathrm{Cu}+2$ & $-51,846$ & 57,23 & $-0,906$ & 0,395 & \\
\hline $\mathrm{Mn}+2$ & $-54,324$ & 57,23 & $-0,949$ & 0,374 & \\
\hline Tempo & $-4,022$ & 57,23 & $-0,070$ & 0,946 & \\
\hline $\mathrm{Cu}+2 * \mathrm{Cu}+2$ & $-113,411$ & 63,05 & $-1,799$ & 0,115 & \\
\hline $\mathrm{Mn}+2 * M n+2$ & $-118,059$ & 63,05 & $-1,872$ & 0,103 & \\
\hline Tempo*Tempo & $-29,885$ & 63,05 & $-0,474$ & 0,650 & \\
\hline $\mathrm{Cu}+2 * \mathrm{Mn}+2$ & $-219,231$ & 74,75 & $-2,933$ & 0,022 & $* * *$ \\
\hline $\mathrm{Cu}+2 *$ Tempo & 96,844 & 74,75 & 1,296 & 0,236 & \\
\hline $\mathrm{Mn}+2 *$ Tempo & $-174,358$ & 74,75 & $-2,333$ & 0,052 & $* * *$ \\
\hline
\end{tabular}

$\mathrm{S}=211,413 \quad$ PRESS $=2000555$

$\mathrm{R}-\mathrm{Sq}=76,52 \% \mathrm{R}-\mathrm{Sq}(\mathrm{pred})=0,00 \% \mathrm{R}-\mathrm{Sq}(\mathrm{adj})=46,33 \%$

Analysis of Variance for Fenoloxidases

$\begin{array}{lcllllll}\text { Source } & \text { DF } & \text { Seq SS } & \text { Adj SS } & \text { Adj MS } & \text { F } & \text { P } \\ \text { Regression } & 9 & 1019474 & 1019474 & 113275 & 2,53 & 0,117 \\ \text { Linear } & 3 & 77166 & 77166 & 25722 & 0,58 & 0,649 \\ \text { Square } & 3 & 239576 & 239576 & 79859 & 1,79 & 0,237 \\ \text { Interaction } & 3 & 702732 & 702732 & 234244 & 5,24 & 0,033 * * * \\ \text { Residual Error } & 7 & 312868 & 312868 & 44695 & & & \\ \text { Lack-of-Fit } & 5 & 210420 & 210420 & 42084 & 0,82 & 0,629 \\ \text { Pure Error } & 2 & 102448 & 102448 & 51224 & & & \\ \text { Total } & 16 & 1332342 & & & & \end{array}$

Estimated Regression Coefficients for Fenoloxidases using data in uncoded units

\begin{tabular}{lc} 
Term & Coef \\
Constant & $-2717,44$ \\
$\mathrm{Cu}+2$ & 4151,50 \\
$\mathrm{Mn}+2$ & 6052,41 \\
$\mathrm{Tempo}$ & 32,9622 \\
$\mathrm{Cu}+2 * \mathrm{Cu}+2$ & $-2666,04$ \\
$\mathrm{Mn}+2 * \mathrm{Mn}+2$ & $-1667,64$ \\
$\mathrm{Tempo}$ Tempo & $-0,697079$ \\
$\mathrm{Cu}+2 * \mathrm{Mn}+2$ & $-3994,93$ \\
$\mathrm{Cu}+2 *$ Tempo & 71,7127 \\
$\mathrm{Mn}+2 *$ Tempo & $-100,083$ \\
\hline
\end{tabular}

Regressão de Superfície de Resposta: Lacase $P$. cinerea versus $\mathrm{Cu}+2$; $\mathrm{Mn+2}$; Tempo

Estimated Regression Coefficients for Lacase using coded units

$\begin{array}{lcccl}\text { Term } & \text { Coef } & \text { SE Coef } & \text { T } & \text { P } \\ \text { Constant } & 106,909 & 156,88 & 0,681 & 0,517\end{array}$




$\begin{array}{lllll}\text { Continuação } & & & & \\ \text { Term } & \text { Coef } & \text { SE Coef } & \mathrm{T} & \mathrm{P} \\ \mathrm{Cu}+2 & -16,374 & 73,71 & -0,222 & 0,831 \\ \mathrm{Mn}+2 & -149,682 & 73,71 & -2,031 & 0,082 \\ \text { Tempo } & -57,156 & 73,71 & -0,775 & 0,464 \\ \mathrm{Cu}+2 * \mathrm{Cu}+2 & -78,327 & 81,21 & -0,964 & 0,367 \\ \mathrm{Mn}+2 * \mathrm{Mn}+2 & -14,513 & 81,21 & -0,179 & 0,863 \\ \text { Tempo*Tempo } & -25,586 & 81,21 & -0,315 & 0,762 \\ \mathrm{Cu}+2 * \mathrm{Mn}+2 & 38,429 & 96,27 & 0,399 & 0,702 \\ \mathrm{Cu}+2 * \text { Tempo } & -98,388 & 96,27 & -1,022 & 0,341 \\ \mathrm{Mn}+2 * \text { Tempo } & 9,260 & 96,27 & 0,096 & 0,926\end{array}$

$\mathrm{S}=272,294 \quad$ PRESS $=3379620$

$\mathrm{R}-\mathrm{Sq}=49,76 \% \mathrm{R}-\mathrm{Sq}($ pred $)=0,00 \% \mathrm{R}-\mathrm{Sq}(\operatorname{adj})=0,00 \%$

Analysis of Variance for Lacase

$\begin{array}{llllllc}\text { Source } & \text { DF } & \text { Seq SS } & \text { Adj SS } & \text { Adj MS } & \text { F } & \text { P } \\ \text { Regression } & 9 & 514013 & 514013 & 57113 & 0,77 & 0,650 \\ \text { Linear } & 3 & 353942 & 353942 & 117981 & 1,59 & 0,275 \\ \text { Square } & 3 & 70130 & 70130 & 23377 & 0,32 & 0,814 \\ \text { Interaction } & 3 & 89941 & 89941 & 29980 & 0,40 & 0,755 \\ \text { Residual Error } & 7 & 519006 & 519006 & 74144 & & \\ \text { Lack-of-Fit } & 5 & 414096 & 414096 & 82819 & 1,58 & 0,431 \\ \text { Pure Error } & 2 & 104910 & 104910 & 52455 & & \\ \text { Total } & 16 & 1033020 & & & & \end{array}$

Estimated Regression Coefficients for Lacase using data in uncoded units

\begin{tabular}{ll} 
Term & Coef \\
Constant & $-966,411$ \\
$\mathrm{Cu}+2$ & 3251,32 \\
$\mathrm{Mn}+2$ & $-889,132$ \\
Tempo & 57,4278 \\
$\mathrm{Cu}+2 * \mathrm{Cu}+2$ & $-1841,29$ \\
$\mathrm{Mn}+2 * \mathrm{Mn}+2$ & $-205,005$ \\
Tempo*Tempo & $-0,596813$ \\
$\mathrm{Cu}+2 * \mathrm{Mn}+2$ & 700,272 \\
$\mathrm{Cu}+2 *$ Tempo & $-72,8555$ \\
$\mathrm{Mn}+2 *$ Tempo & 5,31532 \\
\hline
\end{tabular}

Regressão de Superfície de Resposta: MnP P. cinerea versus $\mathrm{Cu}+2$; $\mathrm{Mn}+2$; Tempo

Estimated Regression Coefficients for MnP using coded units

$\begin{array}{lllll}\text { Term } & \text { Coef } & \text { SE Coef } & \text { T } & \text { P } \\ \text { Constant } & 5,8103 & 10,816 & 0,537 & 0,608 \\ \mathrm{Cu}+2 & 2,7513 & 5,082 & 0,541 & 0,605 \\ \mathrm{Mn}+2 & -6,8613 & 5,082 & -1,350 & 0,219 \\ \text { Tempo } & 0,6482 & 5,082 & 0,128 & 0,902 \\ \mathrm{Cu}+2 * \mathrm{Cu}+2 & -3,1760 & 5,599 & -0,567 & 0,588 \\ \mathrm{Mn}+2 * \mathrm{Mn}+2 & 5,8455 & 5,599 & 1,044 & 0,331 \\ \text { Tempo*Tempo } & -5,4214 & 5,599 & -0,968 & 0,365 \\ \mathrm{Cu}+2 * \mathrm{Mn}+2 & 8,1447 & 6,637 & 1,227 & 0,259 \\ \mathrm{Cu}+2 * T e m p o & -2,5548 & 6,637 & -0,385 & 0,712 \\ \mathrm{Mn}+2 * \text { Tempo } & -2,5604 & 6,637 & -0,386 & 0,711\end{array}$

$\mathrm{S}=18,7731 \quad$ PRESS $=18608,1$

$\mathrm{R}-\mathrm{Sq}=50,71 \% \mathrm{R}-\mathrm{Sq}($ pred $)=0,00 \% \mathrm{R}-\mathrm{Sq}(\operatorname{adj})=0,00 \%$

Analysis of Variance for MnP

$\begin{array}{lllllcc}\text { Source } & \text { DF } & \text { Seq SS } & \text { Adj SS } & \text { Adj MS } & \text { F } & \text { P } \\ \text { Regression } & 9 & 2537,7 & 2537,7 & 281,97 & 0,80 & 0,631 \\ \text { Linear } & 3 & 751,4 & 751,4 & 250,46 & 0,71 & 0,576\end{array}$


Continuação

$\begin{array}{lllllcc}\text { Source } & \text { DF } & \text { Seq SS } & \text { Adj SS } & \text { Adj MS } & \text { F } & \text { P } \\ \text { Square } & 3 & 1151,0 & 1151,0 & 383,67 & 1,09 & 0,414 \\ \text { Interaction } & 3 & 635,3 & 635,3 & 211,78 & 0,60 & 0,635 \\ \text { Residual Error } & 7 & 2467,0 & 2467,0 & 352,43 & & \\ \text { Lack-of-Fit } & 5 & 2295,0 & 2295,0 & 458,99 & 5,34 & 0,165 \\ \text { Pure Error } & 2 & 172,0 & 172,0 & 86,01 & & \\ \text { Total } & 16 & 5004,7 & & & & \end{array}$

Estimated Regression Coefficients for MnP using data in uncoded units

\begin{tabular}{ll} 
Term & \multicolumn{1}{c}{ Coef } \\
Constant & $-21,2818$ \\
$\mathrm{Cu}+2$ & 62,8981 \\
$\mathrm{Mn}+2$ & $-187,645$ \\
Tempo & 6,70050 \\
$\mathrm{Cu}+2 * \mathrm{Cu}+2$ & $-74,6597$ \\
$\mathrm{Mn}+2 * \mathrm{Mn}+2$ & 82,5701 \\
Tempo*Tempo & $-0,126458$ \\
$\mathrm{Cu}+2 * \mathrm{Mn}+2$ & 148,416 \\
$\mathrm{Cu}+2 * \mathrm{Tempo}$ & $-1,89178$ \\
$\mathrm{Mn}+2 *$ Tempo & $-1,46969$ \\
\hline
\end{tabular}

Otimização da Resposta para Descoloração por $P$. cinerea

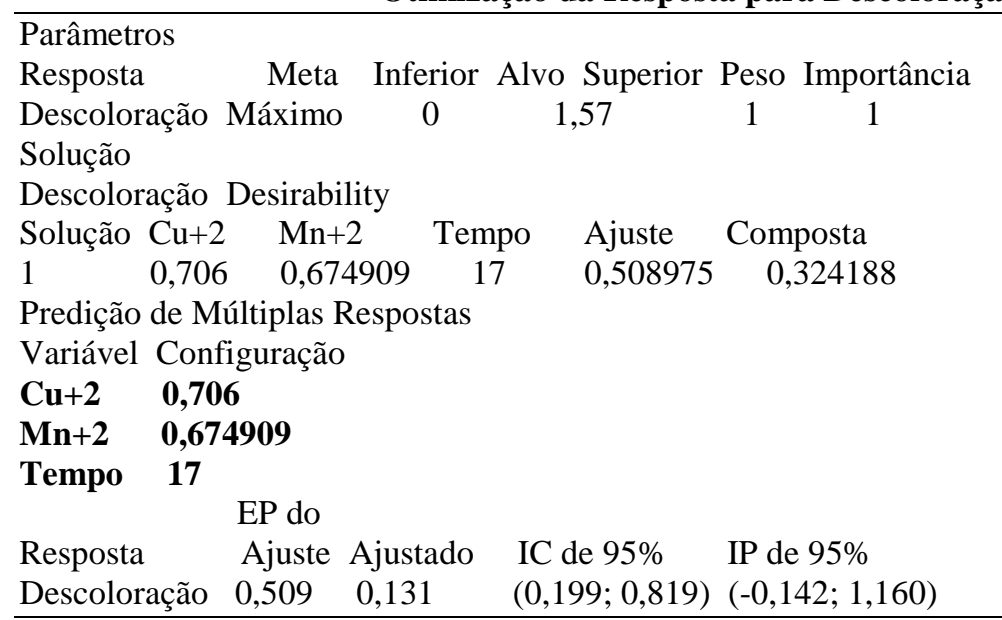

Trametes villosa

\begin{tabular}{lccccc}
\hline Regressão de Superfície de Resposta: Descoloração RB222 por T. $v$ ill \\
\hline Análise de Variância & & & & & \\
Fonte & GL SQ (Aj.) & QM (Aj.) & Valor F & Valor-P \\
Modelo & 9 & 0,432407 & 0,048045 & 1,74 & 0,238 \\
Linear & 3 & 0,267526 & 0,089175 & 3,23 & 0,091 \\
$\mathrm{Cu}+2$ & 1 & 0,147164 & 0,147164 & 5,34 & 0,054 \\
$\mathrm{Mn+2}$ & 1 & 0,079505 & 0,079505 & 2,88 & 0,133 \\
Tempo & 1 & 0,040858 & 0,040858 & 1,48 & 0,263 \\
Quadrado & 3 & 0,101726 & 0,033909 & 1,23 & 0,368 \\
$\mathrm{Cu}+2 *$ Cu+2 & 1 & 0,018497 & 0,018497 & 0,67 & 0,440 \\
Mn+2*Mn+2 & 1 & 0,007055 & 0,007055 & 0,26 & 0,628 \\
Tempo*Tempo & 1 & 0,099278 & 0,099278 & 3,60 & 0,100 \\
Interação 2 Fatores & 3 & 0,063154 & 0,021051 & 0,76 & 0,549 \\
Cu+2*Mn+2 & 1 & 0,021023 & 0,021023 & 0,76 & 0,411 \\
Cu+2*Tempo & 1 & 0,034308 & 0,034308 & 1,24 & 0,301 \\
Mn+2*Tempo & 1 & 0,007824 & 0,007824 & 0,28 & 0,611 \\
Erro & 7 & 0,192968 & 0,027567 & & \\
Falta de ajuste & 5 & 0,189761 & 0,037952 & 23,66 & 0,041 \\
Erro puro & 2 & 0,003208 & 0,001604 & $*$ & $*$ \\
Total & 16 & 0,625375 & & &
\end{tabular}


Continuação

Sumário do Modelo

$\begin{array}{ccll}\text { S } & \text { R2 } & \text { R2(aj) } & \text { R2(pred) } \\ 0,166033 & 69,14 \% & 29,47 \% & 0,00 \%\end{array}$

Coeficientes Codificados

$\begin{array}{lrlllll}\text { Termo } & \text { Efeito } & \text { Coef } & \text { EP de Coef Valor T } & \text { Valor-P } & \text { VIF } \\ \text { Constante } & 0,3793 & 0,0957 & 3,96 & 0,005 & & \\ \text { Cu+2 } & 0,2077 & 0,1039 & 0,0449 & 2,31 & 0,054 & 1,00 \\ \text { Mn+2 } & 0,1527 & 0,0763 & 0,0449 & 1,70 & 0,133 & 1,00 \\ \text { Tempo } & -0,1094 & -0,0547 & 0,0449 & -1,22 & 0,263 & 1,00 \\ \text { Cu+2*Cu+2 } & -0,0811 & -0,0406 & 0,0495 & -0,82 & 0,440 & 1,15 \\ \text { Mn+2*Mn+2 } & -0,0501 & -0,0251 & 0,0495 & -0,51 & 0,628 & 1,15 \\ \text { Tempo*Tempo } & -0,1879 & -0,0940 & 0,0495 & -1,90 & 0,100 & 1,15 \\ \text { Cu+2*Mn+2 } & 0,1025 & 0,0513 & 0,0587 & 0,87 & 0,411 & 1,00 \\ \text { Cu+2*Tempo } & 0,1310 & 0,0655 & 0,0587 & 1,12 & 0,301 & 1,00 \\ \text { Mn+2*Tempo } & 0,0625 & 0,0313 & 0,0587 & 0,53 & 0,611 & 1,00\end{array}$

Equação de Regressão em Unidades Não codificadas Descoloração $=-0,10+(0,3 * \mathrm{Cu}+2)-(0,26 * \mathrm{Mn}+2)+(0,0289 * \mathrm{Tempo})-(0,95 * \mathrm{Cu}+2 * \mathrm{Cu}+2)-$ $(0,354 * \mathrm{Mn}+2 * \mathrm{Mn}+2)-(0,00219 * \mathrm{Tempo} * \mathrm{Tempo})+(0,93 * \mathrm{Cu}+2 * \mathrm{Mn}+2)+(0,0485 * \mathrm{Cu}+2 * \mathrm{Tempo})+$ $(0,0180 * \mathrm{Mn}+2 *$ Tempo $)$

Regressão de Superfície de Resposta: Fenoloxidases T. villosa versus $\mathrm{Cu}+2$; $\mathrm{Mn+2}$; Tempo

Estimated Regression Coefficients for Fenoloxidases using coded units

$\begin{array}{lllll}\text { Term } & \text { Coef } & \text { SE Coef } & \mathrm{T} & \mathrm{P} \\ \text { Constant } & 164,327 & 96,09 & 1,710 & 0,131 \\ \mathrm{Cu}+2 & -33,332 & 45,15 & -0,738 & 0,484 \\ \mathrm{Mn}+2 & 14,448 & 45,15 & 0,320 & 0,758 \\ \text { Tempo } & 34,348 & 45,15 & 0,761 & 0,472 \\ \mathrm{Cu}+2 * \mathrm{Cu}+2 & 45,071 & 49,74 & 0,906 & 0,395 \\ \mathrm{Mn}+2 * \mathrm{Mn}+2 & -12,181 & 49,74 & -0,245 & 0,814 \\ \text { Tempo*Tempo } & -50,239 & 49,74 & -1,010 & 0,346 \\ \mathrm{Cu}+2 * \mathrm{Mn}+2 & -44,043 & 58,97 & -0,747 & 0,479 \\ \mathrm{Cu}+2 * T e m p o & -7,312 & 58,97 & -0,124 & 0,905 \\ \mathrm{Mn}+2 * \text { Tempo } & 28,417 & 58,97 & 0,482 & 0,645\end{array}$

$\mathrm{S}=166,784 \quad$ PRESS $=1350910$

$\mathrm{R}-\mathrm{Sq}=40,14 \% \mathrm{R}-\mathrm{Sq}($ pred $)=0,00 \% \mathrm{R}-\mathrm{Sq}(\operatorname{adj})=0,00 \%$

Analysis of Variance for Fenoloxidases

$\begin{array}{llllllc}\text { Source } & \text { DF } & \text { Seq SS } & \text { Adj SS } & \text { Adj MS } & \text { F } & \text { P } \\ \text { Regression } & 9 & 130563 & 130563 & 14507 & 0,52 & 0,821 \\ \text { Linear } & 3 & 34106 & 34106 & 11369 & 0,41 & 0,752 \\ \text { Square } & 3 & 74051 & 74051 & 24684 & 0,89 & 0,493 \\ \text { Interaction } & 3 & 22406 & 22406 & 7469 & 0,27 & 0,846 \\ \text { Residual Error } & 7 & 194718 & 194718 & 27817 & & \\ \text { Lack-of-Fit } & 5 & 170433 & 170433 & 34087 & 2,81 & 0,283 \\ \text { Pure Error } & 2 & 24285 & 24285 & 12142 & & \\ \text { Total } & 16 & 325281 & & & & \end{array}$

Estimated Regression Coefficients for Fenoloxidases using data in uncoded units

$\begin{array}{ll}\text { Term } & \text { Coef } \\ \text { Constant } & -25,6938 \\ \mathrm{Cu}+2 & -1005,13 \\ \mathrm{Mn}+2 & 475,473 \\ \text { Tempo } & 41,9507 \\ \mathrm{Cu}+2 * \mathrm{Cu}+2 & 1059,52 \\ \mathrm{Mn}+2 * \mathrm{Mn}+2 & -172,057 \\ \text { Tempo*Tempo } & -1,17186\end{array}$


Continuação

Estimated Regression Coefficients for Fenoloxidases using data in uncoded units

\begin{tabular}{ll}
$\mathrm{Cu}+2 * \mathrm{Mn}+2$ & $-802,571$ \\
$\mathrm{Cu}+2 *$ Tempo & $-5,41417$ \\
$\mathrm{Mn}+2 *$ Tempo & 16,3114 \\
\hline
\end{tabular}

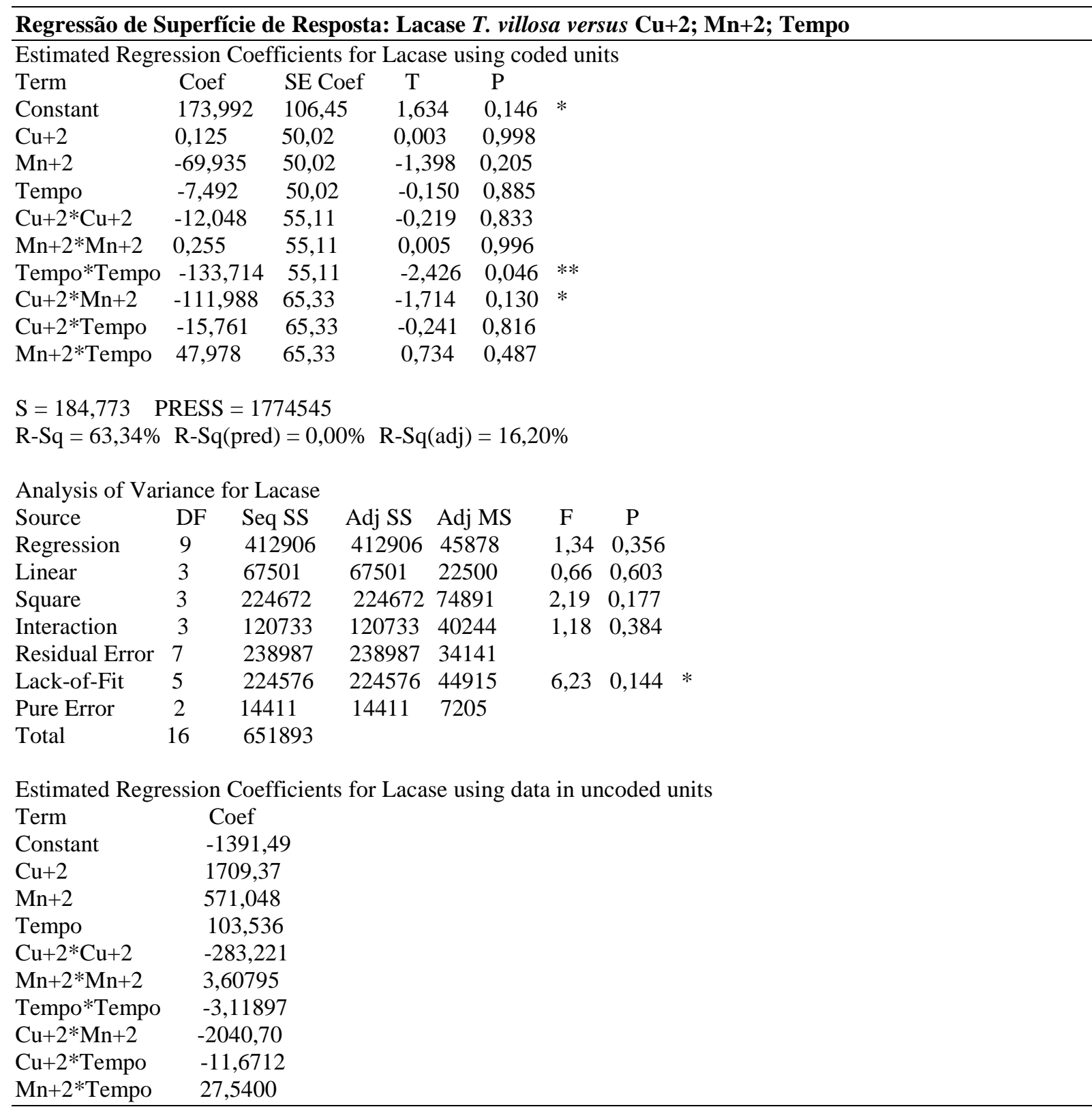

\begin{tabular}{|c|c|c|c|c|}
\hline \multicolumn{5}{|c|}{ Regressão de Superfície de Resposta: MnP T. villosa versus Cu+2; Mn+2; Tempo } \\
\hline \multicolumn{5}{|c|}{ Estimated Regression Coefficients for MnP using coded units } \\
\hline Term & Coef & SE Coef & $\mathrm{T}$ & $\mathrm{P}$ \\
\hline Constant & $-4,36754$ & 5,304 & $-0,823$ & 0,437 \\
\hline $\mathrm{Cu}+2$ & 3,91727 & 2,492 & 1,572 & 0,160 \\
\hline $\mathrm{Mn}+2$ & $-2,57477$ & 2,492 & $-1,033$ & 0,336 \\
\hline Tempo & 0,14158 & 2,492 & 0,057 & 0,956 \\
\hline $\mathrm{Cu}+2 * \mathrm{Cu}+2$ & 0,09531 & 2,746 & 0,035 & 0,973 \\
\hline $\mathrm{Mn}+2 * \mathrm{Mn}+2$ & 4,98053 & 2,746 & 1,814 & $0,113 *$ \\
\hline Tempo*Tempo & 0,71268 & 2,746 & 0,260 & 0,803 \\
\hline $\mathrm{Cu}+2 * \mathrm{Mn}+2$ & $-0,24148$ & 3,255 & $-0,074$ & 0,943 \\
\hline $\mathrm{Cu}+2 *$ Tempo & $-0,66762$ & 3,255 & $-0,205$ & 0,843 \\
\hline $\mathrm{Mn}+2 *$ Tempo & $-0,66763$ & 3,255 & $-0,205$ & 0,843 \\
\hline
\end{tabular}


Continuação

$\mathrm{S}=9,20685 \quad$ PRESS $=3813,26$

$\mathrm{R}-\mathrm{Sq}=50,78 \% \mathrm{R}-\mathrm{Sq}(\mathrm{pred})=0,00 \% \mathrm{R}-\mathrm{Sq}(\operatorname{adj})=0,00 \%$

Analysis of Variance for $\mathrm{MnP}$

$\begin{array}{llllllc}\text { Source } & \text { DF } & \text { Seq SS } & \text { Adj SS } & \text { Adj MS } & \text { F } & \text { P } \\ \text { Regression } & 9 & 612,24 & 612,241 & 68,027 & 0,80 & 0,629 \\ \text { Linear } & 3 & 300,11 & 300,110 & 100,037 & 1,18 & 0,384 \\ \text { Square } & 3 & 304,53 & 304,532 & 101,511 & 1,20 & 0,378 \\ \text { Interaction } & 3 & 7,60 & 7,598 & 2,533 & 0,03 & 0,992 \\ \text { Residual Error } & 7 & 593,36 & 593,362 & 84,766 & & \\ \text { Lack-of-Fit } & 5 & 463,82 & 463,822 & 92,764 & 1,43 & 0,460 \\ \text { Pure Error } & 2 & 129,54 & 129,540 & 64,770 & & \\ \text { Total } & 16 & 1205,60 & & & & \end{array}$

Estimated Regression Coefficients for MnP using data in uncoded units

\begin{tabular}{ll} 
Term & Coef \\
Constant & 4,82002 \\
$\mathrm{Cu}+2$ & 27,3965 \\
$\mathrm{Mn}+2$ & $-77,7132$ \\
Tempo & $-0,0418314$ \\
$\mathrm{Cu}+2 * \mathrm{Cu}+2$ & 2,24054 \\
$\mathrm{Mn}+2 * \mathrm{Mn}+2$ & 70,3525 \\
$\mathrm{Tempo}$ Tempo & 0,0166236 \\
$\mathrm{Cu}+2 * \mathrm{Mn}+2$ & $-4,40028$ \\
$\mathrm{Cu}+2 *$ Tempo & $-0,494374$ \\
$\mathrm{Mn}+2 *$ Tempo & $-0,383222$ \\
\hline
\end{tabular}

Otimização da Resposta para Descoloração por T. villosa

\begin{tabular}{|c|c|c|c|c|c|}
\hline \multicolumn{6}{|c|}{ Parâmetros } \\
\hline \multicolumn{2}{|c|}{ Resposta } & Meta & Inferior & Alvo Superi & ior Peso Import \\
\hline \multicolumn{2}{|c|}{ Descoloração } & Máximo & 0 & 1,57 & 1 \\
\hline \multicolumn{6}{|c|}{ Solução } \\
\hline \multicolumn{6}{|c|}{ Descoloração Desirability } \\
\hline Solução & $\mathrm{Cu}+2$ & $M n+2$ & Tempo & Ajuste & Composta \\
\hline 1 & 1 & 1 & 21,6667 & 0,672397 & 0,428279 \\
\hline \multicolumn{6}{|c|}{ Predição de Múltiplas Respostas } \\
\hline \multicolumn{6}{|c|}{ Variável Configuração } \\
\hline \multicolumn{6}{|c|}{$\mathrm{Cu}+2 \quad 1$} \\
\hline \multicolumn{6}{|c|}{$\mathbf{M n}+2 \quad 1$} \\
\hline \multirow{2}{*}{\multicolumn{2}{|c|}{ Tempo }} & 6667 & & & \\
\hline & & EP do & & & \\
\hline \multirow{2}{*}{\multicolumn{2}{|c|}{$\begin{array}{l}\text { Resposta } \\
\text { Descoloração }\end{array}$}} & Ajuste $A$ & Ajustado & IC de 95\% & IP de $95 \%$ \\
\hline & & 0,672 & 0,266 & $(0,043 ; 1,302)$ & $(-0,069 ; 1,414)$ \\
\hline
\end{tabular}


Fenoloxidases $P$. cinerea versus descoloração

Correlação de Pearson $=-0,122$

Valor-P $=0,641$

Lacases $P$. cinerea versus descoloração

Correlação de Pearson $=-0,087$

Valor-P $=0,740$

MnP P. cinerea versus descoloração

Correlação de Pearson $=-0,265$

Valor-P $=0,304$

Fenoloxidases $\boldsymbol{P}$. ostreatus versus descoloração

Correlação de Pearson $=0,516$

Valor-P $=0,034$

Lacases $\boldsymbol{P}$. ostreatus versus descoloração

Correlação de Pearson $=0,571$

Valor-P $=0,017$

MnP P. ostreatus versus descoloração

Correlação de Pearson $=-0,006$

Valor-P $=0,983$

Fenoloxidases $T$. villosa versus descoloração

Correlação de Pearson $=0,241$

Valor-P $=0,351$

Lacases $T$. villosa versus descoloração

Correlação de Pearson $=0,036$

Valor-P $=0,892$

MnP T. villosa versus descoloração

Correlação de Pearson $=0,091$

Valor-P = 0,729 


\section{APÊNDICE D - Análise estatística item 4.4}

Peniophora cinerea

Regressão de Superfície de Resposta: \%Descoloração RB222 (526nm) por P. cinerea em 24 horas versus ABTS; RBBR; Ácido Graxo

\begin{tabular}{lccccc}
\hline Análise de Variância & & & & & \\
Fonte & GL & SQ (Aj.) & QM (Aj.) & Valor F & Valor-P \\
Modelo & 9 & 0,74012 & 0,082235 & 0,89 & 0,576 \\
Linear & 3 & 0,53480 & 0,178265 & 1,92 & 0,214 \\
ABTS & 1 & 0,45681 & 0,456813 & 4,93 & 0,062 \\
RBBR & 1 & 0,00899 & 0,008993 & 0,10 & 0,764 \\
Ácido Graxo & 1 & 0,06899 & 0,068990 & 0,74 & 0,417 \\
Quadrado & 3 & 0,19486 & 0,064953 & 0,70 & 0,581 \\
ABTS*ABTS & 1 & 0,07359 & 0,073589 & 0,79 & 0,402 \\
RBBR*RBBR & 1 & 0,09010 & 0,090103 & 0,97 & 0,357 \\
Ácido Graxo*Ácido Graxo & 1 & 0,01276 & 0,012759 & 0,14 & 0,722 \\
Interação com 2 Fatores & 3 & 0,01046 & 0,003487 & 0,04 & 0,989 \\
ABTS*RBBR & 1 & 0,00291 & 0,002907 & 0,03 & 0,864 \\
ABTS*Ácido Graxo & 1 & 0,00094 & 0,000936 & 0,01 & 0,923 \\
RBBR*Ácido Graxo & 1 & 0,00662 & 0,006617 & 0,07 & 0,797 \\
Erro & 7 & 0,64846 & 0,092637 & & \\
Falta de ajuste & 5 & 0,39015 & 0,078031 & 0,60 & 0,719 \\
Erro puro & 2 & 0,25830 & 0,129151 & $*$ & $*$ \\
Total & 16 & 1,38857 & & & \\
Samario do Modelo & & & & &
\end{tabular}

Sumário do Modelo

$\begin{array}{clll}\mathrm{S} & \mathrm{R} 2 & \mathrm{R} 2(\mathrm{aj}) & \mathrm{R} 2 \text { (pred) } \\ 0,304363 & 53,30 \% & 0,00 \% & 0,00 \%\end{array}$

Coeficientes Codificados

$\begin{array}{lcclccc}\text { Termo } & \text { Efeito } & \text { Coef } & \text { EP de Coef } & \text { Valor T } & \text { Valor-P } & \text { VIF } \\ \text { Constante } & 0,223 & 0,175 & 1,27 & 0,243 & & \\ \text { ABTS } & 0,3659 & 0,1830 & 0,0824 & 2,22 & 0,062 & 1,00 \\ \text { RBBR } & 0,0513 & 0,0257 & 0,0824 & 0,31 & 0,764 & 1,00 \\ \text { Ácido Graxo } & 0,1422 & 0,0711 & 0,0824 & 0,86 & 0,417 & 1,00 \\ \text { ABTS*ABTS } & 0,1618 & 0,0809 & 0,0908 & 0,89 & 0,402 & 1,15 \\ \text { RBBR*RBBR } & 0,1790 & 0,0895 & 0,0908 & 0,99 & 0,357 & 1,15 \\ \text { Ácido Graxo*Ácido Graxo } & -0,0674 & -0,0337 & 0,0908 & -0,37 & 0,722 & 1,15 \\ \text { ABTS*RBBR } & 0,038 & 0,019 & 0,108 & 0,18 & 0,864 & 1,00 \\ \text { ABTS*Ácido Graxo } & 0,022 & 0,011 & 0,108 & 0,10 & 0,923 & 1,00 \\ \text { RBBR*Ácido Graxo } & 0,058 & 0,029 & 0,108 & 0,27 & 0,797 & 1,00\end{array}$

Equação de Regressão em Unidades Não codificadas $\% \mathrm{D}$ 24h 526nm = 0,305 - 0,234*ABTS - 5,97*RBBR + 0,079*Ácido Graxo + 0,228*ABTS*ABTS + 25,3*RBBR*RBBR - 0,0152*Ácido Graxo*Ácido Graxo + 0,54*ABTS*RBBR + 0,012*ABTS*Ácido Graxo + $0,32 * \mathrm{RBBR} *$ Ácido Graxo

Regressão de Superfície de Resposta: \%Descoloração RB222 (526nm) por $P$. cinerea em 48 horas versus ABTS; RBBR; Ácido Graxo

\begin{tabular}{lccccc}
\hline Análise de Variância & GL SQ (Aj.) & QM (Aj.) & Valor F Valor-P \\
Fonte & 9 & 0,301834 & 0,033537 & 0,34 & 0,930 \\
Modelo & 3 & 0,086692 & 0,028897 & 0,30 & 0,827 \\
Linear & 1 & 0,080021 & 0,080021 & 0,82 & 0,395 \\
ABTS & 1 & 0,001659 & 0,001659 & 0,02 & 0,900 \\
RBBR & 1 & 0,005011 & 0,005011 & 0,05 & 0,827 \\
Ácido Graxo & 3 & 0,201895 & 0,067298 & 0,69 & 0,586 \\
Quadrado & 1 & 0,106916 & 0,106916 & 1,10 & 0,330 \\
ABTS*ABTS & 1 & 0,106916 & 0,106916 & 1,10 & 0,330 \\
RBBR*RBBR & & & & &
\end{tabular}




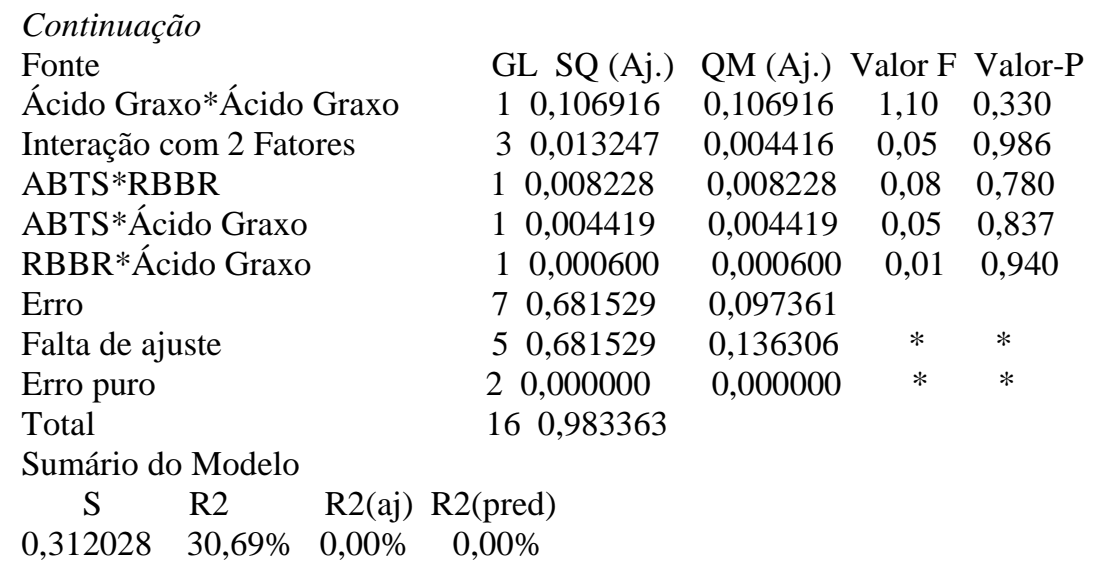

Coeficientes Codificados

$\begin{array}{lcccccr}\text { Termo } & \text { Efeito } & \text { Coef } & \text { EP de Coef } & \text { Valor T } & \text { Valor-P } & \text { VIF } \\ \text { Constante } & -0,029 & 0,180 & -0,16 & 0,876 & & \\ \text { ABTS } & -0,1532 & -0,0766 & 0,0845 & -0,91 & 0,395 & 1,00 \\ \text { RBBR } & -0,0221 & -0,0110 & 0,0845 & -0,13 & 0,900 & 1,00 \\ \text { Ácido Graxo } & 0,0383 & 0,0192 & 0,0845 & 0,23 & 0,827 & 1,00 \\ \text { ABTS*ABTS } & 0,1950 & 0,0975 & 0,0931 & 1,05 & 0,330 & 1,15 \\ \text { RBBR*RBBR } & 0,1950 & 0,0975 & 0,0931 & 1,05 & 0,330 & 1,15 \\ \text { Ácido Graxo*Ácido Graxo } & 0,1950 & 0,0975 & 0,0931 & 1,05 & 0,330 & 1,15 \\ \text { ABTS*RBBR } & 0,064 & 0,032 & 0,110 & 0,29 & 0,780 & 1,00 \\ \text { ABTS*Ácido Graxo } & 0,047 & 0,024 & 0,110 & 0,21 & 0,837 & 1,00 \\ \text { RBBR*Ácido Graxo } & -0,017 & -0,009 & 0,110 & -0,08 & 0,940 & 1,00\end{array}$

Equação de Regressão em Unidades Não codificadas

\%D 48h 526nm = 1,044 - 0,836*ABTS - 6,35*RBBR - 0,224*Ácido Graxo + 0,275*ABTS*ABTS + 27,5*RBBR*RBBR + 0,0440*Ácido Graxo*Ácido Graxo + 0,91*ABTS*RBBR + 0,027*ABTS*Ácido Graxo $0,10 *$ RBBR*Ácido Graxo

Regressão de Superfície de Resposta: \%Descoloração RB222 (610nm)por P. cinerea em 24 horas versus ABTS; RBBR; Ácido Graxo

\begin{tabular}{|c|c|c|c|c|c|}
\hline \multicolumn{6}{|l|}{ Análise de Variância } \\
\hline Fonte & GL & SQ (Aj.) & QM (Aj.) & Valor F & Valor-P \\
\hline Modelo & 9 & 0,47859 & 0,053177 & 0,65 & 0,733 \\
\hline Linear & 3 & 0,28835 & 0,096118 & 1,17 & 0,386 \\
\hline ABTS & 1 & 0,11599 & 0,115987 & 1,42 & 0,273 \\
\hline RBBR & 1 & 0,00000 & 0,000003 & 0,00 & 0,996 \\
\hline Ácido Graxo & 1 & 0,17236 & 0,172364 & 2,10 & 0,190 \\
\hline Quadrado & 3 & 0,12023 & 0,040075 & 0,49 & 0,701 \\
\hline ABTS*ABTS & 1 & 0,03234 & 0,032344 & 0,39 & 0,550 \\
\hline $\mathrm{RBBR} * \mathrm{RBBR}$ & 1 & 0,00593 & 0,005928 & 0,07 & 0,796 \\
\hline Ácido Graxo*Ácido Graxo & 1 & 0,04919 & 0,049185 & 0,60 & 0,464 \\
\hline Interação com 2 Fatores & 3 & 0,07001 & 0,023338 & 0,28 & 0,835 \\
\hline ABTS*RBBR & 1 & 0,01482 & 0,014818 & 0,18 & 0,683 \\
\hline ABTS*Ácido Graxo & 1 & 0,02253 & 0,022534 & 0,27 & 0,616 \\
\hline RBBR*Ácido Graxo & 1 & 0,03266 & 0,032661 & 0,40 & 0,548 \\
\hline Erro & 7 & 0,57362 & 0,081945 & & \\
\hline Falta de ajuste & 5 & 0,21676 & 0,043352 & 0,24 & 0,912 \\
\hline Erro puro & 2 & 0,35686 & 0,178428 & $*$ & $*$ \\
\hline Total & 16 & 1,05221 & & & \\
\hline \multicolumn{6}{|l|}{ Sumário do Modelo } \\
\hline $\begin{array}{lll}S & R 2 & R 2(a j)\end{array}$ & $\mathrm{R} 2(\mathrm{p}$ & & & & \\
\hline $0,286261 \quad 45,48 \% \quad 0,00 \%$ & 0,00 & & & & \\
\hline
\end{tabular}

Coeficientes Codificados 
Continuação

$\begin{array}{lclcccc}\text { Termo } & \text { Efeito } & \text { Coef } & \text { EP de Coef } & \text { Valor T } & \text { Valor-P } & \text { VIF } \\ \text { Constante } & 0,492 & 0,165 & 2,98 & 0,020 & & \\ \text { ABTS } & 0,1844 & 0,0922 & 0,0775 & 1,19 & 0,273 & 1,00 \\ \text { RBBR } & -0,0009 & -0,0004 & 0,0775 & -0,01 & 0,996 & 1,00 \\ \text { Ácido Graxo } & 0,2248 & 0,1124 & 0,0775 & 1,45 & 0,190 & 1,00 \\ \text { ABTS*ABTS } & 0,1073 & 0,0536 & 0,0854 & 0,63 & 0,550 & 1,15 \\ \text { RBBR*RBBR } & -0,0459 & -0,0230 & 0,0854 & -0,27 & 0,796 & 1,15 \\ \text { Ácido Graxo*Ácido Graxo } & -0,1323 & -0,0661 & 0,0854 & -0,77 & 0,464 & 1,15 \\ \text { ABTS*RBBR } & 0,086 & 0,043 & 0,101 & 0,43 & 0,683 & 1,00 \\ \text { ABTS*Ácido Graxo } & -0,106 & -0,053 & 0,101 & -0,52 & 0,616 & 1,00 \\ \text { RBBR*Ácido Graxo } & 0,128 & 0,064 & 0,101 & 0,63 & 0,548 & 1,00\end{array}$

Equação de Regressão em Unidades Não codificadas

\%Desc 24h 610nm= 0,201 - 0,120*ABTS - 1,73*RBBR + 0,213*Ácido Graxo + 0,151*ABTS*ABTS 6,5*RBBR*RBBR - 0,0299*Ácido Graxo*Ácido graxo + 1,21*ABTS*RBBR - 0,060*ABTS*Ácido Graxo + $0,72 * \mathrm{RBBR} *$ Ácido Graxo

\begin{tabular}{|c|c|c|c|c|c|}
\hline \multicolumn{6}{|l|}{$\begin{array}{l}\text { Regressão de Superfície de R } \\
\text { ABTS; RBBR; Ácido Graxo }\end{array}$} \\
\hline \multicolumn{6}{|l|}{ Análise de Variância } \\
\hline Fonte & GL & SQ (Aj.) & $\mathrm{QM}(\mathrm{Aj})$. & Valor F & Valor-P \\
\hline Modelo & 9 & 0,44498 & 0,049442 & 0,44 & 0,873 \\
\hline Linear & 3 & 0,05966 & 0,019888 & 0,18 & 0,908 \\
\hline ABTS & 1 & 0,05404 & 0,054040 & 0,48 & 0,509 \\
\hline RBBR & 1 & 0,00550 & 0,005498 & 0,05 & 0,831 \\
\hline Ácido Graxo & 1 & 0,00012 & 0,000125 & 0,00 & 0,974 \\
\hline Quadrado & 3 & 0,34647 & 0,115491 & 1,04 & 0,434 \\
\hline ABTS*ABTS & 1 & 0,10453 & 0,104531 & 0,94 & 0,365 \\
\hline $\mathrm{RBBR} * \mathrm{RBBR}$ & 1 & 0,10453 & 0,104531 & 0,94 & 0,365 \\
\hline Ácido Graxo*Ácido Graxo & 1 & 0,29953 & 0,299528 & 2,69 & 0,145 \\
\hline Interação com 2 Fatores & 3 & 0,03884 & 0,012948 & 0,12 & 0,948 \\
\hline ABTS*RBBR & 1 & 0,00095 & 0,000952 & 0,01 & 0,929 \\
\hline ABTS*Ácido Graxo & 1 & 0,02172 & 0,021724 & 0,19 & 0,672 \\
\hline RBBR*Ácido Graxo & 1 & 0,01617 & 0,016169 & 0,14 & 0,715 \\
\hline Erro & 7 & 0,78075 & 0,111536 & & \\
\hline Falta de ajuste & 5 & 0,78075 & 0,156151 & $*$ & $*$ \\
\hline Erro puro & 2 & 0,00000 & 0,000000 & $*$ & $*$ \\
\hline Total & & 1,22573 & & & \\
\hline \multicolumn{6}{|l|}{ Sumário do Modelo } \\
\hline $\begin{array}{lll}\mathrm{S} & \mathrm{R} 2 & \mathrm{R} 2(\mathrm{aj})\end{array}$ & R2(pre & ed) & & & \\
\hline $0,333970 \quad 36,30 \% \quad 0,00 \%$ & $0,00 \%$ & & & & \\
\hline \multicolumn{6}{|l|}{ Coeficientes Codificados } \\
\hline Termo & Efeito & Coef & EP de Coef & Valor T & Valor-P VIF \\
\hline Constante & $-0,029$ & 0,192 & $-0,15$ & 0,885 & \\
\hline ABTS & $-0,1259$ & $-0,0629$ & 0,0904 & $-0,70$ & $0,5091,00$ \\
\hline RBBR & $-0,0401$ & $-0,0201$ & 0,0904 & $-0,22$ & $0,8311,00$ \\
\hline Ácido Graxo & $-0,0060$ & $-0,0030$ & 0,0904 & $-0,03$ & $0,9741,00$ \\
\hline ABTS*ABTS & 0,1929 & 0,0964 & 0,0996 & 0,97 & $0,3651,15$ \\
\hline $\mathrm{RBBR} * \mathrm{RBBR}$ & 0,1929 & 0,0964 & 0,0996 & 0,97 & $0,3651,15$ \\
\hline Ácido Graxo*Ácido Graxo & 0,3265 & 0,1632 & 0,0996 & 1,64 & $0,1451,15$ \\
\hline ABTS*RBBR & 0,022 & 0,011 & 0,118 & 0,09 & $0,9291,00$ \\
\hline ABTS*Ácido Graxo & 0,104 & 0,052 & 0,118 & 0,44 & $0,6721,00$ \\
\hline RBBR*Ácido Graxo & 0,090 & 0,045 & 0,118 & 0,38 & $0,7151,00$ \\
\hline \multicolumn{6}{|c|}{$\begin{array}{l}\% \text { Desc 48h 610nm = 1,425 - 0,828*ABTS - 7,36*RBBR - 0,480*Ácido*Graxo + 0,272*ABTS*ABTS + } \\
\text { 27,2*RBBR*RBBR + 0,0737*Ácido Graxo*Ácido Graxo + 0,31*ABTS*RBBR + 0,059*ABTS*Ácido Graxo + } \\
\text { 0,51*RBBR*Ácido Graxo }\end{array}$} \\
\hline
\end{tabular}




\begin{tabular}{|c|c|c|c|c|c|}
\hline \multicolumn{6}{|c|}{ Regressão de Superfície de Resposta: MnP tempo inicial de $P$. cinerea versus ABTS; RBBR; Ácido Graxo } \\
\hline \multicolumn{6}{|c|}{ Análise de Variância } \\
\hline Fonte & GL & SQ (Aj.) & QM (Aj.) & Valor F & Valor-P \\
\hline Modelo & 9 & 665,68 & 73,964 & 0,46 & 0,860 \\
\hline Linear & 3 & 430,64 & 143,546 & 0,90 & 0,488 \\
\hline ABTS & 1 & 12,23 & 12,232 & 0,08 & 0,790 \\
\hline RBBR & 1 & 204,20 & 204,204 & 1,28 & 0,295 \\
\hline Ácido Graxo & 1 & 214,20 & 214,202 & 1,34 & 0,285 \\
\hline Quadrado & 3 & 235,04 & 78,346 & 0,49 & 0,700 \\
\hline ABTS*ABTS & 1 & 23,82 & 23,819 & 0,15 & 0,711 \\
\hline $\mathrm{RBBR} * \mathrm{RBBR}$ & 1 & 84,92 & 84,916 & 0,53 & 0,489 \\
\hline Ácido Graxo*Ácido Graxo & 1 & 93,44 & 93,440 & 0,59 & 0,469 \\
\hline Interação com 2 Fatores & 3 & 0,00 & 0,000 & 0,00 & 1,000 \\
\hline ABTS*RBBR & 1 & 0,00 & 0,000 & 0,00 & 1,000 \\
\hline ABTS*Ácido Graxo & 1 & 0,00 & 0,000 & 0,00 & 1,000 \\
\hline RBBR*Ácido Graxo & 1 & 0,00 & 0,000 & 0,00 & 1,000 \\
\hline Erro & 7 & 1117,27 & 159,610 & & \\
\hline Falta de ajuste & 5 & 1117,27 & 223,454 & $*$ & $*$ \\
\hline Erro puro & 2 & 0,00 & 0,000 & $*$ & $*$ \\
\hline Total & 16 & 1782,95 & & & \\
\hline \multicolumn{6}{|l|}{ Sumário do Modelo } \\
\hline $\begin{array}{lll}S & R 2 & R 2(a j)\end{array}$ & R2(pred) & & & & \\
\hline $12,6337 \quad 37,34 \% \quad 0,00 \%$ & $0,00 \%$ & & & & \\
\hline
\end{tabular}

Coeficientes Codificados

$\begin{array}{lcrrrrr}\text { Termo } & \text { Efeito } & \text { Coef } & \begin{array}{c}\text { EP de } \\ \text { Coef }\end{array} & \text { Valor T } & \text { Valor-P } & \text { VIF } \\ \text { Constante } & 0,84 & 7,28 & 0,12 & 0,911 & & \\ \text { ABTS } & 1,89 & 0,95 & 3,42 & 0,28 & 0,790 & 1,00 \\ \text { RBBR } & -7,74 & -3,87 & 3,42 & -1,13 & 0,295 & 1,00 \\ \text { Ácido Graxo } & 7,92 & 3,96 & 3,42 & 1,16 & 0,285 & 1,00 \\ \text { ABTS*ABTS } & -2,91 & -1,46 & 3,77 & -0,39 & 0,711 & 1,15 \\ \text { RBBR*RBBR } & 5,50 & 2,75 & 3,77 & 0,73 & 0,489 & 1,15 \\ \text { Ácido Graxo*Ácido Graxo } & 5,77 & 2,88 & 3,77 & 0,77 & 0,469 & 1,15 \\ \text { ABTS*RBBR } & 0,00 & 0,00 & 4,47 & 0,00 & 1,000 & 1,00 \\ \text { ABTS*Ácido Graxo } & -0,00 & -0,00 & 4,47 & -0,00 & 1,000 & 1,00 \\ \text { RBBR*Ácido Graxo } & 0,00 & 0,00 & 4,47 & 0,00 & 1,000 & 1,00\end{array}$

Equação de Regressão em Unidades Não codificadas

MnP tempo inicial = 10,9 + 9,8*ABTS - 220*RBBR - 3,8*Ácido Graxo - 4,1*ABTS*ABTS + 776*RBBR*RBBR + 1,30*Ácido Graxo*Ácido Graxo + 0*ABTS*RBBR + 0,00*ABTS*Ácido Graxo + 0,0*RBBR*Ácido Graxo

Regressão de Superfície de Resposta: MnP em 24 horas de P. cinerea versus ABTS; RBBR; Ácido Graxo Análise de Variância

$\begin{array}{llllll}\text { Fonte } & \text { GL } & \text { SQ (Aj.) } & \text { QM (Aj.) } & \text { Valor F } & \text { Valor-P } \\ \text { Modelo } & 9 & 1499,65 & 166,627 & 1,05 & 0,486 \\ \text { Linear } & 3 & 576,12 & 192,041 & 1,21 & 0,375 \\ \text { ABTS } & 1 & 575,57 & 575,568 & 3,62 & 0,099 \\ \text { RBBR } & 1 & 0,00 & 0,000 & 0,00 & 1,000 \\ \text { Ácido Graxo } & 1 & 0,56 & 0,556 & 0,00 & 0,954 \\ \text { Quadrado } & 3 & 923,52 & 307,840 & 1,94 & 0,212 \\ \text { ABTS*ABTS } & 1 & 582,00 & 581,998 & 3,67 & 0,097 \\ \text { RBBR*RBBR } & 1 & 51,96 & 51,962 & 0,33 & 0,585 \\ \text { Ácido Graxo*Ácido Graxo } & 1 & 38,87 & 38,866 & 0,24 & 0,636 \\ \text { Interação com 2 Fatores } & 3 & 0,00 & 0,000 & 0,00 & 1,000 \\ \text { ABTS*RBBR } & 1 & 0,00 & 0,000 & 0,00 & 1,000 \\ \text { ABTS*Ácido Graxo } & 1 & 0,00 & 0,000 & 0,00 & 1,000 \\ \text { RBBR*Ácido Graxo } & 1 & 0,00 & 0,000 & 0,00 & 1,000 \\ \text { Erro } & 7 & 1111,59 & 158,799 & & \end{array}$


Continuação

\section{Fonte}

Falta de ajuste

Erro puro

Total

Sumário do Modelo

$\begin{array}{clll}\text { S } & \text { R2 } & \text { R2(aj) } & \text { R2(pred) } \\ 12,6015 & 57,43 \% & 2,70 \% & 0,00 \%\end{array}$

Coeficientes Codificados

\begin{tabular}{lcccccc} 
& \multicolumn{7}{c}{ EP de } \\
Termo & Efeito & Coef & Coef & Valor T & Valor-P & VIF \\
Constante & 0,64 & 7,26 & 0,09 & 0,932 & & \\
ABTS & 12,99 & 6,49 & 3,41 & 1,90 & 0,099 & 1,00 \\
RBBR & $-0,00$ & $-0,00$ & 3,41 & $-0,00$ & 1,000 & 1,00 \\
Ácido Graxo & 0,40 & 0,20 & 3,41 & 0,06 & 0,954 & 1,00 \\
ABTS*ABTS & 14,39 & 7,20 & 3,76 & 1,91 & 0,097 & 1,15 \\
RBBR*RBBR & $-4,30$ & $-2,15$ & 3,76 & $-0,57$ & 0,585 & 1,15 \\
Ácido Graxo*Ácido Graxo & $-3,72$ & $-1,86$ & 3,76 & $-0,49$ & 0,636 & 1,15 \\
ABTS*RBBR & $-0,00$ & $-0,00$ & 4,46 & $-0,00$ & 1,000 & 1,00 \\
ABTS*Ácido Graxo & $-0,00$ & $-0,00$ & 4,46 & $-0,00$ & 1,000 & 1,00 \\
RBBR*Ácido Graxo & 0,00 & 0,00 & 4,46 & 0,00 & 1,000 & 1,00
\end{tabular}

Equação de Regressão em Unidades Não codificadas

MnP em 24h = -1,6 - 29,7*ABTS + 121 RBBR + 4,3*Ácido Graxo + 20,3*ABTS*ABTS - 607*RBBR*RBBR 0,84*Ácido Graxo*Ácido Graxo - 0*ABTS*RBBR + 0,00*ABTS*Ácido Graxo - 0,0*RBBR*Ácido Graxo

\begin{tabular}{|c|c|c|c|c|c|}
\hline \multicolumn{6}{|c|}{ Regressão de Superfície de Resposta: MnP em 48 horas de $P$. cinerea vers } \\
\hline \multicolumn{6}{|c|}{ Análise de Variância } \\
\hline Fonte & GL & SQ (Aj.) & QM (Aj.) & Valor F & Valor-P \\
\hline Modelo & 9 & 3376,24 & 375,14 & 0,42 & 0,886 \\
\hline Linear & 3 & 2338,41 & 779,47 & 0,88 & 0,497 \\
\hline ABTS & 1 & 491,59 & 491,59 & 0,55 & 0,481 \\
\hline RBBR & 1 & 231,86 & 231,86 & 0,26 & 0,625 \\
\hline Ácido Graxo & 1 & 1614,96 & 1614,96 & 1,82 & 0,220 \\
\hline Quadrado & 3 & 1037,83 & 345,94 & 0,39 & 0,764 \\
\hline ABTS*ABTS & 1 & 40,30 & 40,30 & 0,05 & 0,837 \\
\hline $\mathrm{RBBR} * \mathrm{RBBR}$ & 1 & 7,41 & 7,41 & 0,01 & 0,930 \\
\hline Ácido Graxo*Ácido Graxo & 1 & 892,60 & 892,60 & 1,01 & 0,349 \\
\hline Interação com 2 Fatores & 3 & 0,00 & 0,00 & 0,00 & 1,000 \\
\hline ABTS*RBBR & 1 & 0,00 & 0,00 & 0,00 & 1,000 \\
\hline ABTS*Ácido Graxo & 1 & 0,00 & 0,00 & 0,00 & 1,000 \\
\hline RBBR*Ácido Graxo & 1 & 0,00 & 0,00 & 0,00 & 1,000 \\
\hline Erro & 7 & 6216,90 & 888,13 & & \\
\hline Falta de ajuste & 5 & 6216,90 & 1243,38 & $*$ & $*$ \\
\hline Erro puro & 2 & 0,00 & 0,00 & $*$ & $*$ \\
\hline Total & 16 & 9593,14 & & & \\
\hline \multicolumn{6}{|l|}{ Sumário do Modelo } \\
\hline $\begin{array}{lll}S & R 2 & R 2(a j)\end{array}$ & R2(pre & & & & \\
\hline $29,8015 \quad 35,19 \% \quad 0,00 \%$ & $0,00 \%$ & & & & \\
\hline
\end{tabular}

Coeficientes Codificados

Termo

Constante

ABTS

RBBR

Ácido Graxo

ABTS*ABTS

RBBR*RBBR

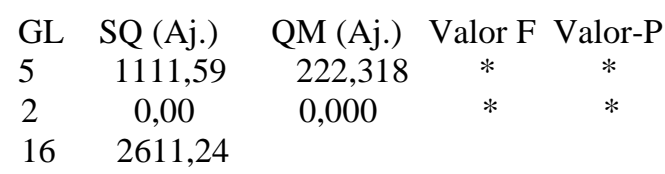


Continuação

$\begin{array}{lcccccc}\text { Termo } & \text { Efeito } & \text { Coef } & \text { Coef } & \text { Valor T } & \text { Valor-P } & \text { VIF } \\ \text { Ácido Graxo*Ácido Graxo } & 17,82 & 8,91 & 8,89 & 1,00 & 0,349 & 1,15 \\ \text { ABTS*RBBR } & -0,0 & -0,0 & 10,5 & -0,00 & 1,000 & 1,00 \\ \text { ABTS*Ácido Graxo } & -0,0 & -0,0 & 10,5 & -0,00 & 1,000 & 1,00 \\ \text { RBBR*Ácido Graxo } & 0,0 & 0,0 & 10,5 & 0,00 & 1,000 & 1,00\end{array}$

Equação de Regressão em Unidades Não codificadas

MnP em 48h = 8,8 - 0,6*ABTS - 23*RBBR - 12,8*Ácido Graxo + 5,3*ABTS*ABTS - 229*RBBR*RBBR + 4,02*Ácido Graxo*Ácido Graxo - 0*ABTS*RBBR + 0,0*ABTS*Ácido Graxo - 0*RBBR*Ácido Graxo

\begin{tabular}{|c|c|c|c|c|c|}
\hline \multicolumn{6}{|l|}{ Análise de Variância } \\
\hline Fonte & GL & SQ (Aj.) & QM (Aj.) & Valor F & Valor-P \\
\hline Modelo & 9 & 2043735 & 227082 & 0,32 & 0,944 \\
\hline Linear & 3 & 509803 & 169934 & 0,24 & 0,868 \\
\hline ABTS & 1 & 56668 & 56668 & 0,08 & 0,787 \\
\hline RBBR & 1 & 66 & 66 & 0,00 & 0,993 \\
\hline Ácido Graxo & 1 & 453070 & 453070 & 0,63 & 0,453 \\
\hline Quadrado & 3 & 1527871 & 509290 & 0,71 & 0,576 \\
\hline ABTS*ABTS & 1 & 1114635 & 1114635 & 1,56 & 0,252 \\
\hline $\mathrm{RBBR} * \mathrm{RBBR}$ & 1 & 808205 & 808205 & 1,13 & 0,323 \\
\hline Ácido Graxo*Ácido Graxo & 1 & 73963 & 73963 & 0,10 & 0,757 \\
\hline Interação com 2 Fatores & 3 & 6061 & 2020 & 0,00 & 1,000 \\
\hline ABTS*RBBR & 1 & 96 & 96 & 0,00 & 0,991 \\
\hline ABTS*Ácido Graxo & 1 & 3220 & 3220 & 0,00 & 0,948 \\
\hline RBBR*Ácido Graxo & 1 & 2744 & 2744 & 0,00 & 0,952 \\
\hline Erro & 7 & 5013661 & 716237 & & \\
\hline Falta de ajuste & 5 & 1232092 & 246418 & 0,13 & 0,970 \\
\hline Erro puro & 2 & 3781569 & 1890785 & $*$ & $*$ \\
\hline Total & 16 & 7057397 & & & \\
\hline \multicolumn{6}{|l|}{ Sumário do Modelo } \\
\hline $\begin{array}{lll}S & R 2 & R 2(a j)\end{array}$ & $\mathrm{R} 2(\mathrm{p}$ & ored) & & & \\
\hline $846,308 \quad 28,96 \% \quad 0,00 \%$ & $0,00^{\circ}$ & & & & \\
\hline
\end{tabular}

Coeficientes Codificados

\begin{tabular}{lclllll} 
& \multicolumn{7}{c}{ EP de } \\
Termo & Efeito & Coef & Coef & Valor T & Valor-P & VIF \\
Constante & 1429 & 488 & 2,93 & 0,022 & & \\
ABTS & 129 & 64 & 229 & 0,28 & 0,787 & 1,00 \\
RBBR & -4 & -2 & 229 & $-0,01$ & 0,993 & 1,00 \\
Ácido Graxo & -364 & -182 & 229 & $-0,80$ & 0,453 & 1,00 \\
ABTS*ABTS & -630 & -315 & 252 & $-1,25$ & 0,252 & 1,15 \\
RBBR*RBBR & -536 & -268 & 252 & $-1,06$ & 0,323 & 1,15 \\
Ácido Graxo*Ácido Graxo & -162 & -81 & 252 & $-0,32$ & 0,757 & 1,15 \\
ABTS*RBBR & 7 & 3 & 299 & 0,01 & 0,991 & 1,00 \\
ABTS*Ácido Graxo & 40 & 20 & 299 & 0,07 & 0,948 & 1,00 \\
RBBR*Ácido Graxo & 37 & 19 & 299 & 0,06 & 0,952 & 1,00
\end{tabular}

Equação de Regressão em Unidades Não codificadas

Lacase tempo inicial $=-125+1819 *$ ABTS $+14477 *$ RBBR $+17 *$ Ácido Graxo $-889 *$ ABTS*ABTS 75675*RBBR*RBBR - 37*Ácido Graxo*Ácido Graxo + 98*ABTS*RBBR + 23*ABTS*Ácido Graxo + 209*RBBR*Ácido Graxo

Regressão de Superfície de Resposta: Lacase em 24 horas de P. cinerea versus ABTS; RBBR; Ácido Graxo Análise de Variância

$\begin{array}{llllll}\text { Fonte } & \text { GL } & \text { SQ (Aj.) } & \text { QM (Aj.) } & \text { Valor F } & \text { Valor-P } \\ \text { Modelo } & 9 & 2356923 & 261880 & 0,50 & 0,838 \\ \text { Linear } & 3 & 559428 & 186476 & 0,35 & 0,788 \\ \text { ABTS } & 1 & 11935 & 11935 & 0,02 & 0,885\end{array}$


Continuação

$\begin{array}{lcllcc}\text { Fonte } & \text { GL } & \text { SQ (Aj.) } & \text { QM (Aj.) } & \text { Valor F } & \text { Valor-P } \\ \text { RBBR } & 1 & 98979 & 98979 & 0,19 & 0,678 \\ \text { Ácido Graxo } & 1 & 448514 & 448514 & 0,85 & 0,387 \\ \text { Quadrado } & 3 & 1771234 & 590411 & 1,12 & 0,404 \\ \text { ABTS*ABTS } & 1 & 1500225 & 1500225 & 2,84 & 0,136 \\ \text { RBBR*RBBR } & 1 & 581873 & 581873 & 1,10 & 0,329 \\ \text { Ácido Graxo*Ácido Graxo } & 1 & 27867 & 27867 & 0,05 & 0,825 \\ \text { Interação com 2 Fatores } & 3 & 26261 & 8754 & 0,02 & 0,997 \\ \text { ABTS*RBBR } & 1 & 17293 & 7293 & 0,03 & 0,861 \\ \text { ABTS*Ácido Graxo } & 1 & 6610 & 6610 & 0,01 & 0,914 \\ \text { RBBR*Ácido Graxo } & 1 & 2358 & 2358 & 0,00 & 0,949 \\ \text { Erro } & 7 & 3693734 & 527676 & & \\ \text { Falta de ajuste } & 5 & 1121605 & 224321 & 0,17 & 0,949 \\ \text { Erro puro } & 2 & 2572129 & 1286065 & * & * \\ \text { Total } & 16 & 6050657 & & & \end{array}$

Sumário do Modelo

$$
\begin{array}{clll}
\text { S } & \text { R2 } & \text { R2(aj) } & \text { R2(pred) } \\
726,413 & 38,95 \% & 0,00 \% & 0,00 \%
\end{array}
$$

Coeficientes Codificados

\begin{tabular}{lcccccc} 
& \multicolumn{7}{c}{ EP de } \\
Termo & Efeito & Coef & Coef & Valor T & Valor-P & VIF \\
Constante & 1410 & 419 & 3,37 & 0,012 & & \\
ABTS & 59 & 30 & 197 & 0,15 & 0,885 & 1,00 \\
RBBR & -170 & -85 & 197 & $-0,43$ & 0,678 & 1,00 \\
Ácido Graxo & -363 & -181 & 197 & $-0,92$ & 0,387 & 1,00 \\
ABTS*ABTS & -731 & -365 & 217 & $-1,69$ & 0,136 & 1,15 \\
RBBR*RBBR & -455 & -228 & 217 & $-1,05$ & 0,329 & 1,15 \\
Ácido Graxo*Ácido Graxo & -100 & -50 & 217 & $-0,23$ & 0,825 & 1,15 \\
ABTS*RBBR & -93 & -46 & 257 & $-0,18$ & 0,861 & 1,00 \\
ABTS*Ácido Graxo & -57 & -29 & 257 & $-0,11$ & 0,914 & 1,00 \\
RBBR*Ácido Graxo & 34 & 17 & 257 & 0,07 & 0,949 & 1,00
\end{tabular}

Equação de Regressão em Unidades Não codificadas

Lacase em 24h $=-170+2324 * A B T S+12239 * R B B R+4 *$ Ácido Graxo - 1031*ABTS*ABTS 64210*RBBR*RBBR - 22,5*Ácido Graxo*Ácido Graxo - 1312*ABTS*RBBR - 32*ABTS*Ácido Graxo + 194*RBBR*Ácido Graxo

\begin{tabular}{lcllll}
\hline \multicolumn{7}{l}{ Regressão de Superfície de Resposta: Lacase em 48 horas $P$. cinerea versus } \\
\hline Análise de Variância & GL & SQ (Aj.) & QM (Aj.) & Valor F & Valor-P \\
Fonte & 9 & 3720591 & 413399 & 0,41 & 0,892 \\
Modelo & 3 & 945670 & 315223 & 0,31 & 0,814 \\
Linear & 1 & 6660 & 6660 & 0,01 & 0,937 \\
ABTS & 1 & 70708 & 70708 & 0,07 & 0,798 \\
RBBR & 1 & 868303 & 868303 & 0,87 & 0,383 \\
Ácido Graxo & 3 & 2772983 & 924328 & 0,92 & 0,478 \\
Quadrado & 1 & 2356998 & 2356998 & 2,35 & 0,169 \\
ABTS*ABTS & 1 & 1112786 & 1112786 & 1,11 & 0,327 \\
RBBR*RBBR & 1 & 215773 & 215773 & 0,22 & 0,657 \\
Ácido Graxo*Ácido Graxo & 3 & 1937 & 646 & 0,00 & 1,000 \\
Interação com 2 Fatores & 1 & 250 & 250 & 0,00 & 0,988 \\
ABTS*RBBR & 1 & 1501 & 1501 & 0,00 & 0,970 \\
ABTS*Ácido Graxo & 1 & 186 & 186 & 0,00 & 0,990 \\
RBBR*Ácido Graxo & 7 & 7006667 & 1000952 & & \\
Erro & 5 & 2364229 & 472846 & 0,20 & 0,934 \\
Falta de ajuste & 2 & 4642439 & 2321219 & $*$ & $*$ \\
Erro puro & 16 & 10727258 & & & \\
Total & & & & &
\end{tabular}


Continuação

Sumário do Modelo

\begin{tabular}{|c|c|c|c|c|c|c|}
\hline $\mathrm{S} \quad \mathrm{R} 2$ & \multicolumn{6}{|c|}{ R2(pred) } \\
\hline $1000,48 \quad 34,68 \% \quad 0,00 \%$ & \multicolumn{6}{|c|}{$0,00 \%$} \\
\hline \multicolumn{7}{|l|}{ Coeficientes Codificados } \\
\hline & & & EP de & & & \\
\hline Termo & Efeito & Coef & Coef & Valor T & Valor-P & VIF \\
\hline Constante & 1735 & 576 & 3,01 & 0,020 & & \\
\hline ABTS & 44 & 22 & 271 & 0,08 & 0,937 & 1,00 \\
\hline RBBR & -144 & -72 & 271 & $-0,27$ & 0,798 & 1,00 \\
\hline Ácido Graxo & -505 & -252 & 271 & $-0,93$ & 0,383 & 1,00 \\
\hline ABTS*ABTS & -916 & -458 & 298 & $-1,53$ & 0,169 & 1,15 \\
\hline $\mathrm{RBBR} * \mathrm{RBBR}$ & -629 & -315 & 298 & $-1,05$ & 0,327 & 1,15 \\
\hline Ácido Graxo*Ácido Graxo & -277 & -139 & 298 & $-0,46$ & 0,657 & 1,15 \\
\hline ABTS*RBBR & -11 & -6 & 354 & $-0,02$ & 0,988 & 1,00 \\
\hline ABTS*Ácido Graxo & -27 & -14 & 354 & $-0,04$ & 0,970 & 1,00 \\
\hline RBBR*Ácido Graxo & -10 & -5 & 354 & $-0,01$ & 0,990 & 1,00 \\
\hline
\end{tabular}

Equação de Regressão em Unidades Não codificadas

Lacase em 48h $=-396+2676 * A B T S+16844 *$ RBBR + 164*Ácido Graxo - 1292*ABTS*ABTS 88796*RBBR*RBBR - 63*Ácido Graxo*Ácido Graxo - 158*ABTS*RBBR - 15*ABTS*Ácido Graxo $54 *$ RBBR*Ácido Graxo

Pleurotus ostreatus

Regressão de Superfície de Resposta: \%Descoloração RB222 (610nm) por P. ostreatus em 24 horas versus ABTS; RBBR; Ácido Graxo

\begin{tabular}{lccccc}
\hline Análise de Variância & & & & & \\
Fonte & GL & SQ (Aj.) & QM (Aj.) & Valor F & Valor-P \\
Modelo & 9 & 0,545717 & 0,060635 & 7,39 & 0,008 \\
Linear & 3 & 0,295233 & 0,098411 & 12,00 & 0,004 \\
ABTS & 1 & 0,008523 & 0,008523 & 1,04 & 0,342 \\
RBBR & 1 & 0,021798 & 0,021798 & 2,66 & 0,147 \\
Ácido Graxo & 1 & 0,264912 & 0,264912 & 32,31 & 0,001 \\
Quadrado & 3 & 0,196195 & 0,065398 & 7,98 & 0,012 \\
ABTS*ABTS & 1 & 0,011461 & 0,011461 & 1,40 & 0,276 \\
RBBR*RBBR & 1 & 0,111700 & 0,111700 & 13,62 & 0,008 \\
Ácido Graxo*Ácido Graxo & 1 & 0,054647 & 0,054647 & 6,66 & 0,036 \\
Interação com 2 Fatores & 3 & 0,054289 & 0,018096 & 2,21 & 0,175 \\
ABTS*RBBR & 1 & 0,039270 & 0,039270 & 4,79 & 0,065 \\
ABTS*Ácido Graxo & 1 & 0,008081 & 0,008081 & 0,99 & 0,354 \\
RBBR*Ácido Graxo & 1 & 0,006938 & 0,006938 & 0,85 & 0,388 \\
Erro & 7 & 0,057400 & 0,008200 & & \\
Falta de ajuste & 5 & 0,049849 & 0,009970 & 2,64 & 0,297 \\
Erro puro & 2 & 0,007552 & 0,003776 & $*$ & $*$ \\
Total & 16 & 0,603118 & & & \\
Sumário do Modelo & & & & & \\
$\quad$ S R2 & R2(aj) & R2(pred) & & & \\
0,0905542 90,48\% 78,25\% & $34,41 \%$ & & &
\end{tabular}

Coeficientes Codificados

$\begin{array}{lllllll}\text { Termo } & \text { Efeito } & \text { Coef } & \text { EP de Coef } & \text { Valor T } & \text { Valor-P } & \text { VIF } \\ \text { Constante } & 0,7432 & 0,0522 & 14,25 & 0,000 & & \\ \text { ABTS } & -0,0500 & -0,0250 & 0,0245 & -1,02 & 0,342 & 1,00 \\ \text { RBBR } & 0,0799 & 0,0400 & 0,0245 & 1,63 & 0,147 & 1,00 \\ \text { Ácido Graxo } & -0,2787 & -0,1393 & 0,0245 & -5,68 & 0,001 & 1,00 \\ \text { ABTS*ABTS } & -0,0639 & -0,0319 & 0,0270 & -1,18 & 0,276 & 1,15 \\ \text { RBBR*RBBR } & 0,1994 & 0,0997 & 0,0270 & 3,69 & 0,008 & 1,15 \\ \text { Ácido Graxo*Ácido Graxo } & 0,1394 & 0,0697 & 0,0270 & 2,58 & 0,036 & 1,15 \\ \text { ABTS*RBBR } & 0,1401 & 0,0701 & 0,0320 & 2,19 & 0,065 & 1,00\end{array}$


Continuação

Termo Efeito Coef EP de Coef Valor T Valor-P VIF

ABTS*Ácido Graxo $\quad 0,0636 \quad 0,0318 \quad 0,0320 \quad 0,99 \quad 0,354 \quad 1,00$

RBBR*Ácido Graxo $\quad 0,0589 \quad 0,0294 \quad 0,0320 \quad 0,92 \quad 0,388 \quad 1,00$

Equação de Regressão em Unidades Não codificadas

\%Desc 610nm 24h = 1,711 - 0,149*ABTS - 7,76*RBBR - 0,3202*Ácido Graxo - 0,0901*ABTS*ABTS + 28,13*RBBR*RBBR + 0,0315*Ácido Graxo*Ácido Graxo + 1,977*ABTS*RBBR + 0,0359*ABTS*Ácido Graxo $+0,332 *$ RBBR*Ácido Graxo

Regressão de Superfície de Resposta: \%Descoloração RB222 (610nm) por P. ostreatus em 48 horas versus ABTS; RBBR; Ácido Graxo

\begin{tabular}{|c|c|c|c|c|c|c|c|c|}
\hline \multicolumn{9}{|l|}{ Análise de Variância } \\
\hline Fonte & & \multicolumn{2}{|c|}{ QM (Aj.) } & \multicolumn{2}{|c|}{ Valor F } & \multicolumn{2}{|c|}{ Valor-P } \\
\hline Modelo & 90,91 & $\begin{array}{c}\text { SQ (Aj.) } \\
0,91856\end{array}$ & \multicolumn{2}{|c|}{0,102063} & 5,04 & & \multicolumn{2}{|c|}{0,022} \\
\hline Linear & \multicolumn{2}{|c|}{0,67893} & \multicolumn{2}{|c|}{0,226310} & \multicolumn{2}{|c|}{11,18} & \multicolumn{2}{|c|}{0,005} \\
\hline ABTS & \multicolumn{2}{|c|}{0,00029} & \multicolumn{2}{|c|}{0,000289} & \multicolumn{2}{|c|}{0,01} & \multicolumn{2}{|c|}{0,908} \\
\hline RBBR & 10,07 & 0,07439 & \multicolumn{2}{|c|}{0,074389} & 3.67 & & \multicolumn{2}{|c|}{0,097} \\
\hline Ácido Graxo & 10,60 & 0,60425 & \multicolumn{2}{|c|}{0,604252} & \multicolumn{2}{|c|}{29,85} & \multicolumn{2}{|c|}{0,001} \\
\hline Quadrado & 30,2 & 0,22320 & \multicolumn{2}{|c|}{0,074400} & \multicolumn{2}{|c|}{3,68} & 71 & \\
\hline ABTS*ABTS & 10,00 & 689 & 0,0 & 06886 & 0,3 & 0,5 & & \\
\hline RBBR*RBBR & 0,20 & 424 & 0,2 & 04242 & 10 , & 0,0 & 16 & \\
\hline Ácido Graxo*Ácido Graxo & 10,05 & 767 & 0,0 & 57673 & 2,8 & 0,1 & 35 & \\
\hline Interação com 2 Fatores & 30,01 & 644 & 0,0 & 05479 & 0,2 & 0,8 & 45 & \\
\hline ABTS*RBBR & 10,0 & 075 & 0,01 & 10752 & 0,5 & 0,4 & 90 & \\
\hline ABTS*Ácido Graxo & 10,0 & 506 & 0,0 & 05061 & 0,2 & 0,6 & 32 & \\
\hline RBBR*Ácido Graxo & 10,00 & 062 & 0,0 & 00622 & 0 , & 0,8 & 66 & \\
\hline Erro & $7 \quad 0,14$ & 171 & 0,02 & 20244 & & & & \\
\hline Falta de ajuste & $5 \quad 0,11$ & 870 & 0,02 & 23740 & 2, & 0,3 & & \\
\hline Erro puro & 20,02 & 301 & 0,0 & 11504 & * & * & & \\
\hline Total & 161,0 & 6027 & & & & & & \\
\hline Sumário do Modelo & & & & & & & & \\
\hline $\begin{array}{lll}S & R 2 & R 2(a j)\end{array}$ & $\mathrm{R} 2(\mathrm{p}$ & red) & & & & & & \\
\hline $0,142282 \quad 86,63 \% \quad 69,45 \%$ & 9,71 & & & & & & & \\
\hline Coeficientes Codificados & & & & & & & & \\
\hline Termo & Efeito & Coef & & EP de & Loef & Valor T & Valor-P & VIF \\
\hline Constante & 0,7785 & 0,08 & & 9,50 & & 0,000 & & \\
\hline ABTS & 0,0092 & 0,00 & 46 & 0,038 & & 0,12 & 0,908 & 1,00 \\
\hline RBBR & 0,1477 & 0,07 & & 0,038 & & 1,92 & 0,097 & 1,00 \\
\hline Ácido Graxo & 0,4209 & $-0,21$ & 04 & 0,038 & & $-5,46$ & 0,001 & 1,00 \\
\hline ABTS*ABTS & 0,0495 & 0,02 & 47 & 0,042 & & 0,58 & 0,578 & 1,15 \\
\hline $\mathrm{RBBR} * \mathrm{RBBR}$ & 0,2696 & 0,13 & 48 & 0,042 & & 3,18 & 0,016 & 1,15 \\
\hline Ácido Graxo*Ácido Graxo 0 & 0,1432 & 0,07 & 16 & 0,042 & & 1,69 & 0,135 & 1,15 \\
\hline ABTS*RBBR & 0,0733 & 0,03 & & 0,050 & & 0,73 & 0,490 & 1,00 \\
\hline ABTS*Ácido Graxo & 0,0503 & 0,02 & & 0,05 & & 0,50 & 0,632 & 1,00 \\
\hline RBBR*Ácido Graxo & $-0,0176$ & $-0,0$ & 088 & 0,05 & & $-0,18$ & 0,866 & 1,00 \\
\hline
\end{tabular}

Equação de Regressão em Unidades Não codificadas

$\%$ Desc 610nm 48h = 1,802 - 0,306*ABTS - 7,15*RBBR - 0,322*Ácido Graxo + 0,070*ABTS*ABTS + 38,0*RBBR*RBBR + 0,0323*Ácido Graxo*Ácido Graxo + 1,03*ABTS*RBBR + 0,0284*ABTS*Ácido Graxo 0,100*RBBR*Ácido Graxo

Regressão de Superfície de Resposta: \%Descoloração de RB222 (em 526nm) por P. ostreatus em 24 horas versus ABTS; RBBR; Ácido Graxo

Análise de Variância

Fonte

Modelo

Linear

ABTS
GL SQ (Aj.) QM (Aj.) Valor F Valor-P

$9 \quad 0,199447 \quad 0,022161 \quad 0,62 \quad 0,753$

$\begin{array}{lllll}3 & 0,042572 & 0,014191 & 0,40 & 0,759\end{array}$

$1 \quad 0,012004 \quad 0,012004 \quad 0,34 \quad 0,580$ 


\begin{tabular}{lccccc} 
Continuação & & & & & \\
Fonte & GL & SQ (Aj.) & QM (Aj.) & Valor F & Valor-P \\
RBBR & 1 & 0,029881 & 0,029881 & 0,84 & 0,391 \\
Ácido Graxo & 1 & 0,000688 & 0,000688 & 0,02 & 0,894 \\
Quadrado & 3 & 0,003478 & 0,001159 & 0,03 & 0,991 \\
ABTS*ABTS & 1 & 0,000083 & 0,000083 & 0,00 & 0,963 \\
RBBR*RBBR & 1 & 0,003216 & 0,003216 & 0,09 & 0,773 \\
Ácido Graxo*Ácido Graxo & 1 & 0,000789 & 0,000789 & 0,02 & 0,886 \\
Interação com 2 Fatores & 3 & 0,153397 & 0,051132 & 1,43 & 0,313 \\
ABTS*RBBR & 1 & 0,034883 & 0,034883 & 0,98 & 0,356 \\
ABTS*Ácido Graxo & 1 & 0,099275 & 0,099275 & 2,78 & 0,140 \\
RBBR*Ácido Graxo & 1 & 0,019239 & 0,019239 & 0,54 & 0,487 \\
Erro & 7 & 0,250221 & 0,035746 & & \\
Falta de ajuste & 5 & 0,237572 & 0,047514 & 7,51 & 0,122 \\
Erro puro & 2 & 0,012650 & 0,006325 & $*$ & $*$ \\
Total & 16 & 0,449668 & & & \\
Sumário do Modelo & R2(aj) & R2(pred) & & & \\
\multicolumn{1}{r}{ S R2 } & 0,00\% & $0,00 \%$ & & & \\
0,189066 44,35\% & & & & &
\end{tabular}

Coeficientes Codificados

$\begin{array}{lclcccc}\text { Termo } & \text { Efeito } & \text { Coef } & \text { EP de Coef } & \text { Valor T } & \text { Valor-P } & \text { VIF } \\ \text { Constante } & 0,551 & 0,109 & 5,06 & 0,001 & & \\ \text { ABTS } & -0,0593 & -0,0297 & 0,0512 & -0,58 & 0,580 & 1,00 \\ \text { RBBR } & 0,0936 & 0,0468 & 0,0512 & 0,91 & 0,391 & 1,00 \\ \text { Ácido Graxo } & -0,0142 & -0,0071 & 0,0512 & -0,14 & 0,894 & 1,00 \\ \text { ABTS*ABTS } & -0,0054 & -0,0027 & 0,0564 & -0,05 & 0,963 & 1,15 \\ \text { RBBR*RBBR } & -0,0338 & -0,0169 & 0,0564 & -0,30 & 0,773 & 1,15 \\ \text { Ácido Graxo*Ácido Graxo } & -0,0167 & -0,0084 & 0,0564 & -0,15 & 0,886 & 1,15 \\ \text { ABTS*RBBR } & 0,1321 & 0,0660 & 0,0668 & 0,99 & 0,356 & 1,00 \\ \text { ABTS*Ácido Graxo } & -0,2228 & -0,1114 & 0,0668 & -1,67 & 0,140 & 1,00 \\ \text { RBBR*Ácido Graxo } & 0,0981 & 0,0490 & 0,0668 & 0,73 & 0,487 & 1,00\end{array}$

Equação de Regressão em Unidades Não codificadas

$\% \mathrm{D} 526 \mathrm{~nm}$ em $24 \mathrm{~h}=0,466+(0,094 *$ ABTS $)-(1,51 * \mathrm{RBBR})+\left(0,085^{*}\right.$ Ácido Graxo $)-(0,008 *$ ABTS*ABTS $)-$ $(4,8 * \mathrm{RBBR} * \mathrm{RBBR})$ - (0,0038*Ácido Graxo*Ácido Graxo) + (1,86*ABTS*RBBR) - (0,1258*ABTS*Ácido Graxo $)+(0,554 *$ RBBR*Ácido Graxo)

\begin{tabular}{lccccc}
\hline \begin{tabular}{l} 
Regressão de Superfície de Resposta: \%Descoloração de RB222 (em 526nm) por P. ostreatus em 48 horas \\
versus ABTS; RBBR; Ácido Graxo \\
\hline Análise de Variância
\end{tabular} GL SQ (Aj.) & QM (Aj.) & Valor F & Valor-P \\
Fonte & 9 & 0,075713 & 0,008413 & 0,28 & 0,961 \\
Modelo & 3 & 0,018303 & 0,006101 & 0,20 & 0,892 \\
Linear & 1 & 0,008473 & 0,008473 & 0,28 & 0,613 \\
ABTS & 1 & 0,005509 & 0,005509 & 0,18 & 0,683 \\
RBBR & 1 & 0,004321 & 0,004321 & 0,14 & 0,717 \\
Ácido Graxo & 3 & 0,027694 & 0,009231 & 0,30 & 0,821 \\
Quadrado & 1 & 0,023759 & 0,023759 & 0,78 & 0,405 \\
ABTS*ABTS & 1 & 0,010655 & 0,010655 & 0,35 & 0,572 \\
RBBR*RBBR & 1 & 0,005453 & 0,005453 & 0,18 & 0,684 \\
Ácido Graxo*Ácido Graxo & 3 & 0,029716 & 0,009905 & 0,33 & 0,806 \\
Interação com 2 Fatores & 1 & 0,001715 & 0,001715 & 0,06 & 0,819 \\
ABTS*RBBR & 1 & 0,003098 & 0,003098 & 0,10 & 0,758 \\
ABTS*Ácido Graxo & 1 & 0,024903 & 0,024903 & 0,82 & 0,395 \\
RBBR*Ácido Graxo & 7 & 0,212002 & 0,030286 & & \\
Erro & 5 & 0,208813 & 0,041763 & 26,19 & 0,037 \\
Falta de ajuste & 2 & 0,003189 & 0,001595 & $*$ & $*$ \\
Erro puro & 16 & 0,287715 & & &
\end{tabular}


Continuação

Sumário do Modelo

$\begin{array}{clll}\text { S } & \text { R2 } & \text { R2(aj) } & \text { R2(pred) } \\ 0,174029 & 26,32 \% & 0,00 \% & 0,00 \%\end{array}$

Coeficientes Codificados

$\begin{array}{lllllll}\text { Termo } & \text { Efeito } & \text { Coef } & \text { EP de Coef } & \text { Valor T } & \text { Valor-P } & \text { VIF } \\ \text { Constante } & 0,550 & 0,100 & 5,49 & 0,001 & & \\ \text { ABTS } & 0,0498 & 0,0249 & 0,0471 & 0,53 & 0,613 & 1,00 \\ \text { RBBR } & 0,0402 & 0,0201 & 0,0471 & 0,43 & 0,683 & 1,00 \\ \text { Ácido Graxo } & -0,0356 & -0,0178 & 0,0471 & -0,38 & 0,717 & 1,00 \\ \text { ABTS*ABTS } & 0,0919 & 0,0460 & 0,0519 & 0,89 & 0,405 & 1,15 \\ \text { RBBR*RBBR } & 0,0616 & 0,0308 & 0,0519 & 0,59 & 0,572 & 1,15 \\ \text { Ácido Graxo*Ácido Graxo } & 0,0440 & 0,0220 & 0,0519 & 0,42 & 0,684 & 1,15 \\ \text { ABTS*RBBR } & -0,0293 & -0,0146 & 0,0615 & -0,24 & 0,819 & 1,00 \\ \text { ABTS*Ácido Graxo } & -0,0394 & -0,0197 & 0,0615 & -0,32 & 0,758 & 1,00 \\ \text { RBBR*Ácido Graxo } & -0,1116 & -0,0558 & 0,0615 & -0,91 & 0,395 & 1,00\end{array}$

Equação de Regressão em Unidades Não codificadas

$\% \mathrm{D} 526 \mathrm{~nm} 48$ horas $=0,529(0,121 *$ ABTS $)+(0,59 * \mathrm{RBBR})+(0,024 *$ Ácido Graxo $)+(0,130 *$ ABTS*ABTS $)+$ $(8,7 * \mathrm{RBBR} * \mathrm{RBBR})+(0,0099 *$ Ácido Graxo*Ácido Graxo $)$ - (0,41*ABTS*RBBR) - (0,0222*ABTS*Ácido Graxo) - (0,630*RBBR*Ácido Graxo)

Regressão de Superfície de Resposta: MnP de P. ostreatus no tempo inicial versus ABTS; RBBR; Ácido Graxo

\begin{tabular}{|c|c|c|c|c|c|c|}
\hline \multicolumn{7}{|l|}{ Análise de Variância } \\
\hline Fonte & \multicolumn{2}{|c|}{ SQ (Aj.) } & QM (Aj.) & ) Valor I & \multicolumn{2}{|c|}{ Valor-P } \\
\hline Modelo & 9 & 1610,30 & 178,922 & 1,44 & \multicolumn{2}{|c|}{0,324} \\
\hline Linear & 69 & 691,66 & 230,553 & 1,85 & \multicolumn{2}{|l|}{0,226} \\
\hline ABTS & 13 & 130,51 & 130,514 & 1,05 & \multicolumn{2}{|l|}{0,340} \\
\hline RBBR & 1 & 262,08 & 262,081 & 2,10 & \multicolumn{2}{|l|}{0,190} \\
\hline Ácido Graxo & 1 & 299,06 & 299,063 & 2,40 & \multicolumn{2}{|c|}{0,165} \\
\hline Quadrado & 67 & 67,39 & 22,462 & 0,18 & \multicolumn{2}{|c|}{0,906} \\
\hline ABTS*ABTS & 35 & 35,69 & 35,685 & 0,29 & \multicolumn{2}{|l|}{0,609} \\
\hline $\mathrm{RBBR} * \mathrm{RBBR}$ & 35 & 35,69 & 35,685 & 0,29 & \multicolumn{2}{|l|}{0,609} \\
\hline Ácido Graxo*Ácido Graxo & 35 & 35,69 & 35,685 & 0,29 & \multicolumn{2}{|l|}{0,609} \\
\hline Interação com 2 Fatores & 85 & 851,25 & 283,751 & 2,28 & \multicolumn{2}{|l|}{0,167} \\
\hline ABTS*RBBR & 18 & 181,64 & 181,642 & 1,46 & \multicolumn{2}{|l|}{0,267} \\
\hline ABTS*Ácido Graxo & 22 & 222,61 & 222,605 & 1,79 & \multicolumn{2}{|c|}{0,223} \\
\hline RBBR*Ácido Graxo & 44 & 447,00 & 447,005 & 3,59 & \multicolumn{2}{|c|}{0,100} \\
\hline Erro & 87 & ,33 & 124,619 & & & \\
\hline Falta de ajuste & 87 & ,33 & 174,467 & $*$ & $*$ & \\
\hline Erro puro & 2 & 00 & 0,000 & $*$ & $*$ & \\
\hline Total & 16 & 32,63 & & & & \\
\hline Sumário do Modelo & & & & & & \\
\hline $\begin{array}{lll}S & R 2 & R 2(a j)\end{array}$ & $\mathrm{R} 2(\mathrm{p}$ & red) & & & & \\
\hline $11,1633 \quad 64,86 \% \quad 19,69 \%$ & 0,00 & & & & & \\
\hline Coeficientes Codificados & & & & & & \\
\hline & & & EP de & & & \\
\hline Termo & Efeito & Coef & Coef & Valor $\mathrm{T}$ & Valor-P & VIF \\
\hline Constante & $-0,53$ & 6,43 & $-0,08$ & 0,936 & & \\
\hline ABTS & $-6,19$ & $-3,09$ & 3,02 & $-1,02$ & 0,340 & 1,00 \\
\hline RBBR & $-8,77$ & $-4,38$ & 3,02 & $-1,45$ & 0,190 & 1,00 \\
\hline Ácido Graxo & 9,36 & 4,68 & 3,02 & 1,55 & 0,165 & 1,00 \\
\hline ABTS*ABTS & 3,56 & 1,78 & 3,33 & 0,54 & 0,609 & 1,15 \\
\hline $\mathrm{RBBR} * \mathrm{RBBR}$ & 3,56 & 1,78 & 3,33 & 0,54 & 0,609 & 1,15 \\
\hline Ácido Graxo*Ácido Graxo & 3,56 & 1,78 & 3,33 & 0,54 & 0,609 & 1,15 \\
\hline ABTS*RBBR & 9,53 & 4,77 & 3,95 & 1,21 & 0,267 & 1,00 \\
\hline ABTS*Ácido Graxo & $-10,55$ & $-5,28$ & 3,95 & $-1,34$ & 0,223 & 1,00 \\
\hline
\end{tabular}


Continuação

Termo Efeito Coef Coef Valor T Valor-P VIF

RBBR*Ácido Graxo $\quad-14,95 \quad-7,48 \quad 3,95 \quad-1,89 \quad 0,100 \quad 1,00$

Equação de Regressão em Unidades Não codificadas

MnP tempo inicial $=-3,3$ - 13,8*ABTS $-98 *$ RBBR + 13,5*Ácido Graxo + 5,03*ABTS*ABTS + 503*RBBR*RBBR + 0,80*Ácido Graxo*Ácido Graxo + 134*ABTS*RBBR - 5,96*ABTS*Ácido Graxo $84,4 * \mathrm{RBBR} *$ Ácido Graxo

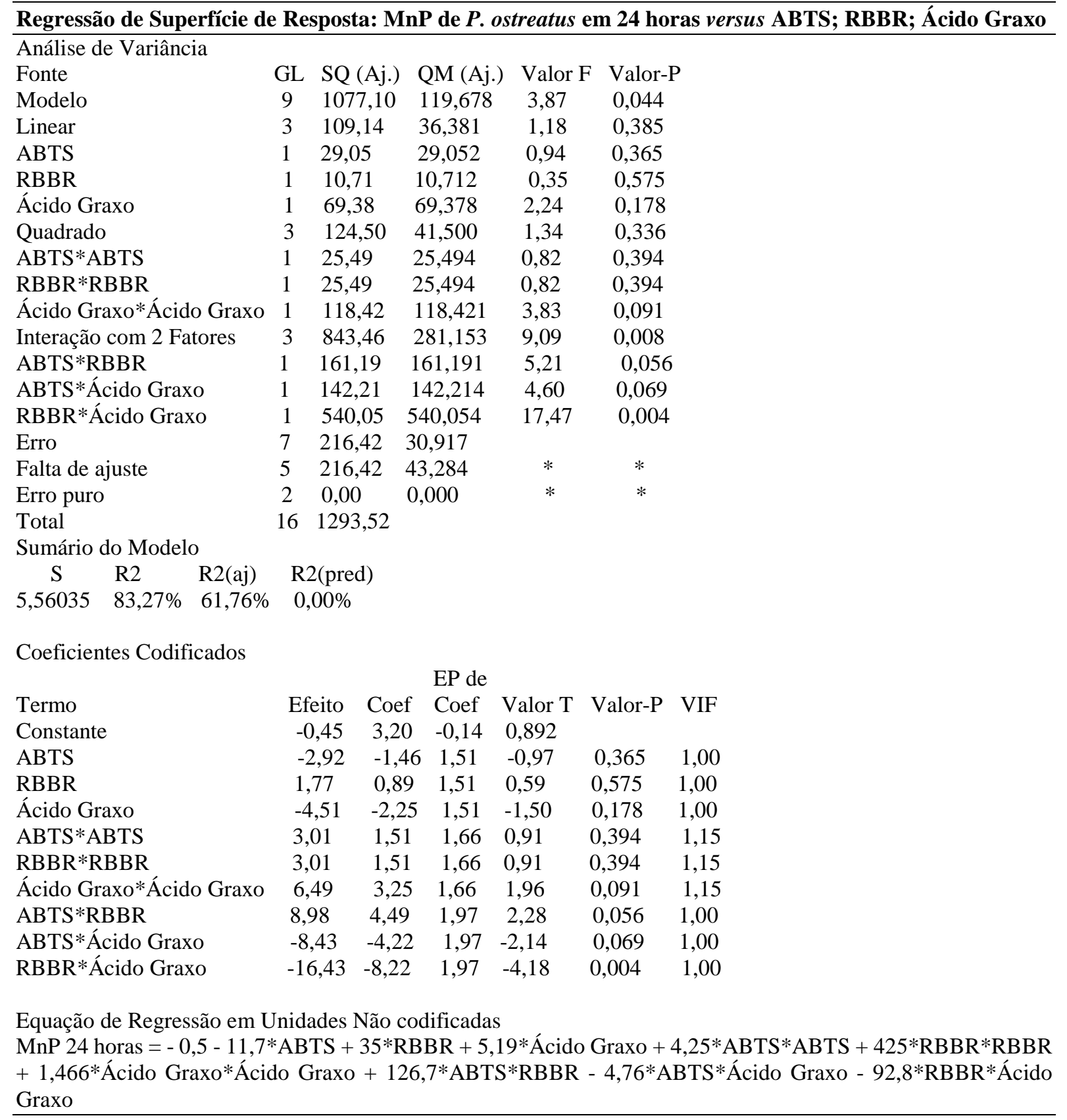

Regressão de Superfície de Resposta: MnP de P. ostreatus em 48 horas versus ABTS; RBBR; Ácido Graxo

Análise de Variância

$\begin{array}{llllll}\text { Fonte } & \text { GL } & \text { SQ (Aj.) } & \text { QM (Aj.) } & \text { Valor F } & \text { Valor-P } \\ \text { Modelo } & 9 & 169,830 & 18,8700 & 1,46 & 0,317 \\ \text { Linear } & 3 & 79,167 & 26,3891 & 2,04 & 0,197 \\ \text { ABTS } & 1 & 5,818 & 5,8182 & 0,45 & 0,524 \\ \text { RBBR } & 1 & 36,675 & 36,6746 & 2,83 & 0,136 \\ \text { Ácido Graxo } & 1 & 36,675 & 36,6746 & 2,83 & 0,136\end{array}$




$\begin{array}{lccccc}\text { Continuação } & & & & \\ \text { Fonte } & \text { GL } & \text { SQ (Aj.) } & \text { QM (Aj.) } & \text { Valor F } & \text { Valor-P } \\ \text { Quadrado } & 3 & 8,264 & 2,7546 & 0,21 & 0,885 \\ \text { ABTS*ABTS } & 1 & 4,376 & 4,3762 & 0,34 & 0,579 \\ \text { RBBR*RBBR } & 1 & 4,376 & 4,3762 & 0,34 & 0,579 \\ \text { Ácido Graxo*Ácido Graxo } & 1 & 4,376 & 4,3762 & 0,34 & 0,579 \\ \text { Interação com 2 Fatores } & 3 & 82,399 & 27,4664 & 2,12 & 0,186 \\ \text { ABTS*RBBR } & 1 & 9,924 & 9,9235 & 0,77 & 0,410 \\ \text { ABTS*Ácido Graxo } & 1 & 9,924 & 9,9235 & 0,77 & 0,410 \\ \text { RBBR*Ácido Graxo } & 1 & 62,552 & 62,5521 & 4,83 & 0,064 \\ \text { Erro } & 7 & 90,636 & 12,9480 & & \\ \text { Falta de ajuste } & 5 & 90,636 & 18,1272 & * & * \\ \text { Erro puro } & 2 & 0,000 & 0,0000 & * & * \\ \text { Total } & 16 & 260,466 & & & \\ \text { Sumário do Modelo } & & & & & \\ \quad \text { S R2 } & \text { R2(aj) } & \text { R2(pred) } & & & \\ \text { 3,59833 65,20\% } & 20,46 \% & 0,00 \% & & & \end{array}$

Coeficientes Codificados

\begin{tabular}{llccccc} 
& \multicolumn{7}{c}{ EP de } \\
Termo & Efeito & Coef & Coef & Valor T & Valor-P & VIF \\
Constante & $-0,19$ & 2,07 & $-0,09$ & 0,931 & & \\
ABTS & $-1,306$ & $-0,653$ & 0,974 & $-0,67$ & 0,524 & 1,00 \\
RBBR & $-3,279$ & $-1,639$ & 0,974 & $-1,68$ & 0,136 & 1,00 \\
Ácido Graxo & 3,279 & 1,639 & 0,974 & 1,68 & 0,136 & 1,00 \\
ABTS*ABTS & 1,25 & 0,62 & 1,07 & 0,58 & 0,579 & 1,15 \\
RBBR*RBBR & 1,25 & 0,62 & 1,07 & 0,58 & 0,579 & 1,15 \\
Ácido Graxo*Ácido Graxo & 1,25 & 0,62 & 1,07 & 0,58 & 0,579 & 1,15 \\
ABTS*RBBR & 2,23 & 1,11 & 1,27 & 0,88 & 0,410 & 1,00 \\
ABTS*Ácido Graxo & $-2,23$ & $-1,11$ & 1,27 & $-0,88$ & 0,410 & 1,00 \\
RBBR*Ácido Graxo & $-5,59$ & $-2,80$ & 1,27 & $-2,20$ & 0,064 & 1,00
\end{tabular}

Equação de Regressão em Unidades Não codificadas

MnP em 48 horas $=-1,70-4,62 *$ ABTS - 15,3*RBBR + 4,11*Ácido Graxo + 1,76*ABTS*ABTS + 176*RBBR*RBBR + 0,282*Ácido Graxo*Ácido Graxo + 31,4*ABTS*RBBR - 1,26*ABTS*Ácido Graxo 31,6*RBBR*Ácido Graxo

Regressão de Superfície de Resposta: Lacase de P. ostreatus no tempo inicial versus ABTS; RBBR; Ácido Graxo

\begin{tabular}{lcllll}
\hline Análise de Variância & & & & & \\
Fonte & GL & SQ (Aj.) & QM (Aj.) & Valor F & Valor-P \\
Modelo & 9 & 24687,9 & 2743,10 & 0,58 & 0,777 \\
Linear & 3 & 5728,4 & 1909,46 & 0,41 & 0,753 \\
ABTS & 1 & 1615,5 & 1615,48 & 0,34 & 0,576 \\
RBBR & 1 & 2263,8 & 2263,85 & 0,48 & 0,510 \\
Ácido Graxo & 1 & 1849,1 & 1849,06 & 0,39 & 0,550 \\
Quadrado & 3 & 7770,9 & 2590,31 & 0,55 & 0,663 \\
ABTS*ABTS & 1 & 634,0 & 633,99 & 0,14 & 0,724 \\
RBBR*RBBR & 1 & 7341,6 & 7341,62 & 1,57 & 0,251 \\
Ácido Graxo*Ácido Graxo & 1 & 35,1 & 35,14 & 0,01 & 0,933 \\
Interação com 2 Fatores & 3 & 11188,6 & 3729,52 & 0,80 & 0,534 \\
ABTS*RBBR & 1 & 250,4 & 250,39 & 0,05 & 0,824 \\
ABTS*Ácido Graxo & 1 & 9970,8 & 9970,84 & 2,13 & 0,188 \\
RBBR*Ácido Graxo & 1 & 967,3 & 967,34 & 0,21 & 0,663 \\
Erro & 7 & 32823,8 & 4689,11 & & \\
Falta de ajuste & 5 & 31659,8 & 6331,97 & 10,88 & 0,086 \\
Erro puro & 2 & 1163,9 & 581,97 & $*$ & $*$ \\
Total & 16 & 57511,7 & & &
\end{tabular}


Continuação

Sumário do Modelo

$\begin{array}{cccl}\mathrm{S} & \mathrm{R} 2 & \mathrm{R} 2(\mathrm{aj}) & \mathrm{R} 2 \text { (pred) } \\ 68,4771 & 42,93 \% & 0,00 \% & 0,00 \%\end{array}$

Coeficientes Codificados

\begin{tabular}{lllllll} 
& \multicolumn{7}{c}{ EP de } \\
Termo & Efeito & Coef & Coef & Valor T & Valor-P & VIF \\
Constante & 183,0 & 39,5 & 4,64 & 0,002 & & \\
ABTS & $-21,8$ & $-10,9$ & 18,5 & $-0,59$ & 0,576 & 1,00 \\
RBBR & $-25,8$ & $-12,9$ & 18,5 & $-0,69$ & 0,510 & 1,00 \\
Ácido Graxo & $-23,3$ & $-11,6$ & 18,5 & $-0,63$ & 0,550 & 1,00 \\
ABTS*ABTS & 15,0 & 7,5 & 20,4 & 0,37 & 0,724 & 1,15 \\
RBBR*RBBR & 51,1 & 25,6 & 20,4 & 1,25 & 0,251 & 1,15 \\
Ácido Graxo*Ácido Graxo & 3,5 & 1,8 & 20,4 & 0,09 & 0,933 & 1,15 \\
ABTS*RBBR & $-11,2$ & $-5,6$ & 24,2 & $-0,23$ & 0,824 & 1,00 \\
ABTS*Ácido Graxo & 70,6 & 35,3 & 24,2 & 1,46 & 0,188 & 1,00 \\
RBBR*Ácido Graxo & 22,0 & 11,0 & 24,2 & 0,45 & 0,663 & 1,00
\end{tabular}

Equação de Regressão em Unidades Não codificadas

Lacase tempo inicial $=456-145 *$ ABTS $-1811 *$ RBBR $-64,1 *$ Ácido Graxo + 21,2*ABTS*ABTS + 7212*RBBR*RBBR + 0,80*Ácido Graxo*Ácido Graxo - 158*ABTS*RBBR + 39,9*ABTS*Ácido Graxo + $124 * \mathrm{RBBR}^{*}$ Ácido Graxo

\begin{tabular}{|c|c|c|c|c|c|c|c|}
\hline \multicolumn{8}{|c|}{ Regressão de Superfície de Resposta: Lacase de P. ostreatus em 24 horas versus ABTS; RBBR; Ácido Graxo } \\
\hline \multicolumn{8}{|c|}{ Análise de Variância } \\
\hline Fonte & \multicolumn{3}{|c|}{ GL SQ (Aj.) } & QM (Aj.) & Valor F & \multicolumn{2}{|l|}{ Valor-P } \\
\hline Modelo & 9 & \multicolumn{2}{|c|}{74674} & 8297,2 & 1,57 & \multicolumn{2}{|l|}{0,281} \\
\hline Linear & 3 & \multicolumn{2}{|c|}{61518} & 20506,1 & 3,89 & \multicolumn{2}{|l|}{0,063} \\
\hline ABTS & 1 & \multicolumn{2}{|c|}{13592} & 13592,1 & 2,58 & \multicolumn{2}{|l|}{0,152} \\
\hline $\mathrm{RBBR}$ & 1 & \multicolumn{2}{|c|}{14143} & 14143,1 & 2,68 & \multicolumn{2}{|l|}{0,145} \\
\hline Ácido Graxo & 1 & \multicolumn{2}{|c|}{33783} & 33783,1 & 6,41 & \multicolumn{2}{|l|}{0,039} \\
\hline Quadrado & 3 & \multicolumn{2}{|c|}{1092} & 364,0 & 0,07 & \multicolumn{2}{|l|}{0,975} \\
\hline ABTS*ABTS & 1 & \multicolumn{2}{|c|}{187} & 186,6 & 0,04 & \multicolumn{2}{|l|}{0,856} \\
\hline $\mathrm{RBBR} * \mathrm{RBBR}$ & 1 & \multicolumn{2}{|c|}{70} & 69,6 & 0,01 & \multicolumn{2}{|l|}{0,912} \\
\hline Ácido Graxo*Ácido Graxo & 1 & \multicolumn{2}{|c|}{702} & 701,9 & 0,13 & \multicolumn{2}{|l|}{0,726} \\
\hline Interação com 2 Fatores & 3 & \multicolumn{2}{|c|}{12064} & 4021,4 & 0,76 & \multicolumn{2}{|l|}{0,550} \\
\hline ABTS*RBBR & 1 & \multicolumn{2}{|c|}{11909} & 11909,4 & 2,26 & \multicolumn{2}{|l|}{0,177} \\
\hline ABTS*Ácido Graxo & 1 & 58 & & 58,4 & 0,01 & 0,919 & \\
\hline RBBR*Ácido Graxo & 1 & 96 & & 96,5 & 0,02 & 0,896 & \\
\hline Erro & 7 & & 904 & 5272,1 & & & \\
\hline Falta de ajuste & 5 & & 389 & 5077,8 & 0,88 & 0,607 & \\
\hline Erro puro & 2 & 115 & 516 & 5757,8 & $*$ & $*$ & \\
\hline Total & 16 & 111 & 1579 & & & & \\
\hline Sumário do Modelo & & & & & & & \\
\hline $\begin{array}{lll}S & R 2 & R 2(a j)\end{array}$ & & (pre & & & & & \\
\hline $72,6090 \quad 66,93 \% \quad 24,40 \%$ & & $00 \%$ & & & & & \\
\hline Coeficientes Codificados & & & & & & & \\
\hline & & & & EP de & & & \\
\hline Termo & Efe & ito & Coef & Coef & Valor T & Г Valor-P & VIF \\
\hline Constante & 225 & & 41,8 & 5,38 & 0,001 & & \\
\hline ABTS & -63 , & & $-31,6$ & 19,7 & $-1,61$ & 0,152 & 1,00 \\
\hline RBBR & 64,4 & & 32,2 & 19,7 & 1,64 & 0,145 & 1,00 \\
\hline Ácido Graxo & -99 & & $-49,8$ & 19,7 & $-2,53$ & 0,039 & 1,00 \\
\hline ABTS*ABTS & $-8,1$ & & $-4,1$ & 21,7 & $-0,19$ & 0,856 & 1,15 \\
\hline $\mathrm{RBBR} * \mathrm{RBBR}$ & 5,0 & & 2,5 & 21,7 & 0,11 & 0,912 & 1,15 \\
\hline Ácido Graxo*Ácido Graxo & -15 & & $-7,9$ & 21,7 & $-0,36$ & 0,726 & 1,15 \\
\hline ABTS*RBBR & 77 & & 38,6 & 25,7 & 1,50 & 0,177 & 1,00 \\
\hline ABTS*Ácido Graxo & 5,4 & & 2,7 & 25,7 & 0,11 & 0,919 & 1,00 \\
\hline
\end{tabular}


Continuação

$\begin{array}{lcccccc}\text { Termo } & \text { Efeito } & \text { Coef } & \text { Coef } & \text { Valor T Valor-P VIF } \\ \text { RBBR*Ácido Graxo } & 6,9 & 3,5 & 25,7 & 0,14 & 0,896 & 1,00\end{array}$

Equação de Regressão em Unidades Não codificadas

Lacase em 24 horas $=407-147^{* A B T S}-787 *$ RBBR - 22,6* Ácido Graxo - 11,5*ABTS*ABTS + 702*RBBR*RBBR - 3,57*Ácido Graxo*Ácido Graxo + 1089*ABTS*RBBR + 3,0*ABTS*Ácido Graxo + 39*RBBR*Ácido Graxo

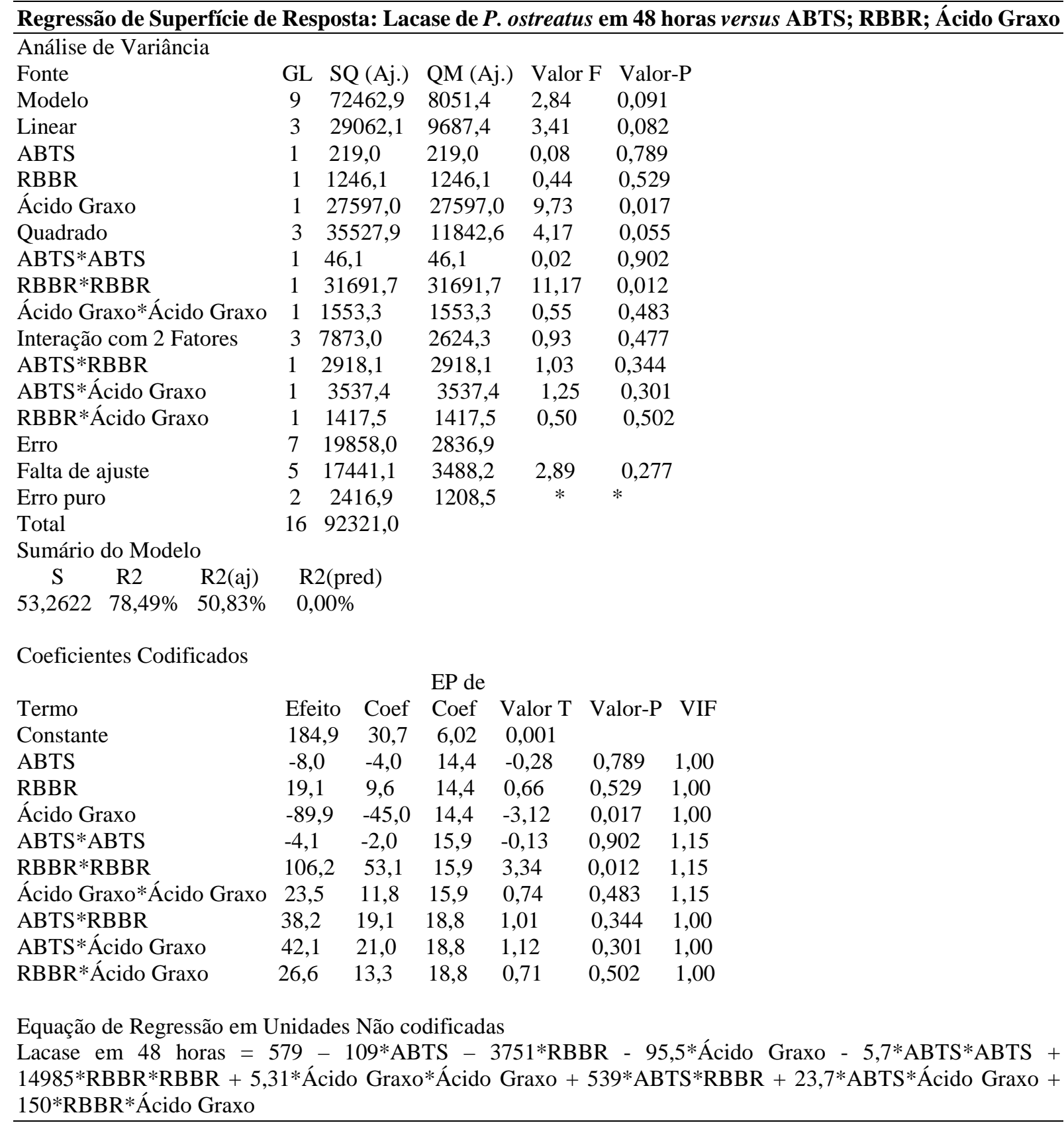

Trametes villosa

Regressão de Superfície de Resposta: \%Descoloração RB222 por T. villosa em 24 horas (610nm) versus ABTS; RBBR; AG; Mn+2

Análise de Variância

Fonte

Modelo

GL SQ (Aj.) QM (Aj.) Valor F Valor-P

Linear

$14 \quad 0,324844 \quad 0,023203 \quad 1,25 \quad 0,345$

$\begin{array}{lllll}4 & 0,171327 & 0,042832 & 2,31 & 0,113\end{array}$ 


\begin{tabular}{|c|c|c|c|c|c|c|}
\hline \multicolumn{7}{|l|}{ Continuação } \\
\hline \multicolumn{2}{|l|}{ Fonte } & GL SQ (Aj.) & QM (Aj.) & Valor F & \multicolumn{2}{|l|}{ Valor-P } \\
\hline \multicolumn{2}{|l|}{ ABTS } & 0,000037 & 0,000037 & $7 \quad 0,00$ & \multicolumn{2}{|l|}{0,965} \\
\hline \multicolumn{2}{|l|}{ RBBR } & 0,063166 & 0,063166 & 3,41 & \multicolumn{2}{|l|}{0,088} \\
\hline \multicolumn{2}{|l|}{$\mathrm{AG}$} & 0,011068 & 0,011068 & 0,60 & \multicolumn{2}{|l|}{0,453} \\
\hline \multicolumn{2}{|l|}{$\mathrm{Mn}+2$} & 0,097057 & 0,097057 & 5,24 & \multicolumn{2}{|l|}{0,039} \\
\hline \multicolumn{2}{|l|}{ Quadrado } & 0,084174 & 0,021043 & 1,14 & \multicolumn{2}{|l|}{0,383} \\
\hline ABTS*ABTS & & 0,0211 & 0,021108 & 1,14 & 0,305 & \\
\hline RBBR*RBBR & & 0,0012 & 0,001205 & 0,07 & 0,803 & \\
\hline $\mathrm{AG}^{*} \mathrm{AG}$ & & 0,0255 & $569 \quad 0,025569$ & 1,38 & 0,261 & \\
\hline $\mathrm{Mn}+2 * M n+2$ & 1 & 0,0187 & $75 \quad 0,018775$ & 1,01 & 0,333 & \\
\hline Interação com 2 & Fatores & 0,0693 & $343 \quad 0,011557$ & 0,62 & 0,709 & \\
\hline ABTS*RBBR & & 0,0577 & 0,05776 & 3,12 & 0,101 & \\
\hline ABTS*AG & 1 & 0,0000 & 0,000000 & 0,00 & 0,998 & \\
\hline ABTS*Mn+2 & 1 & 0,0029 & 0,002912 & 0,16 & 0,698 & \\
\hline RBBR*AG & & 0,0072 & 0,007214 & 0,39 & 0,543 & \\
\hline $\mathrm{RBBR} * \mathrm{Mn}+2$ & 1 & 0,0004 & 0,000437 & 0,02 & 0,880 & \\
\hline $\mathrm{AG}^{*} \mathrm{Mn}+2$ & 1 & 0,0010 & 0,001012 & 0,05 & 0,819 & \\
\hline Erro & & 0,2408 & 0,018530 & & & \\
\hline Falta de ajuste & & 0,1437 & 0,014374 & 0,44 & 0,855 & \\
\hline Erro puro & & 0,0971 & 0,032386 & $*$ & $*$ & \\
\hline Total & & $27 \quad 0,5657$ & 736 & & & \\
\hline Sumário do Mo & lelo & & & & & \\
\hline $\begin{array}{ll}\mathrm{S} & \mathrm{R} 2\end{array}$ & R2(aj) & R2(pre & ed) & & & \\
\hline $0,136126 \quad 57,4$ & $\% 11,56 \%$ & $0,00 \%$ & & & & \\
\hline Coeficientes Co & Hificados & & & & & \\
\hline Termo & Efeito & Coef & EP de Coef & Valor T & Valor-P & VIF \\
\hline Constante & 0,8275 & 0,0681 & 12,16 & 0,000 & & \\
\hline ABTS & $-0,0025$ & $-0,0012$ & 0,0278 & $-0,04$ & 0,965 & 1,00 \\
\hline RBBR & $-0,1026$ & $-0,0513$ & 0,0278 & $-1,85$ & 0,088 & 1,00 \\
\hline $\mathrm{AG}$ & 0,0429 & 0,0215 & 0,0278 & 0,77 & 0,453 & 1,00 \\
\hline $\mathrm{Mn}+2$ & 0,1272 & 0,0636 & 0,0278 & 2,29 & 0,039 & 1,00 \\
\hline ABTS*ABTS & 0,0593 & 0,0297 & 0,0278 & 1,07 & 0,305 & 1,14 \\
\hline $\mathrm{RBBR} * \mathrm{RBBR}$ & 0,0142 & 0,0071 & 0,0278 & 0,25 & 0,803 & 1,14 \\
\hline $\mathrm{AG}^{*} \mathrm{AG}$ & $-0,0653$ & $-0,0326$ & 0,0278 & $-1,17$ & 0,261 & 1,14 \\
\hline $\mathrm{Mn}+2 * \mathrm{Mn}+2$ & 0,0559 & 0,0280 & 0,0278 & 1,01 & 0,333 & 1,14 \\
\hline ABTS*RBBR & $-0,1202$ & $-0,0601$ & 0,0340 & $-1,77$ & 0,101 & 1,00 \\
\hline ABTS*AG & 0,0002 & 0,0001 & 0,0340 & 0,00 & 0,998 & 1,00 \\
\hline ABTS*Mn+2 & $-0,0270$ & $-0,0135$ & 0,0340 & $-0,40$ & 0,698 & 1,00 \\
\hline RBBR*AG & $-0,0425$ & $-0,0212$ & 0,0340 & $-0,62$ & 0,543 & 1,00 \\
\hline $\mathrm{RBBR} * \mathrm{Mn}+2$ & $-0,0105$ & $-0,0052$ & 0,0340 & $-0,15$ & 0,880 & 1,00 \\
\hline $\mathrm{AG}^{*} \mathrm{Mn}+2$ & $-0,0159$ & $-0,0080$ & 0,0340 & $-0,23$ & 0,819 & 1,00 \\
\hline
\end{tabular}

Equação de Regressão em Unidades Não codificadas

\%Desc 610nm 24h = 0,561 + 0,108*ABTS + 2,08*RBBR + 0,181*AG - 0,43*Mn+2 + 0,119*ABTS*ABTS + $2,8 * \mathrm{RBBR} * \mathrm{RBBR}-0,0209 * A G * A G+0,448 * \mathrm{Mn}+2 * \mathrm{Mn}+2-2,40 * A B T S * \mathrm{RBBR}+0,0001 * A B T S * A G-$ $0,108 * A B T S * M n+2-0,340 * R B B R * A G-0,42 * R B B R * M n+2-0,025 * A G * M n+2$

Regressão de Superfície de Resposta: \%Descoloração RB222 por T. villosa em 48 horas (610nm) versus ABTS; RBBR; AG; Mn+2

\begin{tabular}{llllll}
\hline Análise de Variância & & & & & \\
Fonte & GL & SQ (Aj.) & QM (Aj.) & Valor F & Valor-P \\
Modelo & 14 & 0,69460 & 0,049614 & 0,83 & 0,635 \\
Linear & 4 & 0,20796 & 0,051990 & 0,87 & 0,509 \\
ABTS & 1 & 0,00042 & 0,000418 & 0,01 & 0,935 \\
RBBR & 1 & 0,13583 & 0,135828 & 2,27 & 0,156 \\
AG & 1 & 0,05396 & 0,053959 & 0,90 & 0,360 \\
Mn+2 & 1 & 0,01776 & 0,017756 & 0,30 & 0,595 \\
Quadrado & 4 & 0,31363 & 0,078406 & 1,31 & 0,318
\end{tabular}




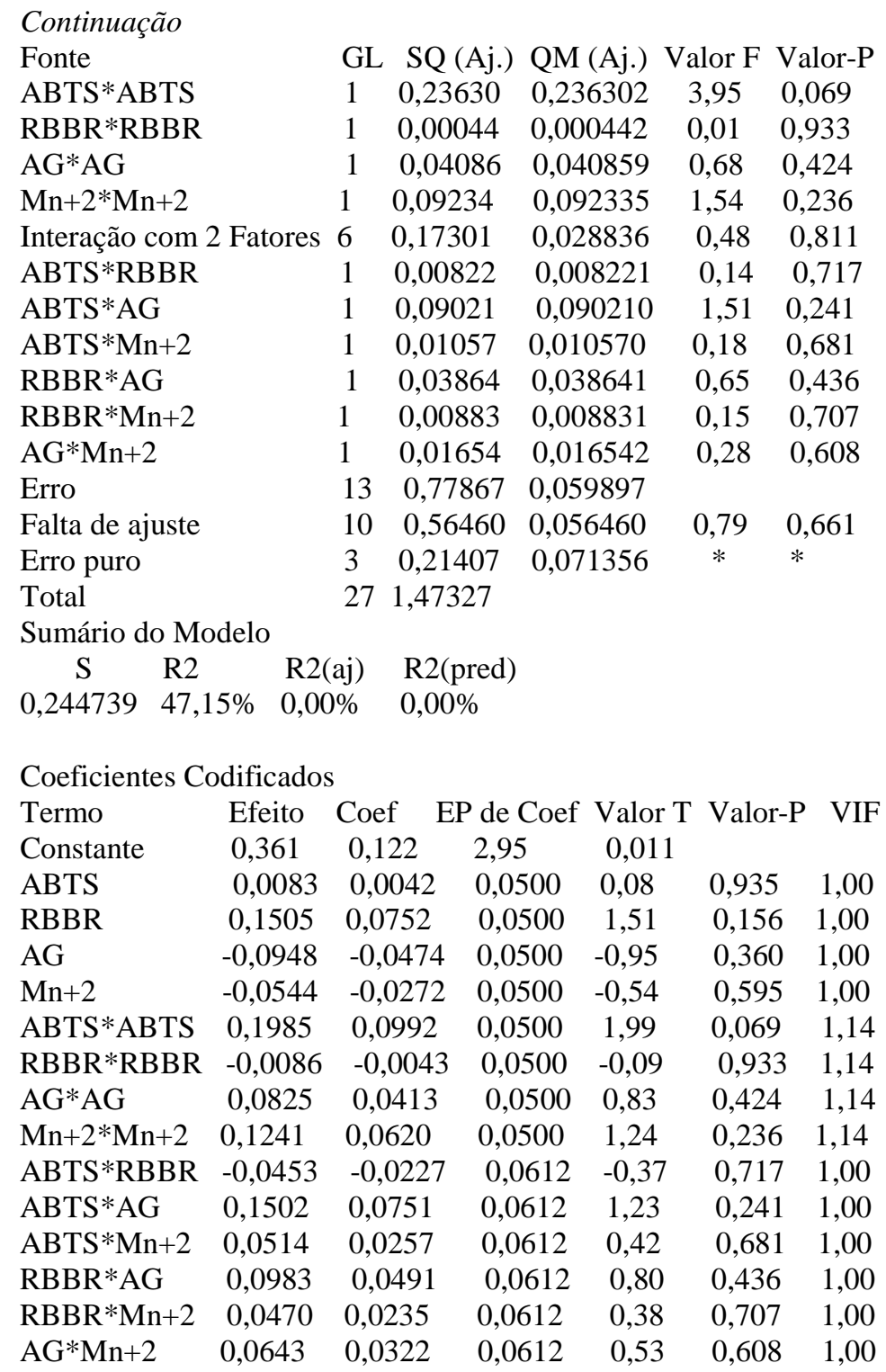

Equação de Regressão em Unidades Não codificadas \% Desc 610nm 48h = 3,00 - 1,201*ABTS - 1,09*RBBR - 0,472*AG - 2,74*Mn+2 + 0,397*ABTS*ABTS $1,7 * \mathrm{RBBR} * \mathrm{RBBR}+0,0264 * \mathrm{AG} * \mathrm{AG}+0,992 * \mathrm{Mn}+2 * \mathrm{Mn}+2-0,91 * \mathrm{ABTS} * \mathrm{RBBR}+0,1201 * \mathrm{ABTS} * \mathrm{AG}+$ $0,206 * A B T S * M n+2+0,786 * R B B R * A G+1,88 * R B B R * M n+2+0,103 * A G * M n+2$

Regressão de Superfície de Resposta: \%Descoloração RB222 (em 526nm) por T. villosa após 24 horas versus ABTS; RBBR; AG; Mn+2

\begin{tabular}{lccccc}
\hline Análise de Variância & & & & & \\
Fonte & GL & SQ (Aj.) & QM (Aj.) & Valor F & Valor-P \\
Modelo & 14 & 0,77760 & 0,055543 & 3,22 & 0,021 \\
Linear & 4 & 0,37932 & 0,094830 & 5,49 & 0,008 \\
ABTS & 1 & 0,00600 & 0,006005 & 0,35 & 0,565 \\
RBBR & 1 & 0,07821 & 0,078212 & 4,53 & 0,053 \\
AG & 1 & 0,24002 & 0,240025 & 13,90 & 0,003 \\
Mn+2 & 1 & 0,05508 & 0,055081 & 3,19 & 0,097 \\
Quadrado & 4 & 0,33584 & 0,083959 & 4,86 & 0,013 \\
ABTS*ABTS & 1 & 0,00574 & 0,005739 & 0,33 & 0,574 \\
RBBR*RBBR & 1 & 0,00047 & 0,000470 & 0,03 & 0,872 \\
AG*AG & 1 & 0,21204 & 0,212043 & 12,28 & 0,004 \\
Mn+2*Mn+2 & 1 & 0,03770 & 0,037700 & 2,18 & 0,163 \\
Interação com 2 Fatores & 6 & 0,06244 & 0,010407 & 0,60 & 0,724
\end{tabular}


Continuação

$\begin{array}{lccccc}\text { Fonte } & \text { GL } & \text { SQ (Aj.) } & \text { QM (Aj.) } & \text { Valor F } & \text { Valor-P } \\ \text { ABTS*RBBR } & 1 & 0,02412 & 0,024120 & 1,40 & 0,258 \\ \text { ABTS*AG } & 1 & 0,00000 & 0,000000 & 0,00 & 0,997 \\ \text { ABTS*Mn+2 } & 1 & 0,02116 & 0,021161 & 1,23 & 0,288 \\ \text { RBBR*AG } & 1 & 0,01409 & 0,014092 & 0,82 & 0,383 \\ \text { RBBR*Mn+2 } & 1 & 0,00006 & 0,000064 & 0,00 & 0,952 \\ \text { AG*Mn+2 } & 1 & 0,00300 & 0,003005 & 0,17 & 0,683 \\ \text { Erro } & 13 & 0,22441 & 0,017262 & & \\ \text { Falta de ajuste } & 10 & 0,16901 & 0,016901 & 0,92 & 0,603 \\ \text { Erro puro } & 3 & 0,05539 & 0,018465 & * & * \\ \text { Total } & 27 & 1,00200 & & & \\ \text { Sumário do Modelo } & & & & & \\ \quad \text { S R2 } & \text { R2(aj) } & \text { R2(pred) } & & \\ \text { 0,131385 77,60\% } & 53,49 \% & 0,00 \% & & & \end{array}$

Coeficientes Codificados

$\begin{array}{lllllll}\text { Termo } & \text { Efeito } & \text { Coef } & \text { EP de Coef } & \text { Valor T } & \text { Valor-P } & \text { VIF } \\ \text { Constante } & 0,7035 & 0,0657 & 10,71 & 0,000 & & \\ \text { ABTS } & 0,0316 & 0,0158 & 0,0268 & 0,59 & 0,565 & 1,00 \\ \text { RBBR } & -0,1142 & -0,0571 & 0,0268 & -2,13 & 0,053 & 1,00 \\ \text { AG } & 0,2000 & 0,1000 & 0,0268 & 3,73 & 0,003 & 1,00 \\ \text { Mn+2 } & 0,0958 & 0,0479 & 0,0268 & 1,79 & 0,097 & 1,00 \\ \text { ABTS*ABTS } & 0,0309 & 0,0155 & 0,0268 & 0,58 & 0,574 & 1,14 \\ \text { RBBR*RBBR } & 0,0088 & 0,0044 & 0,0268 & 0,16 & 0,872 & 1,14 \\ \text { AG*AG } & -0,1880 & -0,0940 & 0,0268 & -3,50 & 0,004 & 1,14 \\ \text { Mn+2*Mn+2 } & 0,0793 & 0,0396 & 0,0268 & 1,48 & 0,163 & 1,14 \\ \text { ABTS*RBBR } & -0,0777 & -0,0388 & 0,0328 & -1,18 & 0,258 & 1,00 \\ \text { ABTS*AG } & 0,0003 & 0,0001 & 0,0328 & 0,00 & 0,997 & 1,00 \\ \text { ABTS*Mn+2 } & -0,0727 & -0,0364 & 0,0328 & -1,11 & 0,288 & 1,00 \\ \text { RBBR*AG } & -0,0594 & -0,0297 & 0,0328 & -0,90 & 0,383 & 1,00 \\ \text { RBBR*Mn+2 } & 0,0040 & 0,0020 & 0,0328 & 0,06 & 0,952 & 1,00 \\ \text { AG*Mn+2 } & -0,0274 & -0,0137 & 0,0328 & -0,42 & 0,683 & 1,00\end{array}$

Equação de Regressão em Unidades Não codificadas

$\%$ D 526nm $24 \mathrm{~h}=0,074+0,354 *$ ABTS $+1,08 *$ RBBR $+0,472 * A G-0,692 * \mathrm{Mn}+2+0,062 * A B T S * A B T S+$ $1,8 * \mathrm{RBBR} * \mathrm{RBBR}-0,0602 * \mathrm{AG} * \mathrm{AG}+0,634 * \mathrm{Mn}+2 * \mathrm{Mn}+2-1,55 * \mathrm{ABTS}$ RBBR + 0,0002*ABTS*AG $0,291 * A B T S * M n+2-0,475 * R B B R * A G+0,16 * R B B R * M n+2-0,044 * A G * M n+2$

Regressão de Superfície de Resposta: \%Descoloração RB222 (em 526nm) por T. villosa após 48 horas versus ABTS; RBBR; AG; Mn+2

\begin{tabular}{lccccc}
\hline Análise de Variância & & & & & \\
Fonte & GL & SQ (Aj.) & QM (Aj.) & Valor F & Valor-P \\
Modelo & 14 & 0,518870 & 0,037062 & 1,31 & 0,314 \\
Linear & 4 & 0,224072 & 0,056018 & 1,99 & 0,156 \\
ABTS & 1 & 0,002911 & 0,002911 & 0,10 & 0,753 \\
RBBR & 1 & 0,194910 & 0,194910 & 6,91 & 0,021 \\
AG & 1 & 0,000004 & 0,000004 & 0,00 & 0,991 \\
Mn+2 & 1 & 0,026248 & 0,026248 & 0,93 & 0,352 \\
Quadrado & 4 & 0,140098 & 0,035025 & 1,24 & 0,341 \\
ABTS*ABTS & 1 & 0,105480 & 0,105480 & 3,74 & 0,075 \\
RBBR*RBBR & 1 & 0,000216 & 0,000216 & 0,01 & 0,932 \\
AG*AG & 1 & 0,000490 & 0,000490 & 0,02 & 0,897 \\
Mn+2*Mn+2 & 1 & 0,038955 & 0,038955 & 1,38 & 0,261 \\
Interação com 2 Fatores & 6 & 0,154700 & 0,025783 & 0,91 & 0,515 \\
ABTS*RBBR & 1 & 0,005039 & 0,005039 & 0,18 & 0,679 \\
ABTS*AG & 1 & 0,104432 & 0,104432 & 3,70 & 0,076 \\
ABTS*Mn+2 & 1 & 0,001183 & 0,001183 & 0,04 & 0,841 \\
RBBR*AG & 1 & 0,001778 & 0,001778 & 0,06 & 0,806 \\
RBBR*Mn+2 & 1 & 0,004803 & 0,004803 & 0,17 & 0,687
\end{tabular}




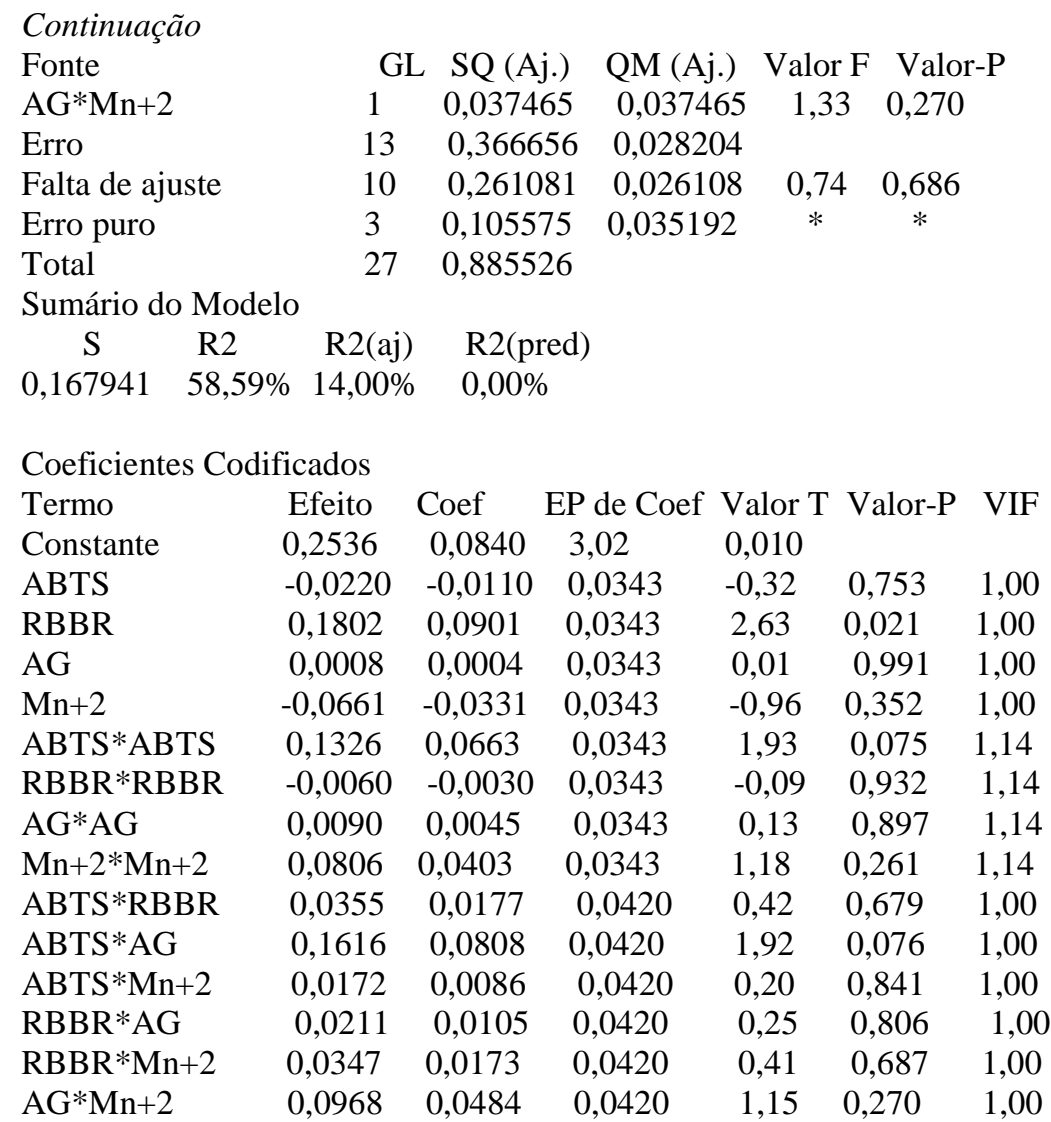

Equação de Regressão em Unidades Não codificadas

\%D 526nm 48h = 2,174 - 1,015*ABTS - 0,48*RBBR - 0,315*AG - 2,02*Mn+2 + 0,265*ABTS*ABTS $1,2 * \mathrm{RBBR} * \mathrm{RBBR}+0,0029 * \mathrm{AG} * \mathrm{AG}+0,645 * \mathrm{Mn}+2 * \mathrm{Mn}+2+0,71 * \mathrm{ABTS}$ RBBR + 0,1293*ABTS*AG + 0,069*ABTS*Mn+2 + 0,169*RBBR*AG + 1,39*RBBR*Mn+2 + 0,155*AG*Mn+2

\begin{tabular}{lccccc}
\hline Regressão de Superfície de Resposta: MnP de T. villosa no tempo ini \\
\hline Análise de Variância & & & & & \\
Fonte & GL & SQ (Aj.) & QM (Aj.) & Valor F & Valor-P \\
Modelo & 14 & 0,204783 & 0,014627 & 0,97 & 0,524 \\
Linear & 4 & 0,038584 & 0,009646 & 0,64 & 0,643 \\
ABTS & 1 & 0,001373 & 0,001373 & 0,09 & 0,767 \\
RBBR & 1 & 0,001373 & 0,001373 & 0,09 & 0,767 \\
AG & 1 & 0,001373 & 0,001373 & 0,09 & 0,767 \\
Mn+2 & 1 & 0,034466 & 0,034466 & 2,29 & 0,154 \\
Quadrado & 4 & 0,004924 & 0,001231 & 0,08 & 0,987 \\
ABTS*ABTS & 1 & 0,002154 & 0,002154 & 0,14 & 0,711 \\
RBBR*RBBR & 1 & 0,002154 & 0,002154 & 0,14 & 0,711 \\
AG*AG & 1 & 0,002154 & 0,002154 & 0,14 & 0,711 \\
Mn+2*Mn+2 & 1 & 0,002154 & 0,002154 & 0,14 & 0,711 \\
Interação com 2 Fatores & 6 & 0,161275 & 0,026879 & 1,79 & 0,179 \\
ABTS*RBBR & 1 & 0,051699 & 0,051699 & 3,43 & 0,087 \\
ABTS*AG & 1 & 0,051699 & 0,051699 & 3,43 & 0,087 \\
ABTS*Mn+2 & 1 & 0,002059 & 0,002059 & 0,14 & 0,717 \\
RBBR*AG & 1 & 0,051699 & 0,051699 & 3,43 & 0,087 \\
RBBR*Mn+2 & 1 & 0,002059 & 0,002059 & 0,14 & 0,717 \\
AG*Mn+2 & 1 & 0,002059 & 0,002059 & 0,14 & 0,717 \\
Erro & 13 & 0,195741 & 0,015057 & & \\
Falta de ajuste & 10 & 0,195741 & 0,019574 & $*$ & $*$ \\
Erro puro & 3 & 0,000000 & 0,000000 & $*$ & $*$ \\
Total & 27 & 0,400524 & & & \\
& & & & & $*$
\end{tabular}


Continuação

Sumário do Modelo

$\begin{array}{clll}\text { S } & \text { R2 } & \text { R2(aj) } & \text { R2(pred) } \\ 0,122707 & 51,13 \% & 0,00 \% & 0,00 \%\end{array}$

Coeficientes Codificados

$\begin{array}{lcclccc}\text { Termo } & \text { Efeito } & \text { Coef } & \text { EP de Coef } & \text { Valor T } & \text { Valor-P } & \text { VIF } \\ \text { Constante } & -0,0000 & 0,0614 & -0,00 & 1,000 & & \\ \text { ABTS } & 0,0151 & 0,0076 & 0,0250 & 0,30 & 0,767 & 1,00 \\ \text { RBBR } & -0,0151 & -0,0076 & 0,0250 & -0,30 & 0,767 & 1,00 \\ \text { AG } & 0,0151 & 0,0076 & 0,0250 & 0,30 & 0,767 & 1,00 \\ \text { Mn+2 } & 0,0758 & 0,0379 & 0,0250 & 1,51 & 0,154 & 1,00 \\ \text { ABTS*ABTS } & 0,0189 & 0,0095 & 0,0250 & 0,38 & 0,711 & 1,14 \\ \text { RBBR*RBBR } & 0,0189 & 0,0095 & 0,0250 & 0,38 & 0,711 & 1,14 \\ \text { AG*AG } & 0,0189 & 0,0095 & 0,0250 & 0,38 & 0,711 & 1,14 \\ \text { Mn+2*Mn+2 } & 0,0189 & 0,0095 & 0,0250 & 0,38 & 0,711 & 1,14 \\ \text { ABTS*RBBR } & -0,1137 & -0,0568 & 0,0307 & -1,85 & 0,087 & 1,00 \\ \text { ABTS*AG } & 0,1137 & 0,0568 & 0,0307 & 1,85 & 0,087 & 1,00 \\ \text { ABTS*Mn+2 } & 0,0227 & 0,0113 & 0,0307 & 0,37 & 0,717 & 1,00 \\ \text { RBBR*AG } & -0,1137 & -0,0568 & 0,0307 & -1,85 & 0,087 & 1,00 \\ \text { RBBR*Mn+2 } & -0,0227 & -0,0113 & 0,0307 & -0,37 & 0,717 & 1,00 \\ \text { AG*Mn+2 } & 0,0227 & 0,0113 & 0,0307 & 0,37 & 0,717 & 1,00\end{array}$

Equação de Regressão em Unidades Não codificadas MnP tempo inicial $=-0,038-0,151 * A B T S+4,55 * R B B R-0,061 * A G-0,242 * \mathrm{Mn}+2+0,038 * A B T S * A B T S+$ $3,8 * \mathrm{RBBR} * \mathrm{RBBR}+0,0061 * \mathrm{AG} * \mathrm{AG}+0,152 * \mathrm{Mn}+2 * \mathrm{Mn}+2-2,27 * \mathrm{ABTS} * \mathrm{RBBR}+0,0909 * \mathrm{ABTS} * \mathrm{AG}+$ $0,091 * A B T S * M n+2-0,909 * R B B R * A G-0,91 * R B B R * M n+2+0,0363 * A G * M n+2$

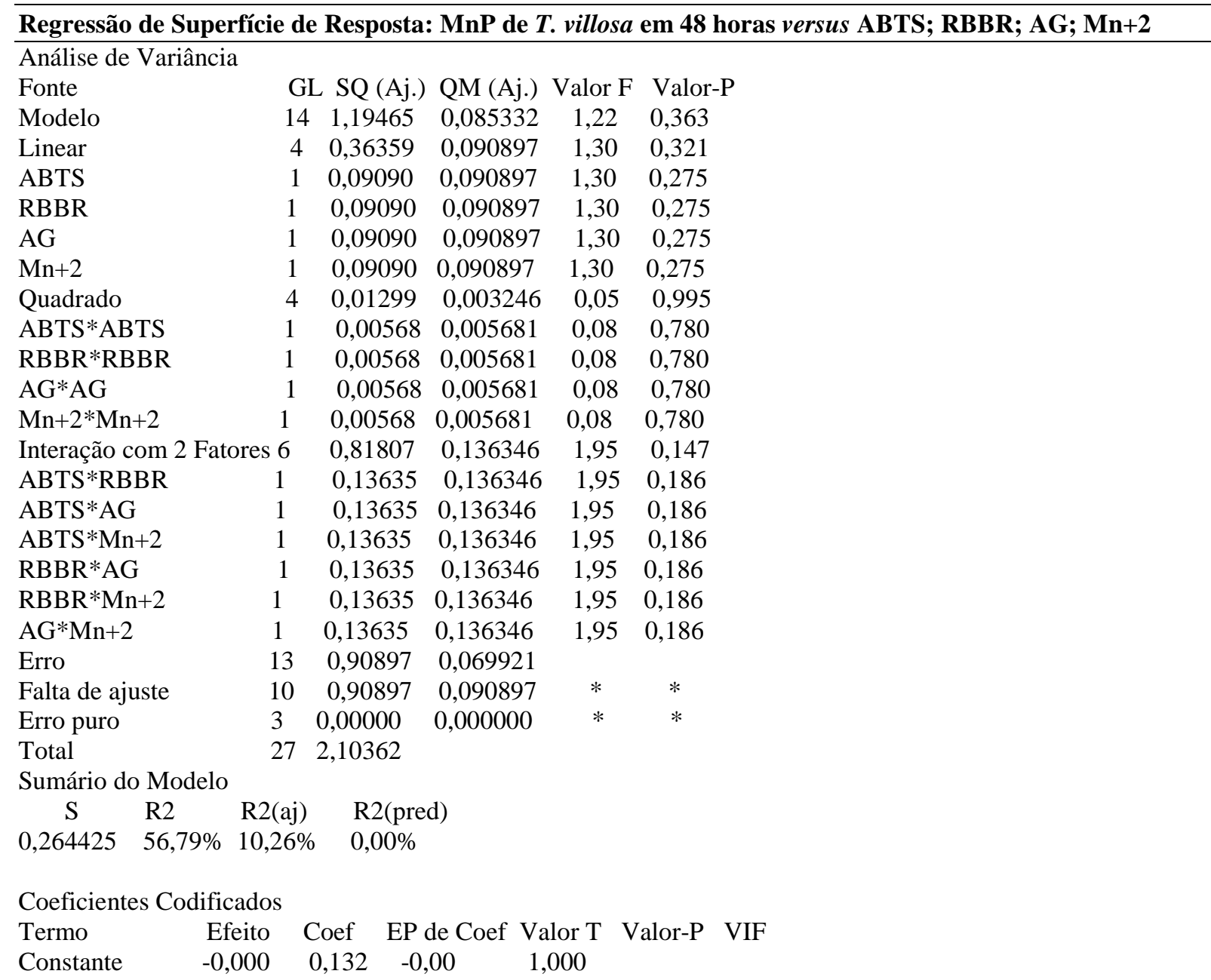




$\begin{array}{lcccccc}\begin{array}{l}\text { Continuação } \\ \text { Termo }\end{array} & \text { Efeito } & \text { Coef } & \text { EP de Coef } & \text { Valor T } & \text { Valor-P } & \text { VIF } \\ \text { ABTS } & 0,1231 & 0,0615 & 0,0540 & 1,14 & 0,275 & 1,00 \\ \text { RBBR } & -0,1231 & -0,0615 & 0,0540 & -1,14 & 0,275 & 1,00 \\ \text { AG } & 0,1231 & 0,0615 & 0,0540 & 1,14 & 0,275 & 1,00 \\ \text { Mn+2 } & -0,1231 & -0,0615 & 0,0540 & -1,14 & 0,275 & 1,00 \\ \text { ABTS*ABTS } & 0,0308 & 0,0154 & 0,0540 & 0,29 & 0,780 & 1,14 \\ \text { RBBR*RBBR } & 0,0308 & 0,0154 & 0,0540 & 0,29 & 0,780 & 1,14 \\ \text { AG*AG } & 0,0308 & 0,0154 & 0,0540 & 0,29 & 0,780 & 1,14 \\ \text { Mn+2*Mn+2 } & 0,0308 & 0,0154 & 0,0540 & 0,29 & 0,780 & 1,14 \\ \text { ABTS*RBBR } & -0,1846 & -0,0923 & 0,0661 & -1,40 & 0,186 & 1,00 \\ \text { ABTS*AG } & 0,1846 & 0,0923 & 0,0661 & 1,40 & 0,186 & 1,00 \\ \text { ABTS*Mn+2 } & -0,1846 & -0,0923 & 0,0661 & -1,40 & 0,186 & 1,00 \\ \text { RBBR*AG } & -0,1846 & -0,0923 & 0,0661 & -1,40 & 0,186 & 1,00 \\ \text { RBBR*Mn+2 } & 0,1846 & 0,0923 & 0,0661 & 1,40 & 0,186 & 1,00 \\ \text { AG*Mn+2 } & -0,1846 & -0,0923 & 0,0661 & -1,40 & 0,186 & 1,00\end{array}$

Equação de Regressão em Unidades Não codificadas

MnP 48 horas $=-0,55+0,738 * A B T S-2,46 *$ RBBR $+0,295 * A G-0,00 * \mathrm{Mn}+2+0,062 * A B T S * A B T S+$ $6,2 * \mathrm{RBBR} * \mathrm{RBBR}+0,0098 * \mathrm{AG} * \mathrm{AG}+0,246 * \mathrm{Mn}+2 * \mathrm{Mn}+2-3,69 * \mathrm{ABTS} * \mathrm{RBBR}+0,148 * \mathrm{ABTS} * \mathrm{AG}-$ 0,738*ABTS*Mn+2 - 1,48*RBBR*AG + 7,38*RBBR*Mn+2 - 0,295*AG*Mn+2

\begin{tabular}{|c|c|c|c|c|c|}
\hline \multicolumn{6}{|c|}{$\begin{array}{l}\text { Regressão de Superfície de Resposta: Lacase de } T \text {. villosa no temp } \\
M n+2\end{array}$} \\
\hline \multicolumn{6}{|l|}{ Análise de Variância } \\
\hline Fonte & GL & SQ (Aj.) & QM (Aj.) & Valor F & Valor-P \\
\hline Modelo & 14 & 397942 & 28424 & 1,80 & 0,149 \\
\hline Linear & 4 & 118267 & 29567 & 1,87 & 0,176 \\
\hline ABTS & 1 & 45460 & 45460 & 2,88 & 0,114 \\
\hline RBBR & 1 & 7582 & 7582 & 0,48 & 0,501 \\
\hline AG & 1 & 65050 & 65050 & 4,12 & 0,063 \\
\hline $\mathrm{Mn}+2$ & 1 & 175 & 175 & 0,01 & 0,918 \\
\hline Quadrado & 4 & 48524 & 12131 & 0,77 & 0,565 \\
\hline ABTS*ABTS & 1 & 33282 & 33282 & 2,11 & 0,170 \\
\hline RBBR*RBBR & 1 & 8760 & 8760 & 0,55 & 0,470 \\
\hline $\mathrm{AG} * \mathrm{AG}$ & 1 & 1727 & 1727 & 0,11 & 0,746 \\
\hline $\mathrm{Mn}+2 * \mathrm{Mn}+2$ & 1 & 43 & 43 & 0,00 & 0,959 \\
\hline Interação com 2 Fatores & 6 & 231151 & 38525 & 2,44 & 0,084 \\
\hline ABTS*RBBR & 1 & 4507 & 4507 & 0,29 & 0,602 \\
\hline ABTS*AG & 1 & 60596 & 60596 & 3,84 & 0,072 \\
\hline ABTS*Mn+2 & 1 & 31995 & 31995 & 2,03 & 0,178 \\
\hline $\mathrm{RBBR} * \mathrm{AG}$ & 1 & 21496 & 21496 & 1,36 & 0,264 \\
\hline $\mathrm{RBBR} * \mathrm{Mn}+2$ & 1 & 10692 & 10692 & 0,68 & 0,425 \\
\hline $\mathrm{AG} * \mathrm{Mn}+2$ & 1 & 101864 & 101864 & 6,45 & 0,025 \\
\hline Erro & 13 & 205343 & 15796 & & \\
\hline Falta de ajuste & 10 & 155369 & 15537 & 0,93 & 0,596 \\
\hline Erro puro & 3 & 49974 & 16658 & $*$ & $*$ \\
\hline Total & 27 & 603286 & & & \\
\hline \multicolumn{6}{|l|}{ Sumário do Modelo } \\
\hline $\begin{array}{lll}\mathrm{S} & \mathrm{R} 2 & \mathrm{R} 2(\mathrm{a}\end{array}$ & & R2(pred) & & & \\
\hline $125,681 \quad 65,96 \% \quad 29,31$ & $1 \%$ & $0,00 \%$ & & & \\
\hline
\end{tabular}

Coeficientes Codificados

EP de

\begin{tabular}{|c|c|c|c|c|c|c|}
\hline Termo & Efeito & Coef & Coef & Valor T & Valor-P & VIF \\
\hline Constante & 469,9 & 62,8 & 7,48 & 0,000 & & \\
\hline ABTS & 87,0 & 43,5 & 25,7 & 1,70 & 0,114 & 1,00 \\
\hline RBBR & 35,5 & 17,8 & 25,7 & 0,69 & 0,501 & 1,00 \\
\hline AG & 104,1 & 52,1 & 25,7 & 2,03 & 0,063 & 1,00 \\
\hline $\mathrm{Mn}+2$ & 5,4 & 2,7 & 25,7 & 0,11 & 0,918 & 1,00 \\
\hline
\end{tabular}


Continuação

\begin{tabular}{lllllll} 
& \multicolumn{7}{c}{ EP de } \\
Termo & Efeito & Coef & Coef & Valor T & Valor-P & VIF \\
ABTS*ABTS & $-74,5$ & $-37,2$ & 25,7 & $-1,45$ & 0,170 & 1,14 \\
RBBR*RBBR & $-38,2$ & $-19,1$ & 25,7 & $-0,74$ & 0,470 & 1,14 \\
AG*AG & 17,0 & 8,5 & 25,7 & 0,33 & 0,746 & 1,14 \\
Mn+2*Mn+2 & 2,7 & 1,3 & 25,7 & 0,05 & 0,959 & 1,14 \\
ABTS*RBBR & 33,6 & 16,8 & 31,4 & 0,53 & 0,602 & 1,00 \\
ABTS*AG & 123,1 & 61,5 & 31,4 & 1,96 & 0,072 & 1,00 \\
ABTS*Mn+2 & $-89,4$ & $-44,7$ & 31,4 & $-1,42$ & 0,178 & 1,00 \\
RBBR*AG & $-73,3$ & $-36,7$ & 31,4 & $-1,17$ & 0,264 & 1,00 \\
RBBR*Mn+2 & 51,7 & 25,9 & 31,4 & 0,82 & 0,425 & 1,00 \\
AG*Mn+2 & $-159,6$ & $-79,8$ & 31,4 & $-2,54$ & 0,025 & 1,00
\end{tabular}

Equação de Regressão em Unidades Não codificadas Lacase tempo inicial $=-560+429 * \mathrm{ABTS}+611 * \mathrm{RBBR}+230 * \mathrm{AG}+757 * \mathrm{Mn}+2-149 * \mathrm{ABTS} * \mathrm{ABTS}-$ $7642 * \mathrm{RBBR} * \mathrm{RBBR}+5,4 * \mathrm{AG} * \mathrm{AG}+22 * \mathrm{Mn}+2 * \mathrm{Mn}+2+671 * \mathrm{ABTS} * \mathrm{RBBR}+98,5 * \mathrm{ABTS} * \mathrm{AG}-$ 358*ABTS*Mn+2 - 586*RBBR*AG +2068*RBBR*Mn+2 -255*AG*Mn+2

\begin{tabular}{|c|c|c|c|c|c|c|c|}
\hline \multicolumn{8}{|c|}{ Regressão de Superfície de Resposta: Lacase de T. villosa em 24 horas versus ABTS; RBBR; AG; Mn+2 } \\
\hline \multicolumn{8}{|c|}{ Análise de Variância } \\
\hline \multicolumn{2}{|c|}{ Fonte } & GL & SQ (Aj.) & $\mathrm{QM}(\mathrm{A}]$ & Aj.) Valo & or F & Valor-P \\
\hline \multicolumn{2}{|l|}{ Modelo } & 14 & 671995 & 48000 & 2,99 & & 0,028 \\
\hline \multicolumn{2}{|l|}{ Linear } & 4 & 26094 & 6524 & 0,41 & & 0,801 \\
\hline \multicolumn{2}{|l|}{ ABTS } & 1 & 1857 & 1857 & 0,12 & & 0,739 \\
\hline \multicolumn{2}{|l|}{ RBBR } & 1 & 532 & 532 & 0,03 & & 0,858 \\
\hline \multicolumn{2}{|l|}{$\mathrm{AG}$} & 1 & 302 & 302 & 0,02 & & 0,893 \\
\hline \multicolumn{2}{|l|}{$\mathrm{Mn}+2$} & 1 & 23403 & 23403 & 1,46 & & 0,249 \\
\hline \multicolumn{2}{|l|}{ Quadrado } & 4 & 62008 & 15502 & 0,97 & & 0,459 \\
\hline \multicolumn{2}{|l|}{ ABTS*ABTS } & 1 & 55662 & 55662 & 3,47 & & 0,085 \\
\hline \multicolumn{2}{|l|}{$\mathrm{RBBR} * \mathrm{RBBR}$} & 1 & 12571 & 12571 & 0,78 & & 0,392 \\
\hline \multicolumn{2}{|l|}{$\mathrm{AG}^{*} \mathrm{AG}$} & 1 & 278 & 278 & 0,02 & & 0,897 \\
\hline \multicolumn{2}{|c|}{$\mathrm{Mn}+2 * \mathrm{Mn}+2$} & 1 & 2200 & 2200 & 0,14 & & 0,717 \\
\hline \multicolumn{2}{|c|}{ Interação com 2 Fatores } & 6 & 583893 & 97315 & 6,06 & & 0,003 \\
\hline \multicolumn{2}{|c|}{ ABTS*RBBR } & 1 & 19079 & 19079 & 1,19 & & 0,295 \\
\hline \multicolumn{2}{|l|}{ ABTS*AG } & 1 & 112678 & 112678 & 7,02 & & 0,020 \\
\hline \multicolumn{2}{|l|}{$\mathrm{ABTS} * \mathrm{Mn}+2$} & 1 & 70220 & 70220 & 4,38 & & 0,057 \\
\hline \multicolumn{2}{|l|}{$\mathrm{RBBR} * \mathrm{AG}$} & 1 & 869 & 869 & 0,05 & & 0,820 \\
\hline \multicolumn{2}{|l|}{$\mathrm{RBBR} * \mathrm{Mn}+2$} & 1 & 8096 & 8096 & 0,50 & & 0,490 \\
\hline \multicolumn{2}{|l|}{$\mathrm{AG}^{*} \mathrm{Mn}+2$} & 1 & 372951 & 372951 & 23,2 & & 0,000 \\
\hline \multicolumn{2}{|l|}{ Erro } & 13 & 208593 & 316046 & & & \\
\hline \multicolumn{2}{|l|}{ Falta de ajuste } & 10 & 193337 & 719334 & 3,80 & & 0,150 \\
\hline \multicolumn{2}{|l|}{ Erro puro } & 3 & 15255 & 5085 & $*$ & & $*$ \\
\hline \multicolumn{2}{|c|}{ Total } & 27 & 880587 & & & & \\
\hline Sumário do Mo & delo & & & & & & \\
\hline $\mathrm{S} \quad \mathrm{R} 2$ & R2 & & R2(pred) & & & & \\
\hline $126,671 \quad 76,31$ & $\% \quad 50,8$ & $0 \%$ & $0,00 \%$ & & & & \\
\hline Coeficientes Co & dificado & & & & & & \\
\hline & & & EP de & & & & \\
\hline Termo & Efeito & Coef & Coef & Valor T & Valor-P & VIF & IF \\
\hline Constante & 519,7 & 63,3 & 8,21 & 0,000 & & & \\
\hline ABTS & 17,6 & 8,8 & 25,9 & 0,34 & 0,739 & 1,00 & \\
\hline RBBR & 9,4 & 4,7 & 25,9 & 0,18 & 0,858 & 1,00 & \\
\hline AG & $-7,1$ & $-3,5$ & 25,9 & $-0,14$ & 0,893 & 1,00 & \\
\hline $\mathrm{Mn}+2$ & 62,5 & 31,2 & 25,9 & 1,21 & 0,249 & 1,00 & \\
\hline ABTS*ABTS & $-96,3$ & $-48,2$ & 25,9 & $-1,86$ & 0,085 & 1,14 & \\
\hline RBBR*RBBR & $-45,8$ & $-22,9$ & 25,9 & $-0,89$ & 0,392 & 1,14 & \\
\hline $\mathrm{AG}^{*} \mathrm{AG}$ & $-6,8$ & $-3,4$ & 25,9 & $-0,13$ & 0,897 & 1,14 & \\
\hline $\mathrm{Mn}+2 * \mathrm{Mn}+2$ & $-19,2$ & $-9,6$ & 25,9 & $-0,37$ & 0,717 & 1,14 & \\
\hline
\end{tabular}


Continuação

\begin{tabular}{lllllll} 
& \multicolumn{7}{c}{ EP de } \\
Termo & Efeito & Coef & Coef & Valor T & Valor-P & VIF \\
ABTS*RBBR & 69,1 & 34,5 & 31,7 & 1,09 & 0,295 & 1,00 \\
ABTS*AG & 167,8 & 83,9 & 31,7 & 2,65 & 0,020 & 1,00 \\
ABTS*Mn+2 & $-132,5$ & $-66,2$ & 31,7 & $-2,09$ & 0,057 & 1,00 \\
RBBR*AG & 14,7 & 7,4 & 31,7 & 0,23 & 0,820 & 1,00 \\
RBBR*Mn+2 & $-45,0$ & $-22,5$ & 31,7 & $-0,71$ & 0,490 & 1,00 \\
AG*Mn+2 & $-305,3$ & $-152,7$ & 31,7 & $-4,82$ & 0,000 & 1,00
\end{tabular}

Equação de Regressão em Unidades Não codificadas Lacase 24 horas $=-1504+459 * A B T S+2049 * R B B R+351 * A G+2363 * M n+2-193 * A B T S * A B T S-$ 9155*RBBR*RBBR - 2,2*AG*AG - 153*Mn+2*Mn+2 + 1381*ABTS*RBBR + 134,3*ABTS*AG $530 *$ ABTS $* \mathrm{Mn}+2+118 * \mathrm{RBBR} * \mathrm{AG}-1800 * \mathrm{RBBR} * \mathrm{Mn}+2-489 * \mathrm{AG} * \mathrm{Mn}+2$

\begin{tabular}{|c|c|c|c|c|c|c|c|}
\hline \multicolumn{8}{|c|}{ Regressão de Superfície de Resposta: Lacase de T. villosa em 48 horas versus ABTS; RBBR; AG; Mn+2 } \\
\hline \multicolumn{8}{|c|}{ Análise de Variância } \\
\hline \multicolumn{2}{|c|}{ Fonte } & GL SC & SQ (Aj.) & $\mathrm{QM}(\mathrm{A}$ & Aj.) & or F & Valor-P \\
\hline \multicolumn{2}{|l|}{ Modelo } & 144 & 487692 & 34835 & 1,69 & & 0,176 \\
\hline \multicolumn{2}{|l|}{ Linear } & 4 & 15367 & 3842 & 0,19 & & 0,941 \\
\hline \multicolumn{2}{|l|}{ ABTS } & 1 & 9910 & 9910 & 0,48 & & 0,500 \\
\hline \multicolumn{2}{|l|}{ RBBR } & 1 & 40 & 40 & 0,00 & & 0,966 \\
\hline \multicolumn{2}{|l|}{ AG } & 1 & 3891 & 3891 & 0,19 & & 0,671 \\
\hline \multicolumn{2}{|l|}{$\mathrm{Mn}+2$} & 15 & 1526 & 1526 & 0,07 & & 0,790 \\
\hline \multicolumn{2}{|l|}{ Quadrado } & 4 & 111910 & 27977 & 1,36 & & 0,302 \\
\hline \multicolumn{2}{|l|}{ ABTS*ABTS } & 1 & 104167 & 10416 & 5,05 & & 0,043 \\
\hline \multicolumn{2}{|l|}{$\mathrm{RBBR} * \mathrm{RBBR}$} & 1 & 22157 & 22157 & 1,07 & & 0,319 \\
\hline \multicolumn{2}{|l|}{$\mathrm{AG} * \mathrm{AG}$} & 1 & 14749 & 14749 & 0,72 & & 0,413 \\
\hline \multicolumn{2}{|c|}{$\mathrm{Mn}+2 * \mathrm{Mn}+2$} & 1 & 19697 & 19697 & 0,96 & & 0,346 \\
\hline \multicolumn{2}{|c|}{ Interação com 2 Fatores } & 6 & 360416 & 6006 & 2,91 & & 0,050 \\
\hline \multicolumn{2}{|c|}{ ABTS*RBBR } & 1 & 2835 & 2835 & $0,1<$ & & 0,717 \\
\hline \multicolumn{2}{|l|}{ ABTS*AG } & 1 & 70056 & 70056 & 3,4 & & 0,088 \\
\hline \multicolumn{2}{|l|}{ ABTS*Mn+2 } & 68 & 68836 & 68836 & 3,3 & & 0,091 \\
\hline \multicolumn{2}{|l|}{$\mathrm{RBBR} * \mathrm{AG}$} & 1 & 315 & 315 & 0,0 & & 0,904 \\
\hline \multicolumn{2}{|l|}{$\mathrm{RBBR} * \mathrm{Mn}+2$} & 1 & 4004 & 4004 & 0,1 & & 0,667 \\
\hline \multicolumn{2}{|l|}{$\mathrm{AG}^{*} \mathrm{Mn}+2$} & 1 & 214369 & 21436 & 10 & & 0,007 \\
\hline \multicolumn{2}{|l|}{ Erro } & 13 & 268017 & 20617 & & & \\
\hline \multicolumn{2}{|l|}{ Falta de ajuste } & 10 & 190470 & 19047 & 0,7 & & 0,689 \\
\hline Erro puro & & 3 & 77547 & 25849 & $*$ & & $*$ \\
\hline Total & & 27 & 755709 & & & & \\
\hline Sumário do Mo & delo & & & & & & \\
\hline $\mathrm{S} \quad \mathrm{R} 2$ & R2(a & & R2(pred) & & & & \\
\hline $143,585 \quad 64,53$ & $3 \% \quad 26,3$ & $4 \%$ & $0,00 \%$ & & & & \\
\hline Coeficientes Co & odificados & & & & & & \\
\hline & & & EP de & & & & \\
\hline Termo & Efeito & Coef & Coef & Valor T & Valor-P & VIF & \\
\hline Constante & 649,0 & 71,8 & 9,04 & 0,000 & & & \\
\hline ABTS & 40,6 & 20,3 & 29,3 & 0,69 & 0,500 & 1,00 & \\
\hline RBBR & 2,6 & 1,3 & 29,3 & 0,04 & 0,966 & 1,00 & \\
\hline AG & $-25,5$ & $-12,7$ & $7 \quad 29,3$ & $-0,43$ & 0,671 & 1,00 & \\
\hline $\mathrm{Mn}+2$ & $-15,9$ & $-8,0$ & 29,3 & $-0,27$ & 0,790 & 1,00 & \\
\hline ABTS*ABTS & $-131,8$ & $-65,9$ & 29,3 & $-2,25$ & 0,043 & 1,14 & \\
\hline RBBR*RBBR & $-60,8$ & $-30,4$ & 29,3 & $-1,04$ & 0,319 & 1,14 & \\
\hline $\mathrm{AG} * \mathrm{AG}$ & $-49,6$ & $-24,8$ & 29,3 & $-0,85$ & 0,413 & 1,14 & \\
\hline $\mathrm{Mn}+2 * \mathrm{Mn}+2$ & $-57,3$ & $-28,6$ & 29,3 & $-0,98$ & 0,346 & 1,14 & \\
\hline ABTS*RBBR & $-26,6$ & $-13,3$ & 35,9 & $-0,37$ & 0,717 & 1,00 & \\
\hline ABTS*AG & 132,3 & 66,2 & 35,9 & 1,84 & 0,088 & 1,00 & \\
\hline ABTS*Mn+2 & $-131,2$ & $-65,6$ & 35,9 & $-1,83$ & 0,091 & 1,00 & \\
\hline RBBR*AG & 8,9 & 4,4 & 35,9 & 0,12 & 0,904 & 1,00 & \\
\hline
\end{tabular}




\section{Continuação}

\begin{tabular}{lllllll} 
& \multicolumn{7}{c}{ EP de } \\
Termo & Efeito & Coef & Coef & Valor T & Valor-P & VIF \\
RBBR*Mn+2 & $-31,6$ & $-15,8$ & 35,9 & $-0,44$ & 0,667 & 1,00 \\
AG*Mn+2 & $-231,5$ & $-115,8$ & 35,9 & $-3,22$ & 0,007 & 1,00
\end{tabular}

Equação de Regressão em Unidades Não codificadas Lacase 48 horas $=-1628+881 *$ ABTS $+4077 *$ RBBR $+327 * A G+2462 * \mathrm{Mn}+2-264 * A B T S * A B T S-$ 12154*RBBR*RBBR - 15,9*AG*AG - 458*Mn+2*Mn+2 - 532*ABTS*RBBR + 105,9*ABTS*AG 525*ABTS*Mn+2 + 71*RBBR*AG - 1266* RBBR*Mn+2 - 370*AG*Mn+2 


\section{APÊNDICE E - Análise estatística item 4.5}

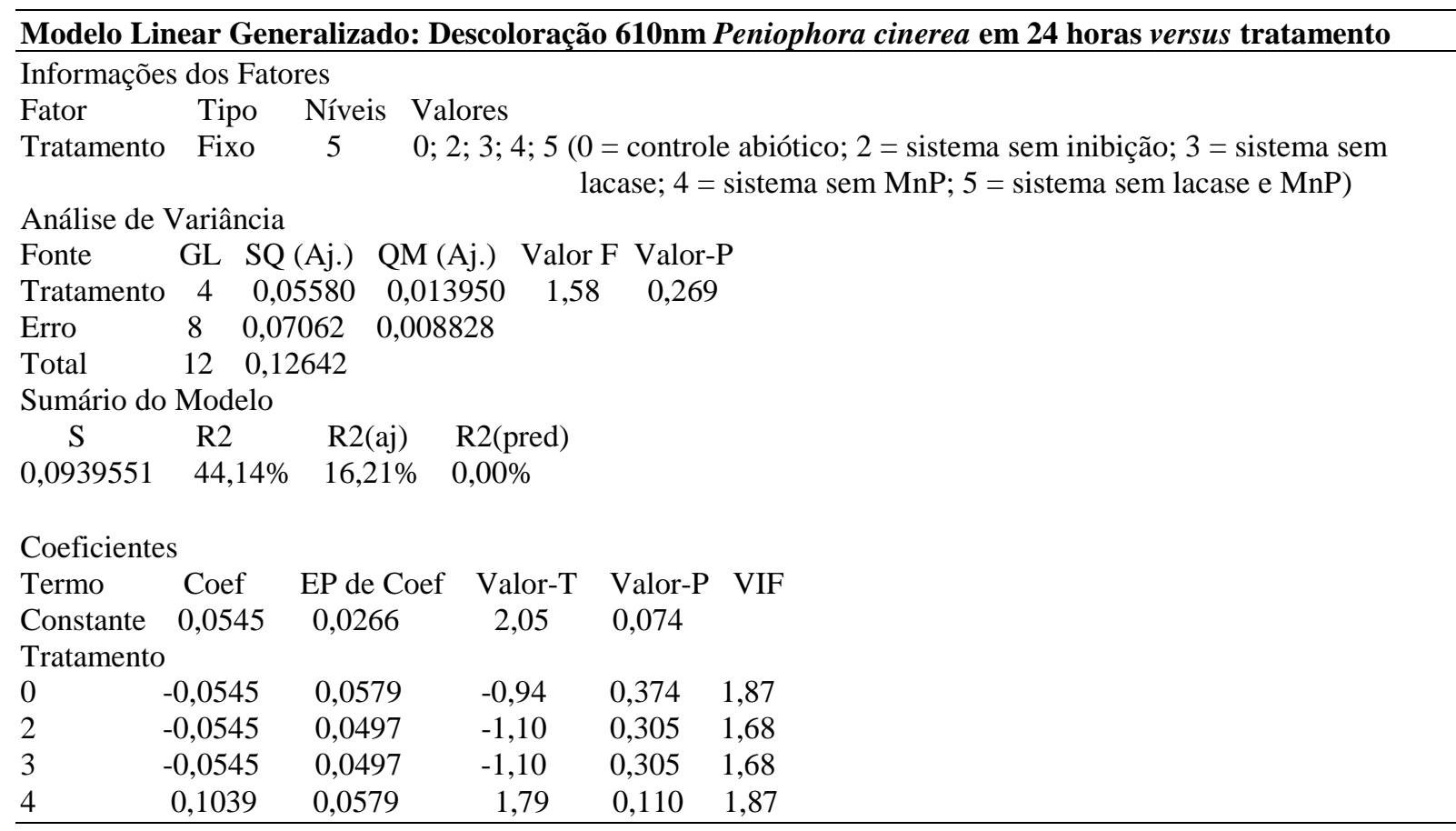

\section{Modelo Linear Generalizado: Descoloração 610nm Peniophora cinerea em 48 horas versus tratamento} Informações dos Fatores
Fator Tipo Níveis Valores
Tratamento Fixo $5 \quad$ 0; 2; 3; 4; 5 (0 = controle abiótico; 2 = sistema sem inibição; $3=$ sistema sem lacase; 4 = sistema sem MnP; 5 = sistema sem lacase e MnP)

Análise de Variância

$\begin{array}{llllll}\text { Fonte } & \text { GL } & \text { SQ (Aj.) } & \text { QM (Aj.) } & \text { Valor F } & \text { Valor-P } \\ \text { Tratamento } & 4 & 0,2131 & 0,05329 & 3,47 & 0,063 \\ \text { Erro } & 8 & 0,1230 & 0,01538 & & \\ \text { Total } & 12 & 0,3362 & & & \\ \text { Sinat } & 12 & & & & \end{array}$

Sumário do Modelo

$\begin{array}{ccll}\mathrm{S} & \mathrm{R} 2 & \mathrm{R} 2(\mathrm{aj}) & \mathrm{R} 2 \text { (pred) } \\ 0,124007 & 63,40 \% & 45,11 \% & 0,00 \%\end{array}$

$\begin{array}{llclll}\begin{array}{l}\text { Coeficientes } \\ \text { Termo }\end{array} & \text { Coef } & \text { EP de Coef } & \text { Valor-T } & \text { Valor-P } & \text { VIF } \\ \text { Constante } & 0,4300 & 0,0351 & 12,26 & 0,000 & \\ \text { Tratamento } & & & & & \\ 0 & -0,2553 & 0,0764 & -3,34 & 0,010 & 1,87 \\ 2 & -0,0040 & 0,0656 & -0,06 & 0,953 & 1,68 \\ 3 & -0,0027 & 0,0656 & -0,04 & 0,968 & 1,68 \\ 4 & 0,1405 & 0,0764 & 1,84 & 0,103 & 1,87\end{array}$

Comparações Pareadas de Tukey

Informações de Agrupamento Usando Método de Tukey e Confiança de 90\%

Tratamento N Média Agrupamento

$\begin{array}{rrrl}4 & 2 & 0,570489 & \text { A } \\ 5 & 3 & 0,551549 & \text { A } \\ 3 & 3 & 0,427347 & \text { A B } \\ 2 & 3 & 0,426043 & \text { A B } \\ 0 & 2 & 0,174751 & \text { B }\end{array}$

Médias que não compartilham uma letra são significativamente diferentes. 


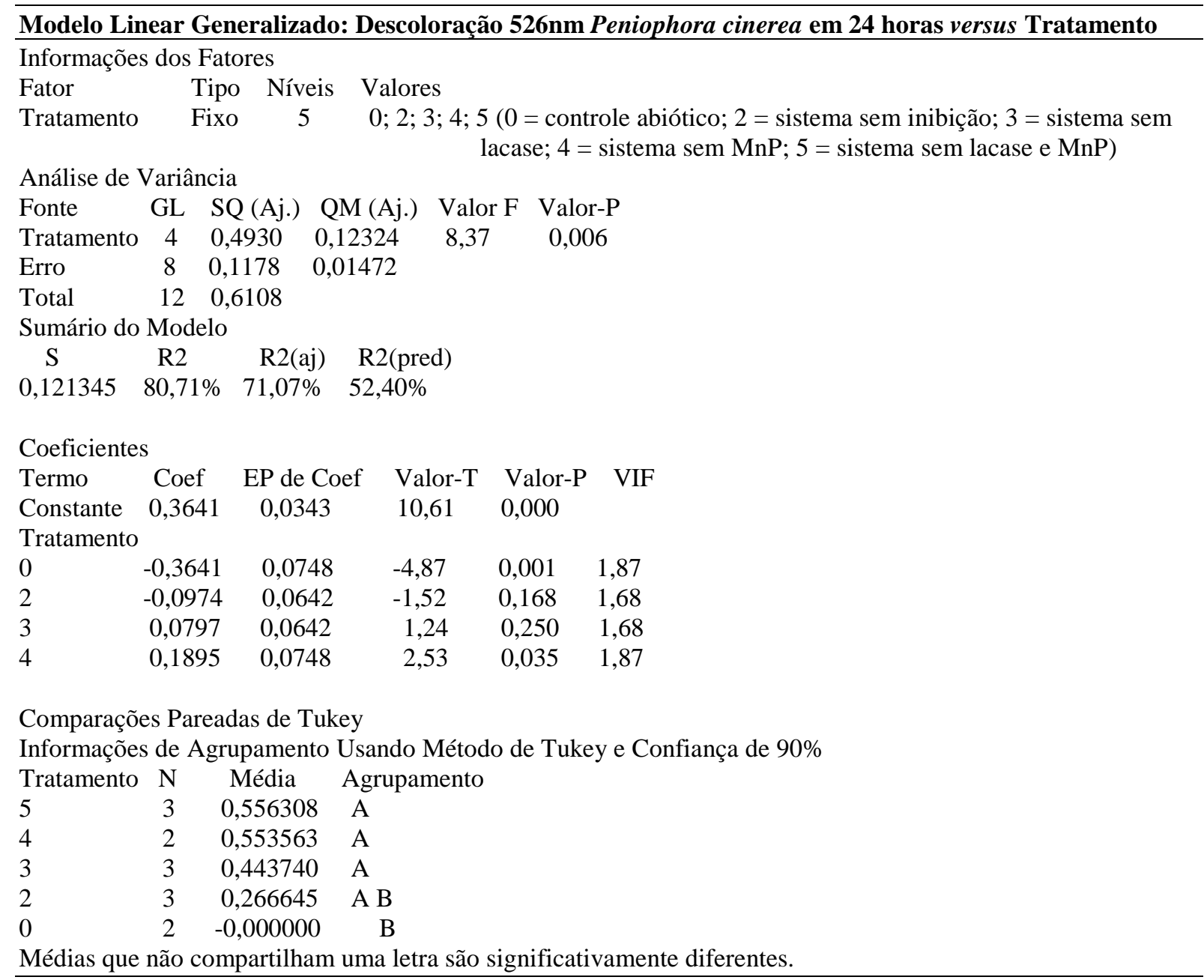

\section{Modelo Linear Generalizado: Descoloração 526nm Peniophora cinerea em 48 horas versus Tratamento}

Informações dos Fatores

Fator Tipo Níveis Valores

Tratamento Fixo 5 0; 2; 3; 4; 5 ( 0 = controle abiótico; 2 = sistema sem inibição; 3 = sistema sem

Análise de Variância

$\begin{array}{lcllll}\text { Fonte } & \text { GL } & \text { SQ (Aj.) } & \text { QM (Aj.) } & \text { Valor F } & \text { Valor-P } \\ \text { Tratamento } & 4 & 0,72687 & 0,18172 & 17,52 & 0,001 \\ \text { Erro } & 8 & 0,08299 & 0,01037 & & \end{array}$

Total $\quad 12 \quad 0,80987$

Sumário do Modelo

$\begin{array}{clll}\text { S } & \text { R2 } & \text { R2(aj) } & \text { R2(pred) } \\ 0,101854 & 89,75 \% & 84,63 \% & 69,54 \%\end{array}$

Coeficientes

\begin{tabular}{|c|c|c|c|c|c|}
\hline Termo & Coef & EP de Coef & Valor-T & Valor-P & VIF \\
\hline Constante & 0,4947 & 0,0288 & 17,17 & 0,000 & \\
\hline \multicolumn{6}{|c|}{ Tratamento } \\
\hline 0 & $-0,4947$ & 0,0628 & $-7,88$ & 0,000 & 1,87 \\
\hline 2 & 0,0077 & 0,0539 & 0,14 & 0,890 & 1,68 \\
\hline 3 & 0,0759 & 0,0539 & 1,41 & 0,197 & 1,68 \\
\hline 4 & 0,1762 & 0,0628 & 2,81 & 0,023 & 1,87 \\
\hline
\end{tabular}

Comparações Pareadas de Tukey

Informações de Agrupamento Usando Método de Tukey e Confiança de 90\% 


\begin{tabular}{lrlcc}
\multicolumn{2}{l}{ Continuação } & \multicolumn{3}{l}{} \\
Tratamento & N & \multicolumn{2}{l}{ Média } & Agrupamento \\
5 & 3 & 0,729702 & A & \\
4 & 2 & 0,670914 & A & \\
3 & 3 & 0,570593 & A & \\
2 & 3 & 0,502410 & A & \\
0 & 2 & $-0,000000$ & & B
\end{tabular}

Médias que não compartilham uma letra são significativamente diferentes.
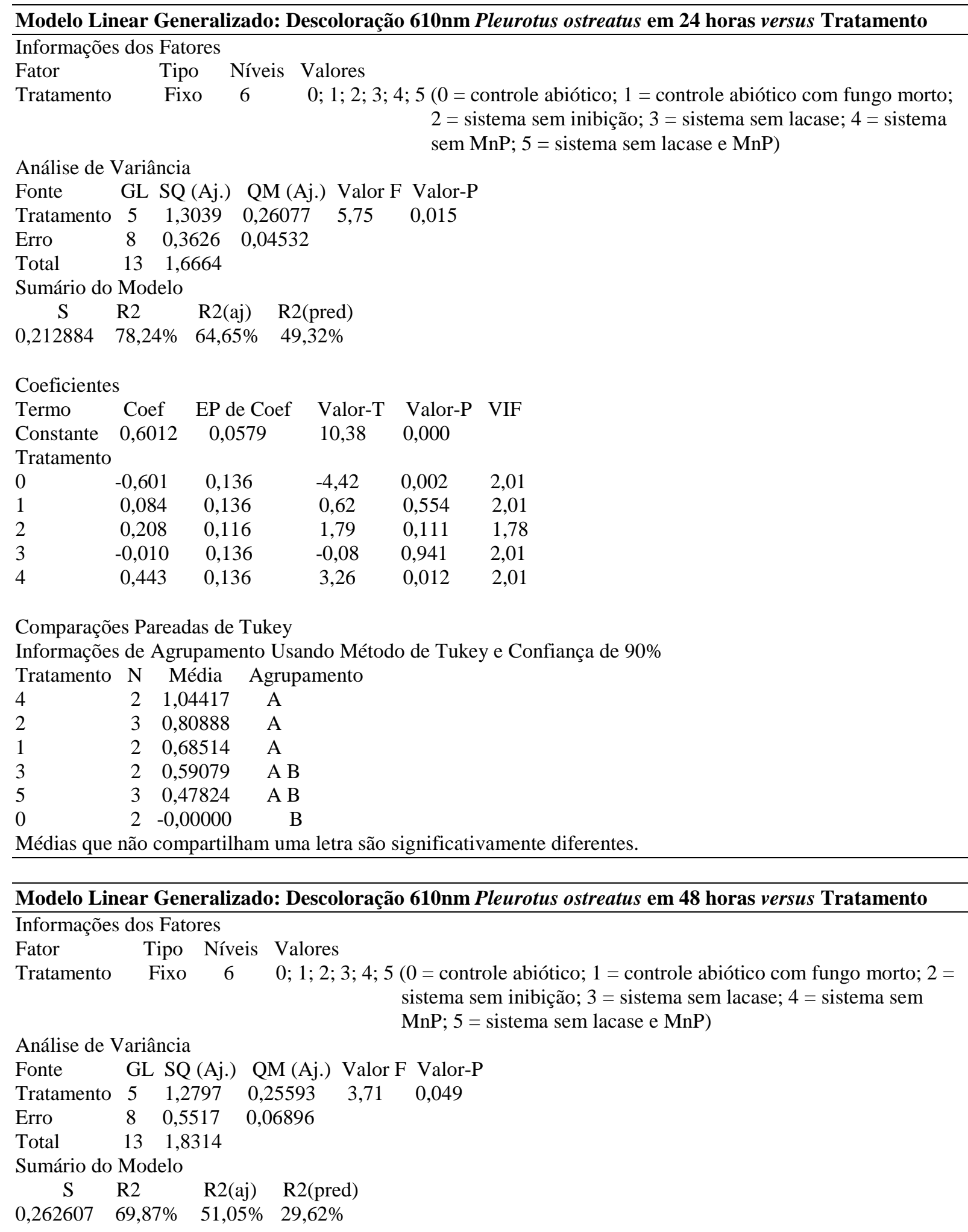


\begin{tabular}{|c|c|c|c|c|c|}
\hline $\begin{array}{l}\text { Continuaç } \\
\text { Coeficient }\end{array}$ & & & & & \\
\hline Termo & Coef & EP de Coef & Valor-T & Valor-P & VIF \\
\hline Constante & 0,7657 & 0,0715 & 10,71 & 0,000 & \\
\hline Tratamentc & & & & & \\
\hline 0 & $-0,493$ & 0,168 & $-2,94$ & 0,019 & 2,01 \\
\hline 1 & 0,057 & 0,168 & 0,34 & 0,741 & 2,01 \\
\hline 2 & 0,267 & 0,143 & 1,87 & 0,098 & 1,78 \\
\hline 3 & $-0,118$ & 0,168 & $-0,71$ & 0,501 & 2,01 \\
\hline 4 & 0,471 & 0,168 & 2,81 & 0,023 & 2,01 \\
\hline
\end{tabular}

Comparações Pareadas de Tukey

Informações de Agrupamento Usando Método de Tukey e Confiança de 90\%

Tratamento N Média Agrupamento

$\begin{array}{llll}4 & 2 & 1,23654 & \text { A } \\ 2 & 3 & 1,03306 & \text { A } \\ 1 & 2 & 0,82305 & \text { A B } \\ 3 & 2 & 0,64753 & \text { A B } \\ 5 & 3 & 0,58167 & \text { A B } \\ 0 & 2 & 0,27263 & \text { B }\end{array}$

Médias que não compartilham uma letra são significativamente diferentes.
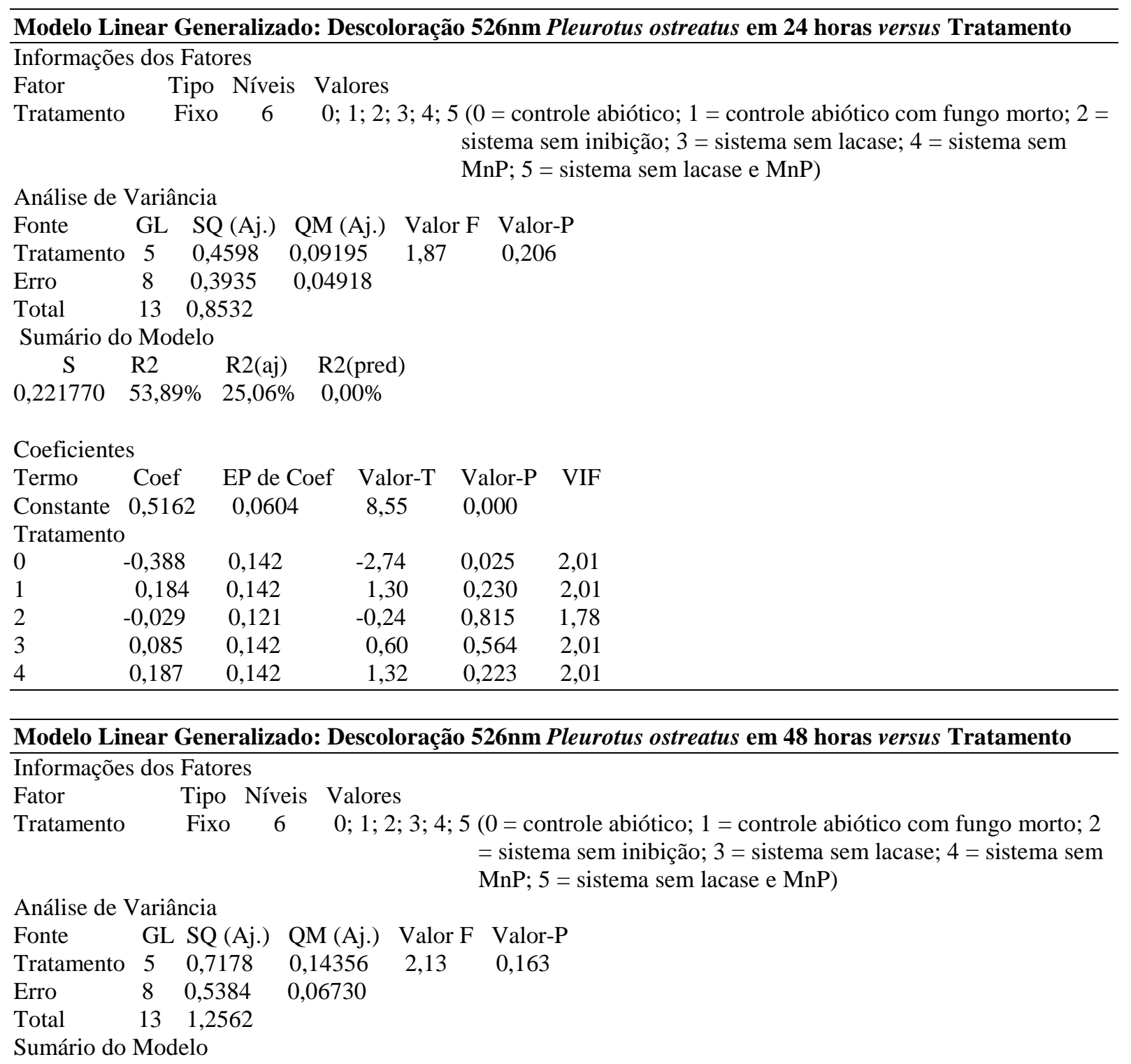


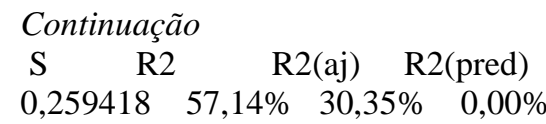

\begin{tabular}{|c|c|c|c|c|c|}
\hline \multicolumn{6}{|c|}{ Coeficientes } \\
\hline Termo & Coef & EP de Coef & Valor-T & Valor-P & VIF \\
\hline Constante & 0,5970 & 0,0706 & 8,46 & 0,000 & \\
\hline \multicolumn{6}{|c|}{ Tratamento } \\
\hline 0 & $-0,473$ & 0,166 & $-2,86$ & 0,021 & 2,01 \\
\hline 1 & 0,195 & 0,166 & 1,17 & 0,274 & 2,01 \\
\hline 2 & $-0,043$ & 0,141 & $-0,30$ & 0,770 & 1,78 \\
\hline 3 & 0,051 & 0,166 & 0,31 & 0,767 & 2,01 \\
\hline 4 & 0,301 & 0,166 & 1,82 & 0,106 & 2,01 \\
\hline
\end{tabular}

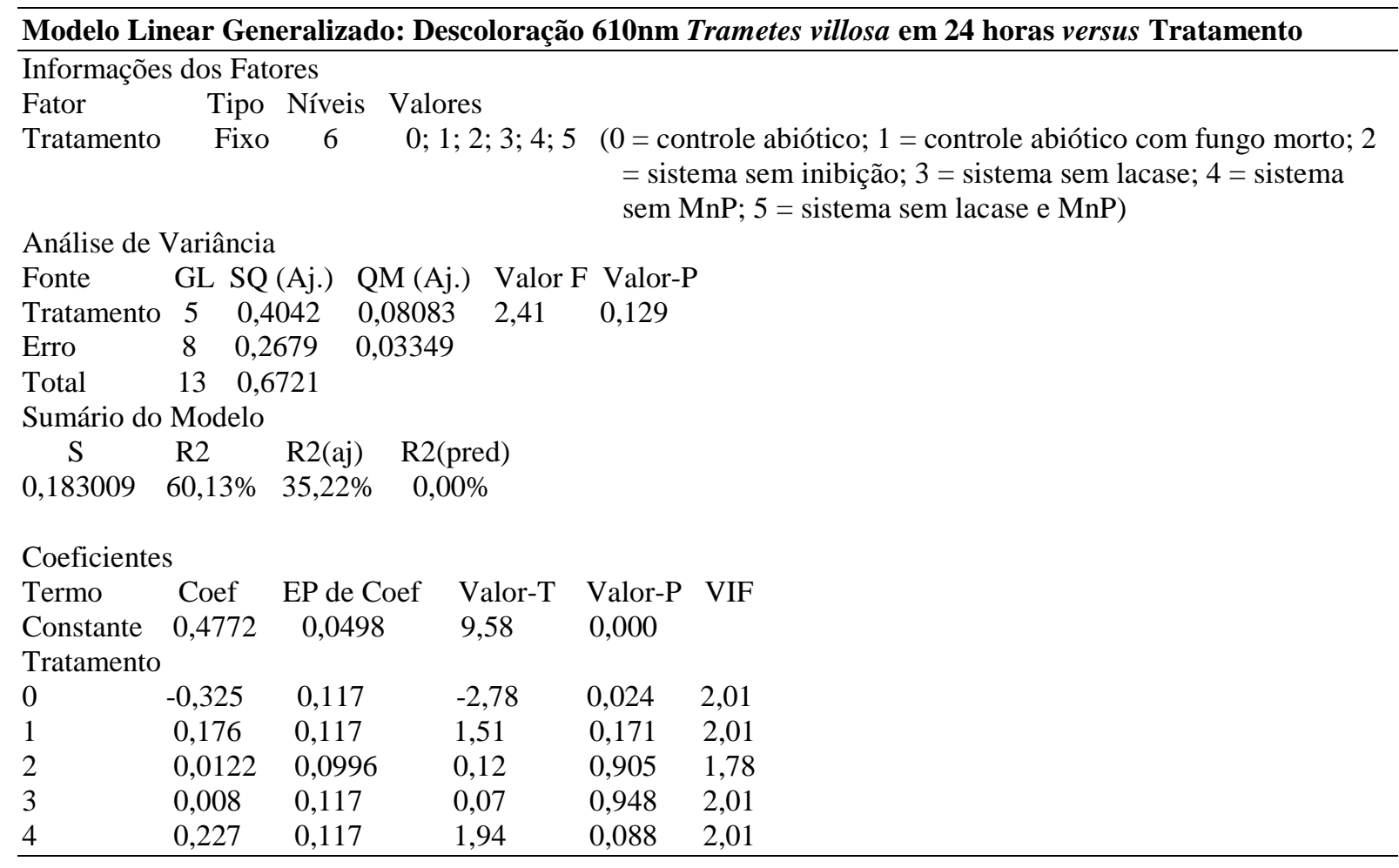

\section{Modelo Linear Generalizado: Descoloração 610nm Trametes villosa em 48 horas versus Tratamento}

Informações dos Fatores

Fator Tipo Níveis Valores

Tratamento Fixo $6 \quad 0 ; 1 ; 2 ; 3 ; 4 ; 5 \quad(0=$ controle abiótico; 1 = controle abiótico com fungo morto; 2 = sistema sem inibição; 3 = sistema sem lacase; 4 = sistema sem MnP; 5 = sistema sem lacase e MnP)

Análise de Variância

$\begin{array}{lcclll}\text { Fonte } & \text { GL } & \text { SQ (Aj.) } & \text { QM (Aj.) } & \text { Valor F } & \text { Valor-P } \\ \text { Tratamento } & 5 & 0,3110 & 0,06220 & 1,34 & 0,340 \\ \text { Erro } & 8 & 0,3723 & 0,04654 & & \\ \text { Total } & 13 & 0,6833 & & & \end{array}$

Sumário do Modelo

$\begin{array}{cllc}\text { S } & \text { R2 } & \text { R2(aj) } & \text { R2(pred) } \\ & & \end{array}$

Coeficientes

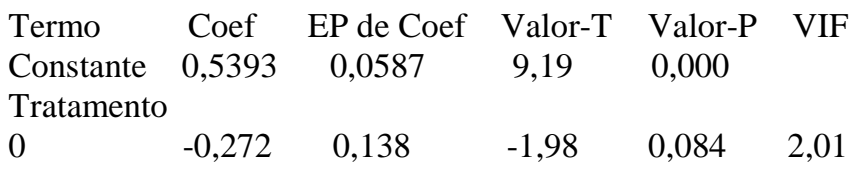


Continuação

\begin{tabular}{lrclll} 
Termo & Coef & EP de Coef & Valor-T & Valor-P & VIF \\
1 & 0,203 & 0,138 & 1,48 & 0,178 & 2,01 \\
2 & $-0,039$ & 0,117 & $-0,33$ & 0,750 & 1,78 \\
3 & $-0,014$ & 0,138 & $-0,10$ & 0,921 & 2,01 \\
4 & 0,181 & 0,138 & 1,31 & 0,226 & 2,01 \\
\hline
\end{tabular}
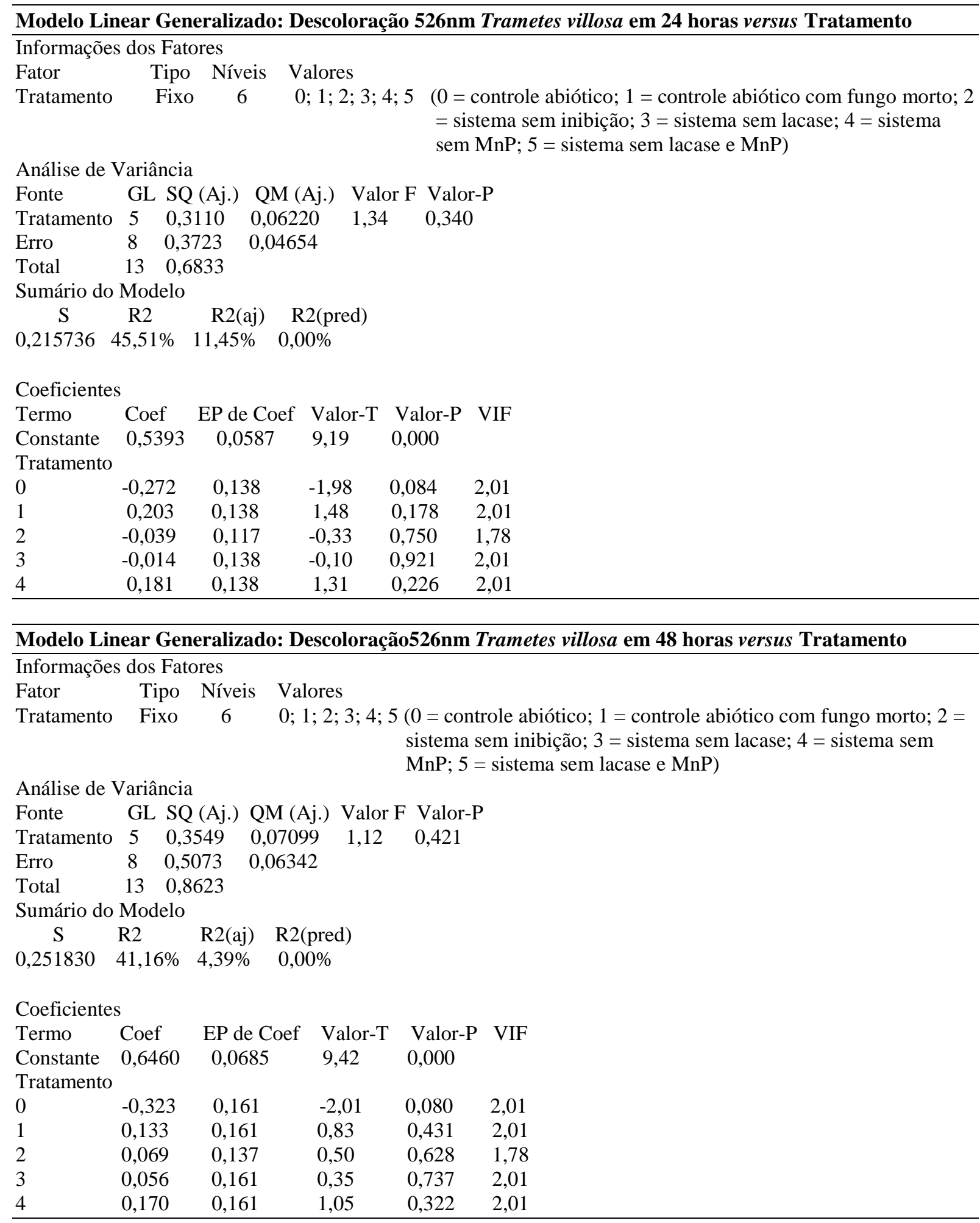
Lacase versus descoloração 610nm

Análise de correlação para Peniophora cinerea

Correlação de Pearson $=-0,516$

Valor-P = 0,041

MnP versus descoloração 610nm

Correlação de Pearson $=-0,236$

Valor-P $=0,378$

Lacase versus descoloração 526nm

Correlação de Pearson $=-0,438$

Valor-P $=0,090$

MnP versus descoloração $526 \mathrm{~nm}$

Correlação de Pearson = -0,110

Valor-P = 0,684

Lacase versus MnP

Correlação de Pearson $=0,185$

Valor-P = 0,492

Atividade redutora de ferro versus descoloração $610 \mathrm{~nm}$

Correlação de Pearson $=$ Valor-P $=$ * Todos os valores na coluna são idênticos

Atividade redutora de ferro versus descoloração $526 \mathrm{~nm}$

Correlação de Pearson $=-0,607$

Valor-P = 0,585

Quelantes de ferro versus descoloração 610nm

Correlação de Pearson $=$ Valor-P $=$ *Todos os valores na coluna são idênticos.

Quelantes de ferro versus descoloração 526nm

Correlação de Pearson $=0,692$

Valor-P $=0,513$

Quelantes de ferro versus atividade redutora de ferro

Correlação de Pearson $=-0,994$

Valor-P $=0,071$

Lacase versus atividade redutora de ferro

Correlação de Pearson $=-0,711$

Valor-P $=0,497$

Lacase versus quelantes de ferro

Correlação de Pearson $=0,785$

Valor-P $=0,426$

MnP versus atividade redutora de ferro

Correlação de Pearson $=-0,550$

Valor-P = 0,629

MnP versus quelantes de ferro

Correlação de Pearson $=0,640$

Valor-P $=0,558$ 
Lacase versus descoloração 610nm

Análise de correlação para Pleurotus ostreatus

Correlação de Pearson $=0,658$

Continuação

Valor-P = 0,003

Lacase versus descoloração 526nm

Continuação

Correlação de Pearson $=0,073$

Valor-P $=0,774$

Atividade redutora de ferro versus descoloração $610 \mathrm{~nm}$

Correlação de Pearson $=-0,947$

Valor-P $=0,207$

Atividade redutora de ferro versus descoloração 526nm

Correlação de Pearson $=-0,995$

Valor-P $=0,065$

Quelantes de ferro versus descoloração 610nm

Correlação de Pearson $=0,904$

Valor-P $=0,281$

Quelantes de ferro versus descoloração 526nm

Correlação de Pearson $=1,000$

Valor-P $=0,008$

Lacase versus atividade redutora de ferro

Correlação de Pearson $=0,374$

Valor-P $=0,756$

Lacase versus quelantes de ferro

Correlação de Pearson $=-0,478$

Valor-P = 0,683

Atividade redutora de ferro versus quelantes de ferro

Correlação de Pearson $=-0,993$

Valor-P $=0,073$ 
Lacase versus descoloração 610nm

Análise de correlação para Trametes villosa

Correlação de Pearson = 0,035

Valor-P = 0,889

Lacase versus descoloração 526nm

Correlação de Pearson $=0,189$

Valor-P $=0,452$

Atividade redutora de ferro versus descoloração $610 \mathrm{~nm}$

Correlação de Pearson $=0,528$

Valor-P = 0,646

Quelantes de ferro versus descoloração 610nm

Correlação de Pearson $=-0,430$

Valor-P $=0,717$

Atividade redutora de ferro versus descoloração 526nm

Correlação de Pearson $=-0,790$

Valor-P $=0,420$

Quelantes de ferro versus descoloração 526nm

Correlação de Pearson $=0,716$

Valor-P $=0,492$

Lacase versus quelantes de ferro

Correlação de Pearson $=-0,933$

Valor-P $=0,234$

Lacase versus atividade redutora de ferro

Correlação de Pearson $=0,888$

Valor-P = 0,305 